\title{
RHEOLOGICAL AND MORPHOLOGICAL EVOLUTION OF BASALTIC LAVA FLOWS
}

A Dissertation presented to

the Faculty of the Graduate School

at the University of Missouri

\author{
In Partial Fulfillment \\ of the Requirements for the Degree \\ Doctor of Philosophy
}

By ARIANNA SOLDATI

Dr. Alan G. Whittington, Thesis Supervisor

JULY 2018 
The undersigned, appointed by the Dean of the Graduate School, have examined the dissertation entitled:

\section{RHEOLOGICAL AND MORPHOLOGICAL EVOLUTION OF BASALTIC LAVA FLOWS}

presented by Arianna Soldati, a candidate for the degree of Doctor of Philosophy and hereby certify that, in their opinion, it is worthy of acceptance.

Dr. Alan G. Whittington

Dr. Francisco Gomez

Dr. Kevin L. Shelton

Dr. James Schiffbauer

Dr. Thomas D. Sewell 
Volcanoes not only exist and erupt to provide jobs for volcanologists

Hans-Ulrich Schmincke 


\section{PREFACE}

This thesis includes five complementary chapters, two of which are published and one accepted for publication in peer-reviewed scientific journals, in addition to an introduction and a conclusion chapter. I am the primary author for all these papers and manuscripts. I outline below my contributions and the contributions of my co-authors to each of the manuscripts.

A version of Chapter 2 is published in Bulletin of Volcanology (Soldati et al. 2016). All authors participated in field work. I am responsible for all sample syntheses, sample characterization, analyses, and viscometry experiments. I prepared all tables and figures. Co-author Dr. Alex Sehlke provided training with sample synthesis, as well as training with concentric cylinder and parallel plate viscometry. Co-author Gustavo Chigna guided us during field work and shared essential knowledge of the eruption. Coauthor Alan Whittington provided sampling training and extensive feedback on all drafts of the manuscript.

A version of Chapter 3 is published in Journal of Volcanology and Geothermal Research (Soldati et al. 2017). All authors participated in field work. I am responsible for all sample syntheses, sample characterization, experimental sample analyses, and viscometry experiments. I prepared all tables and figures. Co-author Jordon Beem flew the unmanned aerial vehicle (UAV) and generated the flow Digital Elevation Model (DEM) and surface map. Co-author Timothy Robertson is responsible for natural samples analyses and GPS data collection. Co-author Francisco Gomez provided training in field Global Positioning System (GPS) usage, UAV flight, and data analyses. Co-author Alan Whittington also provided extensive feedback on all drafts of the manuscript. 
A version of Chapter 4 is accepted in Bulletin of Volcanology. All authors participated in field work at different times. I am responsible for all sample preparation and characterization for the North, North-West, and South flows. Co-author Maeva Rhéty is responsible for the sample preparation and characterization for the West flow. I prepared all tables and figures. Co-authors Andy Harris and Alan Whittington provided extensive feedback on all drafts of the manuscript. 


\begin{abstract}
AKNOWLEDGEMENTS
The biggest thank you goes to my supervisor, Prof. Alan Whittington. Through our hundreds of hours of open discussion I became a proper scientist. Your constant teaching, encouragement, and support have been fundamental over these years.

Special thanks to my lab mate Alex Sehlke for getting me acquainted to our laboratory, for being by my side during my first field work experience, and for setting an admirable example of scientific rigorousness.

I would like to acknowledge my supervisory committee members Professors Paco Gomez, Kevin Shelton, Jim Schiffbauer, and Tommy Sewell for their availability and constructive feedback.

Thanks to my international collaborators Nicolas Villeneuve, Andy Harris, and Lucia Gurioli for taking a chance on me and welcoming me in their research groups.

Financial support for my Ph.D. was primarily provided by NSF award EAR1220051 to Prof. Alan Whittington. The Huggins Fellowship and the Department of Geological Sciences provided additional support. Travel to workshops and conferences was funded by the American Geophysical Union, MU Graduate and Professional Council, MU Graduate Students Association, MU Organization Resource Group, MU Office of Graduate Studies, and the Geology Department Travel Fund. My last fieldwork season has been financed by the National Geographic Society and by the Embassy of France in the United States.
\end{abstract}




\section{TABLE OF CONTENTS}

$\begin{array}{lll}\text { ACKNOWLEDGEMENTS } & \text { ii }\end{array}$

LIST OF TABLES viii

LIST OF FIGURES - X

ABSTRACT X xiii

CHAPTER

1. Introduction 1

1.1. Rationale 1

1.2. Geodynamic settings 2

1.3. Melt formation 4

$\begin{array}{ll}\text { 1.4. Magma ascent and eruption } & 6\end{array}$

$\begin{array}{ll}\text { 1.5. Lava as a silicate melt } & 7\end{array}$

1.6. Lava flow modeling and hazard 9

1.7. Dissertation outline 11

2. Field and experimental constraints on the rheology of arc basaltic lavas: the January 2014 Eruption of Pacaya (Guatemala) 12

2.1. Introduction 12

2.1.1. Lava rheology and morphology 12

2.1.2. Integration of field- and laboratory-based constraints on lava rheology 16

2.1.3. Tectonic setting and recent activity 
2.2.1. Field observations

2.2.2. Density measurements and porosity calculations

2.2.3. Rheology experiments: sample preparation

2.2.4. Parallel plate viscometry

2.2.5. Concentric cylinder viscometry

2.2.6. Chemical analyses

2.2.7. Evaluation of phase volume fractions

2.2.8. Iron-redox determination

2.3. Results

2.3.1. Sample characterization

2.3.2. Field observations

2.3.3. Liquid viscosity

2.3.4. Experimental phase equilibria

2.3.5. Subliquidus rheology

2.4.1. Laboratory constraints on two-phase rheology

2.4.2. Laboratory constraints on three-phase rheology

2.4.3. Field constraints on three-phase rheology

3. Emplacement Dynamics and Timescale of a Holocene Flow from the Cima Volcanic Field (CA): Insights from Rheology and Morphology 
3.1.1. Monogenetic volcanic fields, lava rheology, and morphology

3.1.2. Geological setting

3.2. Methods

3.2.1. Field data acquisition

3.2.2. Photogrammetric processing and morphometry

3.2.3. Rheology experiments: sample preparation

3.2.4. Parallel plate viscometry

3.2.5. Concentric cylinder viscometry

3.2.6. Density measurements

3.2.7. Chemical analyses

3.2.8. Evaluation of phase volume fractions

3.2.9. Iron-redox determination

3.3.4. Geothermometry 
3.4.2. Effect of crystals on lava rheology

3.4.3. Yield strength: experimental constraints

3.4.4. Yield strength: morphological constraints

3.4.5. Pahoehoe to ' $a$ ' $\bar{a}$ transition

3.4.6. Eruption temperature

4. Topographic constraints on lava flow system structure: the December 2010 eruption of Piton de La Fournaise (La Réunion)

4.1.1. Piton de La Fournaise: the December 2010 eruption and lava flow field 
4.4.3. Effect of textural parameters

5. Conclusion

VITA 


\section{LIST OF TABLES}

Tables

Page

2.1 Sample locations

2.2 Geochemical analyses of sample 14PA04 and of subliquidus experimental glasses

2.3 Density and porosity of each sample

2.4 Field viscosity estimates of the 2014 Pacaya south flow at upflow, midflow, and downflow locations shown in Figure 2.3

2.5 High-temperature and near-glass transition viscosity measurements of remelted and evolved compositions

2.6 Subliquidus strain, stress, and viscosity measurements

3.1 Sample locations

3.2 Geochemical analyses of sample 14CIMA07 and of subliquidus experimental glasses

3.3 2D crystal and bubble fraction estimates of each sample

3.4 High-temperature and near-glass transition viscosity measurements of remelted and evolved compositions

3.5 Subliquidus strain, stress, and viscosity measurements

3.6 Fitted rheological parameters for subliquidus experiments and relative errors

3.7 Monte Carlo-simulated mean values and standard errors of rheological parameters for subliquidus experiments and relative errors 
4.2 Bulk rock geochemical analyses

4.3 Crystallinity and porosity of each sample

\section{Supplementary Tables}

3.1 Whole rock analyses of additional natural samples

3.2 EMPA analyses of phases (glass, plagioclase and olivine) used for geothermometry

3.3 EMPA analyses of mineral (oxide and plagioclase) phases crystallized by each subliquidus experimental run

4.1 Flow dimensions and underlying terrain slope

4.2 Glass EMPA major elements analyses

4.3 Olivine EMPA major elements analyses

4.4 Pyroxene EMPA major elements analyses 


\section{LIST OF FIGURES}

$\begin{array}{ll}\text { Figures } & \text { Page }\end{array}$

$\begin{array}{ll}2.1 \text { Aerial map and sample locations } & 18\end{array}$

2.2 Petrography of near-vent and flow front samples $\quad 30$

2.3 Video recording locations and example frames 34

2.4 Topographic profiles and relative locations 36

2.5 High temperature and near glass transition viscosity measurements of remelted and evolved compositions, fitted with the TVF equations 38

2.6 Crystal fraction developed by each experimental run 40

2.7 Subliquidus viscosity 41

2.8 Crystallization delay in subliquidus experiments 43

2.9 Variations of consistency, flow index, and relative viscosity as a function of crystal fraction compared with other studies 45

2.10Viscosity as a function of temperature and crystallinity 47

3.1 Aerial map, field view, DEM with transverse profiles and sample $\begin{array}{ll}\text { locations } & 60\end{array}$

$\begin{array}{lll}3.2 & \text { Elevation profiles } & 73\end{array}$

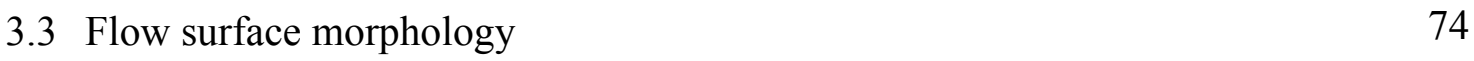

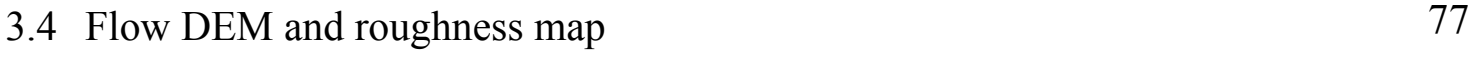

3.5 Total alkali vs. silica diagram for lava compositions whose subliquidus $\begin{array}{ll}\text { rheology has been studied } & 78\end{array}$

3.6 Petrography of lobe, main flow, and core extrusion samples 80 
3.8 Surface morphology and crystal fraction developed by each experiment

3.9 Monte Carlo simulations-based RMSD frequencies of rheological models compared, resulting from

3.10 Viscosity as a function of temperature and crystallinity

3.11 Yield strength vs. crystal fraction plot for all subliquidus experiments and field estimates

3.12 Pahoehoe to 'a' $\bar{a}$ transition in a strain rate vs. apparent viscosity plot

3.13 Constraints on magma chamber and eruption temperature

3.14 Emplacement history reconstruction

4.1 Thickness map

4.2 Thermal imagery

4.3 Structural map and sample location

4.4 Flow system architecture typifying photos and cross sections

4.5 Cross sections typifying the key features of the flow

4.6 Back-scattered SEM images exemplifying mineral texture and geochemical data for each mineral phase

4.7 Emplacement temperatures of each sample obtained through geothermometry 


\section{Supplementary Figures}

3.1 High temperature and near glass transition viscosity measurements of remelted and evolved compositions, fitted with the TVF equations

3.2 SEM images of post-experimental samples for subliquidus runs

3.3 Effective viscosity-time histories for subliquidus experimental runs 


\begin{abstract}
Over 500 million people live in proximity of an active volcano globally. Although lava flows rarely endanger human life, they often destroy critical infrastructure. Advancing our understanding of lava flow dynamics is therefore critical to developing accurate hazard assessment, with key socio-economic impacts for many communities. This work focuses on basaltic lava rheology, which exerts a first-order control on flow dynamics and is reflected in lava morphology. In particular, I address the following research questions: (1) How does the rheology of active flows evolve during emplacement; and (2) How can we use flow morphology to infer the rheology of inactive flows?
\end{abstract}

The physical properties of a lava flow vary as it flows away from the source vent, cooling and crystallizing along the way. Temperature $(T)$ controls crystal fraction $\left(\Phi_{\mathrm{c}}\right)$ and residual liquid composition $(X)$. The combination of these three factors $\left(T, X, \Phi_{\mathrm{c}}\right)$ contributes to determining the main rheological properties of lava: viscosity $(\eta)$ and yield strength $(\sigma \square)$. Additionally, other external factors, such as underlying topography and magma effusion rate, also play important roles by modulating the applied stress $(\sigma)$ and resulting strain rate $(\dot{\gamma})$ experienced by a flow. Flow morphology reflects changes in rheological properties, eruptive parameters, and pre-existing topography, with the potential of revealing important clues as to the emplacement conditions of flows whose active stage was not observed.

At Pacaya volcano (GT) I estimated the rheology of an active basaltic lava flow in the field through particle image velocimetry, and compared it with experimental rheological measurements (Soldati et al. 2016). The complementary field and laboratory 
data sets allowed me to isolate the individual contributions of cooling, crystallization, and changing ground slope to the nearly four-fold effective viscosity increase observed in the field over $550 \mathrm{~m}$ downflow distance. I concluded that in this case decreasing slope is the single most important factor, followed by crystallization.

At Cima volcanic field (CA, U.S.A.) I used a combination of morphological (airborne photogrammetry-generated digital elevation model of the terrain), geochemical, and rheological data (the first ever for that composition) to reconstruct the eruption temperature, emplacement timescale, and emplacement history of the flow (Soldati et al. 2017). I inferred that lava emerged from the vent at a temperature of $1112^{\circ} \pm 60^{\circ} \mathrm{C}$ and reached its final length in about a week, through a multi-stage eruption process. Additionally, I used Monte Carlo simulations to propagate experimental uncertainties, and to select the rheological model (Bingham) that best describes the data.

At Piton de La Fournaise (La Réunion, FR DOM), I addressed the longstanding question of how pre-existing topography controls lava flow system structure in volumelimited flows (Soldati et al., accepted). I concluded that a steep slope results in a single, stable channel, whereas a gentle slope results in an unstable, braided channel. The findings of this study allow us to interpret and explain the observed flow structure on the basis of pre-existing volcano topography, and to forecast future flow structure. This allowed me to determine that rheology neither affects nor is affected by flow system configuration. 


\section{CHAPTER 1}

\section{Introduction}

\subsection{Rationale}

Basaltic lavas, the main surficial expression of magmatic processes, cover large portions of the surface of the Earth (e.g. Greeley 1982, Swanson et al. 1975, Tolan et al. 1989) and of several other terrestrial bodies such as Venus (e.g. Head et al. 1992) and Mars (e.g. Mouginis-Mark et al. 1992). These terrestrial bodies have differentiated into a core, mantle, and crust owing to magmatic processes: melt formation, migration, and emplacement. On Earth, melting currently occurs mainly in the crust and upper mantle. Because melts are less dense than said source regions, they tend to ascend towards the surface. It has been speculated that in the deep lower mantle melts may instead be denser than the crystals with which they are in equilibrium (e.g. Stolper et al. 1981, Agee 1998). While the majority of melts come to final emplacement below the surface, some are erupted at the surface (median ratio of 5:1, depending on tectonic setting; White et al. 2006). Phenomena associated with volcanic eruptions, such as lava flows, pyroclastic flows, ash fall, and lahars, represent serious hazards to the over 500 million people living in the proximity of an active volcano (Small and Naumann 2001). Although lava flows rarely endanger human life, they often destroy critical infrastructure. Much still remains to be unraveled about lava flow dynamics, and the aim of this dissertation is to contribute to their understanding by focusing on the rheological properties of lava. 


\subsection{Geodynamic settings}

The rigid outermost layer of our planet, the lithosphere, is broken into seven major and several minor tectonic plates. These plates are not static, but rather move relative to each other. Three fundamentally different types of plate boundaries ensue from their motion:

1. Divergent (or constructive) boundaries: plates move away from each other at a spreading center, marked by a mid-ocean ridge. New oceanic lithosphere is formed at these locations.

2. Convergent (or destructive) boundaries: plates move toward each other at a subduction zone, with the denser plate plunging beneath the other, resulting in an ocean trench. Old oceanic lithosphere is destroyed at these locations.

3. Transform (or conservative) boundaries: plates slide horizontally past each other, along a fault system. Lithosphere is neither formed nor destroyed at these locations.

The total area occupied by Earth's lithosphere remains constant, but plate boundaries are dynamic and their location and type evolve through time.

Most - but not all - volcanoes are located at plate boundaries. Volcanoes mark the loci where magma breaks through the Earth's crust and reaches the surface. Volcanism occurs at divergent and convergent boundaries (but usually not at transform boundaries); furthermore, intraplate volcanism is also possible. 62 vol\% of Earth's magma flux, amounting to about $21 \mathrm{~km}^{3}$ per year, is currently produced along divergent plate margins, $26 \mathrm{vol} \%$ along convergent plate margins, and $12 \mathrm{vol} \%$ in intraplate settings (Fisher and Schmincke 1984).

At fast-spreading divergent boundaries, mantle material is drawn upward by plates' movement and, as it decompresses, it partially melts (decompression melting; see Section 
1.3). Volcanic activity associated with divergent boundaries occurs at mid-ocean ridges (e.g. Mid-Atlantic Ridge; East Pacific Rise), and is typically submarine, with the notable exception of Iceland.

At convergent boundaries, the subducting plate, which has become hydrated as a result of seafloor alteration, experiences progressively higher temperatures, which cause it to release its fluids (mainly water). These fluids will lower the melting point of the mantle wedge situated between the lower and upper plate, prompting magma generation via flux melting (see Section 1.3). As a result, a chain of volcanoes will form on the upper plate parallel to the subduction zone at a distance of $50 \mathrm{~km}$ (Solomon Islands; Dickinson 1973) to $250 \mathrm{~km}$ (e.g. Eastern Alaska; Dickinson 1973). If the upper plate is also oceanic, an oceanic arc will form (e.g. Alaskan-Aleutian arc, U.S.A.); if the upper plate is continental a continental arc will form (e.g. Cascades range, U.S.A.).

At transform boundaries (e.g. San Andreas Fault), the mechanisms that can generate magma typically do not operate, hence volcanism rarely occurs.

Intraplate volcanism is explained with the theory of hot spots. Hot spots, an integral part of the Earth's mantle convection system, are areas where a plume of hot mantle material rises from as deep as the core-mantle boundary (Wilson 1963, Morgan 1971). During ascent, plumes melt due to decompression (see Section 1.3). The hotspot reference frame appears to be fixed (Wang and Liu 2006); whereas tectonic plates move, resulting in a "hotspot track" marked by a series of volcanoes aligned in the direction of plate motion and progressively older away from the hotspot location. The overriding plate can be either oceanic or continental. If the upper plate is oceanic, the host spot-plate interaction will result in the formation of a linear volcanic chain (e.g. the Hawaiian-Emperor seamount chain and Hawaiian islands were formed by the Hawaii hot spot). If the upper 
plate is continental, a succession of volcanic centers will ensue (e.g. the eastern Snake River Plain and present-day Yellowstone caldera were formed by the Yellowstone hotspot). However, part of the scientific community opposes the plume theory, and rather explains intraplate volcanism with the plate theory. The plate theory ascribes intraplate volcanism to shallow melting processes associated with plate tectonics, particularly extension (e.g. Foulger 2007, Anderson 2007). Further details on the hot spot controversy may be found in Foulger (2005) and Foulger and Jurdy (2007).

In my dissertation, I focus on a continental arc volcano (Pacaya, Guatemala), a continental intraplate volcano (Cima, CA), and an oceanic hotspot volcano (Piton de la Fournaise, La Réunion), all of which have recently produced and/or currently produce basaltic lava.

\subsection{Melt formation}

At the present time, the Earth's crust and mantle are solid under normal conditions. In fact, the geotherm (the temperature increase of terrestrial rocks with increasing depth) does not normally intersect the solidus (the temperature above which a rock begins to melt) of the mantle. Since volcanism is the eruption of partially molten rock (magma), the first stage of any volcanic process must be melting, which can occur in response to three different changes. The thermodynamic state of a system in equilibrium, such as the mantle, is defined by its chemical composition and two extrinsic parameters (e.g. its temperature and pressure). Therefore, to cause a change of state such as melting, one of those parameters must change. In order for melting to occur on our planet, the geotherm must intersect the solidus, which on Earth happens only at particular geodynamic settings, as discussed in the previous section. 
Melt can therefore be generated by one of the following three mechanisms:

1. Heating: directly raising rock temperature, for example by conduction, will cause it to melt by raising the local geotherm.

2. Decompression: adiabatically lowering the pressure of rock, for example through rapid ascent, will cause it to melt by making the local geotherm intersect the mantle solidus.

3. Fluxing: adding components, such as water, that preferentially partition into the melt rather than the solid, expands the stability field of the liquid and lowers the solidus temperature relative to dry rock. It follows that a water-bearing system can be partially molten at temperatures where an equivalent but dry system would be entirely solid.

Melting by decompression and by fluxing dominate in the asthenosphere, because mass transport occurs much faster than heat transport there. Decompression prevails at midocean ridges and hot spots, whereas fluxing prevails in arc settings. Melting by heating through conductive heat flow can occur in the crust, where mass transport is slow; deep crustal hot zones (Annen et al. 2006) represent a notable example in arc settings. Other processes that could generate heat (e.g. impact, radioactive decay, viscous dissipation) are no longer routinely sufficiently intense to induce conspicuous rock melting on present-day Earth.

Rocks melt incongruently: the composition of the melt is different from that of the source rock. This happens because the different minerals within the source rock melt over different temperature intervals. For example, the most common rock found in the mantle is peridotite, which is composed of four minerals: olivine, orthopyroxene, clinopyroxene, and an aluminous phase (plagioclase, spinel, or garnet depending on pressure). During 
eutectic melting of peridotite, clinopyroxene and the aluminous phase melt are consumed first. As a consequence, peridotite-derived melts, called basalts, are enriched in the elements contained in clinopyroxene and aluminous phases relative to peridotite. Rocks only melt partially usually, because the temperatures achieved in the Earth's mantle and crust are not typically high enough to drive the melting process to completion nowadays.

\subsection{Magma ascent and eruption}

After formation, magma rises buoyantly, and can either be emplaced as an intrusive body (pluton, batholith, laccolith, sill, or dyke depending on its geometry) or reach the surface during a volcanic eruption.

If magma does reach the surface, it can erupt either effusively or explosively, depending on volatile content, magma viscosity, and ascent rate among other factors.

In my dissertation, I focus on effusive eruptions. Effusive eruptions consist of the emission of fluid lava, without fragmentation, which then flows downhill as a lava flow. Lava flows are the single most common feature on the surfaces of the terrestrial planets. They cover $90 \%$ of Venus, $70 \%$ of the Earth (note that ocean floors are entirely paved with lava), $50 \%$ of Mars, and $20 \%$ of the Moon (Kilburn 2000). Whereas lava flows rarely endanger human lives, due to their modest advance speed that typically allows people to easily outrun them, they usually destroy buildings and infrastructure located in their path, resulting in heavy financial losses (e.g. Annen and Wagner 2003). The 1977 and 2002 eruptions of Nyiragongo (DRC) represent two of the very rare cases of casualties directly caused by lava flows, due to their unusually low viscosity and high velocity (Komorowski et al. 2002; Baxter et al. 2003). Flow-diversion strategies attempted so far, such as aerial bombing (Mauna Loa 1935, 1942), earthen barriers 
(Kilauea 1955, 1960; Etna 2001, 2002), water cooling (Heimay 1973), and levée breach (Etna 1669, 1983, 1991-1993) have not proved entirely successful (Dietterich et al. 2015).

The main factors controlling lava flows advance are effusion rate (Harris and Rowland 2008 and references therein), lava physical properties (e.g. crystal content and viscosity; e.g. MacDonald 1963; Kesztheyi and Self 1998), and flow environment (e.g. ground slope, irrespective of whether the eruption occurs on land or below water or ice; e.g. Chadwick et al. 2013; Dietterich and Cashman 2014; Conway et al. 2015). Each of these factors can vary significantly among different eruptions, as well as during a single eruptive event, resulting in a wide range of possible lava emplacement mechanisms.

Lava flows are limited in their spatial extent for different reasons. Following Guest et al. (1987), we distinguish between cooling-limited and volume-limited flows. Coolinglimited flows stop advancing because lava has cooled and crystallized to such an extent that further flow is rheologically impossible (Walker 1973). In contrast, volume-limited flows stop before reaching their rheologically possible maximum length because the lava supply has ended: the eruption has ceased, the effusion rate has momentarily dropped, or the lava flux has been locally and temporarily halted by a blockage (e.g. Tarquini and Coppola 2018). However, in the initial stages the two systems may be indistinguishable. In my dissertation, I focus on the effect of lava physical properties and pre-existing topography on flow advance.

\subsection{Lava as a silicate melt}

The vast majority of lavas emitted on Earth are silicate melts. The main structural unit of a silicate melt is the silicon tetrahedron, that is, a silicon cation $\left(\mathrm{Si}^{4+}\right)$ surrounded by four 
oxygen anions $\left(\mathrm{O}^{2-}\right)$. Silicon may be substituted by aluminium $\left(\mathrm{Al}^{3+}\right)$, but because of the charge difference this substitution requires the presence of one or more balancing cations (e.g. $\mathrm{K}^{+}, \mathrm{Na}^{+}, \mathrm{Mg}^{2+}, \mathrm{Ca}^{2+}$ ) nearby in the melt structure. Silica and alumina tetrahedra may form complex networks through polymerization (i.e. by sharing oxygens). The more oxygens are being shared between tetrahedra, the more polymerized a melt is. Octahedrally-coordinated cations in excess of what is needed to charge-balance $\mathrm{AlO}_{4}$ tetrahedra are called network modifiers. Network-modifiers break oxygen bridges between tetrahedra and turn bridging oxygens into non-bridging oxygens, which no longer contribute to melt polymerization. The ratio of non-bridging oxygen (NBO) over tetrahedrally coordinated cations $(\mathrm{T})$, commonly expressed as $\mathrm{NBO} / \mathrm{T}$, approximates the theoretical state of polymerization of the melt (Mysen, 1988). Viscosity increases with the degree of polymerization (typically approximated by the $\mathrm{SiO}_{2}$ content) of a melt. In fact, during viscous flow the tetrahedra must move past one another, which requires stretching their oxygen bonds. The more such bonds are present, the more energy is required to do so.

The specific composition of lava depends on the nature of the source (e.g. mantle vs. crust), the means by which the solidus was exceeded (e.g. decompression vs. fluxing), and the processes that have affected the melt during storage and ascent (e.g. crystallization, assimilation, mixing) (Rogers and Hawkesworth 2000). Lava is typically classified on the basis of its silica $\left(\mathrm{SiO}_{2}\right)$ and total alkali $\left(\mathrm{Na}_{2} \mathrm{O}+\mathrm{K}_{2} \mathrm{O}\right)$ content (Le Maitre 1984). My dissertation focuses on basaltic lavas, the most abundant on Earth.

Basalts can be classified as either alkaline or sub-alkaline (Irvine and Baragar, 1971). Alkaline basalts are silica-undersaturated, whereas sub-alkaline basalts are silicasaturated. Sub-alkaline basalts can be further classified as either tholeiitic or calc- 
alkaline, depending on their oxidation state. Tholeiitic basalts are more reduced, therefore they crystallize iron-poor silicates (e.g. forsteritic olivine) first, resulting in an initial iron enrichment of the residual melt. By contrast, calc-alkaline basalts are more oxidized and therefore crystallize iron oxides (e.g. magnetite) first, resulting in a steady iron depletion of the residual melt.

Basaltic magmas are generated by partial melting of the peridotite mantle by adiabatic decompression beneath mid-ocean ridges (tholeiitic MORB), by adiabatic decompression in mantle plumes (alkaline and tholeiitic OIB), and by depression of the melting point by the addition of volatiles in subduction zones (tholeiitic and calc-alkaline basalts). In continental regions, basalts are also produced by adiabatic melting of upwelling mantle in regions of extension and in response to conductive heating of lower crust intruded or underplated by basaltic magmas.

\subsection{Lava flow modeling and hazard}

Hazard is defined as the probability that any given area will be affected by a potentially destructive process. Vulnerability is the estimated cost of foreseeable damage. The product of hazard and vulnerability identifies risk (e.g. Fournier d'Albe 1979).

Lava flows represent the main hazard associated with effusive volcanism. Volcanic flanks tend to be densely inhabited, partly because of the fertile soil associated with volcanic terrains and partly because of the availability of land parcels. This population trend is continuing even nowadays - for example, over the past 50 years, both Mt. Vesuvius and Mt. Etna, in Italy, have been increasingly urbanized. New settlements are often sited in areas that have been invaded by lava in historical times, making them very vulnerable (Behncke et al. 2005). An adequate urban developing plan requires lava flow 
hazard maps. To produce such maps, we need to predict with a certain degree of confidence where would lava flows go in the event of an eruption - in other words, we need to model their dynamics. Real-time forecasting of lava flow paths is also critical during volcanic crises. Simulating the advance of lava flows on pre-existing volcano topography represents a major challenge in volcanology (Favalli et al. 2005) because lava flows are complex multiphase systems whose temperature and rheology vary both in space and time (e.g. Fink and Zimbelman 1990). One modeling approach is to simplify and solve the governing physical equations of lava flows (e.g. FLOWGO); another option relies on stochastic modeling (e.g. DOWNFLOW); and a third solution is based on Cellular Automata (e.g. MAGFLOW).

FLOWGO (Harris and Rowland 2001) is a kinematic model that describes the down-flow thermal and rheological evolution of channelized lava flows. As the control volume of lava advances down a channel it cools and crystallizes, a surface crust grows, and the heat budget and rheology of the flow evolve. By estimating down-flow heat loss and velocity changes, the model calculates the point at which the control volume becomes stationary, giving the maximum distance lava flowing in the channel can extend. Consequently this model assumes a cooling-limited flow.

DOWNFLOW (Favalli et al. 2005) is a stochastic model that relies on the effect of topography on lava flow advance and forecasts possible lava flow paths with the aim of hazard assessment and mitigation. The potential inundation area of the flow is determined by considering a number of steepest paths over stochastic perturbations of the original topography, neglecting both the temperature and rheology of lava.

In MAGFLOW (Del Negro et al. 2008) the system evolution is expressed as local interactions of the constituent parts, identified as cells. The states of the cells are the 
thickness of lava and the quantity of heat, and they are synchronously updated according to local rules that depend on values of the cell and the values of neighbors within certain proximity. The evolution function is a steady-state solution of the Navier-Stokes equations for the motion of a Bingham fluid, in which the conservation of mass is guaranteed both locally and globally. For the cooling mechanism, the model only considers the radiative heat loss from the surface of the flow and the change of the temperature due to mixing of lavas in adjacent cells with different temperatures.

\subsection{Dissertation outline}

In this dissertation I address the syn-emplacement rheological evolution of basaltic lava flows and its effect on flow dynamics. Additionally, I examine the effect of underlying topography on flow emplacement.

In Chapter 2, I focus on the 2012 eruption of Pacaya (Guatemala). I compare field estimates and laboratory measurements of lava viscosity and evaluate the relative contribution of intrinsic and extrinsic factors in driving downflow viscosity increases.

In Chapter 3, I reconstruct the emplacement of a Holocene flow in the Cima Volcanic Field (CA). Additionally, I present experimental data for these lavas and evaluate and compare three different rheological fitting models and their associated uncertainties.

In Chapter 4, I assess the effect of pre-existing slope on channel network structure in the case study of the 2010 eruption of Piton de La Fournaise (La Réunion) and compare it to what has been observed at other basaltic volcanoes. 


\section{CHAPTER 2}

\section{Field and experimental constraints on the rheology of arc basaltic lavas: the January 2014 Eruption of Pacaya (Guatemala)}

\subsection{Introduction}

\subsubsection{Lava rheology and morphology}

The interpretation of lava morphology requires a detailed understanding of how its physical properties vary as it flows away from the source vent, cooling and crystallizing along the way. Important physical properties of lavas include viscosity $(\eta)$ and yield strength $\left(\sigma_{y}\right)$, both of which depend on temperature $(T)$ and crystal fraction $\left(\Phi_{c}\right)$ (e.g. Spera 2000). The crystal fraction itself varies with $T$, along with the residual liquid composition $(X)$, and all three factors $\left(T, X, \Phi_{c}\right)$ are important in controlling lava viscosity. Thermodynamic models such as MELTS (Ghiorso and Sack 1995) allow the prediction of crystal fraction and residual liquid composition of a lava if thermodynamic equilibrium were maintained during flow emplacement. However, experimental work is necessary to overcome the discrepancy between model output and natural occurrences, as lava flow cooling often entails disequilibrium crystallization.

Viscosity data for silicate liquids as a function of temperature are usually fit with a nonArrhenian Vogel-Tamman-Fulcher (VTF) equation (Vogel 1921) of the form 
$\log _{10} \eta=\mathrm{A}+\mathrm{B} /(T-\mathrm{C})$

where A represents theoretical viscosity at infinite temperature, B is an activation energy, and $\mathrm{C}$ is a temperature term. Empirical viscosity models are now available to predict liquid viscosities as a function of temperature and composition (Hui and Zhang 2007; Giordano et al. 2008), although they are not necessarily able to predict the viscosity evolution of the melt during crystallization with the accuracy required for lava flow modeling (e.g. Sehlke et al. 2014). As magma crystallizes, certain elements are preferentially removed from the melt phase, which is therefore typically driven to a more silica-rich composition, more viscous than the original melt.

A variety of rheological behaviors, described by constitutive relations linking the applied force (shear stress, $\sigma$ ) and resulting deformation rate (strain rate, $\dot{\gamma}$ ), can be observed in magma under different conditions. The simplest relation is Newtonian behavior, in which a straight line whose slope is the material viscosity $(\eta)$ goes through the origin

$\sigma=\eta \dot{\gamma}$

Silicate melts are Newtonian, except at very high strain rates (Webb and Dingwell 1990). However, several experimental studies (e.g. Shaw et al. 1968; Ryerson et al. 1988) demonstrated that lavas are shear-thinning, as the presence of crystals and bubbles alters their rheological behavior, which is then best described by the Herschel-Bulkley constitutive relation

$\sigma=K \dot{\gamma}^{n}+\sigma_{y}$

where $K[\mathrm{~Pa} \cdot \mathrm{s}]$ is the consistency, i.e. the effective viscosity at a strain rate of $1 \mathrm{~s}^{-1}$ and $\sigma_{y}$ $[\mathrm{Pa}]$ is the yield strength, i.e. the strength which needs to be overcome before flow is 
initiated. If no yield strength is present, the constitutive relationship is referred to as power law.

We use the term "effective viscosity" to refer to the ratio of stress to strain rate observed either in the field or in the laboratory, while acknowledging that the behavior of lava and other suspensions is rarely Newtonian. The rheology of two-phase (melt + crystals and melt + bubbles) lavas was recently reviewed by Mader et al. (2013). Many issues are still debated in the field of lava rheology, including the existence of a yield strength (Ryerson et al. 1988; Ishibashi 2009), the rate of increase of effective viscosity with crystal fraction (Ishibashi and Sato 2010; Costa et al. 2009), and the influence of crystal size and shape distribution on effective viscosity and shear-thinning behavior (Mueller et al. 2011; Cimarelli et al. 2011; Faroughi and Huber 2014). Furthermore, lavas are typically threephase materials, with both rigid crystals and deformable bubbles, leading to further complexity in rheological behavior depending on their relative sizes (e.g. Phan-Thiem and Pham 1997; Truby et al. 2015).

The micro-scale physical properties of lava, such as crystal and bubble content, control its rheological properties (viscosity and yield strength), which in turn determine the macroscopic flow surface morphometry (Hulme 1974). These parameters vary along and across the lava flow through space and time (Griffiths 2000), with the final morphology of the flow recording the last stage of these variations. For example, Hawaiian basalts typically erupt as hot, crystal poor, fast-flowing pahoehoe lavas characterized by a smooth and ropey surface texture, which downstream cool and crystallize leading to the morphological transition to rough and blocky `a`a (e.g. Peterson and Tilling 1980; Hon et 
al. 2003; Robert et al. 2014). Similar transitions have been observed in basaltic lava flows at other volcanoes, including Pacaya (Guatemala), the focus of this study.

The viscosity of an active lava flow can be inferred from Jeffreys' equation (Jeffreys 1925)

$h=\left(g \rho(\sin a) d^{2}\right) /(3 v)$

where $\eta[\mathrm{Pa} \cdot \mathrm{s}]$ is the viscosity, $g\left[\mathrm{~m} / \mathrm{s}^{2}\right]$ the gravitational constant, $\rho\left[\mathrm{kg} / \mathrm{m}^{3}\right]$ the bulk density, $a\left[^{\circ}\right]$ the flow slope, $d[\mathrm{~m}]$ the flow depth, and $v[\mathrm{~m} / \mathrm{s}]$ the surface flow velocity. Jeffreys' equation is designed to calculate the viscosity of a Newtonian fluid, as that is effectively the ratio of stress to strain rate. In the case of non-isothermal lava flows containing crystals and/or bubbles, this is a simplifying yet useful assumption. Furthermore, Jeffreys' equation is based on a sheet of fluid flowing down a uniform slope, not on a channelized flow. As shown by Lev and James (2014), Jeffreys' equation may overestimate the viscosity of a flow occurring in a channel of unknown geometry. However, when estimating the viscosity of active flows, the uncertainty arising from estimation of flow depth is typically larger than that associated with channel geometry. Therefore Jeffreys' equation provides a useful first-order viscosity estimate. A synergy of optical flow analyses of the flow velocity field and numerical models is capable of generating more accurate rheological results, but its application to natural lava flows may be challanging (Lev et al. 2012).

Although in the field of rheology the existence of yield strength is not universally accepted (e.g. Barnes 1999), large-scale lava flow morphology has traditionally been interpreted through yield strength (Hulme 1974). When a flow is no longer active, yield 
strength can be estimated from lava flow thickness, because the critical thickness $h_{c}$ required for flows to advance depends on $s_{y}$ (Hulme 1974)

$h_{c}=\sigma_{y} / \rho g$ tana

Levée width $w$ depends on the same parameters (Hulme 1974)

$w=\sigma_{y} / 2 \rho g a^{2}$

Sparks et al. (1976) noted that yield strength estimates may depend on the equation chosen to obtain them: flow thickness-based estimates are consistently slightly higher than levée width-based estimates for narrow channels.

\subsubsection{Integration of field- and laboratory- based constraints on lava rheology}

Few studies previously compared field- and laboratory-based rheological measurements of lava flows. Gauthier (1973) conducted field measurements of Etna lavas viscosity using observed flow velocity and steel spear insertion $\left(\eta=260 \mathrm{~Pa} \cdot \mathrm{s}\right.$ at $\left.1130{ }^{\circ} \mathrm{C}\right)$ and laboratory measurements with rotating cylinder viscometry $(60<\eta<400 \mathrm{~Pa} \cdot \mathrm{s})$. A yield strength of 4.5-30 $\mathrm{Pa}$ was detected at the liquidus $\left(1200^{\circ} \mathrm{C}\right)$. Pinkerton and Norton (1995) measured the viscosity of Etna lavas using a rotating vane viscometer $\left(1,385<\eta<1,630 \mathrm{~Pa} \cdot \mathrm{s}\right.$ at $\left.1095{ }^{\circ} \mathrm{C}\right)$ and laboratory measurements using concentric cylinder viscometry in a reducing atmosphere at unit strain rates $\left(\eta=150 \mathrm{~Pa} \cdot \mathrm{s}\right.$ at $1125{ }^{\circ} \mathrm{C}$ to $\eta=3,000 \mathrm{~Pa} \cdot \mathrm{s}$ at $1084{ }^{\circ} \mathrm{C}$ ). The detected maximum yield strength was $78 \mathrm{~Pa}$ at $1087^{\circ} \mathrm{C}$. Fink and Zimbelman (1986) calculated viscosity and yield strength values for tholeiitic basalts from Kilauea, using levée height and width and ground slope by applying the methods developed by Hulme (1974) and Moore et al. (1978), which assume a Bingham rheology. $\left(\eta=2 \cdot 10^{5} \mathrm{~Pa} \cdot \mathrm{s}\right.$ at $1127{ }^{\circ} \mathrm{C}$ to $\eta=8.2 \cdot 10^{6} \mathrm{~Pa} \cdot \mathrm{s}$ at $\left.1094{ }^{\circ} \mathrm{C}\right)$. Their yield strength 
estimates were $1,500-50,000 \mathrm{~Pa}$, in agreement with laboratory values measured in the $1150-1100{ }^{\circ} \mathrm{C}$ temperature range. We infer that field- and laboratory-based viscosity estimates are consistent and can therefore be valuably combined. Here we investigate the rheology of basaltic lavas from Pacaya, Guatemala, which threaten human settlements and coffee plantations on the volcano slopes.

\subsubsection{Tectonic setting and recent activity}

Pacaya belongs to the Central American Volcanic Arc, generated by the subduction of the Cocos Plate underneath the Caribbean plate. Pacaya is currently in the third phase of its eruptive history (Eggers 1971), which built the currently active MacKenney Cone through basaltic lava flow and tephra emissions over the past $23 \mathrm{ky}$. An arcuate collapse scarp (2000-400 years ago; Vallance et al. 1995) forms a topographical barrier to most lava flows along its western side. The current cycle of activity began in 1961 after nearly a century of repose, and so far consists of eight distinct eruptions through 2013 (Rose et al. 2013), with the January 2014 eruption being the ninth. Further details on the eruptive history of Pacaya can be found in Eggers (1971), Bardintzeff and Deniel (1992), Matías Gomez (2009), and Rose et al. (2013).

On January $9^{\text {th }} 2014$, following a few hours of strombolian activity, Pacaya emitted two lava flows (Fig. 2.1) from different vents, one on the west side and one on the south side. The vents are aligned along a NNW-trending crack traversing the volcano's summit, which developed during the May 2010 eruption (Schaefer et al. 2013). The western flow was extremely short-lived, lasting only 3 days, while the southern flow remained active until April $15^{\text {th }} 2014$. The western flow came to a halt after $2.5 \mathrm{~km}$, while the southern 
flow reached a total length of $4.2 \mathrm{~km}$. Despite its constant unrest and its proximity to major cities, the only previous rheological investigation of Pacaya lavas was by Bollasina (2014), who measured the rheology of lavas emitted during the 2010 eruption. Our goal in this study was to accurately characterize the rheological behavior of the 2014 Pacaya lavas through laboratory experiments, to compare these results with field-based estimates, and to assess the roles of different factors such as cooling, crystallization, and ground slope in affecting rheological behavior of the lava along the flow.

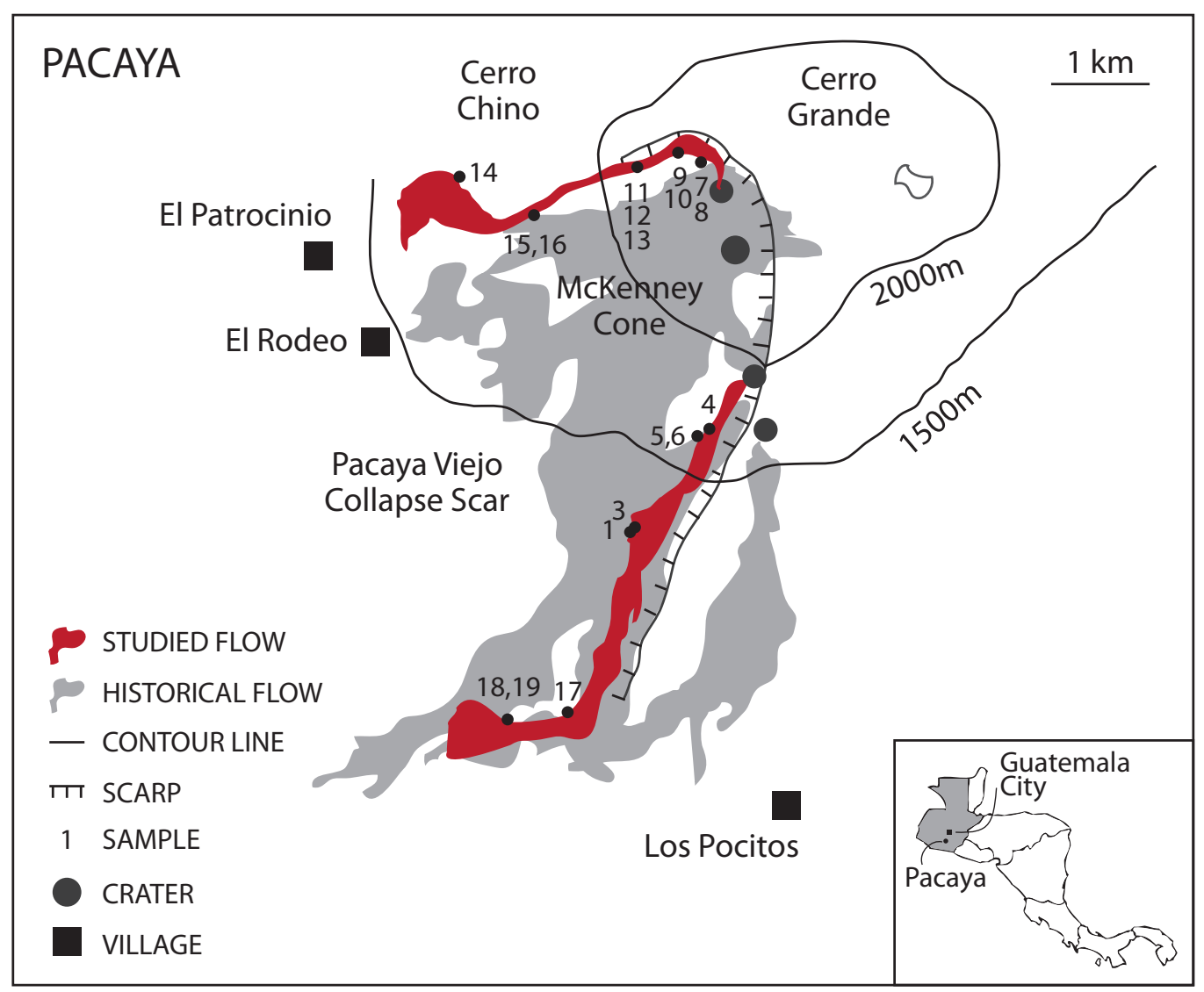

Figure 2.1 Aerial map of Pacaya based on CONRED (COordinadora Nacional para la REducción de Desastres; www.conred.gob.gt) maps and laser range-finder measurements. 2014 lava flows are highlighted in red, and their source vents are shown. Older flows outline based on Rose et al. 2013. Location of collected samples is also indicated. 


\subsection{Methods}

\subsubsection{Field Observations}

We conducted fieldwork at Pacaya in January 2014, shortly after the beginning of the eruption. A total of 18 lava samples were collected (Table 2.1), 16 from along the middle of the channel and the levées of the west and south 2014 flows, and 2 quenched directly at the active 'a'a front of the south flow, which did not advance further after our field campaign (Fig. 2.1).

\begin{tabular}{|c|c|c|c|c|c|c|}
\hline Flow & Sample & $\begin{array}{c}\text { Easting } \\
\mathbf{m}\end{array}$ & $\begin{array}{c}\text { Northing } \\
\text { m }\end{array}$ & $\begin{array}{c}\text { Elevation } \\
\mathbf{m}\end{array}$ & $\begin{array}{c}\text { Vent } \\
\text { m }\end{array}$ & Notes \\
\hline \multirow{8}{*}{ Southern } & 14PA04 & 0758584 & 1589556 & 1601 & 550 & abandoned channel \\
\hline & 14PA05 & 0758260 & 1589555 & 1548 & 880 & W levée \\
\hline & 14PA06 & 0758260 & 1589555 & 1548 & 880 & W breakout lobe \\
\hline & 14PA01 & 0757880 & 1588730 & 1406 & 1650 & W lobe front \\
\hline & 14PA03 & 0757876 & 1588730 & 1541 & 1655 & W levée \\
\hline & 14PA17 & 0757229 & 1587292 & 1227 & 3420 & active lobe (quenched) \\
\hline & 14PA18 & 0756716 & 1587160 & 1157 & 4210 & active front \\
\hline & 14PA19 & 0756716 & 1587160 & 1157 & 4210 & active front slab \\
\hline \multirow{10}{*}{ Western } & 14PA07 & 0758382 & 1591861 & 2148 & 90 & spatter \\
\hline & 14PA08 & 0758335 & 1591845 & 2271 & 240 & lobe margin \\
\hline & 14PA09 & 9758135 & 1591876 & 2216 & 470 & $S$ levée \\
\hline & 14PA10 & 0758153 & 1591904 & 2220 & 470 & main channel \\
\hline & 14PA11 & 0757740 & 1592062 & 2131 & 910 & S levée lobe \\
\hline & 14PA12 & 0757731 & 1591998 & 2120 & 910 & main channel \\
\hline & 14PA13 & 0757731 & 1591998 & 2120 & 910 & main channel \\
\hline & 14PA15 & 0756803 & 1591789 & 1716 & 1850 & main channel \\
\hline & 14PA16 & 0756801 & 1591774 & 1719 & 1850 & S levée \\
\hline & 14PA14 & 0756214 & 1592001 & 1661 & 2490 & flow front \\
\hline
\end{tabular}

Table 2.1 Location (UTM coordinates, WGS84) of collected samples. 
We recorded sample locations using a hand-held Garmin eTrex GPS. In combination with the GPS, a TruPulse 360R laser range finder was used to make longitudinal and transverse topographic profiles of both flows. Several videos of the active southern flow were acquired with a Canon EOS T1i DSLR camera, from a location near the vent looking down onto two different sections of the flow from the ancient collapse scarp, and from a flow levée further downstream, for a total of three different flow sections. Videos were captured at $1020 \times 780$ pixel resolution at 20 frames per second. The flow velocity was then calculated with the free software $\operatorname{Tracker}^{\circledR} 4.87$, using naturally occurring lava blocks transported on top of the flow as tracer particles. Tracker ${ }^{\circledR}$ refers to a chosen model frame in order to identify the feature of interest (in our case the rafted block) in subsequent frames and provide its spatial coordinates. A sampling rate of 5 frames per second was chosen to eliminate the effects of video instability. Video frame scale was calibrated using distances between the recording location and reference points across and along the flow channel, which were measured using the laser range-finder. Consequently, distance traveled has an uncertainty of $\sim 25 \%$, while time is known very precisely.

\subsubsection{Density measurements and porosity calculations}

The density $(\rho)$ of each sample was measured with each of the following three different techniques: (1) pycnometric $\left(\rho_{D R E}\right),(2)$ geometric $\left(\rho_{g}\right)$, and (3) Archimedean $\left(\rho_{A}\right)$. The $2 \sigma$ precision given below is based on 5 repeat measurements of one powder batch or one rock core per sample. Pycnometry allows accurate measurement of the volume of a known mass of powder by displacing a known pressure of gas (helium) and then applying 
the Boyle-Mariotte law. The obtained density measurement is a dense rock equivalent (DRE) density, because it expresses the density of the solid part of the sample only. The technique has a $2 \sigma$ precision better than $50 \mathrm{~kg} / \mathrm{m}^{3}$, or better than $2 \%$ of the average pycnometric density value. Geometric density is obtained by measuring the height and diameter of a cylindrical sample with a micrometer, and then dividing the calculated volume by its mass. Geometric density is therefore a bulk density, including both the solid part of the sample and the bubbles trapped inside it. The technique has a $2 \sigma$ precision better than $20 \mathrm{~kg} / \mathrm{m}^{3}$, or better than $1 \%$ of the average geometric density value. The Archimedean density is obtained by measuring the mass of a sample in air, and subsequently while immersed in anhydrous ethanol. This includes the solid part of the sample and only the isolated bubbles, since porosity is efficiently penetrated by ethanol during the pre-measurement 12 hours immersion period. The technique has a $2 \sigma$ precision better than $200 \mathrm{~kg} / \mathrm{m}^{3}$, or better than $8 \%$ of the average Archimedean density value. The lower precision of this technique probably reflects variably effective penetration of sample porosity by ethanol. The combination of these three density measurements allowed us to calculate the total $\left(\Phi_{t o t}\right)$, interconnected $\left(\Phi_{\text {int }}\right)$, and isolated porosity $\left(\Phi_{i s}\right)$ with the following relationships (Avard and Whittington 2012):

$\Phi_{t o t}=1-\left(\rho_{g} / \rho_{D R E}\right)$

$\Phi_{\text {int }}=1-\left(\rho_{g} / \rho_{A}\right)$

$\Phi_{i s}=\left(\rho_{g} / \rho_{A}\right)-\left(\rho_{g} / \rho_{D R E}\right)$

\subsubsection{Rheology experiments: sample preparation}

Sample 14PA04 was chosen as the experimental starting material. It is the sample 
collected closest to the SE vent and its bulk chemistry typifies that of all the collected samples. 14PA04 was crushed and melted in an iron-saturated $\mathrm{Pt}_{90}-\mathrm{Rh}_{10}$ crucible inserted in an MHI Z-series box furnace. The sample was melted in air for one hour at $1600{ }^{\circ} \mathrm{C}$ and splat-quenched on a copper plate. The resulting glass was again crushed, melted, and quenched with the same procedure in order to ensure homogenization of the sample. The resulting glass was used to perform all viscosity tests.

Additionally, we synthesized a glass (14PA04evo) corresponding to the composition of the interstitial, evolved melt of the lowest temperature $\left(1199^{\circ} \mathrm{C}\right)$ subliquidus experiment. The synthesis was done from oxide and carbonate powders in the MHI box furnace, following the same homogenization procedure as for the natural (remelted) sample.

\subsubsection{Parallel plate viscometry}

Viscosity of cylindrical cores (diameter $\emptyset=6.6 \mathrm{~mm}$, height $5 \mathrm{~mm}<\mathrm{h}<10 \mathrm{~mm}$ ) of glass was measured by uniaxial compression in a Theta Industries Rheotronic III parallel plate viscometer, over the $\sim 10^{8} \mathrm{~Pa} \cdot \mathrm{s}$ to $\sim 10^{12} \mathrm{~Pa} \cdot \mathrm{s}$ range. The load used was $1,500 \mathrm{~g}$, and the applied stresses ranged from $3.79 \cdot 10^{5} \mathrm{~Pa}$ to $4.12 \cdot 10^{5} \mathrm{~Pa}$. The temperature was measured with a K-type thermocouple positioned next to the sample core. The viscometer was checked against NIST standard glasses, indicating an accuracy of better than $0.06 \mathrm{log}$ units (Whittington et al. 2009). Sample longitudinal deformation over time data were collected at alternating higher and lower temperatures, in order to detect possible sample crystallization, which would have resulted in a deviation from the trend of previous measurements during the same experiment in a log viscosity vs. inverse temperature plot. The maximum shortening of the glass cores was $6.8 \%$.

Assuming perfect slip, the stress $(\sigma)$ is calculated as: 
$\sigma=\frac{M g}{V / h}$

where $M[\mathrm{~kg}]$ is the load, $g\left[\mathrm{~m} / \mathrm{s}^{2}\right]$ the gravitational constant, $V\left[\mathrm{~m}^{3}\right]$ the volume of the sample, and $h[\mathrm{~m}]$ the sample height (Dingwell 1995).

The volumetric strain rate $(\dot{\gamma})$ is calculated from the relation:

$\dot{\gamma}=3 \frac{\Delta h / h}{\Delta t}$

Resulting strain rates ranged between $1.33 \cdot 10^{-7} \mathrm{~s}^{-1}$ and $1.26 \cdot 10^{-4} \mathrm{~s}^{-1}$.

The effective viscosity is then obtained as the ratio of stress to volumetric strain rate.

\subsubsection{Concentric cylinder viscometry}

A Theta Industries Rheotronic II Rotating viscometer was used to perform both superliquidus and subliquidus experiments. We used a Brookfield DV3TRV Rheometer measuring head for liquid experiments and a Brookfield HBDV-III Ultra measuring head for subliquidus measurements. Both are able to measure in the $10^{-1}-10^{5} \mathrm{~Pa} \cdot \mathrm{s}$ viscosity range, depending on spindle geometry and immersion depth; however, the HBDV-III Ultra has a stronger full range spring torque $\left(57,496 \cdot 10^{-4} \mathrm{Nm}\right)$ compared to the Brookfield DV3TRV $\left(7,187 \cdot 10^{-4} \mathrm{Nm}\right)$, which enables a wider range of viscosity values to be obtained at the greater strain rates (and therefore greater torques) characteristic of subliquidus experiments. The sample was placed in an iron-saturated $\mathrm{Pt}_{90}-\mathrm{Rh}_{10}$ cylindrical crucible $(\mathrm{h}=65 \mathrm{~mm}$; ID $=30.125 \mathrm{~mm}$ ) held stationary in the furnace by three alumina rods. Temperature was measured with an $\mathrm{Al}_{2} \mathrm{O}_{3}$-sheathed S-type thermocouple positioned outside the bottom of the crucible. An alumina spindle covered by an ironsaturated $\mathrm{Pt}_{90}-\mathrm{Rh}_{10}$ sleeve with a flat tip $(\mathrm{l}=65 \mathrm{~mm} ; \mathrm{OD}=3.75 \mathrm{~mm})$ was immersed in the melt to a depth of about $20 \mathrm{~mm}$ via an attached micrometer, and made to rotate at 
selected speeds by the measuring head. After the experiment, the spindle was raised out of the melt, and the actual immersion depth was verified by measuring the residual melt covering the $\mathrm{Pt}_{90}-\mathrm{Rh}_{10}$ sleeve.

The computer records torque values as percentages of the maximum spring torque of the used measuring head.

The stress $(\sigma)$ is then calculated as

$\sigma=\frac{M}{2 \pi\left(r_{s}^{2} l\right)}$

where $M[\mathrm{~N} \cdot \mathrm{m}]$ is the measured torque, $r_{s}[\mathrm{~m}]$ the spindle radius, and $l[\mathrm{~m}]$ the measured spindle immersion depth.

The strain rate $(\dot{\gamma})$ is calculated from the relation

$\dot{\gamma}=\frac{2 \omega}{n\left(1-\left(r_{s} / r_{c}\right)^{2 / n}\right)}$

where $\omega[\mathrm{rad} / \mathrm{s}]$ is the angular velocity of the spindle, $r_{c}[\mathrm{~m}]$ the crucible inner radius, and $n$ the flow index. The flow index is the slope of the measured $\tau$ against $\omega$ on a double natural logarithmic plot. A flow index value of 1 indicates Newtonian behavior, whereas a value of less than 1 indicates shear-thinning behavior.

The effective viscosity is then obtained as the ratio of stress to strain rate.

Liquid experiments started by reaching a temperature of $1550{ }^{\circ} \mathrm{C}$, which was then decreased stepwise by $25^{\circ} \mathrm{C}$ at a time $(\sim 1 \mathrm{~h}$ per step $)$ until crystallization was detected at $1150{ }^{\circ} \mathrm{C}$, both as a deviation from the viscosity predicted from earlier measurements and as a non-Newtonian rheological response of the material. The temperature was increased again to $1550{ }^{\circ} \mathrm{C}$ as the last experimental step, so as to certify that no instrumental drift took place. At each temperature, measurements were made at three different angular velocities in order to verify the Newtonian behavior of the melt. No significant $\left(>2{ }^{\circ} \mathrm{C}\right)$ 
temperature gradient was detected when moving the thermocouple up and down along the crucible height, indicating that the measured temperature is representative of the entire sample

Subliquidus experiments started by equilibrating the melt at $1500{ }^{\circ} \mathrm{C}$ for 30 minutes, in order to ensure the absence of crystals, which was also verified by checking the liquid viscosity against the viscosity measurements previously obtained at the same temperature. Afterwards, the melt was cooled at a rate of $10{ }^{\circ} \mathrm{C} / \mathrm{min}$ until the target temperature was reached. The melt was then left to equilibrate at that temperature for at least 12 hours. About 10 viscosity measurements were subsequently performed at constant temperature but different angular velocities (0.4-20 rpm), each one lasting 30 minutes. No slip between the spindle and lava was detected during any of the experiments. At the end of the experiment the spindle was raised out of the melt, and the crucible was rapidly removed from the assembly and quenched in a water bath. We expect that the crystallinity observed in quenched products reflects that at experimental conditions.

Samples were extracted from the crucible by drilling cores with a $25 \mathrm{~mm}$ diameter drill bit, and polished sections were prepared from the recovered material. The same crucible was then used for the next subliquidus experiment. A few grams of the originally homogenized glass were added to replace the material drilled out after each experiment.

\subsubsection{Chemical analysis}

Bulk rock chemical analyses were performed by Inductively Coupled Plasma Optical Emission Spectroscopy (ICP-OES) at Actlabs Inc. (Ontario, Canada). Calibration was 
performed using one of 7 USGS and CANMET certified reference materials during the analysis for every group of ten samples.

The microscopic composition of post-experiment samples was analyzed at Washington University in St. Louis on a JEOL JXA-8200 electron microprobe equipped with five wavelength-dispersive spectrometers (WDS) and a JEOL (e2v / Gresham) silicon-drift energy-dispersive spectrometer (EDS). Operating conditions were $15 \mathrm{kV}$ accelerating potential and $25 \mathrm{nA}$ probe current for a $5 \mu \mathrm{m}$ beam diameter. Silicate and oxide standards were used for calibration, and data were corrected with CITZAF (Armstrong 1995). A minimum of five individual analyses were performed on each glass, and at least three individual analyses were obtained for each crystal phase (plagioclase, oxides) in every sample.

\subsubsection{Evaluation of phase volume fractions}

In order to quantify the crystal fraction at each subliquidus experiment, both radial and longitudinal sections of the crucible contents were analyzed. Several backscattered electron images (BSE) were acquired at 50x magnification. Crystallinity estimates of subliquidus experimental runs were obtained by processing a minimum of 3 BSE images of radial and longitudinal sections of each experiment with the free software $\mathrm{JMicroVision}^{\circledR}$ in order to quantify the crystal fraction of each phase (plagioclase, oxides, glass matrix), obtaining results consistent within 5 vol\%. A few images at higher magnification $(150 \mathrm{x}, 450 \mathrm{x})$ were also collected and processed, and lead to coherent crystallinity estimates. 


\subsubsection{Iron-redox determination}

Concentric cylinder subliquidus experiments, which maintain the samples at magmatic temperatures for about 24 hours at atmospheric conditions, may result in sample oxidization. Iron redox state has an influence on melt viscosity, because oxidized melts are slightly more viscous than equivalent reduced melts (Dingwell and Virgo 1988). Therefore the iron oxidation state of the natural rock and of all the experimental samples was measured to assess the possible influence of iron redox state on magma viscosity. We used a combination of wet chemistry and ultraviolet/visible (UV/Vis) photospectrometry, following the method developed by Wilson (1960) and modified by Schuessler et al. (2008) and Sehlke et al. (2014). Full details of the method and calibration are given in Sehlke et al. (2014).

\subsection{Results}

\subsubsection{Sample Characterization}

According to the TAS classification, lavas erupted during the 2014 Pacaya eruption are basalts (Table 2.2), slightly but consistently lower in alkali (by $0.2 \mathrm{wt} \%$ ) than recent eruptive products of Pacaya over the years 1996-2010 (Morgan et al. 2013; Robert 2014; Bollasina 2014). The southern flow is slightly more evolved than the western flow, in contrast to the previous effusive eruption of 2010, when the western flow was more evolved than the southern flow. The measured $\mathrm{Fe}^{2+} / \mathrm{Fe}_{\text {tot }}$ ratio is $0.75 \pm 0.05$ in all samples. 


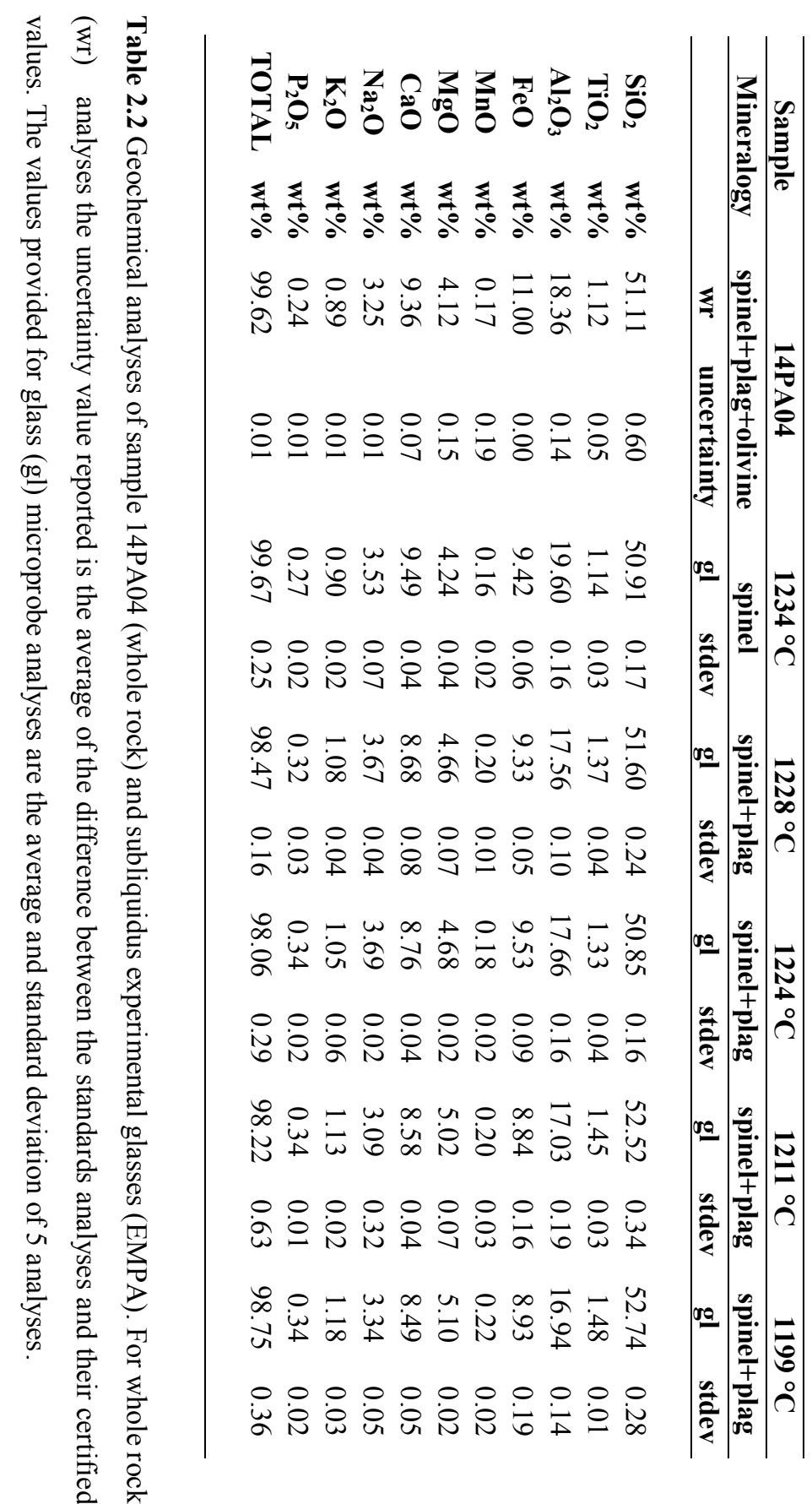


All samples collected from both flows are mineralogically alike, being constituted of plagioclase and olivine phenocrysts immersed in a microcrystalline matrix of plagioclase and oxides (Fig. 2.2). All samples collected after cooling contained $\sim 40 \%$ phenocrysts and $\sim 40 \%$ microlites, with $\sim 20 \%$ bubbles and no visible glass. Samples collected from the active southern flow front and quenched with water have a similar bubble content $(\sim 20 \%)$ and phenocryst population $(\sim 40 \%)$, but fewer microlites $(\sim 20 \%)$ and $\sim 20 \%$ interstitial glass instead, indicating that while the phenocrysts are pre-eruptive, about half of the microlites developed during or post-emplacement.

The DRE density of the samples is $2,995 \mathrm{~kg} / \mathrm{m}^{3}$ on average, while the bulk density varies from 862 to $2,617 \mathrm{~kg} / \mathrm{m}^{3}$ due to porosity ranging from $12 \mathrm{vol} \%$ to $70 \mathrm{vol} \%$. The intercore, intra-sample variability is as high as $1,120 \mathrm{~kg} / \mathrm{m}^{3}$, demonstrating great heterogeneity of bubble content on the $\mathrm{cm}$ scale. The western flow shows higher and more variable porosity than the southern flow. If only the samples collected from the levées are considered, a trend of decreasing porosity exists downflow for both flows, while the channel samples do not display a distinct porosity trend. All density and porosity data are reported in Table 2.3. 

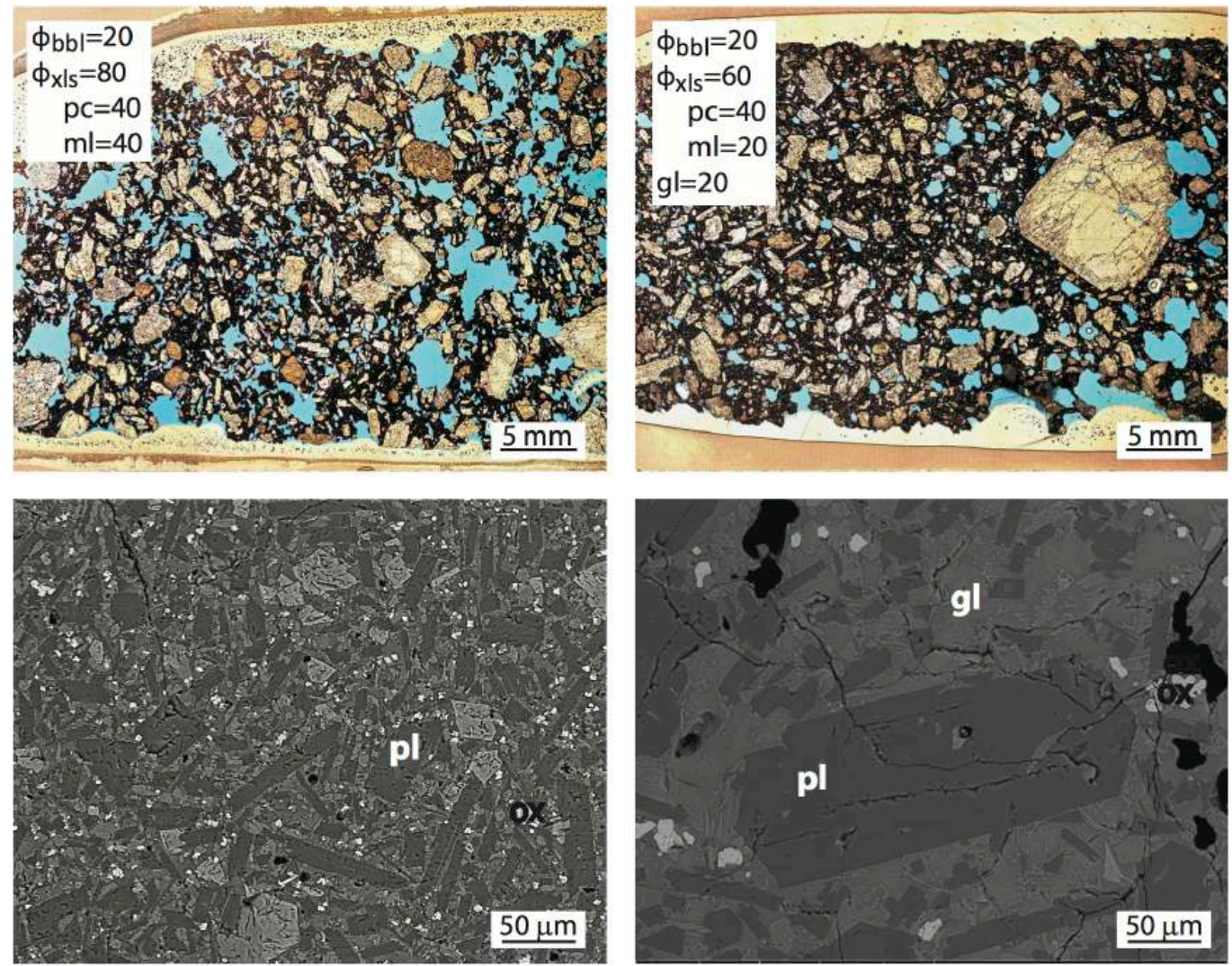

Figure 2.2 Thin sections in transmitted light (top) and BSE (bottom) images illustrating the petrography of samples near the vent (14PA04, left) and at the flow front (14PA19, right). The mineralogy consists of plagioclase and olivine phenocrysts $(\mathrm{pc})$ immersed in a microcrystalline (ml) matrix of plagioclase and oxides; glass ( $\mathrm{gl}$ ) is only present in the sample quenched from the flow front. Bubbles appear blue in thin sections and black in BSE images. 
IE

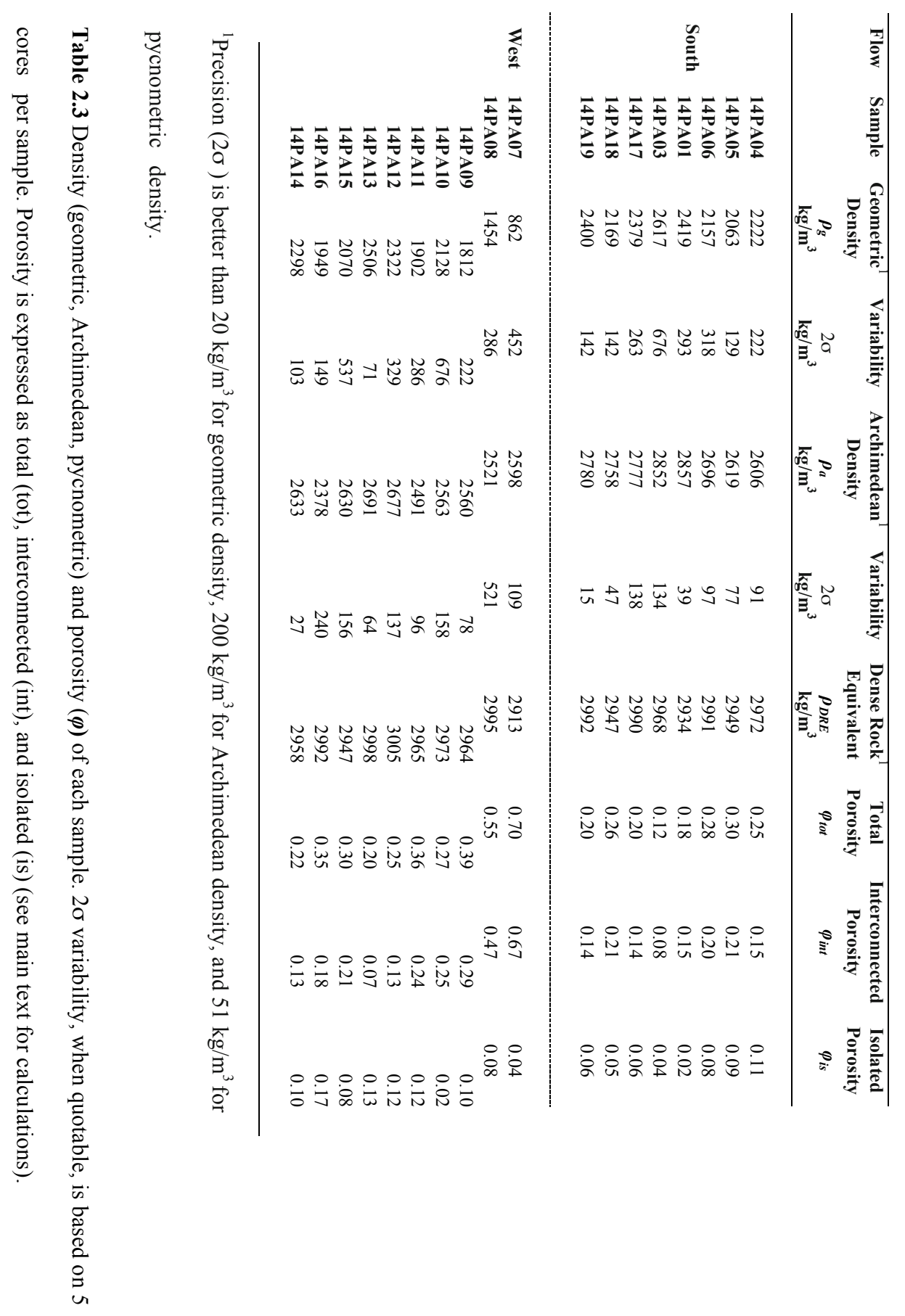




\subsubsection{Field Observations}

\section{Active southern flow}

The 2014 southern flow was emitted from a vent at an altitude of $1,675 \mathrm{~m}$, inside the Pacaya Viejo collapse scar, where all recent flows were located except for the 2010 Los Pocitos flow. This southern flow extended to a length of $4.2 \mathrm{~km}$, and had a welldeveloped channel in its upper section. Its flow direction from the vent was initially SSW, but a westerly turn was imposed by pre-existing topography at about $3.4 \mathrm{~km}$ from the vent (Fig. 2.1). We were able to record video of the southern flow activity on January $15^{\text {th }}$ and $16^{\text {th }} 2014$ at three different locations (Fig. 2.3a), one near the vent (50 m away), one looking down from the Pacaya Viejo collapse scarp, and one further downstream (600 m away) observing the flow from its western levée. Flow velocities were extracted from the video using Tracker $^{\circledR}$, and the viscosity was then calculated using Jeffreys' equation (Jeffreys 1925). The bulk density of the samples measured in the laboratory was $2,300 \pm 180 \mathrm{~kg} / \mathrm{m}^{3}$ on average, while the slope and width of the flow were directly measured in the field with the laser range finder and varied respectively between $45^{\circ}$ and $4 \pm 1 \mathrm{~m}$ upflow, and $4^{\circ}$ and $8 \pm 2 \mathrm{~m}$ downflow. Flow depth was more difficult to estimate; the maximum depth was constrained by the levée height $(2-5 \mathrm{~m})$, consistently with the commonly used half-flow width approximation (Hulme 1974). Our best depth estimates were $2 \pm 1 \mathrm{~m}$ near the vent and $4 \pm 1 \mathrm{~m}$ further downflow. The flow surface velocity in the middle of the flow, extracted from the recorded videos, was $2.8 \pm 0.7 \mathrm{~m} / \mathrm{s}$ upflow, $2.0 \pm 0.5$ $\mathrm{m} / \mathrm{s}$ midflow, and $0.3 \pm 0.1 \mathrm{~m} / \mathrm{s}$ downflow (Fig. 2.3b). Near the vent, where the flow was channelized and still incandescent, this led to a viscosity estimate of 7,600 $\mathrm{Pa} \cdot \mathrm{s}$ (between 
1,900 and 17,100 $\mathrm{Pa} \cdot \mathrm{s}$ including uncertainties). At $\sim 175 \mathrm{~m}$ away from the vent the flow split briefly into two separate channels, which only slightly perturbed the flow velocity and estimated viscosity. In the more distal 'a'a part of the flow, $600 \mathrm{~m}$ away from the vent, the viscosity was estimated to have increased to $28,000 \mathrm{~Pa} \cdot \mathrm{s}$ (between 12,300 and 40,200 $\mathrm{Pa} \cdot \mathrm{s}$ including uncertainties). A summary of these calculations is given in Table 2.4 .

\begin{tabular}{|c|c|c|c|c|c|c|c|}
\hline Location & $\begin{array}{c}\text { Velocity } \\
v \\
\mathrm{~m} / \mathrm{s}\end{array}$ & $\begin{array}{c}\text { Density }^{1} \\
\rho \\
\mathrm{kg} / \mathrm{m}^{3}\end{array}$ & $\begin{array}{c}\text { Slope } \\
\theta \\
\circ \\
\end{array}$ & $\begin{array}{c}\text { Depth } \\
d \\
\text { m }\end{array}$ & $\begin{array}{c}\text { Stress } \\
\sigma \\
\mathrm{Pa}\end{array}$ & $\begin{array}{c}\text { Strain } \\
\dot{\gamma} \\
\mathrm{s}^{-1}\end{array}$ & $\begin{array}{c}\text { Viscosity } \\
\eta \\
\mathrm{Pa} \cdot \mathbf{s}\end{array}$ \\
\hline Upflow & 2.8 & 2,300 & 45 & $2 \pm 1$ & $32,000 \pm 16,000$ & $4.20_{-1.40}^{+4.20}$ & $7,600_{-5,700}^{+9,500}$ \\
\hline Midflow & 2.0 & 2,300 & 30 & $2 \pm 1$ & $22,600 \pm 11,300$ & $3.06_{-1.02}^{+3.06}$ & $7,400_{-5,500}^{+9,200}$ \\
\hline Downflow & 0.3 & 2,300 & 4 & $4 \pm 1$ & $6,300 \pm 1,600$ & $0.23_{-0.08}^{+0.05}$ & $28,000_{-15,700}^{+12,200}$ \\
\hline
\end{tabular}

${ }^{1}$ Bulk density measurements on samples from the southern flow have a $2 \sigma$ variability of \pm 360 $\mathrm{kg} / \mathrm{m}^{3}$.

Table 2.4 Field viscosity estimates of the 2014 Pacaya south flow at upflow, midflow, and downflow locations shown in Figure 2.3. 

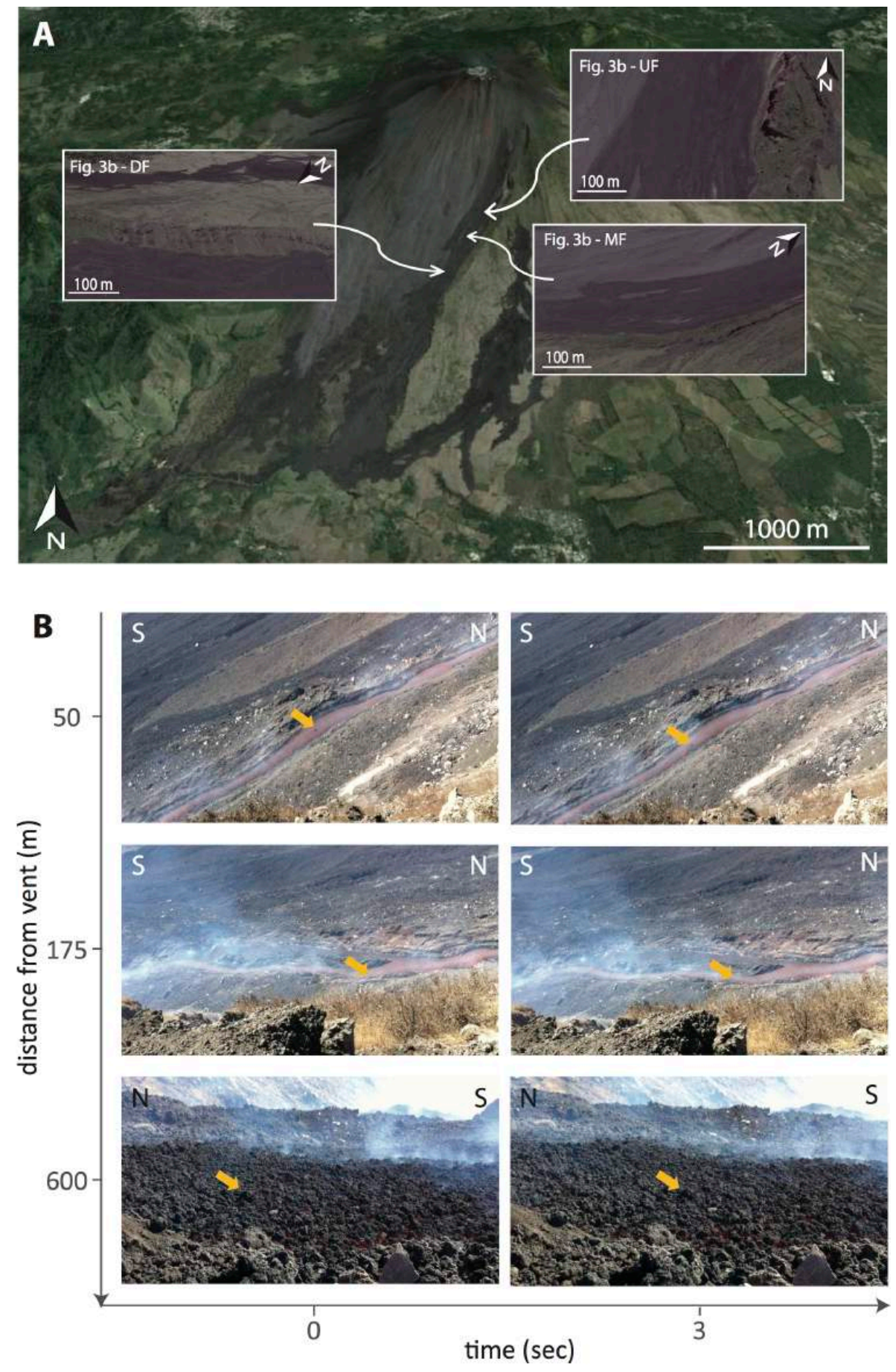

Figure 2.3 a) Location of video recordings used to extract the south flow velocity; b) example frames of videos used to extract flow velocity at each of the three different locations considered. Arrows indicate lava blocks used as tracer particles. 
Inactive western flow

We visited the 2014 western flow on January $16^{\text {th }} 2014,5$ days after it had stopped flowing. The effusion took place from a new vent, located at the base of the SSE-NNW trending crack that splits the summit edifice of Pacaya, and very close to the $2010 \mathrm{NW}$ vent. While descending the western flank of Pacaya, the flow was channelized; upon reaching the plain surrounding the volcano, the lava spread out into a flow front about $500 \mathrm{~m}$ wide. The total flow length was about $2.5 \mathrm{~km}$, which is longer than the $1.8 \mathrm{~km}$ long $2010 \mathrm{NW}$ flow. We were able to do a number of traverses across the flow at different distances from the vent and therefore to trace topographic profiles of the flow by GPS and laser range finder (Fig. 2.4). In profile 1, i.e. about $300 \mathrm{~m}$ from the vent, the apparent width of the main channel is $20 \mathrm{~m}$. However, since the profile was not perfectly perpendicular to the flow, the real channel width was about $16 \mathrm{~m}$, the same as in profiles 2 and 3 , situated $1,300 \mathrm{~m}$ and $1,800 \mathrm{~m}$ from the vent respectively. The internal levée height is between $2 \mathrm{~m}$ and $4 \mathrm{~m}$. A second, outer set of levées is present in all profiles, suggesting that initial extrusion rates were high, followed by a sustained period of lower extrusion rate. In profile 2 it is possible to see how the 2014 flow briefly split, exposing part of the underlying 2010 flow, before reconnecting downflow. 

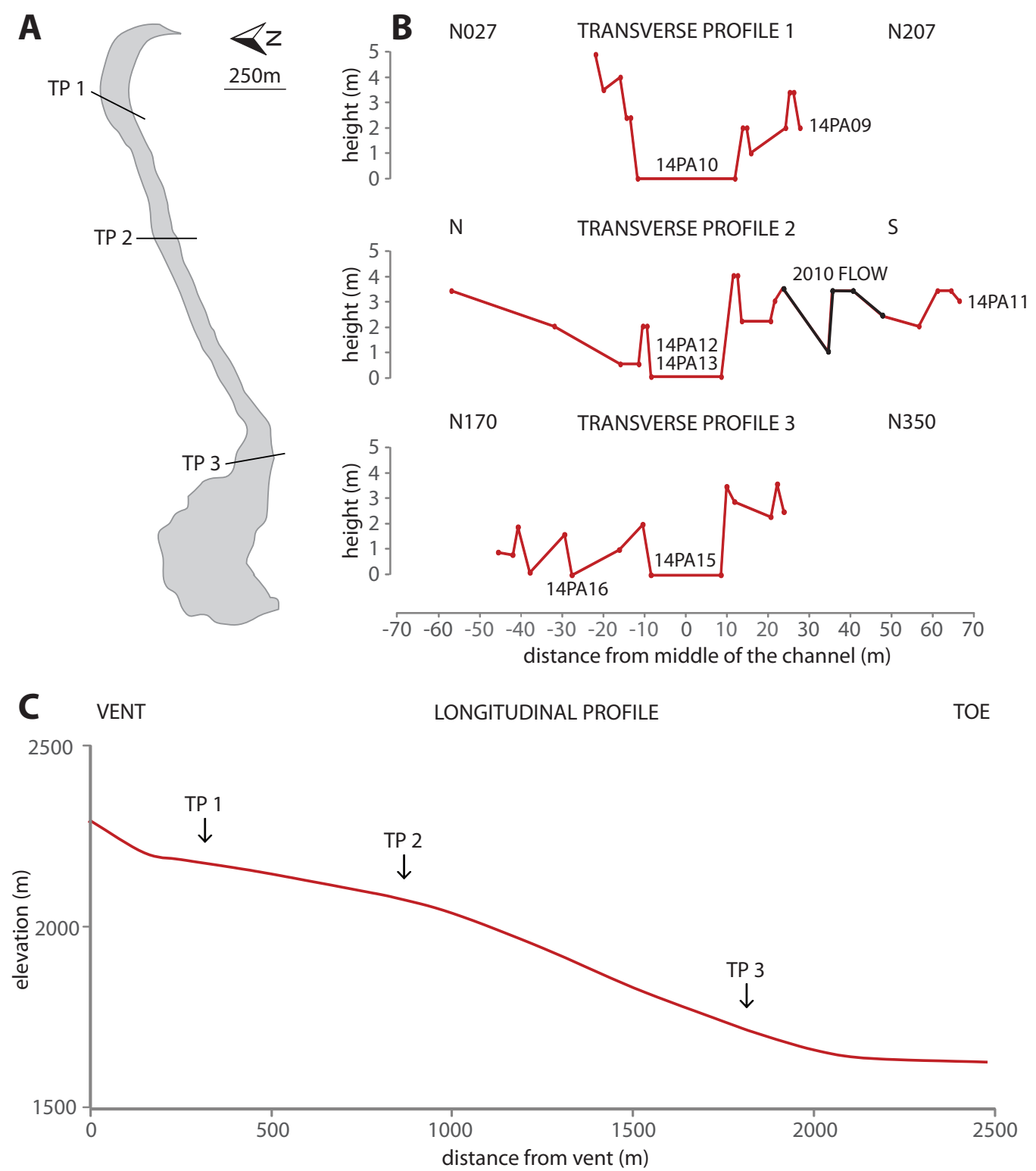

Figure 2.4 a) Location of topographic profiles of the western flow; b) transverse profiles from laser range finder and GPS measurements, with sample locations indicated; c) longitudinal profile from GoogleEarth ${ }^{\circledR}$, with transverse profile locations indicated. 


\subsubsection{Liquid Viscosity}

Viscosity measurements were obtained in the $1555-1150{ }^{\circ} \mathrm{C}$ temperature range via concentric cylinder viscometry, and in the $725-655{ }^{\circ} \mathrm{C}$ temperature range by parallel plate viscometry, spanning 11 orders of magnitude between $3.02 \mathrm{~Pa} \cdot \mathrm{s}$ and $6.92 \cdot 10^{11} \mathrm{~Pa} \cdot \mathrm{s}$ (Table 2.5a). The data were least-squares fitted with the VTF equation (Vogel 1921). The best-fit equation is:

$\log _{10} \eta=-4.35+6071.6 /(T-558.3)$

where $T[\mathrm{~K}]$ is the temperature. The 34 data points were reproduced with a root-meansquare deviation (RMSD) of $0.06 \log$ units, confirming that no crystallization occurred during the liquid-only concentric cylinder experiment. Existing viscosity models failed to reproduce the data within a factor of 3, with an RMSD of $0.52 \log$ units for the Giordano et al. (2008) model and 0.59 log units for the Hui and Zhang (2007) model (Fig. 2.5). The fitting allowed us to interpolate the viscosity of the melt at magmatic (subliquidus) conditions, inaccessible to direct measurement because of rapid crystallization. The response of the melt appeared to be Newtonian down to $1150{ }^{\circ} \mathrm{C}$, where crystallization was finally detected.

The best-fit VTF equation (RMSD $=0.10 \log$ units) for the viscosity of the evolved composition, based on data collected from both the concentric cylinder and parallel plate viscometer (Table 2.5b) was:

$\log _{10} \eta=-3.57+5030.9 /(T-620.8)$

The interstitial melt of other subliquidus experimental runs (between $1234{ }^{\circ} \mathrm{C}$ and 1211 ${ }^{\circ} \mathrm{C}$ ) was not synthesized, as Getson and Whittington (2007) showed that evolving melt viscosity along the liquid line of descent typically follows a quasi-linear trend between 
the highest and lowest temperatures. Linear interpolation between the melt viscosity at the highest temperature and the evolved melt viscosity at the lowest temperature allowed us to take into account both the temperature and compositional effect when calculating the relative viscosity $\left(\eta_{\text {rel }}=\eta_{\text {mixture }} / \eta_{\text {melt }}\right)$ for all intermediate temperatures. The uncertainty from making this linear interpolation is small, and comparable to the analytical uncertainty in measurements.

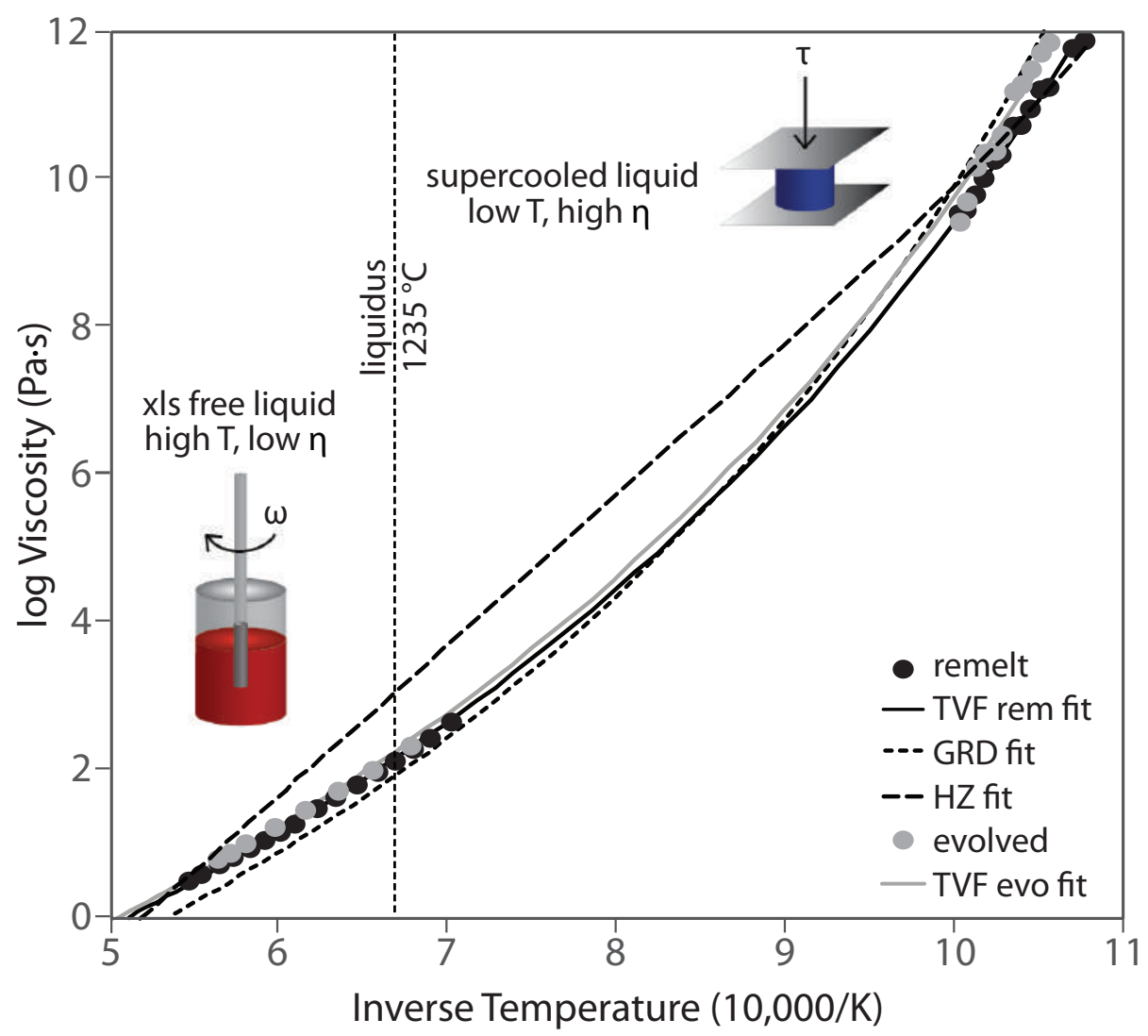

Figure 2.5 Viscosity measurements obtained via concentric cylinder $\left(1555-1150{ }^{\circ} \mathrm{C}\right)$ and parallel plate $\left(725-655{ }^{\circ} \mathrm{C}\right)$ viscometry on the remelt (black circles) and evolved (grey circles) compositions. The two data sets are fitted with the TVF equations $\log \eta=-4.40+6071 /(T-558.3)$ (remelt composition; continuous black curve) and $\log \eta=-3.57+5030 /(T-620.8)$ (evolved composition; continuous grey curve). The viscosities predicted by the Giordano (2008) and Hui and Zhang (2007) models for the remelt composition are shown as well (dashed black curves). 


\begin{tabular}{|c|c|c|c|c|c|c|c|}
\hline \multicolumn{4}{|c|}{ Concentric cylinder } & \multicolumn{4}{|c|}{ Parallel plate } \\
\hline Temperature & Stress & Strain Rate & Viscosity & Temperature & Stress & Strain Rate & Viscosity \\
\hline$T$ & $\sigma$ & $\dot{\gamma}$ & $\eta$ & $T$ & $\sigma$ & $\dot{\gamma}$ & $\eta$ \\
\hline${ }^{\circ} \mathbf{C}$ & $\mathbf{P a}$ & $1 / \mathrm{s}$ & $\mathbf{P a} \cdot \mathbf{s}$ & ${ }^{\circ} \mathbf{C}$ & $\mathbf{P a}$ & $1 / \mathrm{s}$ & $\mathbf{P a} \cdot \mathbf{s}$ \\
\hline \multicolumn{8}{|c|}{ viscosity data for remelt composition } \\
\hline 1554 & $1.62 \cdot 10^{2}$ & $5.33 \cdot 10^{1}$ & $3.05 \cdot 10^{0}$ & 732.6 & $3.82 \cdot 10^{5}$ & $3.75 \cdot 10^{-5}$ & $1.02 \cdot 10^{10}$ \\
\hline 1530 & $1.82 \cdot 10^{2}$ & $4.89 \cdot 10^{1}$ & $3.73 \cdot 10^{0}$ & 724.4 & $4.02 \cdot 10^{5}$ & $1.26 \cdot 10^{-4}$ & $3.19 \cdot 10^{9}$ \\
\hline 1495 & $2.23 \cdot 10^{2}$ & $4.44 \cdot 10^{1}$ & $5.02 \cdot 10^{0}$ & 720.3 & $4.12 \cdot 10^{5}$ & $1.16 \cdot 10^{-4}$ & $3.54 \cdot 10^{9}$ \\
\hline 1471 & $2.23 \cdot 10^{2}$ & $3.55 \cdot 10^{1}$ & $6.28 \cdot 10^{0}$ & 719.6 & $3.99 \cdot 10^{5}$ & $3.73 \cdot 10^{-5}$ & $1.07 \cdot 10^{10}$ \\
\hline 1441 & $2.22 \cdot 10^{2}$ & $2.66 \cdot 10^{1}$ & $8.33 \cdot 10^{0}$ & 714.8 & $4.06 \cdot 10^{5}$ & $7.11 \cdot 10^{-5}$ & $5.71 \cdot 10^{9}$ \\
\hline 1415 & $1.90 \cdot 10^{2}$ & $1.78 \cdot 10^{1}$ & $1.07 \cdot 10^{1}$ & 709.9 & $4.05 \cdot 10^{5}$ & $4.26 \cdot 10^{-5}$ & $9.53 \cdot 10^{9}$ \\
\hline 1389 & $1.23 \cdot 10^{2}$ & $8.88 \cdot 10^{0}$ & $1.39 \cdot 10^{1}$ & 703.7 & $3.96 \cdot 10^{5}$ & $2.37 \cdot 10^{-5}$ & $1.67 \cdot 10^{10}$ \\
\hline 1366 & $1.98 \cdot 10^{2}$ & $1.11 \cdot 10^{1}$ & $1.78 \cdot 10^{1}$ & 700.3 & $4.08 \cdot 10^{5}$ & $2.08 \cdot 10^{-5}$ & $1.96 \cdot 10^{10}$ \\
\hline 1332 & $2.26 \cdot 10^{2}$ & $7.77 \cdot 10^{0}$ & $2.91 \cdot 10^{1}$ & 693.3 & $3.93 \cdot 10^{5}$ & $8.08 \cdot 10^{-6}$ & $4.86 \cdot 10^{10}$ \\
\hline 1304 & $1.81 \cdot 10^{2}$ & $4.44 \cdot 10^{0}$ & $4.08 \cdot 10^{1}$ & 689.2 & $3.97 \cdot 10^{5}$ & $8.02 \cdot 10^{-6}$ & $4.96 \cdot 10^{10}$ \\
\hline 1273 & $1.34 \cdot 10^{2}$ & $2.22 \cdot 10^{0}$ & $6.02 \cdot 10^{1}$ & 684.1 & $4.02 \cdot 10^{5}$ & $4.85 \cdot 10^{-6}$ & $8.29 \cdot 10^{10}$ \\
\hline 1244 & $1.59 \cdot 10^{2}$ & $1.78 \cdot 10^{0}$ & $8.94 \cdot 10^{1}$ & 678.8 & $3.94 \cdot 10^{5}$ & $2.63 \cdot 10^{-6}$ & $1.50 \cdot 10^{11}$ \\
\hline 1221 & $1.67 \cdot 10^{2}$ & $1.33 \cdot 10^{0}$ & $1.25 \cdot 10^{2}$ & 674.2 & $4.03 \cdot 10^{5}$ & $2.48 \cdot 10^{-6}$ & $1.62 \cdot 10^{11}$ \\
\hline 1197 & $8.02 \cdot 10^{1}$ & $4.44 \cdot 10^{-1}$ & $1.81 \cdot 10^{2}$ & 669.6 & $4.00 \cdot 10^{5}$ & $9.17 \cdot 10^{-7}$ & $4.36 \cdot 10^{11}$ \\
\hline 1176 & $1.14 \cdot 10^{2}$ & $4.44 \cdot 10^{-1}$ & $2.56 \cdot 10^{2}$ & 661.6 & $3.92 \cdot 10^{5}$ & $7.18 \cdot 10^{-7}$ & $5.45 \cdot 10^{11}$ \\
\hline \multirow[t]{3}{*}{1150} & $1.88 \cdot 10^{2}$ & $4.44 \cdot 10^{-1}$ & $4.23 \cdot 10^{2}$ & 655.8 & $3.97 \cdot 10^{5}$ & $1.33 \cdot 10^{-7}$ & $2.98 \cdot 10^{12}$ \\
\hline & & & & 655.5 & $4.01 \cdot 10^{5}$ & $5.79 \cdot 10^{-7}$ & $6.92 \cdot 10^{11}$ \\
\hline & & & & 648.7 & $3.79 \cdot 10^{5}$ & $1.57 \cdot 10^{-7}$ & $2.42 \cdot 10^{12}$ \\
\hline \multicolumn{8}{|c|}{ viscosity data for evolved composition } \\
\hline 1550 & $2.05 \cdot 10^{2}$ & $3.33 \cdot 10^{1}$ & $6.15 \cdot 10^{0}$ & 715.8 & $3.99 \cdot 10^{5}$ & $2.88 \cdot 10^{-4}$ & $3.54 \cdot 10^{9}$ \\
\hline 1477 & $1.66 \cdot 10^{2}$ & $2.22 \cdot 10^{1}$ & $7.46 \cdot 10^{0}$ & 707.6 & $3.99 \cdot 10^{5}$ & $1.85 \cdot 10^{-5}$ & $2.16 \cdot 10^{10}$ \\
\hline 1450 & $3.31 \cdot 10^{2}$ & $3.33 \cdot 10^{1}$ & $9.94 \cdot 10^{0}$ & 706.8 & $4.01 \cdot 10^{5}$ & $1.75 \cdot 10^{-5}$ & $2.30 \cdot 10^{10}$ \\
\hline 1400 & $2.20 \cdot 10^{2}$ & $1.33 \cdot 10^{1}$ & $1.65 \cdot 10^{1}$ & 697.9 & $4.01 \cdot 10^{5}$ & $1.07 \cdot 10^{-5}$ & $3.76 \cdot 10^{10}$ \\
\hline 1351 & $2.84 \cdot 10^{2}$ & $9.99 \cdot 10^{0}$ & $2.84 \cdot 10^{1}$ & 694.3 & $3.96 \cdot 10^{5}$ & $2.69 \cdot 10^{-6}$ & $1.47 \cdot 10^{11}$ \\
\hline 1301 & $2.29 \cdot 10^{2}$ & $4.44 \cdot 10^{0}$ & $5.15 \cdot 10^{1}$ & 688.6 & $3.97 \cdot 10^{5}$ & $2.18 \cdot 10^{-6}$ & $1.82 \cdot 10^{11}$ \\
\hline 1252 & $2.19 \cdot 10^{2}$ & $2.22 \cdot 10^{0}$ & $9.84 \cdot 10^{1}$ & 686.1 & $3.97 \cdot 10^{5}$ & $1.36 \cdot 10^{-6}$ & $2.92 \cdot 10^{11}$ \\
\hline \multirow[t]{2}{*}{1202} & $1.85 \cdot 10^{2}$ & $8.88 \cdot 10^{-1}$ & $208 \cdot 10^{2}$ & 676.7 & $3.98 \cdot 10^{5}$ & $8.18 \cdot 10^{-7}$ & $4.86 \cdot 10^{11}$ \\
\hline & & & & 672.2 & $3.95 \cdot 10^{5}$ & $5.86 \cdot 10^{-7}$ & $6.74 \cdot 10^{11}$ \\
\hline
\end{tabular}

Table 2.5 High temperature and near glass transition viscosity measurements of a) remelted and b) evolved composition, corresponding to glass quenched from the $1199{ }^{\circ} \mathrm{C}$ experiment. 


\subsubsection{Experimental Phase Equilibria}

Crystallinity of experimental subliquidus runs varies between $0.1 \mathrm{vol} \%$ and $40 \mathrm{vol} \%$ with decreasing temperatures (from $1234{ }^{\circ} \mathrm{C}$ to $1199{ }^{\circ} \mathrm{C}$ ). The dominant crystalline phase found in the glass matrix is plagioclase, with minor spinel (up to $3.2 \mathrm{vol} \%$ at $1199{ }^{\circ} \mathrm{C}$ ) present. Above a crystallinity of $24 \mathrm{vol} \%$ to $35 \mathrm{vol} \%$, plagioclase crystals display a strong preferred orientation (Fig. 2.6), seen both in the transverse and longitudinal sections.

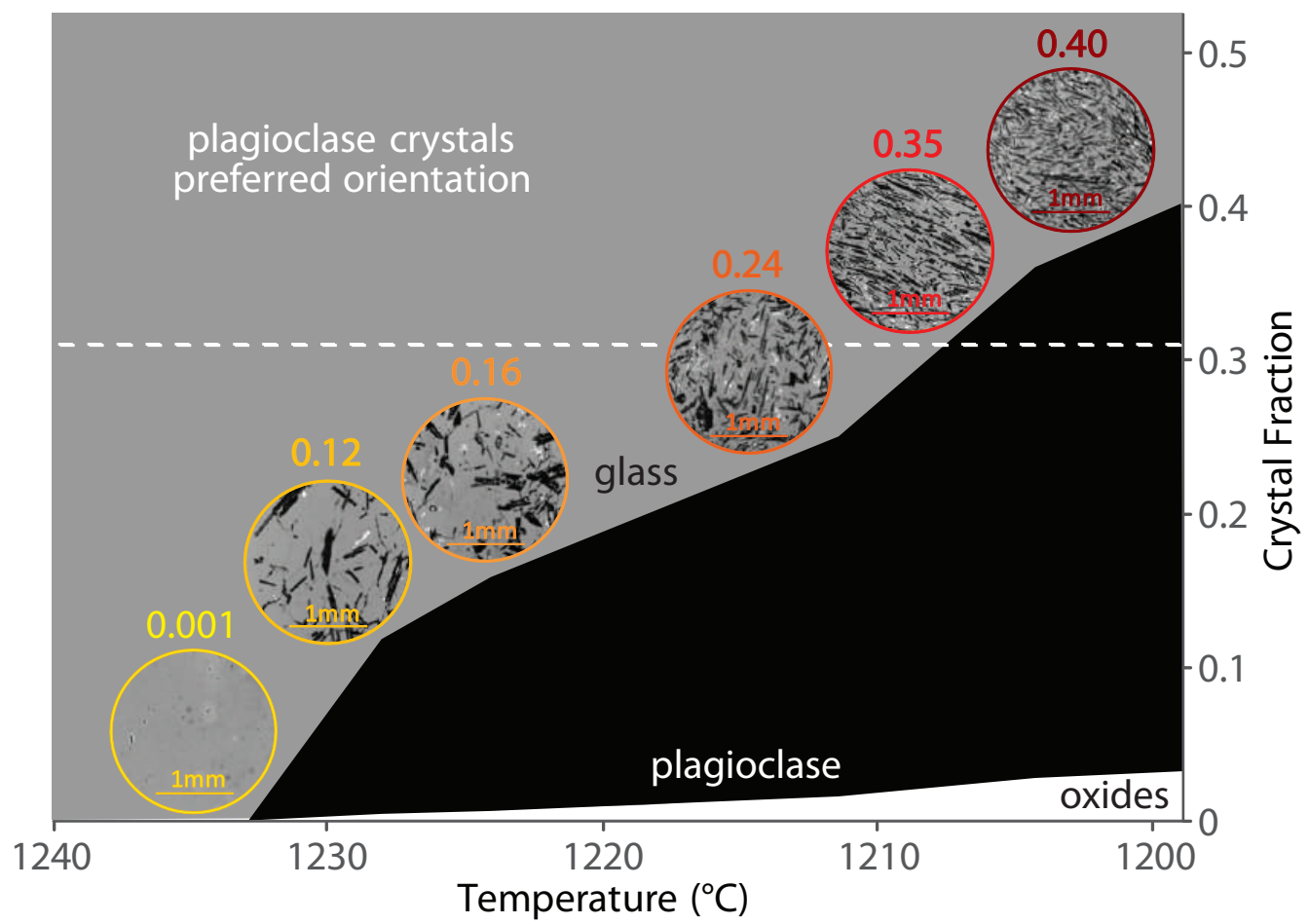

Figure 2.6 Crystal fraction developed by each experimental run. The most abundant phase crystalized is plagioclase (black), with minor oxides (white) present; glass matrix is displayed in grey; the original BSE greyscale is retained. Crystal fraction increases with decreasing temperature. At $\phi_{c}>0.24-0.35$ plagioclase crystals display a preferred orientation.

The measured iron redox state of each subliquidus experimental run was $\mathrm{Fe}^{2+} / \mathrm{Fe}_{\mathrm{tot}}=0.30 \pm 0.05$ across the whole temperature range $\left(1234-1199{ }^{\circ} \mathrm{C}\right)$. In comparison, 
the experimental products were more oxidized than the natural rock $\left(\mathrm{Fe}^{2+} / \mathrm{Fe}_{\mathrm{tot}}=0.75 \pm 0.05\right)$, leading to the crystallization of oxides instead of olivine.

\subsubsection{Subliquidus Rheology}

Five subliquidus viscosity measurements were performed with the concentric cylinder viscometer; the results are reported in Table 2.6. SEM images of the $1234{ }^{\circ} \mathrm{C}$ run disclosed the presence of a very low crystal fraction $(\sim 0.001)$. The lower temperature limit was imposed by the working range of the instrument, which did not allow viscosity measurement below $1199^{\circ} \mathrm{C}$ for this composition, due to the high crystal fraction at that temperature. Subliquidus measurements thus had to be restricted to the $1234-1199{ }^{\circ} \mathrm{C}$ temperature interval (Fig. 2.7).

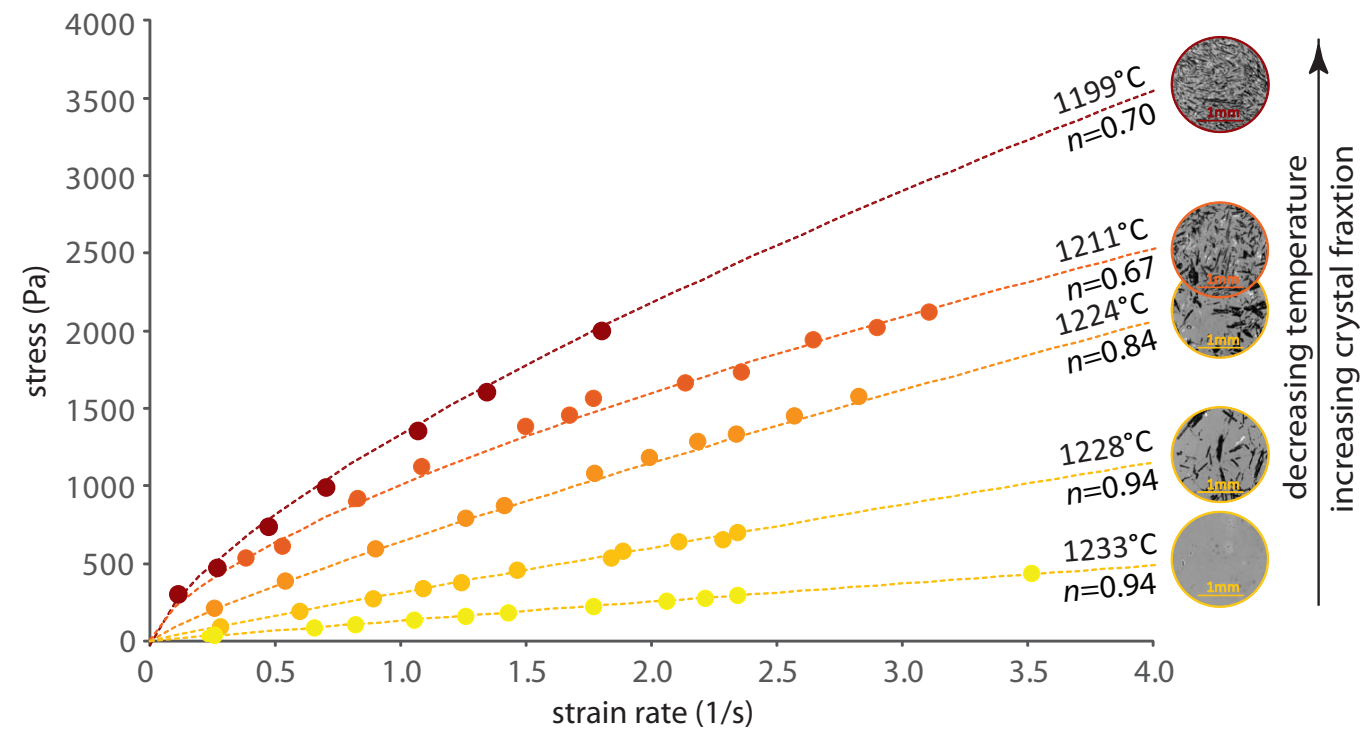

Figure 2.7 Subliquidus viscosity data at 5 temperatures between $1234{ }^{\circ} \mathrm{C}$ and $1199{ }^{\circ} \mathrm{C}$, presented in a rheological map (stress vs. strain rate plot). Experimental data are best fit by a power law equation. Lower temperature runs have a higher viscosity and are increasingly non-Newtonian. 


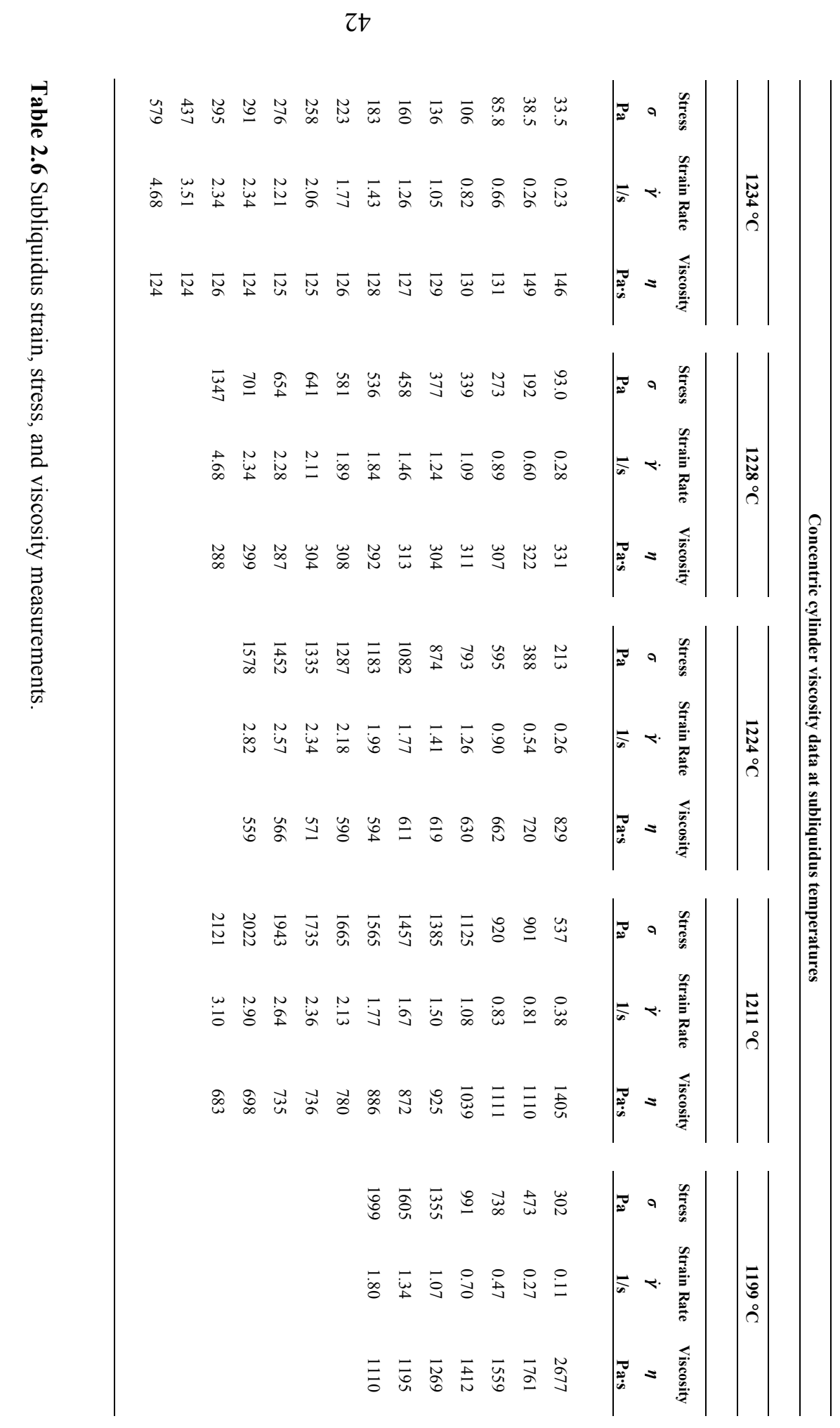


During all subliquidus experiments, a crystallization delay was observed (Fig. 2.8). The delay was shorter for experiments with greater undercooling (1 hour), progressively lengthening in those experiments conducted at temperatures closer to the liquidus (2 hours). The viscosity vs. time plots of the two experiments conducted at lowest temperatures $\left(1199{ }^{\circ} \mathrm{C}\right.$ and $\left.1211^{\circ} \mathrm{C}\right)$ show that effective viscosity increased for $1-2$ hours, then peaked and decreased gradually for up to 5 hours before achieving steady-state.

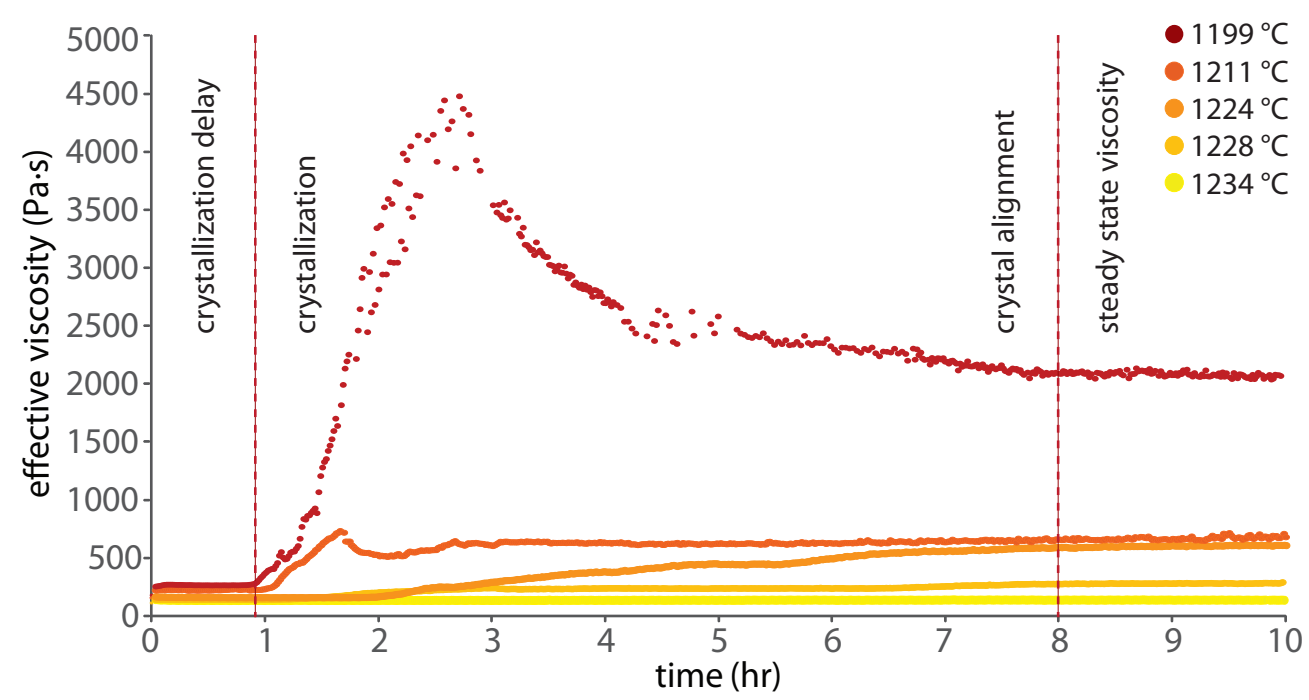

Figure 2.8 Plot of effective viscosity vs. time, showing crystallization delay and steady-state effective viscosity achievement in subliquidus experiments.

Rheological data reported in Table 2.6 were obtained after steady-state effective viscosity had been achieved.

The rheological behavior observed at subliquidus temperatures in our experiments is best described by a power law rheology (Table 2.7). The consistency value of our experiments (Fig. 2.9a) increased from $136 \mathrm{~Pa} \cdot \mathrm{s}$ to $1,336 \mathrm{~Pa} \cdot \mathrm{s}$ as temperature decreased from $1233{ }^{\circ} \mathrm{C}$ to $1199{ }^{\circ} \mathrm{C}$, while calculated flow indices progressively decreased from 0.94 at $1234^{\circ} \mathrm{C}$ to 
0.70 at $1199{ }^{\circ} \mathrm{C}$ (Fig. $2.9 \mathrm{~b}$ ), indicating that the degree of shear-thinning increased with decreasing temperatures. The best fits of Eq. 3 returned $\sigma_{y}$ values within error of zero, even at the highest crystal fractions.

\begin{tabular}{|c|c|c|c|c|}
\hline $\begin{array}{c}\text { Temperature } \\
\boldsymbol{T} \\
{ }^{\circ} \mathrm{C} \\
\end{array}$ & $\begin{array}{c}\text { Crystal Fraction } \\
\phi_{c}\end{array}$ & $\begin{array}{c}\text { Flow Index } \\
n\end{array}$ & $\begin{array}{c}\text { Consistency } \\
K \\
\mathrm{~Pa} \cdot \mathrm{s} \\
\end{array}$ & $\begin{array}{c}\text { Yield Strength } \\
\sigma_{y} \\
\mathbf{P a} \\
\end{array}$ \\
\hline $1199 \pm 0.1$ & $0.40 \pm 0.01$ & $0.70 \pm 0.05$ & $1336 \pm 50$ & $-36 \pm 46$ \\
\hline $1211 \pm 0.1$ & $0.24 \pm 0.02$ & $0.67 \pm 0.03$ & $990 \pm 49$ & $39 \pm 71$ \\
\hline $1224 \pm 0.3$ & $0.16 \pm 0.01$ & $0.84 \pm 0.01$ & $663 \pm 12$ & $-5 \pm 20$ \\
\hline $1228 \pm 0.4$ & $0.12 \pm 0.01$ & $0.94 \pm 0.02$ & $316 \pm 7$ & $-6 \pm 14$ \\
\hline $1234 \pm 0.2$ & $0.001 \pm 0.00$ & $0.94 \pm 0.01$ & $136 \pm 2$ & $-6 \pm 4$ \\
\hline
\end{tabular}

Table 2.7 Fitting parameters for subliquidus experiments flows curves and relative standard deviations $(2 \sigma)$. 
Figure 2.9 Variations of

a) consistency $(K)$, b) flow index $(n)$, and c) relative viscosity as a function of crystal fraction for 2014 Pacaya lavas (red circles), and compared with other studies (black and grey symbols). In c) we also plot the predictions of the Mader et al. (2013) algorithm using an aspect ratio of 5 , both for rough and smooth particles.
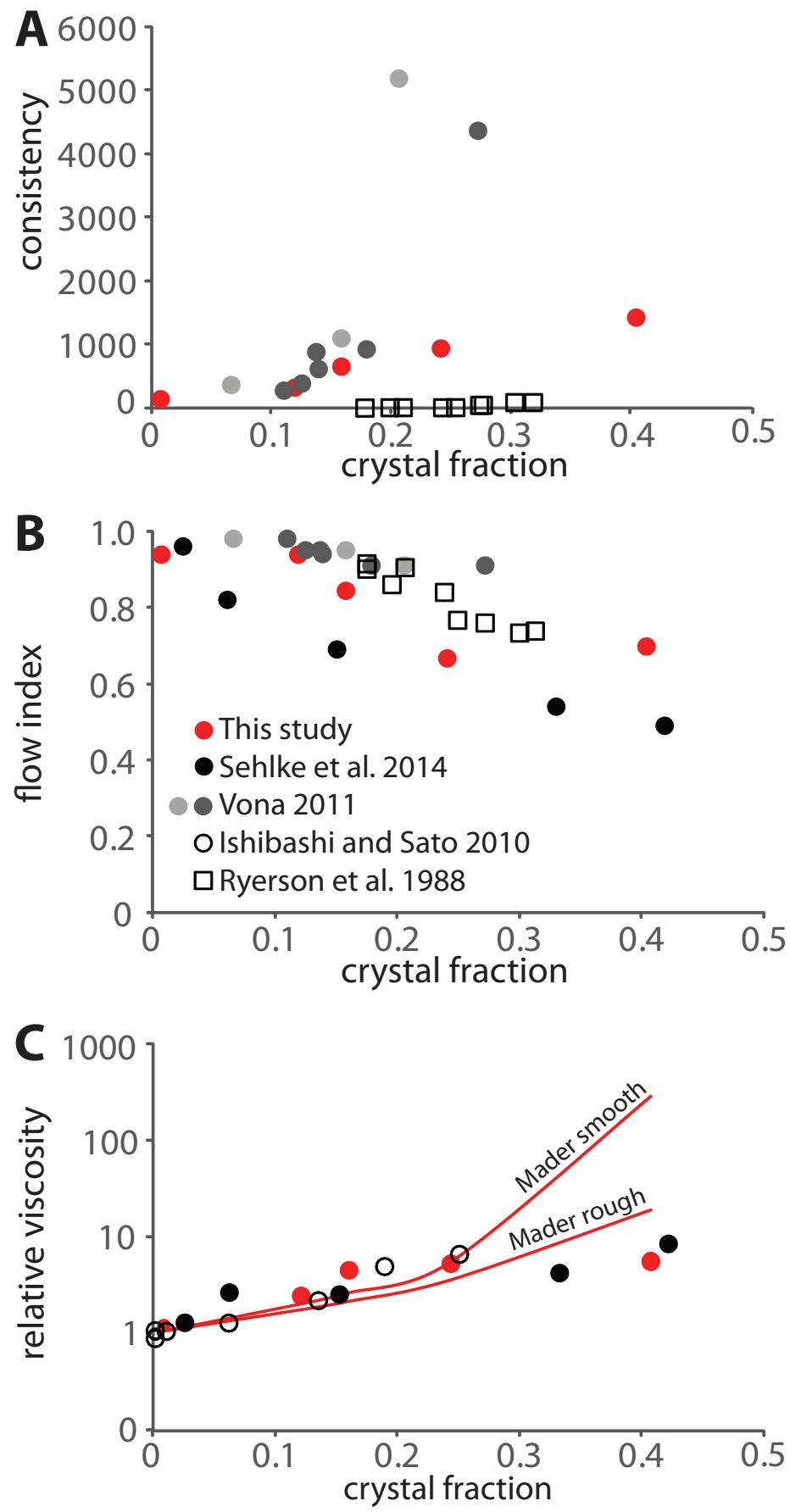


\subsection{Discussion}

\subsubsection{Laboratory constraints on two-phase rheology}

Magma is a mixture of 3 phases: liquid (melt), solid (crystals), and gas (bubbles). Onephase melt viscosity can be predicted knowing its temperature, composition, and water content (Giordano et al. 2008; Hui and Zhang 2007), although not without significant uncertainty (Sehlke et al. 2014). Two-phase viscosity of melt + crystals (Marsh 1981; Pinkerton and Stevenson 1992; Costa et al. 2009; Mueller et al. 2010; Ishibashi and Sato 2007) or melt + bubbles (Manga et al. 1998; Manga and Loewenberg 2001; Rust and Manga 2002; Pal 2003; Llewellin and Manga 2005; Faroughi and Huber 2015) mixtures has been studied extensively and recently reviewed by Mader et al. (2013). Constitutive models exist for both cases, although models for bubble-bearing magmas (Llewellin and Manga 2005; Faroughi and Huber 2015) are also based on physical theory, while those for crystal-bearing magmas (Roscoe 1952, Costa et al. 2009) are entirely empirical. Here we compare our experimental data with previous studies and model predictions in terms of relative viscosity, non-Newtonian behavior, and yield strength.

\section{Relative viscosity}

At $1199{ }^{\circ} \mathrm{C}$, the evolved melt was only $\sim 1.1$ times more viscous $(218 \mathrm{~Pa} \cdot \mathrm{s}$, VTF fit) than the initial melt composition (196 Pa·s, VTF fit). The melt viscosity itself almost doubled from $113 \mathrm{~Pa} \cdot \mathrm{s}$ for the starting melt at $1234^{\circ} \mathrm{C}$ to $218 \mathrm{~Pa} \cdot \mathrm{s}$ for the evolved melt at $1199{ }^{\circ} \mathrm{C}$ (Fig. 2.5). However, the viscosity of the crystal-bearing mixture increased by an order of magnitude, from $136 \mathrm{~Pa} \cdot \mathrm{s}$ to $1,336 \mathrm{~Pa} \cdot \mathrm{s}$, over the same temperature range, as the crystal 
fraction increased from $f_{c}=0.001$ to $f_{c}=0.40$ (Fig. 2.7). This demonstrates that, for this lava flow, the chemical effect of melt evolution on magma viscosity was minor compared to the physical effect of crystal growth (Fig. 2.10).

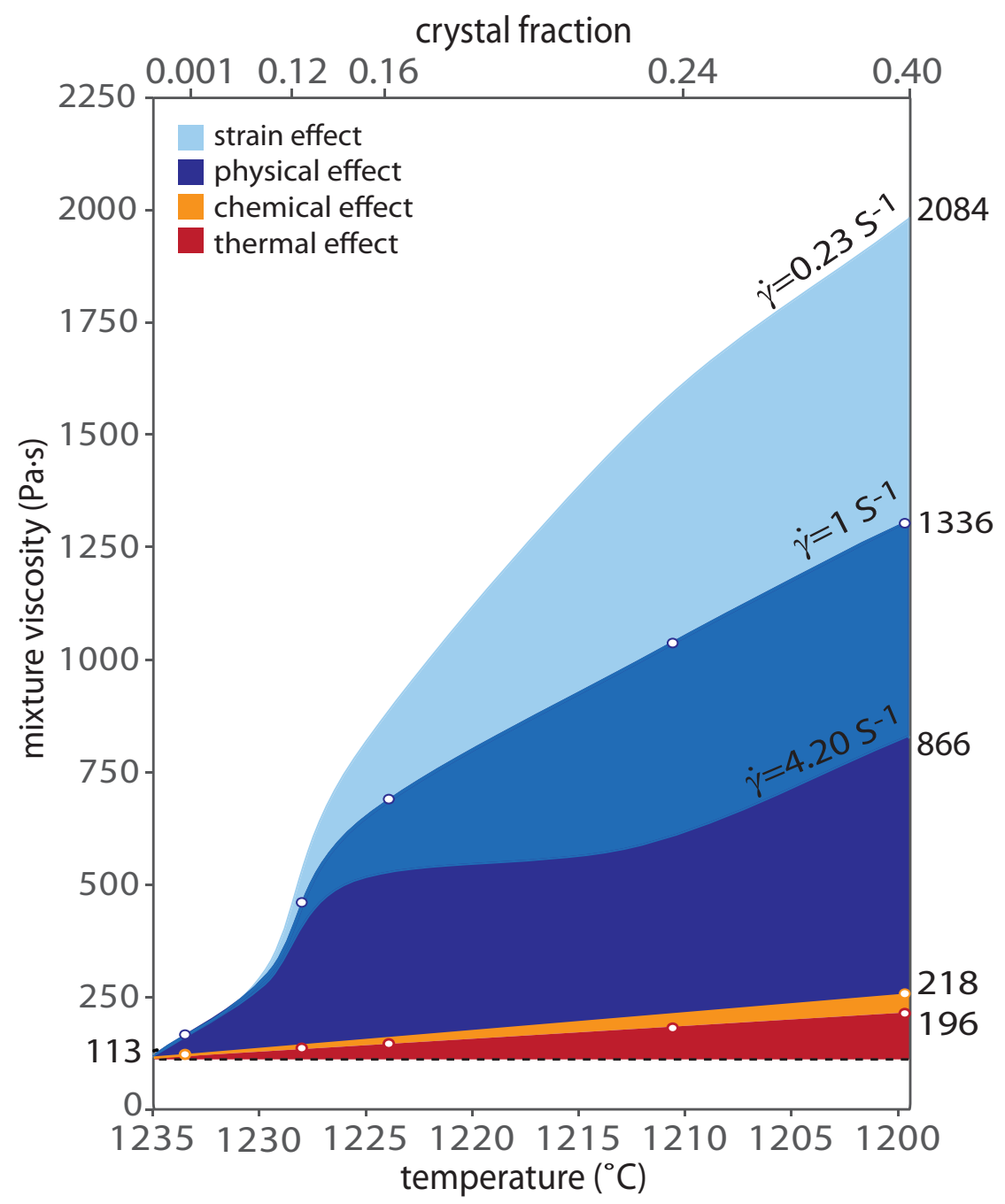

Figure 2.10 Viscosity of 2014 Pacaya lavas at a strain rate of $1 \mathrm{~s}^{-1}$ (unless otherwise specified) as a function of temperature and crystallinity. Remelt composition is shown in red, evolved composition in orange, and two-phase (melt + crystals) mixture in different shades of blue depending on the specified strain rates considered, comprised between the highest $\left(4.20 \mathrm{~s}^{-1}\right)$ and lowest $\left(0.23 \mathrm{~s}^{-1}\right)$ values estimated in the field. 
The relative viscosity of our subliquidus experiments increases with a quasi-linear trend, as do those of Mauna Ulu (Sehlke et al. 2014) and Fuji (Ishibashi and Sato 2010). The viscosity model of Mader et al. (2013) for suspensions containing smooth or rough particles instead predicts a non-linear growth trend, and while it fits quite well up to crystallinities $<0.24$, it overestimates the viscosity of more crystalline samples by one (rough particles) or two (smooth particles) orders of magnitude (Fig. 2.9c). This could be due to the fact that the Mader et al. (2013) model is not geared towards poly-disperse suspensions. In our experiments, the plagioclase crystals are noticeably larger than the oxides (Fig. 2.6). In the natural samples, phenocrysts and microlites coexist as two very distinct size populations (Fig. 2.2). As shown by Cimarelli et al. (2011), Faroughi and Huber (2014), and Moitra and Gonnermann (2015), direct comparison of mono- and poly-disperse suspensions is not straightforward.

\section{Shear-thinning behavior}

The presence of crystals also causes the lava rheology to become non-Newtonian. Previous experiments on the rheology of two-phase (melt + crystals) mafic lavas indicate that threshold values for non-Newtonian behavior onset range from 0.05 (Ishibashi and Sato 2007 on Mt. Fuji basalt) to 0.25 (Ryerson et al. 1988 on picrite). This variability is ascribed to the different mineral assemblages crystallized by each composition. Crystals with high aspect ratio, such as plagioclase, can more promptly induce pseudoplastic behavior, since even a small fraction of acicular crystals engenders interactions among crystals, altering the rheological behavior of the suspension (Cimarelli et al. 2011). The unambiguous detection of pseudoplasticity also depends on the experimental conditions 
and apparatus sensitivity. In our experiments, pseudoplastic behavior was observed at all temperatures where crystals were present; however, a particularly marked increase in the deviation from Newtonian behavior was observed at a crystal fraction between 0.12 and 0.16, where the flow index began to decrease sharply (Fig. 2.9b).

In contrast to experimental samples, only a very weak crystal alignment was observed in the groundmass of samples collected from the lava flow (Fig. 2.2). This implies that, while flow appears to be laminar in the uppermost channel section, crystal alignment was achieved neither in the channel nor previously during conduit ascent. Indeed, we calculated that lava would have to flow for at least $50 \mathrm{~km}$ in order to reach the amount of finite strain at which we observed an effective viscosity reduction in our experiments, which we interpreted as being due to crystal alignment. We calculated this distance by multiplying the experimental strain rates of $2.2 \mathrm{~s}^{-1}$ by the time gap of at least 2 hours between the effective viscosity peak (end of crystallization) and the achievement of a constant effective viscosity (end of crystal alignment) observed in the laboratory experiments (Fig. 2.8). Lava flows at Pacaya have not exceeded $5.5 \mathrm{~km}$ in recent years, therefore their lack of crystal alignment is not surprising.

\section{Yield strength}

For the 2014 western Pacaya flow, application of Eq. 5 (with $h_{\mathrm{c}}=2 \pm 1 \mathrm{~m}, r=2,300 \mathrm{~kg} / \mathrm{m}^{3}$, $g=9.8 \mathrm{~m} / \mathrm{s}^{2}, a=45^{\circ}$ ) leads to a yield strength estimate of $\sim 45,200 \pm 22,600 \mathrm{~Pa}$, while use of Eq. 6 (with $w=1.5 \pm 0.5 \mathrm{~m}$ ) results in a yield strength of $\sim 41,700 \pm 13,900 \mathrm{~Pa}$. The biggest uncertainty is in flow thickness / levée height, so these estimates could be in error by as much as a factor of 2 . Near the flow toe, where ground slope was $\sim 3^{\circ}$, and the flow front 
was $\sim 3 \mathrm{~m}$ high, yield strength is estimated at $\sim 340,000 \mathrm{~Pa}$ from Eq. 5. In contrast, laboratory experiments did not reveal a yield strength even at the highest investigated crystal volume fraction of 0.40 . Although our laboratory subliquidus rheology data were fit using the Herschel-Bulkley constitutive law, which allows for the existence of a yield strength, the best values returned were always within error of zero. This suggests that yield strength develops between crystal fractions of 0.40 in laboratory experiments and 0.75 lava dense rock equivalent in the field for this basaltic composition.

\subsubsection{Laboratory constraints on three-phase rheology}

Few studies have focused on three-phase rheology, where crystals and bubbles coexist in a melt. Truby et al. (2015) developed an effective medium treatment of the issue, in which the bubble suspension is treated as a continuous medium suspending the crystals. Although experimentally validated, this model is only applicable when bubbles are smaller than crystals, which is often not the case in magmas, and does not apply to the lava flows at Pacaya. Phan-Thien and Pham (1997) obtained the viscosity of three-phase mixtures via a multi stage process in which a series of incremental additions of crystals and bubbles of various sizes to a starting melt allows to calculate the effective viscosity of the mixture at each step, and to use it as a starting point for the next step. The model is limited in that it is based on a single strain rate of $1 \mathrm{~s}^{-1}$ and treats bubbles as rigid spheres, so that bubbles should always increase the mixture bulk viscosity. However, for 2014 Pacaya lavas the melt + crystal viscosity measured in the laboratory is already higher than the three-phase viscosity predicted by the Phan-Thien and Pham (1997) model, which

points to the model underestimating viscosity. The strain rate variation between $4.2 \mathrm{~s}^{-1}$ 
and $0.2 \mathrm{~s}^{-1}$, together with the presence of crystals with two distinct size populations, may at least partially explain this discrepancy. However, it is likely that the model simply cannot be applied to lavas with such a high crystallinity and high viscosity. For the 2014 eruption at Pacaya, we can turn to field observations to place constraints on three-phase rheological behavior.

\subsubsection{Field constraints of three-phase rheology}

Viscosity in both the upper channel and 'a'a portions of the flow was estimated from the video recordings. Effective viscosity estimates were influenced by slope, density, and depth: stress was calculated from the measured density, measured ground slope, and assumed depth, and strain rate was calculated from the observed velocity and an assumed depth. The estimated effective viscosity was $7,600_{-5,700}^{+9,500} \mathrm{~Pa} \cdot \mathrm{s}$ upflow, which increased by a factor of 3.7 to to $28,000_{-15,700}^{+12,200} \mathrm{~Pa} \cdot \mathrm{s}$ only $\sim 550 \mathrm{~m}$ downflow.

A direct temperature measurement is not available for the 2014 eruption, but upflow thermocouple-based temperature measurements of the compositionally similar 2010 flow by one of us [G.C.] are around $1200{ }^{\circ} \mathrm{C}$. Comparison of crystal fraction in natural and experimental samples collected from the 2014 eruption also lead to an estimate of about $1200{ }^{\circ} \mathrm{C}$. Although the surface temperature of the flow clearly decreased from the incandescent magma fully exposed near the vent, to the colder 'a`a blocks towards the toe, the flow interior probably remained thermally insulated. While `a a lava flows do not develop a proper crust, the top blocks cool down quickly in contact with the air, and subsequently prevent the core of the flow from radiating the majority of its heat.

Comparison with experimental data collected at $1199{ }^{\circ} \mathrm{C}$ (Fig. 2.11), pertinent to the 
upper channel conditions, indicates that the decrease in ground slope from $45^{\circ}$ at $50 \mathrm{~m}$ from the vent to $4^{\circ}$ at $600 \mathrm{~m}$ from the vent should result in a factor of 2.9 increase in effective viscosity, simply due to pseudoplastic behavior. This was calculated by noting that when the strain rate in the experiment was $4.2 \mathrm{~s}^{-1}$, corresponding to the observed strain rate near the vent at Pacaya, the effective stress in the experiment was 3,637 Pa, and the effective viscosity was $866 \mathrm{~Pa} \cdot \mathrm{s}$. Reducing the effective stress by a factor of 11.25 , equivalent to reducing the slope from $45^{\circ}$ to $4^{\circ}$, resulted in a predicted strain rate of $0.13 \mathrm{~s}^{-1}$ and an effective viscosity of $2,476 \mathrm{~Pa} \cdot \mathrm{s}$, an increase of 2.9 times. Strain estimates based on Jeffreys' equation for the studied downflow location yield a slightly higher strain rate of $0.23 \mathrm{~s}^{-1}$ due to flow depth increase. The additional increase in effective viscosity observed between the proximal and distal locations must have resulted from cooling and crystallization.

The factor of 2.9 is a minimum constraint on the effect of ground slope on viscosity, because the degree of non-Newtonian behavior increases with crystal fraction. The additional factor of 1.3 viscosity increase observed, corresponding to 6,054 $\mathrm{Pa} \cdot \mathrm{s}$, could result entirely from cooling of $70{ }^{\circ} \mathrm{C}$, based on the VTF equation for the evolved liquid. This is a maximum estimate of the amount of cooling, because any temperature decrease should also result in an increase in crystal fraction, which would in turn increase the viscosity. Alternatively, this additional viscosity increase of $6,054 \mathrm{~Pa} \cdot \mathrm{s}$ could result entirely from further crystallization of an already undercooled melt. A combination of cooling and crystallization is the most likely possibility. As in the laboratory experiments, the chemical effect of evolving residual melt of the flow is expected to be negligible compared to the physical effects of decreasing strain rate and increasing crystal fraction. 
We conclude that pre-existing topography has a fundamental role in determining flow rheology, by affecting the stress and strain rate imposed on the lava. For the 2014 southern Pacaya flow, strain rate decrease accounts for most of the observed effective viscosity increase, at least within our observation range (between $50 \mathrm{~m}$ and $600 \mathrm{~m}$ from the vent).

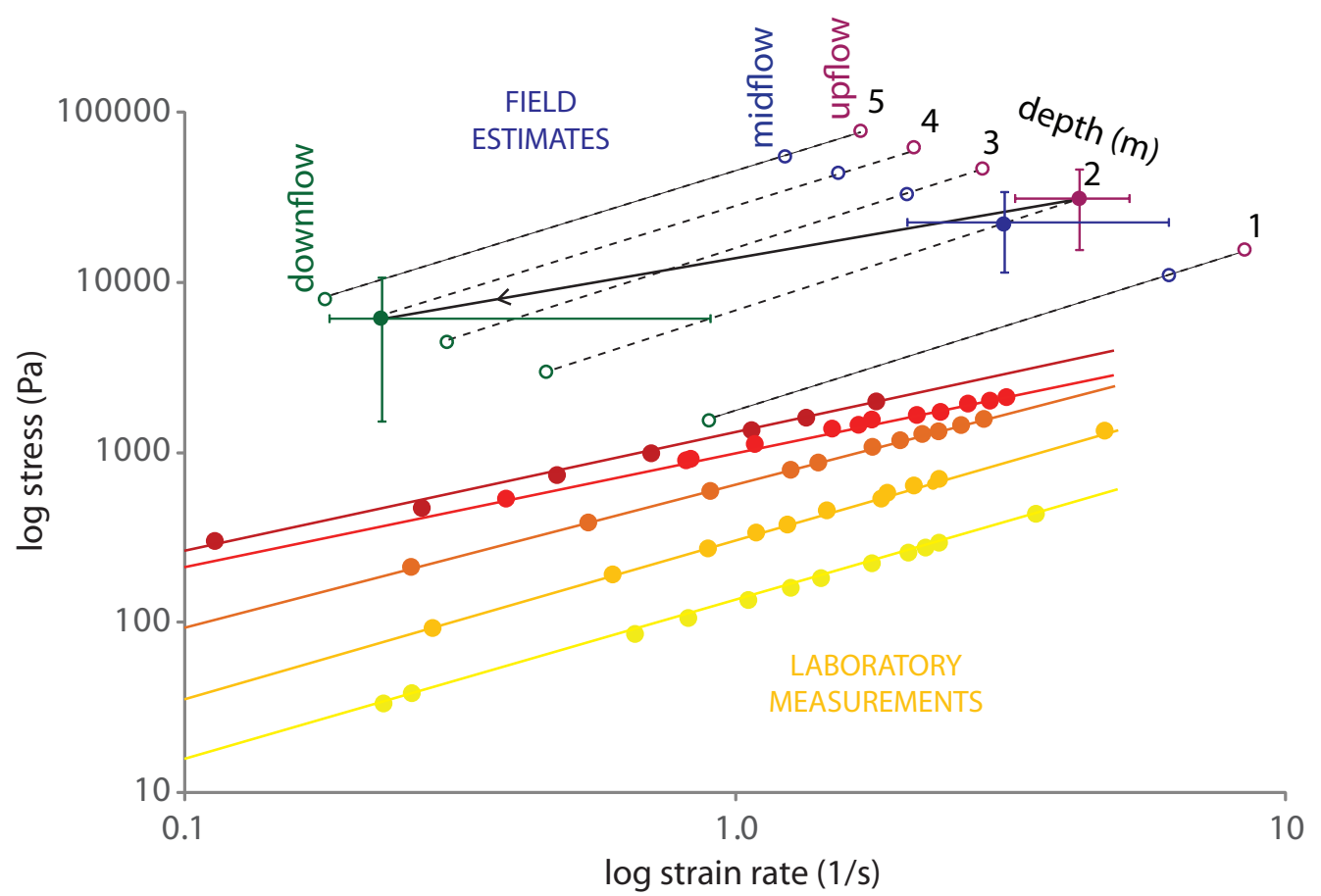

Figure 2.11 Log stress vs. log strain rate plot showing subliquidus experimental data (yellow to red color shades) compared to viscosity estimates based on field measurements (data in Table 2.4). A range of plausible depths is presented for field estimates, and the most likely viscosity path is shown (solid black line).

Bubbles are also omnipresent in the flow, and they can be expected to significantly affect the lava rheology. As shown by Llewellin and Manga (2005), "soft", deformed bubbles such as those observed in our natural samples form in response to a fluid dynamic regime 
in which viscous forces prevail over surface tension forces (capillary number $\mathrm{Ca}>1$ ). Specifically, we calculate a range of capillary numbers of $2<\mathrm{Ca}<73$, based on the strain rates estimated in the field, effective viscosities measured in the laboratory at $1200{ }^{\circ} \mathrm{C}$, and the observed bubble sizes (1-5 mm). Hence the presence of bubbles should result in a decrease in the effective bulk viscosity of the lava, of up to 50\% (Llewellin and Manga 2005). The bubble population is extremely heterogeneous throughout the flow, as highlighted by the significant variability of density even within individual samples (Table 2.3). As a consequence, we speculate that large viscosity variations must exist at the local (cm to $\mathrm{m}$ ) scale. However, we do not observe any systematic increase or decrease in the bubble fraction, size, or shape (thin sections observations) downflow. We therefore assume that the effect of bubbles on the rheology of the flow is similar for both the uppermost and downflow sections. This assumption allows us to infer the relative effects of cooling, chemical evolution, crystallization, and slope decrease along the lava flow. The rheological effect of bubbles certainly causes a discrepancy between field- and laboratory- based viscosity estimates. However, as shown by Fig. 2.11, field-based (bubble rich) viscosity estimates are higher than laboratory-based (bubble free) measurements. It is therefore apparent that the lower temperature and higher crystallinity which characterize lava in the field play a more prominent role than bubbles in determining its rheology. It is interesting to note that the isothermal flow curves measured in the laboratory and the preferred path estimated from the field observations are almost parallel (Fig. 2.11), substantiating the utility of integrating the two techniques when studying the rheology of a lava flow. 


\subsection{Conclusions}

Through the integration of field observations and laboratory experiments, we assessed how the rheological properties of the January 2014 Pacaya lava flows evolved both in space and time. In the laboratory, we measured the rheology of lava during cooling and crystallization from $1234{ }^{\circ} \mathrm{C}$ to $1199{ }^{\circ} \mathrm{C}$, and we observed increasing viscosity and increasing shear-thinning behavior with increasing crystal fraction. In the field, we estimated a 3.7-fold effective viscosity increase, from $\sim 7,600 \mathrm{~Pa} \cdot \mathrm{s}$ to $\sim 28,000 \mathrm{~Pa} \cdot \mathrm{s}$, of a flow erupted at $\sim 1200{ }^{\circ} \mathrm{C}$. Our laboratory and field measurements are complementary, as they span contiguous temperature ranges. Accounting for the differences in crystal and bubble fraction, the two data sets are mutually consistent. We show that near the vent, the rheological behavior of the studied flow was mainly controlled by the influence of preexisting topography. By analogy with experimentally determined constitutive relations, we calculated that the slope reduction accounts for about a $2.9 \mathrm{x}$ increase in effective viscosity, while cooling and crystallization account for no more than a $1.3 \mathrm{x}$ increase. Our results should apply qualitatively to other volcanoes with dramatic variations in slope, especially for high crystallinity lavas that display shear-thinning behavior. Furthermore, our results reinforce the necessity of incorporating the complex relations between slope, flow velocity and lava rheology into models of lava flow emplacement. 


\section{CHAPTER 3}

\section{Emplacement Dynamics and Timescale of a Holocene Flow from the Cima Volcanic Field (CA): Insights from Rheology and Morphology}

\subsection{Introduction}

\subsubsection{Monogenetic volcanic fields, lava rheology and morphology}

Monogenetic volcanic fields, i.e. spatial and temporal clusters of cinder and scoria cones, tuff rings, and other single-eruption volcanic features, are widespread in the western United States of America. Examples are located in Nevada (Southwest Nevada Volcanic Field), Arizona (San Francisco Volcanic Field), New Mexico (Zuni-Bandera Volcanic Field), and California (Cima Volcanic Field) among other locations (Wood and Kienle 1992). Monogenetic volcanism has a significant hazard potential (Valentine and Connor 2015). Volcanic activity can begin abruptly, and it can range from effusive to mildly explosive. Although field observations of active flows are ideal for studying the evolving rheology of

lava, such direct observations are rare, especially for monogenetic continental intraplate volcanism, with the notable exception of the 1943-1952 eruption of Parícutin, Mexico (Foshag and Gonzales 1956). The preserved morphology of inactive lava flows records their rheological development, particularly in the waning stages of emplacement, and therefore represent a valid alternative to syn-eruptive observations (Gregg and Fink 2000). 
Subaerial basaltic lava flows present a complex surface morphology, which can be described in Hawai'ian terminology on a continuous spectrum between the pahoehoe and 'a'ā end-members (Dutton 1884). Pahoehoe surface texture is smooth and ropey; 'a' $\bar{a}$ surface texture is rough and blocky. These different flow surface textures partly reflect differences in lava's internal structure. For example, the development of a yield strength due to increasing groundmass crystal fraction favors 'a'ā morphology (Sato 1995; Soule and Cashman 2005). Physical and rheological properties vary continuously along and across the lava flow through space and time (e.g. Griffiths 2000), driven by cooling, crystallization, and topographic variations. The last stage of these variations is frozen in the final morphology of the flow (Hulme 1974). Flow emplacement conditions also contribute to shaping the flow surface appearance (Macdonald 1953; Cashman et al. 1999). High effusion temperatures and associated low viscosities favor the formation of pahoehoetype flows, while low effusion temperatures, corresponding to higher viscosities, favor the formation of 'a'ā fields (e.g. Kilburn 1987; Rowland and Walker 1990; Cashman et al. 1999). A flow may transition across the morphological spectrum in space and time. Peterson and Tilling (1980) developed the qualitative concept of a transition threshold zone (TTZ): low viscosity lavas need to experience higher strain rates in order to begin the transition to ' $a$ ' $\bar{a}$, while more viscous lavas transition to ' $a$ ' $\bar{a}$ at lower strain rates. The rheological conditions of the TTZ were recently quantified experimentally for Hawai'ian lavas (Sehlke et al. 2014). The transition in flow morphology can occur either way depending on the conditions. For example, a decrease in slope causing a decrease in strain rate can cause a reversal in surface flow morphology from ' $a$ 'à to pahoehoe (e.g. Calvari and Pinkerton 1998; Hon et al. 2003). However, for a single quantum of magma the 
transition can only be crossed forward, from pahoehoe to 'a' $\bar{a}$, as brittle crust cannot revert to plastic lava (Kilburn 1981). Both pahoehoe and 'a'ā morphologies have been reported in lava flows associated with scoria cones (e.g., Craters of the Moon, ID; Valentine and Gregg 2008). In summary, flow morphology reflects changes in rheological properties, eruptive parameters, and pre-existing topography, with the potential of revealing important clues as to the emplacement conditions of flows whose active stage was not observed.

In a magmatic system at equilibrium, temperature $(T)$ controls crystal fraction $\left(\Phi_{c}\right)$ and residual liquid composition $(X)$. The combination of these three factors $\left(T, X, \Phi_{c}\right)$ contributes to determining the main rheological properties of a lava: viscosity $(\eta)$ and yield strength $(\sigma \square)$ (e.g. Spera 2000). However, other external factors, such as underlying topography and magma effusion rate, also play an important role by modulating the applied stress $(\sigma)$ and resulting strain rate $(\dot{\gamma})$ experienced by a flow. A constitutive relation between stress, strain rate, viscosity, and yield strength is the most effective way of describing the rheological behavior of a flow. Constitutive relations are typically visualized as stress vs. strain rate flow curves. A variety of options exist, and choosing the most appropriate one is not a trivial task.

Silicate liquids are Newtonian $(\sigma=\eta \dot{\gamma})$, except at very high strain rates (Webb and Dingwell 1990). Experiments on crystal-bearing lavas and on analog particle-bearing suspensions have produced a broad spectrum of results and interpretations that were reviewed by Mader et al. (2013). For example, Ishibashi and Sato (2010) found that a Bingham model ( $\sigma=$ $\left.\eta \dot{\gamma}+\sigma_{\square}\right)$ best described the subliquidus rheology of Fuji basalts up to a crystal fraction of 0.25. On the other hand, Soldati et al. (2016) found clear evidence of shear-thinning behavior in Pacaya basalts at crystal fractions as low as 0.001 , and hence fitted their data 
to a power-law model ( $\sigma=\mathrm{K} \dot{\gamma}^{n}$, where $n$ is the flow index and $\mathrm{K}$ is the consistency). Sehlke et al. (2014) detected both shear-thinning behavior and the existence of a yield strength in Mauna Ulu basalts, and therefore used a Herschel-Bulkley model $\left(\sigma=\mathrm{K} \dot{\gamma}^{n}+\sigma \square\right.$; Herschel and Bulkley 1926) to describe their rheological data. The Herschel-Bulkley model allows the most fitting flexibility, as it includes all parameters that are selectively dropped in special cases (e.g. the Bingham model does not allow shear-thinning behavior, and the power-law model does not allow for a yield strength).

Natural lavas are typically three-phase materials, with both rigid crystalline inclusions and deformable bubbles, which makes their rheological behavior even more complex. Although there are models available for predicting such behavior (Phan-Thien and Pham 1997; Truby et al. 2014), natural scenarios cannot yet be reproduced in all of their complexities, which include rate of effective viscosity increase with crystal fraction (e.g. Costa 2005; Costa et al. 2009; Ishibashi 2009) and the effects of crystal size and shape distributions on effective viscosity and shear-thinning behavior (e.g. Castruccio et al. 2010, Cimarelli et al. 2011; Mueller et al. 2011; Faroughi and Huber 2014; Moitra and Gonnermann 2015).

Monogenetic scoria cones may produce lava flows in different ways (Valentine and Gregg 2007). Lava may be effused from an existing vent or a bocca, typically resulting in a horseshoe shaped cone, with the crater opening towards the side where lava flowed out (e.g. Lathrop Wells, NV; Valentine et al. 2007). Alternatively, lava flows associated with scoria cones can be clastogenic, forming from rapidly accumulating, still molten pyroclasts coalescing into a cohesive flow (e.g. Vulcan Cone, NM; Smith et al. 1999). The effusion rate and emplacement timescale of such lava flows are outstanding questions which remain 
open in the study of the eruptive dynamics of monogenetic volcanic fields. In this work, we aim at addressing such questions through a detailed rheological and morphological study of a lava flow in the Cima Volcanic Field (CA).

\subsubsection{Geological setting}
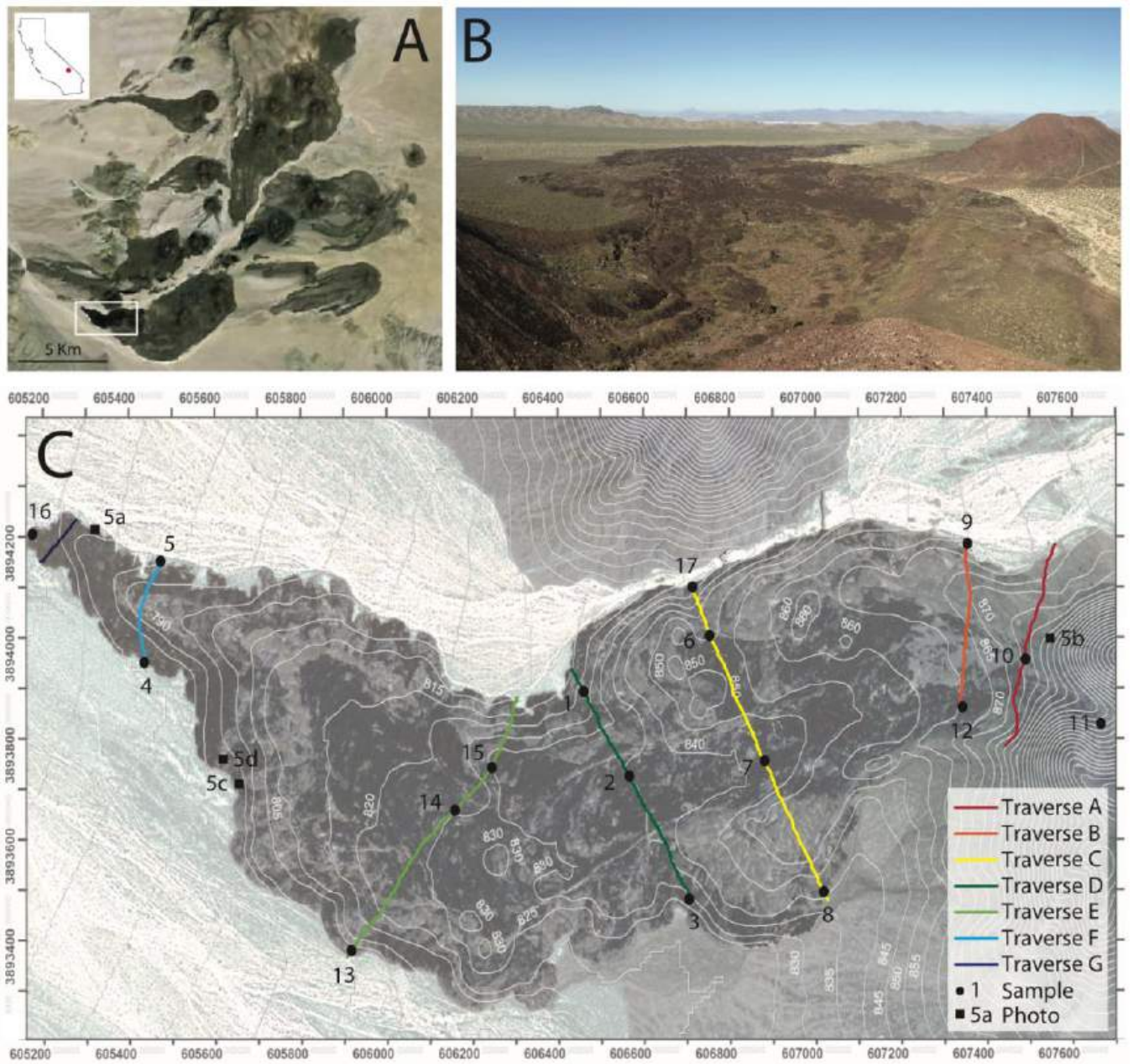

Figure 3.1 (a) Aerial map of Cima Volcanic Field (GoogleEarth ${ }^{\circledR}$ image); (b) downflow, westward view from sample 11 location; (c) studied flow (DEM) with transverse profiles and sample locations. 
Cima Volcanic Field (Fig. 3.1a), located in southeastern California, encompasses roughly 40 cinder cones and 60 associated lava flows, mainly of Quaternary age. Volcanic activity in Cima has been dated as far back as 8 m.y. (Farr 1992), but the peak occurred between 1 m.y. and 0.25 m.y. (Dohrenwend et al. 1984). The most likely cause of volcanism at Cima is the opening of the Farallon slab window, and the associated advanced-stage lithospheric removal (Allison et al. 2013). The activity is monogenetic, hence each cone only had one pulse of activity. This makes it the ideal setting for a morphological study, as we can confidently interpret the observed features in the frame of a single effusive episode.

In this research we focused on the only lava flow whose parent cone can be identified unambiguously (vent A; Dohrenwend et al. 1984), which is situated in the southwest corner of the volcanic field (Fig. 3.1a). The flow (Fig. 3.1b) extrudes from a single breach on the western side of the cinder cone edifice, is about $2 \mathrm{~km}$ long, and has a well-defined channel bound by high levées. The distal part of the flow narrows rapidly after the disappearance of the channel, and many small lobes bound the toe. While sparse core extrusions occur all over the flow, the only spatially extensive patches of smooth lava were observed near the vent, with the rest of flow surface being 'a'à. The surface morphology is very well preserved, thanks to a combination of young age $\left(0.015 \pm 0.005 \mathrm{~m} . \mathrm{y}\right.$. as per ${ }^{14} \mathrm{C}$ dating, which makes it the youngest of the volcanic field) and low erosion and re-vegetation rates associated with the Mojave high desert climate (Dohrenwend et al. 1986). Such conditions are ideal to address the emplacement conditions of lava flows associated with monogenetic volcanism. We approach the issue through a combination of field observations of flow morphology and laboratory experiments on lava rheology, similarly to the approach taken by Robert et al. (2014) and Sehlke et al. (2014) on Mauna Ulu tholeiites. We expect our 
experimental results to be applicable to flows of similar composition erupted in other monogenetic volcanic fields, such as the San Francisco field, AZ (Arculus and Gust, 1995) and the Raton-Clayton field, NM (Stormer 1972). Our field-based inferences pertain specifically to the emplacement conditions of the studied flow.

\subsection{Methods}

\subsubsection{Field Data Acquisition}

We acquired 7 transverse topographic profiles across the lava flow (Fig. 3.1c) using a Trimble ${ }^{\circledR}$ Real Time Kinematic (RTK) GPS system with an average point spacing of $5 \mathrm{~m}$. The south facing slope of the southern levée edge of the flow could not be measured by the RTK GPS because there was no communication with the base station, located at the base of the northern edge of the flow. Consequently, all southern levée measurements were made with a TruPulse 360R hand-held laser rangefinder instead, which has an accuracy of $\pm 30 \mathrm{~cm}$. Traverses A and B covered the proximal zone, traverses $\mathrm{C}, \mathrm{D}$, and $\mathrm{E}$ spanned the center of the flow, and traverses $\mathrm{F}$ and $\mathrm{G}$ bridged the distal portion of the flow. We collected seventeen samples along the traverses, from both the main channel and the levées, and at other key locations including the top of the cinder cone and the flow toe (Fig. 3.1c; Table $3.1)$.

We also conducted a low-altitude photographic survey of the lava flow using a small aerial system that supported a nadir-viewing camera. Aerial photos were acquired from approximately $100 \mathrm{~m}$ above ground using a 20 megapixel Sony RX100 camera with a FOV 
of $65 \times 46$ degrees and a $5472 \times 3648$ pixel resolution, which resulted in $\sim 3 \mathrm{~cm}$ ground pixel resolution. The easternmost part of the flow was covered with the same camera under the same flight conditions by video instead, with a 1920x1080 pixel resolution resulting in a $\sim 9 \mathrm{~cm}$ ground pixel resolution. The area surveyed covered approximately $2 \mathrm{~km}^{2}$ with nearly 1,700 photos. 14 ground control points were located using RTK GPS in order to calculate the precise external geometry of the survey.

\begin{tabular}{cccl}
\hline Sample & $\begin{array}{c}\text { UTM East } \\
\text { m }\end{array}$ & $\begin{array}{c}\text { UTM North } \\
\text { m }\end{array}$ & \\
\hline & & & \\
14CIMA11 & 3893700 & 607650 & Cinder cone, north side of summit \\
14CIMA10 & 3893850 & 607600 & Traverse A, pahoehoe rope \\
14CIMA09 & 3894194 & 607430 & Traverse B, north levée \\
14CIMA12 & 3893789 & 607417 & Traverse B, south levée \\
14CIMA06 & 3893962 & 606747 & Traverse C, side channel \\
14CIMA07 & 3893739 & 606867 & Traverse C, main channel \\
14CIMA17 & 3894140 & 606700 & Traverse C, north levée (camp side) \\
14CIMA08 & 3893504 & 606995 & Traverse C, south levée \\
14CIMA01 & 3893862 & 606472 & Traverse D, north levée \\
14CIMA02 & 3893711 & 606572 & Traverse D, main channel \\
14CIMA03 & 3893491 & 606702 & Traverse D, south levée base \\
14CIMA13 & 3893400 & 605966 & Traverse E, lava tube \\
14CIMA14 & 3893650 & 606191 & Traverse E, main channel \\
14CIMA15 & 3893727 & 606272 & Traverse E, whale back \\
14CIMA05 & 3894090 & 605550 & Traverse F, north levée \\
14CIMA04 & 3893915 & 605514 & Traverse F, south levée base \\
14CIMA16 & 3894200 & 605150 & Flow toe \\
& & & \\
\hline & & &
\end{tabular}

Table 3.1 Sample locations. 


\subsubsection{Photogrammetric Processing and Morphometry}

Photogrammetric processing of photo-survey data was performed using Agisoft Photoscan Pro (www.agisoft.com). Aerial photos were used to construct a high density point cloud ( $\sim 3 \mathrm{~cm}$ point spacing) for the entire flow. Ground-control points constrained the exterior orientation of the survey, along with spatial scale. Owing to the nadir-view of the aerial photographs, the point cloud is more accurately described as a $2.5 \mathrm{D}$ survey, as true $3 \mathrm{D}$ geometries (such as surface recumbency) cannot be completely imaged. Despite the reduction in dimensionality, most vegetation points (in this case, sparse sage brush) were successfully classified and filtered using the CANUPO classifier (Brodu and Lague 2012) implemented in the CloudCompare software package (http://www.cloudcompare.org). The resulting point cloud was meshed using a Poisson surface estimator to produce a $5 \mathrm{~cm}$ pixel digital elevation model (DEM). The DEM was used to calculate the flow volume by subtracting the underlying topography interpolated across the flow edges. The DEM also provided a basis for morphometric analyses of surface roughness. In this study, we are quantifying surface roughness as the standard deviation of measured points from a smoothed, approximate surface, following the approach described by Shepard et al. (2001). The smoothed surface was generated using a $1 \mathrm{~m}$ averaging kernel filter ("FocalMean" function in ArcGIS), therefore we used 400 data points $/ \mathrm{m}^{2}$.

Additionally, we averaged the point cloud points within a defined (20 cm radius) neighborhood about each RTK GPS point for profiles C-G (profiles A and B were outside of the photogrammetric survey area). We then compared the average elevation from the point cloud with the measured RTK GPS points, in order to compare the two survey methodologies. Finally, we extracted point cloud profiles by projecting the point cloud raw 
points within a specified distance $(10 \mathrm{~cm})$ of the straight-line profile (defined by the RTK GPS end points) on to a straight line.

\subsubsection{Rheology experiments: sample preparation}

Sample 14CIMA07 (indicated by the number 7 in Fig. 3.1c) was selected for experimental work, as its bulk chemical composition and petrographic texture were representative of most samples. A $150 \mathrm{~g}$ piece was crushed to fine powder in a shatterbox, and melted in an iron-saturated Pt90-Rh10 crucible in an MHI brand, Z-series box furnace. The sample was melted for 30 minutes at $1600{ }^{\circ} \mathrm{C}$ in air and splat-quenched on a copper plate. The resulting glass was again crushed, melted, and quenched with the same protocol in order to ensure homogenization of the sample. Electron microprobe analysis confirmed homogeneity and that no alkali loss occurred relative to the bulk rock (Table 3.2). Several cylindrical cores were drilled and polished for parallel plate viscometry, while the rest of the glass was retained for concentric cylinder viscometry.

The quenched interstitial melt composition of the lowest temperature subliquidus run (1160 ${ }^{\circ} \mathrm{C}$ ) was analyzed, and $110 \mathrm{~g}$ of glass of that composition (14CIMA07evo) were synthesized from oxide $\left(\mathrm{SiO}_{2}, \mathrm{TiO}_{2}, \mathrm{Al}_{2} \mathrm{O}_{3}, \mathrm{Fe}_{2} \mathrm{O}_{3}, \mathrm{MnO}, \mathrm{MgO}\right)$ and carbonate $\left(\mathrm{CaCO}_{3}\right.$, $\left.\mathrm{Na}_{2} \mathrm{CO}_{3}, \mathrm{~K}_{2} \mathrm{CO}_{3}\right)$ powders in the box furnace, following the same homogenization procedure as for the natural sample. During this process, all $\mathrm{CO}_{2}$ was driven off. Synthesis of this sample is necessary to isolate the effect of chemical evolution on melt viscosity. 


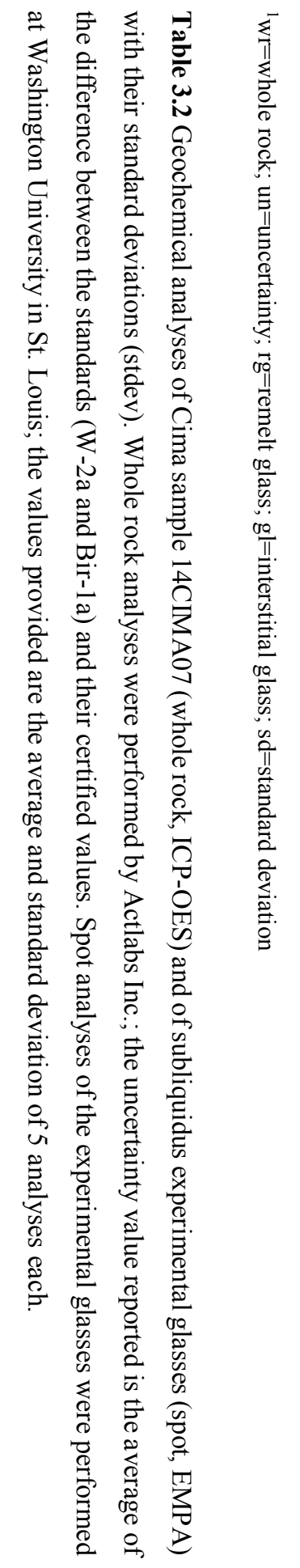

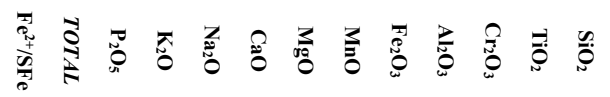

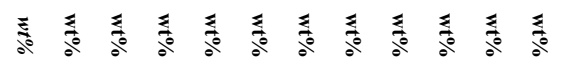

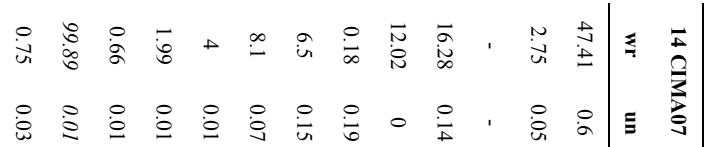

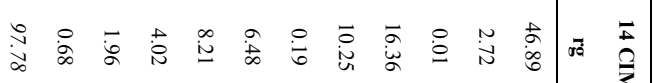

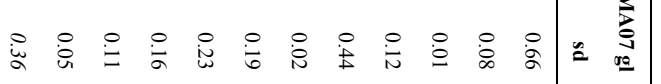

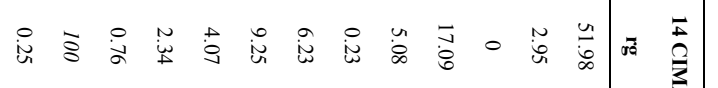

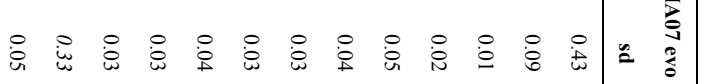

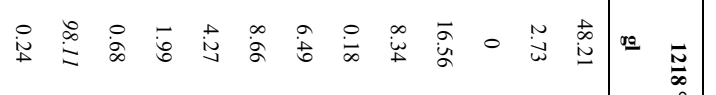

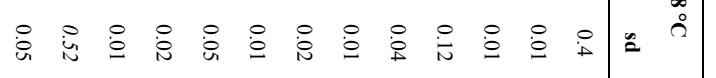

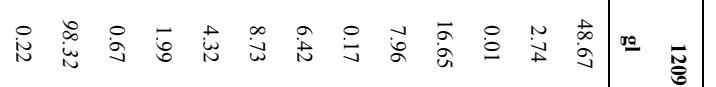

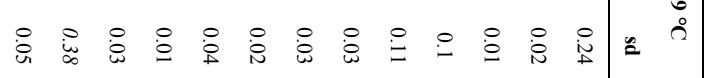

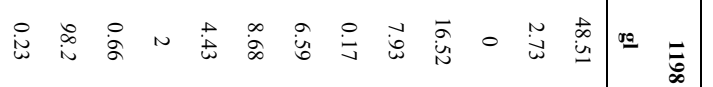

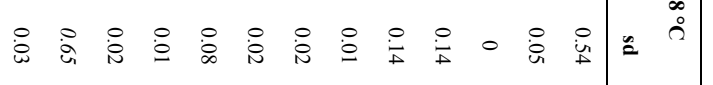

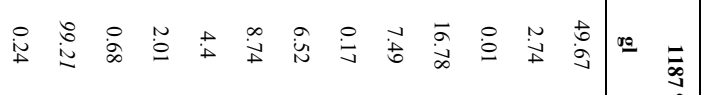

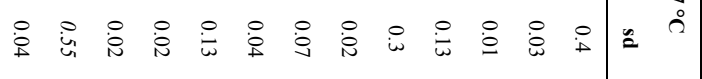

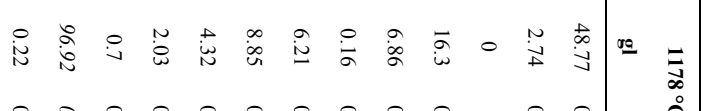

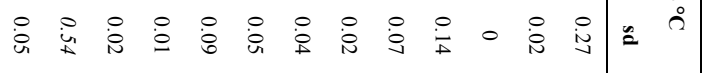

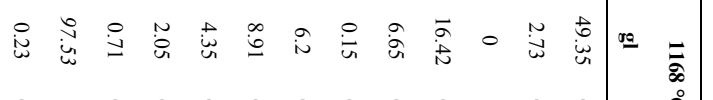

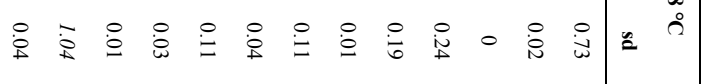

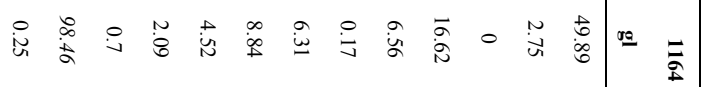

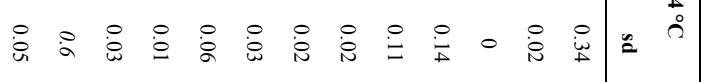

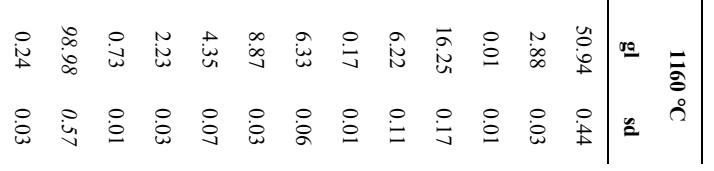




\subsubsection{Parallel plate viscometry}

Cylindrical cores $(\varnothing=6.6 \mathrm{~mm}, 5 \mathrm{~mm}<\mathrm{h}<10 \mathrm{~mm})$ of glass, optically confirmed to be crystal free, were drilled and polished so as to make their faces parallel. Their viscosity was measured in a Theta Industries Rheotronic III parallel plate viscometer, over the $\sim 10^{9} \mathrm{~Pa} \cdot \mathrm{s}$ to $\sim 10^{13} \mathrm{~Pa} \cdot \mathrm{s}$ range. The instrument works by applying a known uniaxial load, typically $1500 \mathrm{~g}$, to a cylindrical sample held at the desired temperature in a furnace. The vertical deformation over time (linear strain rate) was measured with a linear variable displacement transducer (LVDT), and the effective viscosity was obtained as the ratio of stress to volumetric strain rate. Strain rate data were collected at alternating higher and lower temperatures, so that sample crystallization would be apparent in a log viscosity vs. inverse temperature plot as a deviation from the trend established by the data points previously collected during the same experiment. Based on visual inspection, and on the smooth trends of the viscosity data, no crystallization was detected in our experiments. Additionally, density was measured before and after each experiment, and it was found to be consistent within error (a maximum variation of $0.05 \%$ ), further supporting the lack of synexperimental crystallization. Repeatability is typically better than $0.04 \log$ units and comparison with NIST standard glasses indicates an accuracy of $0.06 \log$ units or better (Whittington et al. 2009).

\subsubsection{Concentric cylinder viscometry}

A Theta Industries Rheotronic II Rotating viscometer was used to perform both superliquidus and subliquidus experiments ( $\sim 1 \mathrm{~Pa} \cdot \mathrm{s}$ to $\sim 2,000 \mathrm{~Pa} \cdot \mathrm{s}$ viscosity range). All experiments were conducted in air, consequently at atmospheric pressure in the absence of 
volatiles. We used a Brookfield DV3TRV Rheometer measuring head for superliquidus experiments and a Brookfield HBDV-III Ultra measuring head for subliquidus experiments, where more torque was required. Full instrumental details can be found in Soldati et al. (2016). The sample was placed in an iron-saturated Pt90-Rh10 cylindrical crucible $($ height $=65 \mathrm{~mm}$; inner diameter $=30.125 \mathrm{~mm})$ lowered into a furnace. An alumina spindle covered by an iron-saturated $\mathrm{Pt}_{90}-\mathrm{Rh}_{10}$ sleeve (height $=65 \mathrm{~mm}$; outer diameter $=$ $3.75 \mathrm{~mm}$ ) was immersed in the melt to a depth of about $20 \mathrm{~mm}$ and made to rotate by the measuring head at selected speeds (1-250 rotations per minute), corresponding to a specific strain rate calculated as:

$$
\dot{\gamma}=\frac{2 \omega}{n\left(1-\left(r_{s} / r_{c}\right)^{2 / n}\right)}
$$

where $\omega=$ spindle angular velocity $[\mathrm{rad} / \mathrm{s}], r_{c}=$ crucible inner radius $[\mathrm{m}]$, and $n=$ flow index.

The exact immersion depth was verified after each experiment by measuring the height to which melt coated the spindle. The computer recorded torque values as percentages of the maximum spring torque of the measuring head, which were used to calculate the stress with the following equation:

$$
\sigma=\frac{M}{2 \pi\left(r_{s}^{2} l\right)}
$$

where $\mathrm{M}=$ torque $[\mathrm{N} \cdot \mathrm{m}], r_{\mathrm{s}}=$ spindle radius $[\mathrm{m}]$, and $l=$ spindle immersion depth $[\mathrm{m}]$. The crucible+spindle assembly was calibrated with two different silicon oils of certified viscosity.

Only data recorded after steady-state torque readings had been achieved were used to calculate effective viscosity, obtained as the ratio of stress to strain rate:

$$
\eta=\frac{\sigma}{\dot{\gamma}}
$$


Steady torque readings were typically achieved within 2 to 5 minutes in superliquidus experiments, and after several hours in subliquidus experiments, and lasted at least 15 minutes in superliquidus experiments, and at least 30 minutes in subliquidus experiments. Both superliquidus and subliquidus experiments started by heating the sample to $1500{ }^{\circ} \mathrm{C}$ and letting the melt thermally and chemically equilibrate for 30 minutes while continuously stirring it, with the objective of dissolving pre-existing crystal nuclei. In order to ensure that crystals were no longer present, the viscosity was checked to be Newtonian by varying the strain rate.

For superliquidus experiments, starting at $1500^{\circ} \mathrm{C}$, the temperature was decreased stepwise by $25^{\circ} \mathrm{C}$ at a time ( $\sim 1 \mathrm{~h}$ per step). At each temperature, measurements were made at three different angular velocities. For subliquidus experiments the melt was cooled at $10{ }^{\circ} \mathrm{C} / \mathrm{min}$ until the target temperature was reached, and the melt was left to equilibrate at that temperature for at least 12 hours. Temperature is monitored with an S-type thermocouple located along the crucible, at about the same level as the spindle immersion depth.

About 10 measurements were subsequently performed at constant temperature but alternating higher and lower angular velocities, so that if any hysteresis had occurred (which it did not) it would have been noticeable. At the end of each subliquidus experiment the spindle was raised out of the melt, and the crucible was rapidly removed from the assembly and quenched in a water bath. We estimate a cooling rate of at least $\sim 10{ }^{\circ} \mathrm{C} / \mathrm{s}$ through the glass transition, and therefore expect that the crystal fraction observed in quenched products records that at experimental conditions. Samples were extracted from the crucible by drilling cores with a $25 \mathrm{~mm}$ diameter drill bit, and polished sections were prepared from the recovered material. The same crucible was then used for the next 
subliquidus experiment. A few grams of the originally homogenized glass were added as a replacement of the material drilled out after each experiment.

\subsubsection{Density measurements}

Dense-rock equivalent (DRE) densities of powdered rock samples were measured by helium pycnometry using a Quantachrome manual pycnometer. Densities of glass cores before and after parallel-plate viscometry were measured by the Archimedean method, using anhydrous ethanol as the immersion liquid. The geometric density of samples used for field-based yield strength estimates was measured by dividing their volume by their weigth.

\subsubsection{Chemical analyses}

Samples $7,10,13,16$, and 17, representing key flow locations spanning the full flow length from vent to toe, were powdered for analysis. Bulk rock chemical analyses were performed by Inductively Coupled Plasma Optical Emission Spectroscopy (ICP-OES) at Actlabs Inc. (Ontario, Canada). Calibration was implemented using USGS and CANMET certified reference materials during the analysis.

The compositions of phases in rock samples 7,10 , and 16 , and every post-subliquidus experimental sample, were analyzed at Washington University in St. Louis on a JEOL JXA-8200 electron microprobe equipped with five wavelength-dispersive spectrometers (WDS) and a JEOL (e2v / Gresham) silicon-drift energy-dispersive spectrometer (EDS). Samples were analyzed for $\mathrm{Si}, \mathrm{Mg}, \mathrm{Fe}, \mathrm{Al}, \mathrm{Mn}, \mathrm{Na}, \mathrm{K}, \mathrm{Ti}, \mathrm{P}, \mathrm{Cr}$, and $\mathrm{Ca}$. Operating conditions were $15 \mathrm{kV}$ accelerating potential and $25 \mathrm{nA}$ probe current with a $4 \mu \mathrm{m}$ beam 
diameter. Silicate and oxide standards were used for calibration, and data were corrected with CITZAF (Armstrong 1995). A minimum of five individual analyses were performed on each glass, and at least three individual analyses were obtained for each crystal phase in every post-experiment sample.

\subsubsection{Evaluation of phase volume fractions}

In order to quantify the crystal fraction of each subliquidus experiment, both radial and longitudinal sections of the crucible contents were analyzed. Several backscattered electron images (BSE) were acquired at 50x magnification. At least three gray-scale images per sample were then processed with the free software JMicroVision ${ }^{\circledR}$ in order to quantify the crystal fraction of each phase. The same technique was used to determine crystal and bubble fraction of thin section photomicrographs obtained from the natural samples. Data acquired from different images and different orientations of the same sample were consistent within $2 \mathrm{vol} \%$ for all samples for the sum of all mineral phases present.

\subsubsection{Iron-redox determination}

Concentric cylinder subliquidus experiments, which maintain the samples at magmatic temperatures for about 24 hours at atmospheric conditions, typically result in some degree of sample oxidization. Oxidized melts are slightly more viscous than equivalent reduced melts (e.g. Dingwell and Virgo 1988, Chevrel et al. 2013). Therefore the iron oxidation state of the natural rock and of all the experimental samples was measured to assess the possible influence of iron redox state on magma viscosity. We used a combination of wet

chemistry and ultraviolet/visible (UV/Vis) photo-spectrometry, following the method 
developed by Wilson (1960) and modified by Schuessler et al. (2008). Full details of the equipment, method and calibration are given in Sehlke et al. (2014). Each measurement set (ferrous iron $\mathrm{Fe}^{2+}$ and total iron $\Sigma \mathrm{Fe}^{2+}$ ) was checked against USGS standards basalt BIR1a and diabase W-2a, with $2 \sigma$ accuracy better than $0.15 \mathrm{wt} \%$ and reproducibility of 0.05 $\mathrm{wt} \%$, based on 3 samples per experimental run.

\subsection{Results}

\subsubsection{Field Observations}

Cross-flow topographic profiles from the RTK GPS traverses reveal the downflow evolution of flow morphology (Figs. 3.1c and 3.2). Traverses A and B, made nearest to the cone, show an incipient channel surrounded on both sides by thick lobes with steep levées and external margins. In traverses $\mathrm{C}$ and $\mathrm{D}$ the main channel broadens. The north side of the flow around traverse $\mathrm{C}$ is bounded by steep cliffs due to fluvial erosion, which give the misleading appearance of a vertical flow margin. By traverse $F$, the channel has disappeared. There is a lava tube (Fig. 3.3a) emerging from the southern end of traverse E, which cannot be seen in the profile, which suggests that lava transport may have occurred primarily by tube rather than by surface channel. The topography of the DEM suggests that a surface channel was present early in the history of the flow, however its 
NE

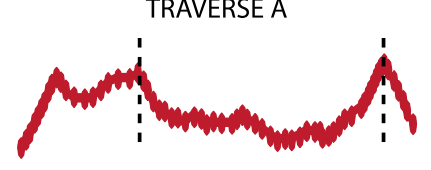

$\mathrm{N}$

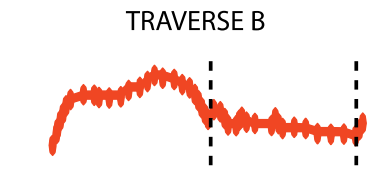

$S$

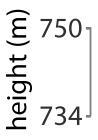

NW TRAVERSE C SE

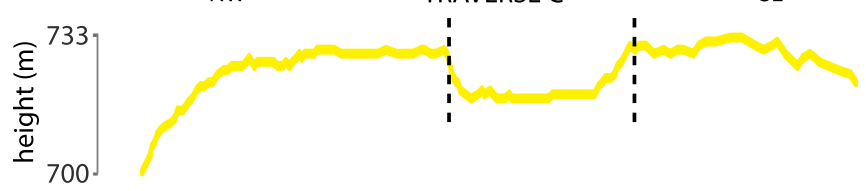

NW TRAVERSE D SE
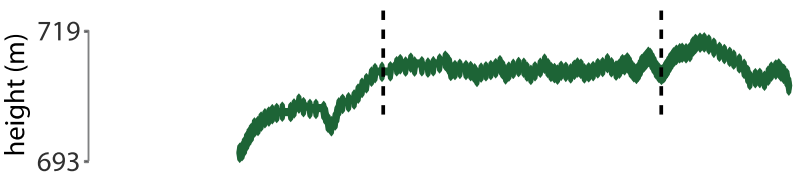

NE

TRAVERSE E

SW

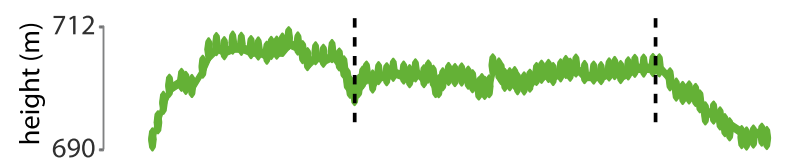

$\mathrm{N}$

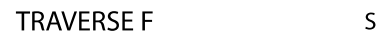

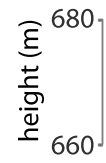

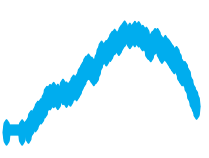

NE

TRAVERSE G

SW

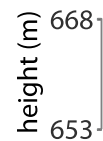

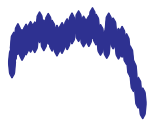

0

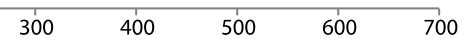

Figure 3.1 Elevation profiles of the 7 KGPS traverses made across the studied flow shown with $3 \mathrm{x}$ vertical exaggeration. Vertical dashed lines highlight the boundary between central channel and levées where it is present (traverses A-E). The south side of traverses B, C and D is incomplete due to GPS signal shadow zone; laser range-finder measurement allowed levée height estimates at those locations. 
topographic signature has since been partly erased by inflation (traverses D and E). In traverses $\mathrm{F}$ and $\mathrm{G}$ the flow gradually narrows to a point. The overall maximum flow height above the surrounding wash plain is $36 \mathrm{~m}$. Channel depth is comprised between $\sim 5 \mathrm{~m}$ (traverses D, E) and $\sim 15 \mathrm{~m}$ (traverses A, C). Channel width varies between $\sim 50 \mathrm{~m}$ (traverses B, C) and $\sim 200 \mathrm{~m}$ (traverses D, E). The average flow thickness in the channel, obtained as the altitude difference between the flow DEM and the interpolated ground surface, is $2 \mathrm{~m}$.
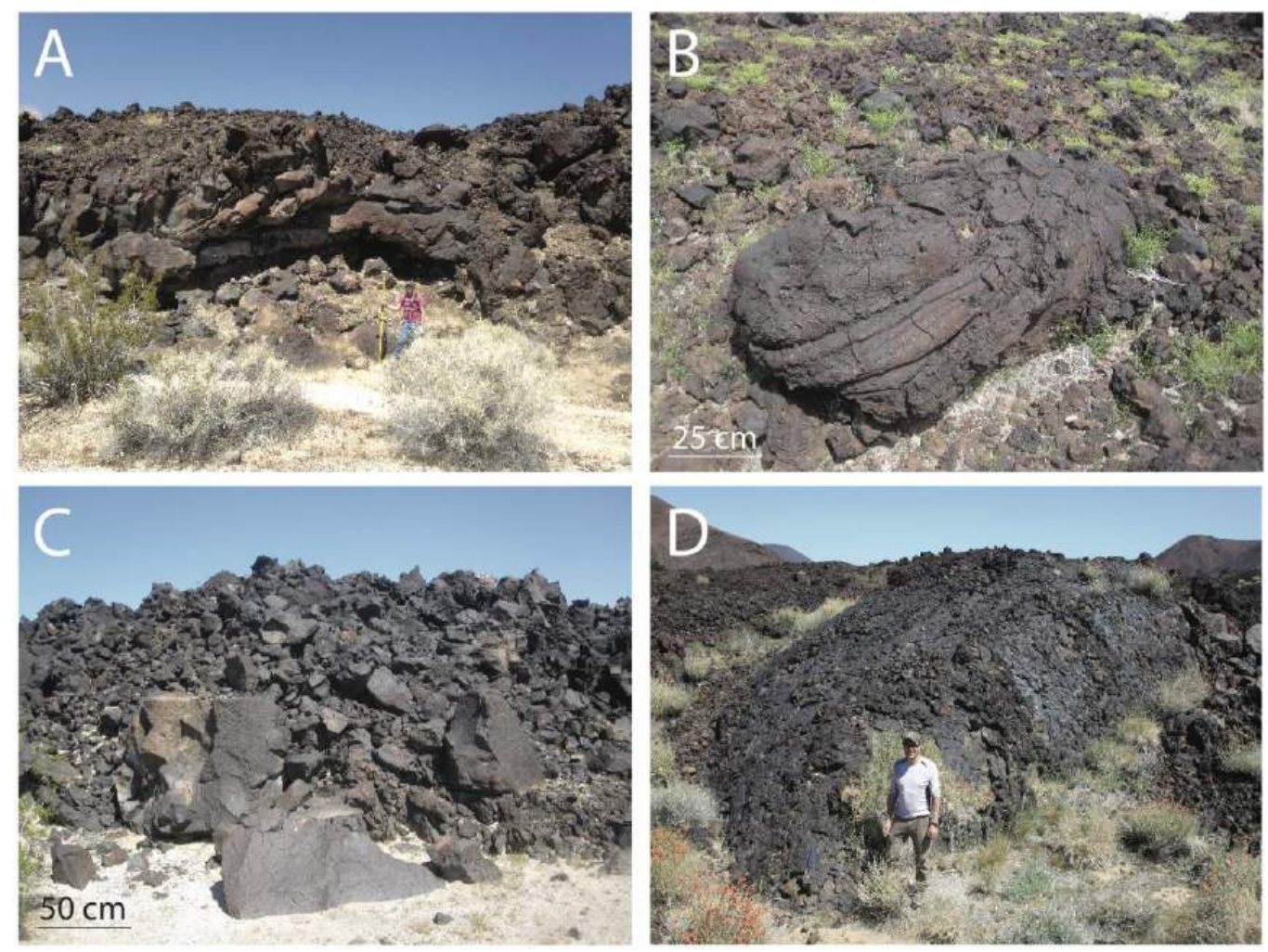

Figure 3.2 Surface morphologies: (a) lava tube exit (T.R. for scale); (b) core extrusion; (c) 'a'ā; (d) whaleback outcrop. 
Morphologically, we observed that the transition from smooth core extrusions to jagged lava blocks zone for this lava flow begins just outside the breach in the cinder cone and lasts until traverse B, where smooth lava surfaces (e.g. Fig. 3.3b) can no longer be consistently found; all lava surfaces downflow of traverse B are 'a' à (e.g. Fig. 3.3c), except for the inflated whaleback outcrop (Fig. 3.3d). The proximal part of the flow (traverses A, B, and C) appears to cut through an older flow of limited areal extent, which may represent an earlier stage of the cone's single effusive episode. The 'a'à block size increases downflow, from an average of about $10 \mathrm{~cm}$ near the cone to as much as $50 \mathrm{~cm}$ diameter at midflow.

\subsubsection{Morphometry}

Comparison of cross-flow topographic profiles obtained from RTK GPS survey and point cloud extraction revealed an average residual (difference between RTK GPS elevation and point cloud elevation) of $0.115 \mathrm{~m}$, with a standard deviation of $0.258 \mathrm{~m}$. The photogrammetric point cloud is therefore reasonably well validated, with a small discrepancy possibly resulting from incomplete filtering of vegetation.

The deviation of the RTK profiles from a straight line precludes their usage for 1D morphometrical analyses. We therefore extracted higher resolution profiles from the validated point cloud instead.

Low altitude photogrammetry is an efficient means of identifying key lava flow features, such as levées and channels (e.g. Baldi et al. 2002), and of mapping surface texture. We generated a DEM (Fig. 3.4a) from the aerial photographs with a resolution of $5 \mathrm{~cm}$, much

finer than the pre-existing DEM at $1 \mathrm{~m}$ resolution provided by the National Agriculture 
Imagery Program (NAIP). We used the DEM to calculate the volume of the Cima lava flow, which was $\sim 0.015 \mathrm{~km}^{3}$. We calculated roughness in two dimensions (Shepard et al. 2001) across the entire extent of the flow. The color-coded map displaying the calculated roughness parameter (Fig. 3.4b) allows clear identification of morphological variation across the lava flow, distinguishing a smoother channel surface from rougher levées, as well as differentiating an earlier broad flow near the cinder cone from the later breakout tube or channel. The early lobes can be clearly identified as low-roughness $(<2 \mathrm{~cm})$ areas. Roughness is also low $(<2 \mathrm{~cm})$ in the main channel, while it becomes higher $(2-7 \mathrm{~cm})$ at the flow margins, especially close to the toe. The majority of the core extrusions found in the field are very close to the vent, outside of the flight path coverage, and therefore cannot be identified in the roughness map. The roughness values for the Cima lava flow DTM match well with the value of $4.8 \pm 0.8 \mathrm{~cm}$ obtained by Brétar et al. (2013) for 'a'ā lava at Piton de la Fournaise, although their resolution was millimetric, while our was centimetric. In our case, the lower end roughness values do not correspond to pahoehoe surface textures, as found at Piton de La Fournaise by Brétar et al. (2013), but rather simply to 'a'ā surface textures smoother than the main flow 'a'ā surface textures, most likely as a consequence of a higher degree of inflation, or possibly as a consequence of sand accumulation due to their higher elevation above the desert plain with respect to the rest of the flow. 

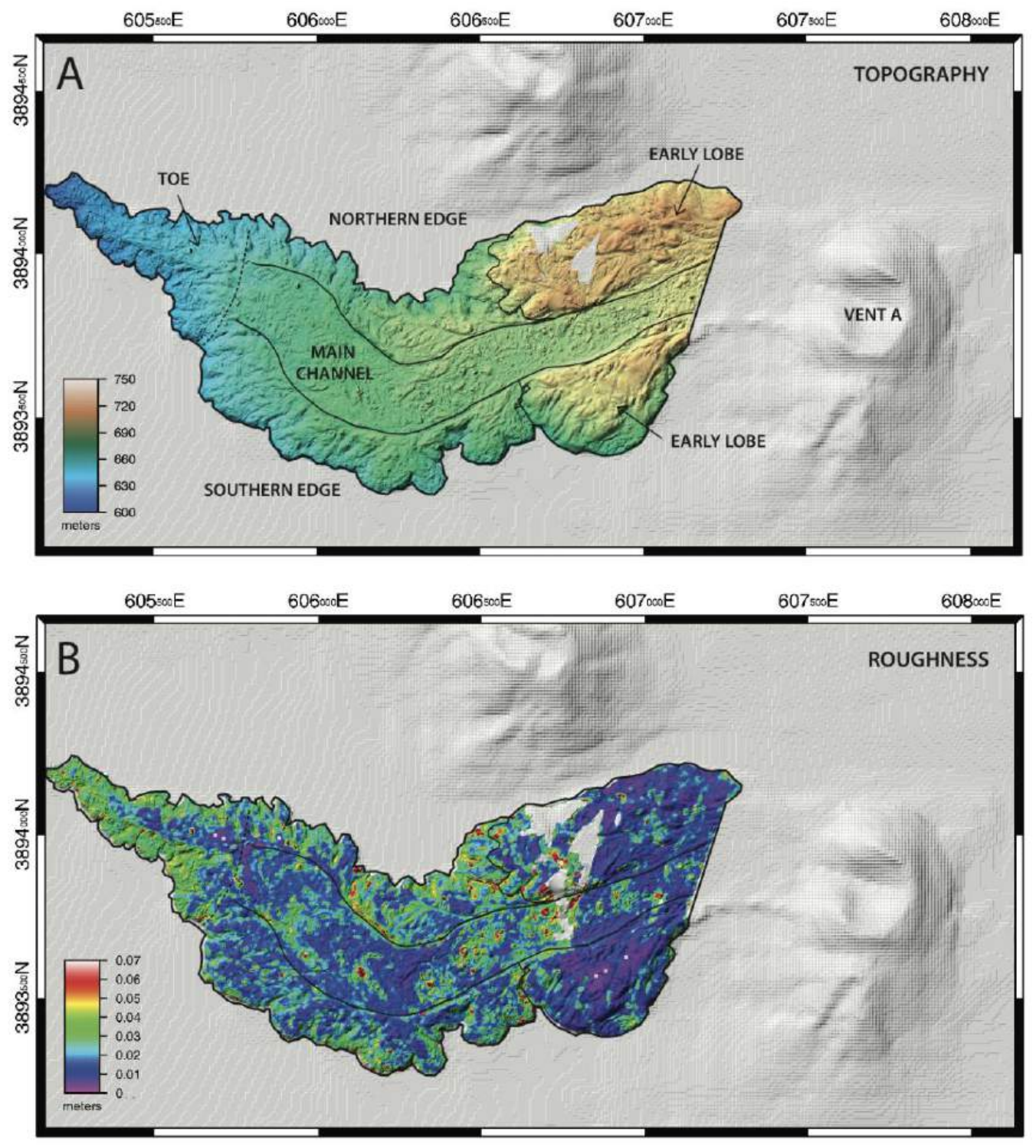

Figure 3.3 Flow (a) DEM and (b) roughness map. The DEM has been constructed on the basis of $\sim 17,000$ aerial photos with the software Agisoft Photoscan. The roughness map shows the standard deviation of measured points from a smoothed, approximate surface ( $1 \mathrm{~m}$ averaging). In both images the main channel and early lobes have been outlined for clarity. 


\subsubsection{Flow Sample Characterization}

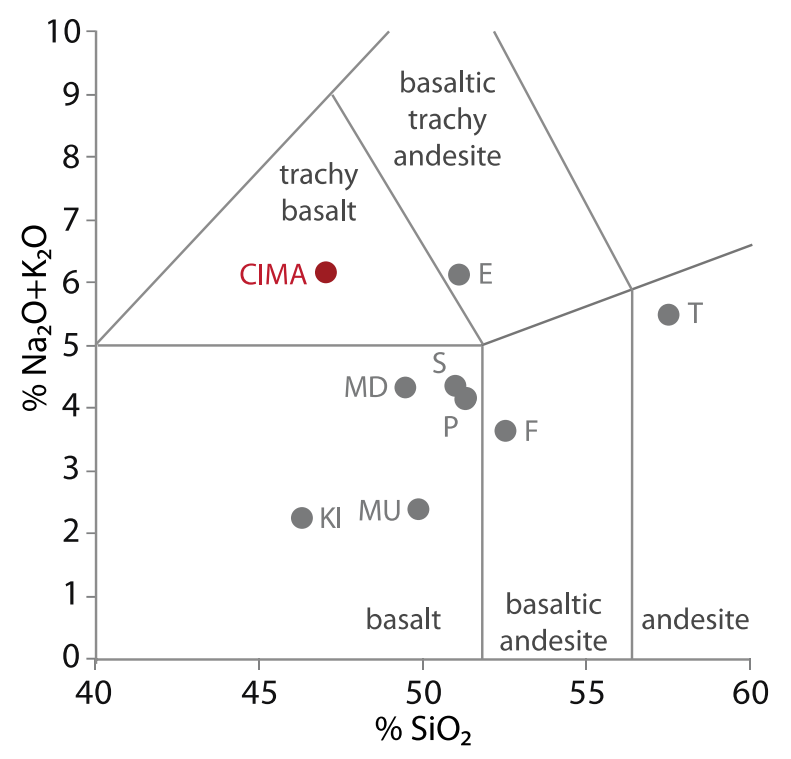

Figure 3.4 Total alkali vs. silica diagram (Le Maitre 1984) showing that Cima lavas are classified as trachybasalts. All other lava compositions whose subliquidus rheology has been studied are also shown for comparison. (KI=Kilauea Iki, Ryerson et al. 1988; MU=Mauna Ulu, Sehlke et al. 2014; MD=Matsuura District, Ishibashi and Sato 2007; E=Etna, Vona 2011; S=Stromboli, Vona et al. 2011; F=Fuji, Ishibashi 2009; T=Tungurahua, Chevrel et al. 2015).

A total of 17 samples were collected from different flow locations, listed in Table 3.1 and plotted in Figure 3.1c. About half the samples (10, 9, 12, 17, 6, 8, 1, and 3) were collected from the early lobes of the flow, while the rest $(11,7,2,13,14,15,5,4$, and 16) come from the main flow (Table 3.3). More specifically, samples 7, 2, and 14 are from inside the main channel, while sample 6 was collected from a smaller side channel. Samples 9, 12, $17,8,1,3,5$, and 4 are from the flow levées. Sample 16 was collected at the flow toe. Sample 10 is a striated extrusion of dense lava found in the flow just outside the cinder cone wall, as is sample 15 , specifically representing an inflated area broken up by cooling 
joints, found along traverse E, that we refer to as the "whaleback". Sample 13 was collected from a lava tube. Sample 11 is taken from the top of the cinder cone.

Based on the TAS classification, Cima lavas are trachybasalts (Supplementary Table 3.1; Fig. 3.5). Little variation is observed across the flow, with $2 \sigma$ standard deviations typically at or below $3 \%$ relative from the average for any given analyte, with the exception of $\mathrm{K}_{2} \mathrm{O}$ $(2 \sigma$ standard deviation $=6 \%$ relative $)$.

The dense rock equivalent density of the samples, measured via helium pycnometry, is $2,894 \mathrm{~kg} / \mathrm{m}^{3}$ on average, with a $2 \sigma$ standard deviation of $13 \mathrm{~kg} / \mathrm{m}^{3}(\mathrm{n}=5)$. Bubble fraction determined from photomicrographs is highly variable, from $0.02-0.54$, and displays no clear trend either down-flow or across-flow (Table 3.3).

All collected samples are porphyritic (Fig. 3.6), with only the core extrusions (e.g. Fig 3.6c) showing strong crystal alignment (trachytic texture). The dense material of the whole-rock samples contains between 5 and 26 vol \% phenocrysts (crystal size $>0.5 \mathrm{~mm}$ ) of which $\sim 70 \%$ is plagioclase (An60-65), $\sim 25 \%$ pyroxene (diopside), and $\sim 5 \%$ olivine (Fo70-85). Phenocrysts are overwhelmingly euhedral, and plagioclase aspect ratios vary between 2 and 8. Plagioclase and olivine phenocrysts are systematically normally zoned from core to rim. The range of bulk compositions is small, suggesting that the phenocrysts grew from the same magma batch in which they are found (Supplementary Table 3.1). The microcrystalline matrix, making up the rest of the dense material, consists mostly of plagioclase and iron oxides (magnetite), and generally minor glass. There is a systematic difference in microlite content between the early lobes and the main flow (Table 3.3). As a result, the total crystal fraction (Table 3.3 ) ranges between $\sim 0.52$ and $\sim 0.99$ of the dense material. Samples $4,5,7,9,11,14,15$, and 16 , from the main flow, are the less crystalline 
(0.52-0.67). Samples 2 and 13 have an intermediate crystal fraction of 0.82-0.84. Samples $1,3,6,8,9,10,12$ and 17 , from the early flow lobes, are almost completely crystalline (0.89-0.99 of dense material).

\begin{tabular}{ccccc}
\hline Sample & bubble fraction & total crystal fraction $^{\mathbf{1}}$ & phenocryst fraction $^{\mathbf{1}}$ & microlite fraction $^{\mathbf{1}}$ \\
\hline Early lobes & $0.14 \pm 0.13$ & $0.95 \pm 0.04$ & $0.15 \pm 0.07$ & $0.81 \pm 0.06$ \\
14CIMA10 & 0.04 & 0.94 & 0.10 & 0.84 \\
14CIMA09 & 0.43 & 0.91 & 0.07 & 0.84 \\
14CIMA12 & 0.13 & 0.89 & 0.07 & 0.82 \\
14CIMA17 & 0.05 & 0.95 & 0.23 & 0.72 \\
14CIMA06 & 0.09 & 0.99 & 0.26 & 0.73 \\
14CIMA08 & 0.10 & 0.98 & 0.14 & 0.84 \\
14CIMA01 & 0.22 & 0.97 & 0.18 & 0.79 \\
14CIMA03 & 0.09 & 0.98 & 0.11 & 0.87 \\
Main flow & $0.19 \pm 0.17$ & $0.66 \pm 0.11$ & $0.11 \pm 0.04$ & $0.55 \pm 0.10$ \\
14CIMA11 & 0.24 & 0.59 & 0.05 & 0.54 \\
14CIMA07 & 0.08 & 0.62 & 0.10 & 0.52 \\
14CIMA02 & 0.06 & 0.82 & 0.09 & 0.72 \\
14CIMA13 & 0.10 & 0.84 & 0.18 & 0.66 \\
14CIMA14 & 0.61 & 0.52 & 0.09 & 0.43 \\
14CIMA15 & 0.24 & 0.60 & 0.11 & 0.49 \\
14CIMA05 & 0.18 & 0.63 & 0.18 & 0.45 \\
14CIMA04 & 0.11 & 0.67 & 0.08 & 0.59 \\
14CIMA16 & 0.05 & 0.63 & 0.11 & 0.52 \\
\hline
\end{tabular}

Table 3.3 2D crystal and bubble fraction estimates for Cima lava samples.
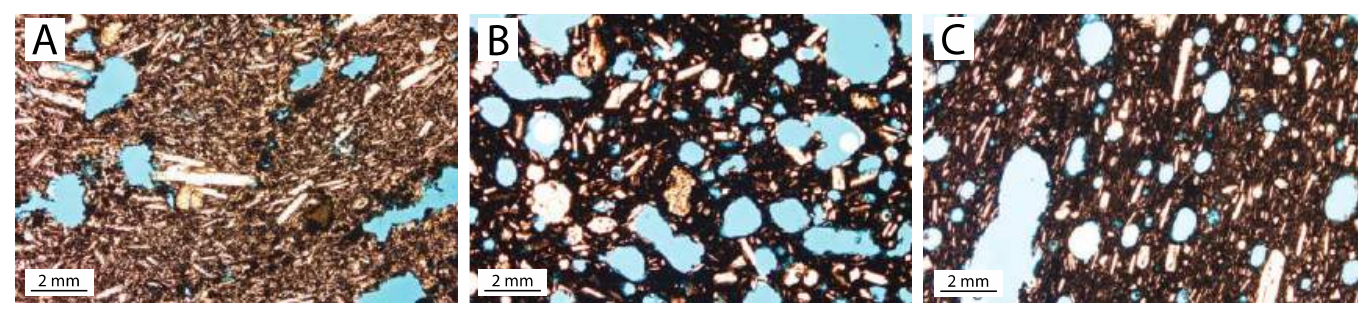

Figure 3.6 Thin sections in transmitted plane polarized light of samples (a) 14CIMA06, from one of the early lobes, (b) 14CIMA 11, from the channel near the vent, and (c) 14CIMA15, a core extrusion. The samples were vacuum impregnated with blue epoxy, hence bubbles appear blue in plane polarized light. 


\subsubsection{Geothermometry}

We tried to apply three different geothermometers to two samples, one from the vent (CIMA07) and one from the toe (CIMA16), using the glass, olivine phenocryst rim, and plagioclase microlite compositions determined by electron microprobe (Supplementary Table 3.2). Ultimately, only one of the geothermometers considered proved suitable. The limiting factor in the number of samples considered was the ability to find glass patches suitable for microprobe analyses, which is necessary to apply mineral-glass equilibrium geothermometers. Temperature estimates based simply on the $\mathrm{MgO}$ content of the liquid (Putirka 2008, Eq. 14) could not be relied upon, because the melt is not olivine-saturated, as revealed by the absence of olivine in the microcrystalline matrix. The olivine-liquid equilibrium geothermometer (Putirka 2008, Eq. 22) could not be applied either, as olivine in these two samples (Fo77-78) and liquid are not in equilibrium, as indicated by the ironmagnesium partition coefficient $\mathrm{K}_{\mathrm{D}}(\mathrm{Fe}-\mathrm{Mg})^{\mathrm{ol}-\mathrm{liq}}=0.09$, instead of the equilibrium value of $0.30 \pm 0.03$ determined by Roeder and Emslie (1970). Plotting our data on a Rhodes diagram of olivine Mg\# vs. liquid Mg\# (Putirka 2008) reveals olivine removal, consistent with preeruptive olivine settling in the magma chamber prior to the eruption. Olivine cores are not in equilibrium with the bulk rock either, being more fayalitic than the equilibrium composition, which also supports pre-eruptive olivine settling.

Temperature estimates based on feldspar-liquid equilibrium (Putirka 2008, Eq. 23) do not vary, yielding consistent values of $1112 \pm 60{ }^{\circ} \mathrm{C}$ along the entire flow length for anhydrous conditions. The calculated sodium-calcium partition coefficient $\mathrm{K}_{\mathrm{D}}(\mathrm{Na}-\mathrm{Ca})^{\mathrm{fps}-\mathrm{liq}}$ is 0.03 , which is within the range $0.10 \pm 0.11$ consistent with crystal-liquid equilibrium (Hamada and Fuji 2007). Addition of water lowers the temperature estimates by $40{ }^{\circ} \mathrm{C}$ for every 1 
$\mathrm{wt} \%$ of water added, still within the thermometer uncertainty for a $\sim 1 \mathrm{wt} \%$ water content. We also modeled crystallization under anhydrous conditions at atmospheric pressure using MELTS (Gualda et al. 2012), for an oxygen fugacity of FMQ+2, calculated based on the oxidation state of samples collected in the field. Beginning with the bulk rock composition of sample CIMA07 (Table 3.2), MELTS predicts a crystal fraction of 0.60 , consistent with the average crystal fraction of the collected samples, at a temperature of $1110{ }^{\circ} \mathrm{C}$, in good agreement with feldspar-liquid geothermometry. The residual liquid composition predicted by MELTS at a crystal fraction of 0.60 is similar to the measured glass composition, albeit slightly higher in $\mathrm{SiO}_{2}$ and lower in $\mathrm{Al}_{2} \mathrm{O}_{3}$.

\subsubsection{Liquid Viscosity}

Concentric cylinder viscometry provided liquid viscosity data in the $1550-1200{ }^{\circ} \mathrm{C}$ temperature range, while parallel plate viscometry was used in the $725-670{ }^{\circ} \mathrm{C}$ temperature range. The measurement at $1550^{\circ} \mathrm{C}$ resulted in torque values of $\sim 9 \%$ of the maximum achievable with this spring, which is just below the calibrated range (10-90\%) and consequently has slightly higher uncertainties. The measurement at $1200^{\circ} \mathrm{C}$ shows a systematic dependence on strain rate (non-Newtonian behaviour), suggesting the onset of crystallization. This is consistent with the liquidus calculated using MELTS (Gualda et al. 2012), which is $\sim 1220^{\circ} \mathrm{C}$ for anhydrous melt. Combining both techniques, we obtained viscosity measurements spanning 12 orders of magnitude between $1.45 \mathrm{~Pa} \cdot \mathrm{s}$ and $1.25 \times 10^{12}$ $\mathrm{Pa} \cdot \mathrm{s}$ (Table 3.4). However, a gap exists in the data at magmatic (subliquidus) conditions, due to crystallization of the melt upon cooling below the liquidus. Melt viscosity can be 
reliably interpolated in this interval using the non-Arrhenian Vogel-Tamman-Fulcher (VTF) equation (Vogel 1921). The best least-squares fit achieved is:

$\log \eta=-5.00+6072 /(T-588.9)$

where $\eta[\mathrm{Pa} \cdot \mathrm{s}]=$ viscosity and $T[\mathrm{~K}]=$ temperature.

This VTF fit reproduces the 15 data with a root-mean-square deviation (RMSD) of 0.12 $\log$ units (Supplementary Fig. 3.1). In comparison, the fit obtained with the model of Giordano et al. (2008) has an RMSD of 0.21 log units.

In addition to the effect of temperature, the chemical evolution of the interstitial melt needs to be taken into account separately. In order to do so, we measured the synthetic evolved liquid composition (4CIMA07evo) viscosity (Table 3.4). The best-fit VTF equation ( $\mathrm{RMSD}=0.07 \log$ units for 13 data points) for the evolved composition is:

$\log \eta=-4.33+6004 /(T-577.8)$

The fit obtained with the model of Giordano et al. (2008) also reproduces the experimental data well, with an RMSD of 0.08 log units.

The viscosities of the bulk remelt and evolved liquids are $\sim 0.4 \log$ units apart at liquidus temperatures, and closer than that at temperatures below $\sim 1000{ }^{\circ} \mathrm{C}$ (Supplementary Fig. 3.1). Getson and Whittington (2007) showed that evolving melt viscosity along the liquid line of descent typically follows a quasi-linear trend between the highest and lowest temperatures. Consequently, we did not synthesize the interstitial melt of other subliquidus experimental runs (between $1218^{\circ} \mathrm{C}$ and $1164{ }^{\circ} \mathrm{C}$ ), but rather did a linear interpolation between the bulk melt viscosity at the highest temperature and the evolved melt viscosity at the lowest temperature. The uncertainty associated with linear interpolation is small, and comparable to the analytical uncertainty in measurements. This allowed us to take into 
account both the temperature and compositional effect when calculating the relative viscosity for all intermediate temperatures.

\begin{tabular}{|c|c|c|c|c|c|c|c|}
\hline \multicolumn{4}{|c|}{ CC superliquidus remelt } & \multicolumn{4}{|c|}{ PP remelt } \\
\hline $\begin{array}{c}\text { Temperature } \\
\mathbf{T} \\
{ }^{\circ} \mathbf{C} \\
\end{array}$ & $\begin{array}{c}\text { Stress } \\
\text { o } \\
\mathbf{P a} \\
\end{array}$ & $\begin{array}{c}\text { Strain Rate } \\
\gamma \\
1 / \mathrm{s} \\
\end{array}$ & $\begin{array}{c}\text { Viscosity } \\
\eta \\
\mathrm{Pa} \cdot \mathbf{s} \\
\end{array}$ & $\begin{array}{c}\text { Temperature } \\
\mathbf{T} \\
{ }^{\circ} \mathbf{C} \\
\end{array}$ & $\begin{array}{c}\text { Stress } \\
\sigma \\
\mathrm{Pa} \\
\end{array}$ & $\begin{array}{c}\text { Strain Rate } \\
\gamma \\
1 / \mathrm{s} \\
\end{array}$ & $\begin{array}{c}\text { Viscosity } \\
\eta \\
\text { Pa.s } \\
\end{array}$ \\
\hline \multirow[t]{3}{*}{1550} & $3.49 \cdot 10^{1}$ & $2.22 \cdot 10^{1}$ & $1.57 \cdot 10^{0}$ & 724.6 & $3.84 \cdot 10^{5}$ & $6.13 \cdot 10^{5}$ & $6.26 \cdot 10^{9}$ \\
\hline & $3.89 \cdot 10^{1}$ & $2.66 \cdot 10^{1}$ & $1.46 \cdot 10^{0}$ & 715.4 & $3.86 \cdot 10^{5}$ & $3.69 \cdot 10^{5}$ & $1.04 \cdot 10^{10}$ \\
\hline & $3.78 \cdot 10^{1}$ & $3.11 \cdot 10^{1}$ & $1.21 \cdot 10^{0}$ & 700.6 & $3.81 \cdot 10^{5}$ & $4.89 \cdot 10^{6}$ & $7.78 \cdot 10^{10}$ \\
\hline \multirow[t]{3}{*}{1500} & $8.65 \cdot 10^{1}$ & $3.77 \cdot 10^{1}$ & $2.29 \cdot 10^{0}$ & 694.0 & $3.97 \cdot 10^{5}$ & $3.97 \cdot 10^{6}$ & $9.99 \cdot 10^{10}$ \\
\hline & $7.09 \cdot 10^{1}$ & $3.33 \cdot 10^{1}$ & $2.13 \cdot 10^{0}$ & 690.9 & $3.97 \cdot 10^{5}$ & $1.91 \cdot 10^{6}$ & $2.09 \cdot 10^{11}$ \\
\hline & $6.28 \cdot 10^{1}$ & $2.66 \cdot 10^{1}$ & $2.36 \cdot 10^{0}$ & 683.4 & $3.79 \cdot 10^{5}$ & $1.43 \cdot 10^{6}$ & $2.64 \cdot 10^{11}$ \\
\hline \multirow[t]{3}{*}{1400} & $1.94 \cdot 10^{2}$ & $3.77 \cdot 10^{1}$ & $5.14 \cdot 10^{0}$ & 681.2 & $3.95 \cdot 10^{5}$ & $6.31 \cdot 10^{7}$ & $6.27 \cdot 10^{11}$ \\
\hline & $1.61 \cdot 10^{2}$ & $3.33 \cdot 10^{1}$ & $4.83 \cdot 10^{0}$ & 671.0 & $3.96 \cdot 10^{5}$ & $3.29 \cdot 10^{7}$ & $1.20 \cdot 10^{12}$ \\
\hline & $2.47 \cdot 10^{2}$ & $4.44 \cdot 10^{1}$ & $5.56 \cdot 10^{0}$ & & & & \\
\hline \multirow[t]{3}{*}{1350} & $3.49 \cdot 10^{2}$ & $3.77 \cdot 10^{1}$ & $9.25 \cdot 10^{0}$ & & & & \\
\hline & $3.09 \cdot 10^{2}$ & $3.33 \cdot 10^{1}$ & $9.28 \cdot 10^{0}$ & & & & \\
\hline & $2.63 \cdot 10^{2}$ & $2.89 \cdot 10^{1}$ & $9.11 \cdot 10^{0}$ & & & & \\
\hline \multirow[t]{3}{*}{1300} & $3.62 \cdot 10^{2}$ & $2.22 \cdot 10^{1}$ & $1.63 \cdot 10^{1}$ & & & & \\
\hline & $2.82 \cdot 10^{2}$ & $1.78 \cdot 10^{1}$ & $1.59 \cdot 10^{1}$ & & & & \\
\hline & $2.15 \cdot 10^{2}$ & $1.33 \cdot 10^{1}$ & $1.62 \cdot 10^{1}$ & & & & \\
\hline \multirow[t]{3}{*}{1250} & $2.64 \cdot 10^{2}$ & $8.88 \cdot 10^{0}$ & $2.98 \cdot 10^{1}$ & & & & \\
\hline & $2.00 \cdot 10^{2}$ & $6.66 \cdot 10^{0}$ & $3.01 \cdot 10^{1}$ & & & & \\
\hline & $1.33 \cdot 10^{2}$ & $4.44 \cdot 10^{0}$ & $3.00 \cdot 10^{1}$ & & & & \\
\hline \multirow[t]{3}{*}{1200} & $3.71 \cdot 10^{2}$ & $5.55 \cdot 10^{0}$ & $6.68 \cdot 10^{1}$ & & & & \\
\hline & $2.55 \cdot 10^{2}$ & $3.33 \cdot 10^{0}$ & $7.67 \cdot 10^{1}$ & & & & \\
\hline & $9.27 \cdot 10^{1}$ & $1.11 \cdot 10^{0}$ & $8.35 \cdot 10^{1}$ & & & & \\
\hline \multicolumn{4}{|c|}{ CC superliquidus evo } & \multicolumn{4}{|c|}{ PP evo } \\
\hline \multirow[t]{3}{*}{1485} & $3.00 \cdot 10^{2}$ & $4.44 \cdot 10^{1}$ & $6.77 \cdot 10^{0}$ & 724.57 & $4.69 \cdot 10^{5}$ & $4.42 \cdot 10^{5}$ & $1.06 \cdot 10^{10}$ \\
\hline & $2.26 \cdot 10^{2}$ & $3.33 \cdot 10^{1}$ & $6.79 \cdot 10^{0}$ & 714.30 & $4.71 \cdot 10^{5}$ & $1.95 \cdot 10^{5}$ & $2.41 \cdot 10^{10}$ \\
\hline & $1.53 \cdot 10^{2}$ & $2.22 \cdot 10^{1}$ & $6.91 \cdot 10^{0}$ & 709.17 & $4.65 \cdot 10^{5}$ & $1.10 \cdot 10^{5}$ & $4.23 \cdot 10^{10}$ \\
\hline \multirow[t]{3}{*}{1400} & $4.14 \cdot 10^{2}$ & $4.44 \cdot 10^{1}$ & $9.33 \cdot 10^{0}$ & 703.82 & $4.66 \cdot 10^{5}$ & $7.60 \cdot 10^{6}$ & $6.14 \cdot 10^{10}$ \\
\hline & $3.12 \cdot 10^{2}$ & $3.33 \cdot 10^{1}$ & $9.36 \cdot 10^{0}$ & 693.97 & $4.63 \cdot 10^{5}$ & $3.00 \cdot 10^{6}$ & $1.54 \cdot 10^{11}$ \\
\hline & $2.06 \cdot 10^{2}$ & $2.22 \cdot 10^{1}$ & $9.29 \cdot 10^{0}$ & 689.19 & $5.05 \cdot 10^{5}$ & $2.23 \cdot 10^{6}$ & $2.27 \cdot 10^{11}$ \\
\hline \multirow[t]{3}{*}{1398} & $3.40 \cdot 10^{2}$ & $2.22 \cdot 10^{1}$ & $1.53 \cdot 10^{1}$ & 680.36 & $5.06 \cdot 10^{5}$ & $1.51 \cdot 10^{6}$ & $3.35 \cdot 10^{11}$ \\
\hline & $4.36 \cdot 10^{2}$ & $2.89 \cdot 10^{1}$ & $1.51 \cdot 10^{1}$ & & & & \\
\hline & $2.34 \cdot 10^{2}$ & $1.55 \cdot 10^{1}$ & $1.51 \cdot 10^{1}$ & & & & \\
\hline \multirow[t]{3}{*}{1350} & $2.29 \cdot 10^{2}$ & $8.88 \cdot 10^{0}$ & $2.58 \cdot 10^{1}$ & & & & \\
\hline & $4.55 \cdot 10^{2}$ & $1.78 \cdot 10^{1}$ & $2.56 \cdot 10^{1}$ & & & & \\
\hline & $3.40 \cdot 10^{2}$ & $1.33 \cdot 10^{1}$ & $2.56 \cdot 10^{1}$ & & & & \\
\hline \multirow[t]{3}{*}{1300} & $4.12 \cdot 10^{2}$ & $8.88 \cdot 10^{0}$ & $4.64 \cdot 10^{1}$ & & & & \\
\hline & $2.05 \cdot 10^{2}$ & $4.44 \cdot 10^{0}$ & $4.61 \cdot 10^{1}$ & & & & \\
\hline & $3.04 \cdot 10^{2}$ & $6.66 \cdot 10^{0}$ & $4.56 \cdot 10^{1}$ & & & & \\
\hline \multirow[t]{3}{*}{1200} & $3.98 \cdot 10^{2}$ & $2.22 \cdot 10^{0}$ & $1.79 \cdot 10^{2}$ & & & & \\
\hline & $1.99 \cdot 10^{2}$ & $1.11 \cdot 10^{0}$ & $1.79 \cdot 10^{2}$ & & & & \\
\hline & $2.84 \cdot 10^{2}$ & $1.55 \cdot 10^{0}$ & $1.82 \cdot 10^{2}$ & & & & \\
\hline
\end{tabular}

Table 3.4 Superliquidus $(\mathrm{CC}=$ concentric cylinder $)$ and near glass transition $(\mathrm{PP}=$ parallel plate) viscosity measurements of remelted composition and evolved composition. Italicized data at $1200^{\circ} \mathrm{C}$ reflect the onset of crystallization and were not used in VTF fitting of liquid viscosity. 


\subsubsection{Subliquidus Rheology}

Eight subliquidus viscosity experiments were performed with the concentric cylinder viscometer between $1218^{\circ} \mathrm{C}$ and $1160{ }^{\circ} \mathrm{C}$ (Table 3.5; Fig. 3.7). The upper temperature limit, $1218{ }^{\circ} \mathrm{C}$, was chosen to be just below the liquidus. The lower limit, $1160{ }^{\circ} \mathrm{C}$, marked the temperature where the effective viscosity of the lava approached the upper end of the working range of the instrument. An experiment at $1150^{\circ} \mathrm{C}$ was attempted, but maximum torque was repeatedly exceeded, preventing measurements.

The rheological data are sets of points in stress-strain rate space, which can be mathematically fitted by different equations, representing different model behaviors. Fitting the data with different equations results in different estimations of rheological parameters. In Newtonian materials such as silicate melts, such curves are in fact straight lines. This typically happens when the flow index, i.e. the slope in a ln torque vs. ln angular velocity plot, is equal to 1 . In subliquidus experiments (2-phase, silicate melt + crystals) the flow index usually decreases with increasing crystal fraction, indicating a shift from Newtonian to non-Newtonian rheological response of the material and an increasing degree of shear-thinning of the magma with increasing crystal fraction. The flow index can also be fitted to the stress and strain rate data instead, following different rheological models. We fitted three different rheological equations to our data: Bingham, power law, and Herschel-Bulkley (Fig. 3.7). The RMSD is strongly affected by the quality of fit to the measurement at the highest stress for each curve. The Herschel-Bulkley fit (allowing for both yield strength and shear-thinning) reproduces our data most accurately, having a lower RMSD than Bingham (allowing for yield strength only) and an identical or lower RMSD than power law (allowing for shear-thinning only) at all temperatures, and an overall 
RMSD of $19 \mathrm{~Pa}$ compared to $25 \mathrm{~Pa}$ for power law and $24 \mathrm{~Pa}$ for Bingham. (Table 3.6) This is unsurprising, as the Herschel-Bulkley model allows for the maximum flexibility. We therefore calculated the standard error (SE) of each fit at each temperature as well (Table 3.6). Standard error accounts for the number of fit parameters used, penalizing models achieving an equivalent quality of fit with a higher number of fit parameters. Comparing standard errors reveals that at three highest temperatures, at which magma does not display yield strength according to a Herschel-Bulkley fit, but does according to a Bingham fit, a power law model reproduces the data best, i.e. more accurately with the smallest number of parameters, highlighting the shear-thinning behavior of lava, even at the lowest crystal fraction of 0.016 . However, at all lower temperatures, where a yield strength exists according to both Herschel-Bulkley and Bingham models, the standard error of the Herschel-Bulkley model is significantly lower, underscoring the necessity of accounting for both shear-thinning and yield strength when modeling their rheology.

The viscosity obtained through a Bingham fit increases from $\eta \sim 92 \mathrm{~Pa} \cdot \mathrm{s}$ at $T=1218{ }^{\circ} \mathrm{C}$ to $\eta \sim 561 \mathrm{~Pa} \cdot \mathrm{s}$ at $T=1164{ }^{\circ} \mathrm{C}$ following a power-law trend, and then reaches $\eta \sim 1041 \mathrm{~Pa} \cdot \mathrm{s}$ at $T=1160{ }^{\circ} \mathrm{C}$. For a power-law fit, the consistency increases from $\mathrm{K} \sim 102 \mathrm{~Pa} \cdot \mathrm{s}$ at $T=1218{ }^{\circ} \mathrm{C}$ to $\mathrm{K} \sim 750 \mathrm{~Pa} \cdot \mathrm{s}$ at $T=1164{ }^{\circ} \mathrm{C}$ along a power-law trend, and then increases rapidly to $\mathrm{K} \sim 1740$ $\mathrm{Pa} \cdot \mathrm{s}$ at $T=1160{ }^{\circ} \mathrm{C}$. For a Herschel-Bulkley fit, the consistency increases exponentially from $\mathrm{K} \sim 102 \mathrm{~Pa} \cdot \mathrm{s}$ at $T=1218{ }^{\circ} \mathrm{C}$ to $\mathrm{K} \sim 554 \mathrm{~Pa} \cdot \mathrm{s}$ at $T=1164{ }^{\circ} \mathrm{C}$, and then increases abruptly to $\mathrm{K} \sim 1361 \mathrm{~Pa} \cdot \mathrm{s}$ at $T=1160{ }^{\circ} \mathrm{C}$. 

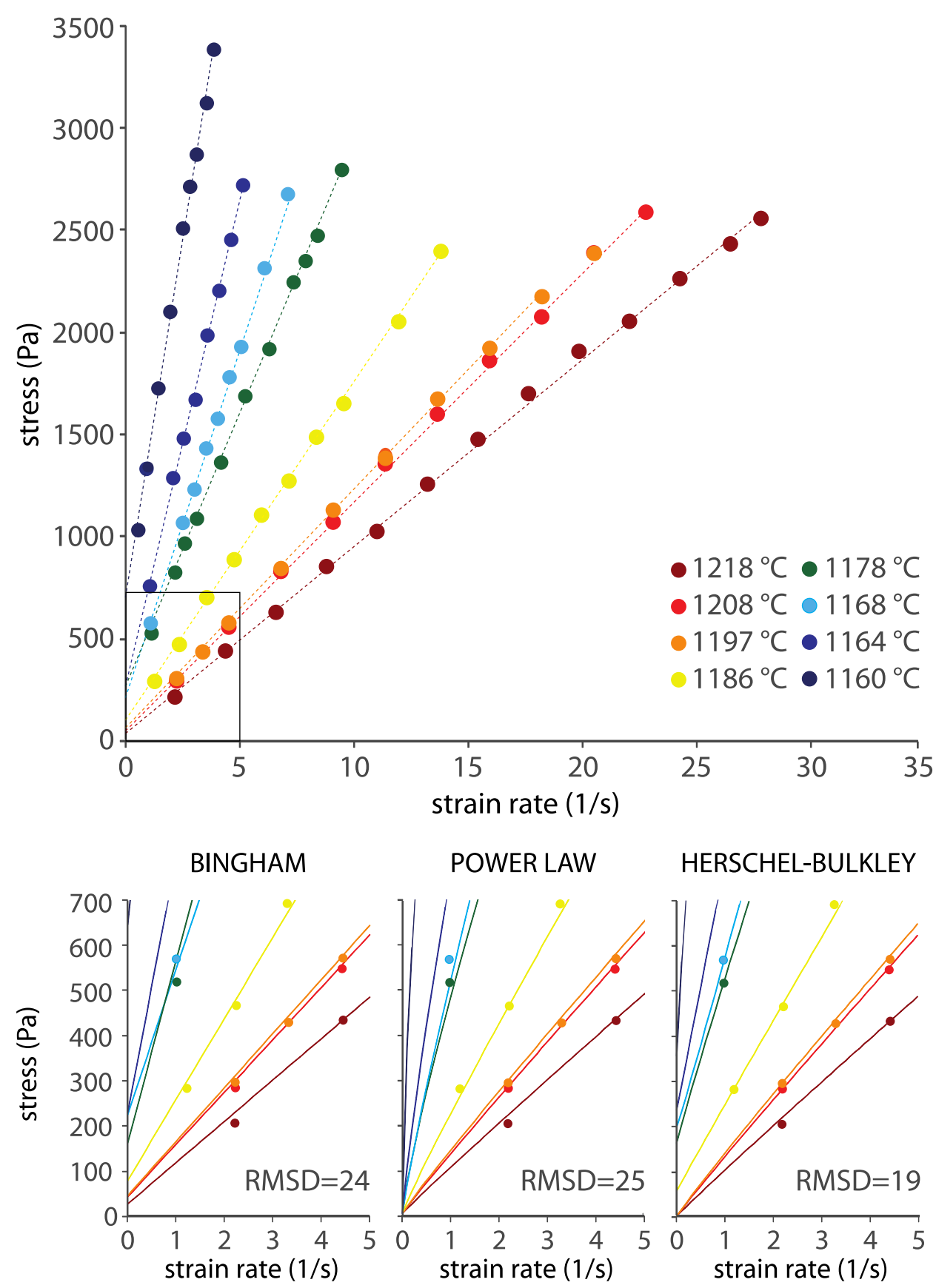

Figure 3.7 Top: Subliquidus viscosity data at 8 different temperatures between $1228^{\circ} \mathrm{C}$ and 1160 ${ }^{\circ} \mathrm{C}$, presented in a rheological map (stress vs. strain rate plot) and fitted a with a Herschel-Bulkley model. Bottom: Bingham, power law, and Herschel-Bulkley fits close-ups. 


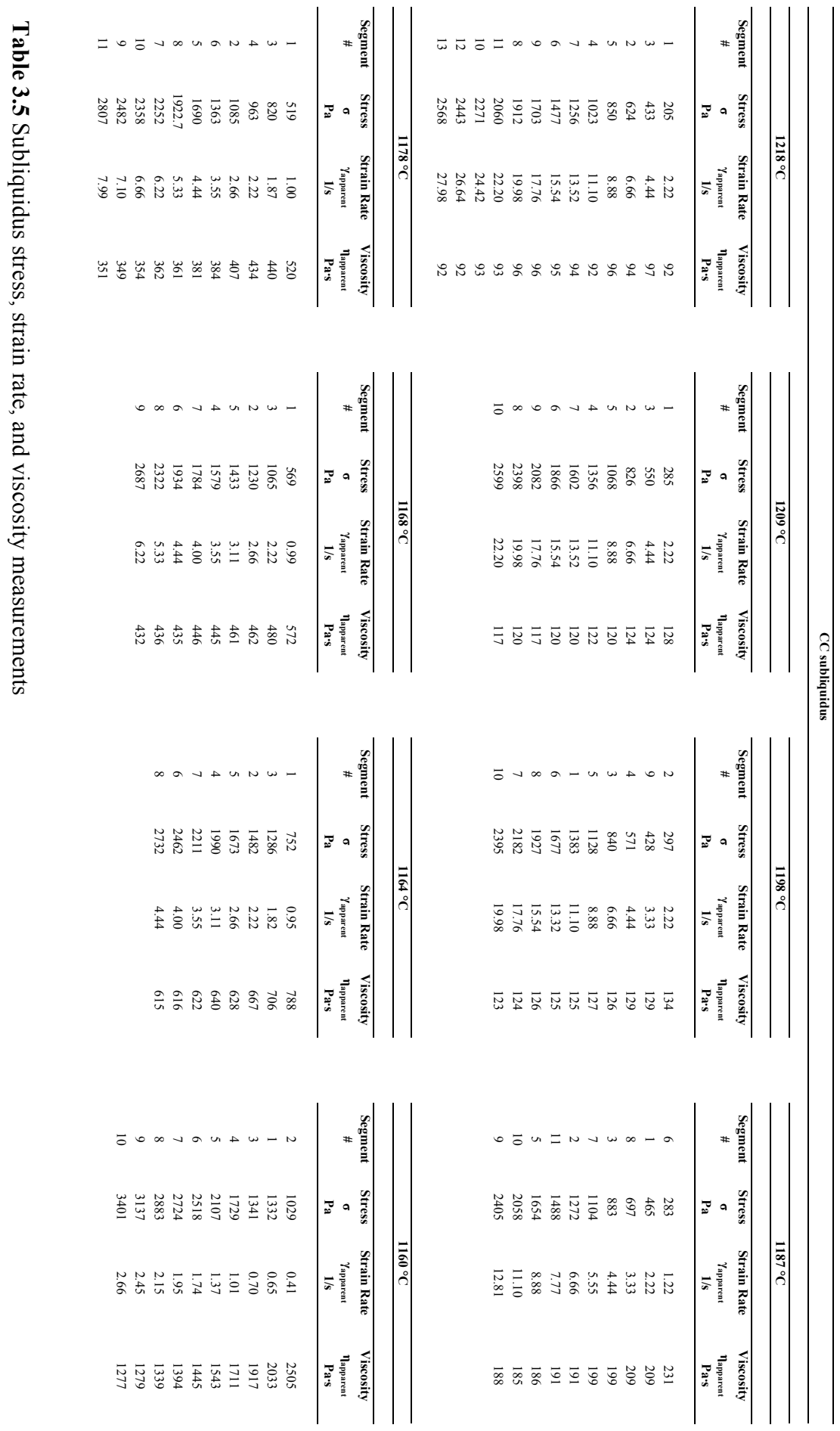


For a power-law fit, our subliquidus experiments display a range of flow indices decreasing from $n=0.97$ at $T=1218{ }^{\circ} \mathrm{C}$ to $n=0.67$ at $T=1160{ }^{\circ} \mathrm{C}$, while for a Herschel-Bulkley fit flow indices decrease from $n=0.97$ at $T=1218^{\circ} \mathrm{C}$ to $n=0.81$ at $T=1160{ }^{\circ} \mathrm{C}$.

Flow indices independently calculated from a $\ln$ torque vs. In angular velocity plot decrease from $n=0.99$ at $T=1218{ }^{\circ} \mathrm{C}$ to $n=0.65$ at $T=1160^{\circ} \mathrm{C}$, in better agreement with power law fits. This is not surprising because calculation of flow indices as proposed by Stein and Spera (1998) is inherently based on a power-law model. The difference between $n$ calculated using power-law and Herschel-Bulkley equations is highest at the lowest temperature, because this is where crystal fraction and apparent yield strength are highest. When fitting a power-law curve that is constrained to pass through the origin, the curvature is necessarily greater, and the resulting flow index is consequently smaller.

With a Bingham fit, yield strength is within error of zero at $\phi_{c}=0.016$. At $\phi_{c}=0.023-0.026$ the yield strength has a value of 41-77 $\mathrm{Pa}$. At $\phi_{\mathrm{c}}=0.036-0.058$, yield strength gradually increases up to $\sim 230 \mathrm{~Pa}$. A further crystal fraction increase to $\phi_{\mathrm{c}}=0.106$ almost triples yield strength value, which reaches $\sigma_{y}=647 \pm 62 \mathrm{~Pa}$.

Applying the Herschel-Bulkley fit, the calculated yield strength remains within error of zero for the three highest temperature subliquidus experiments, then increases from $\sigma_{\mathrm{y}}=56 \pm 24 \mathrm{~Pa}$ at $T=1187^{\circ} \mathrm{C}$ to $\sigma_{\mathrm{y}}=357 \pm 41 \mathrm{~Pa}$ at $T=1160{ }^{\circ} \mathrm{C}$. In terms of crystal fraction, at $\phi_{\mathrm{c}}=0.026$ the yield strength has a low value of $\sigma_{\mathrm{y}}=56 \pm 24 \mathrm{~Pa}$. Between $\phi_{\mathrm{c}}=0.036$ and $\phi_{\mathrm{c}}=0.058$ the yield strength increases steadily to $\sim 240 \mathrm{~Pa}$, and by $\phi_{\mathrm{c}}=0.106$ it has risen steeply to $\sigma_{\mathrm{y}}=357 \pm 41 \mathrm{~Pa}$. 


\begin{tabular}{|c|c|c|c|c|c|c|c|c|c|c|}
\hline Temperature & $T$ & ${ }^{\circ} \mathrm{C}$ & $1218.3 \pm 0.9$ & $1209.0 \pm 0.7$ & $1197.5 \pm 0.1$ & $1186.5 \pm 0.3$ & $1177.7 \pm 0.4$ & $1168.4 \pm 0.2$ & $1164.1 \pm 0.4$ & $1159.9 \pm 0.4$ \\
\hline Crystal Fraction & $\phi_{\mathrm{c}}$ & & $\begin{array}{c}0.0160 \\
\pm 0.0065\end{array}$ & $\begin{array}{c}0.0231 \\
\pm 0.0124\end{array}$ & $\begin{array}{c}0.0238 \\
\pm 0.0043\end{array}$ & $\begin{array}{c}0.0260 \\
\pm 0.0034\end{array}$ & $\begin{array}{c}0.0356 \\
\pm 0.0014\end{array}$ & $\begin{array}{c}0.0462 \\
\pm 0.0061\end{array}$ & $\begin{array}{c}0.0577 \\
\pm 0.0083\end{array}$ & $\begin{array}{c}0.1061 \\
\pm 0.0108\end{array}$ \\
\hline Viscosity B & $\eta$ & Pa's & $92.0 \pm 1.9$ & $116.5 \pm 2.1$ & $120.1 \pm 2.4$ & $180.4 \pm 3.4$ & $322.2 \pm 6.1$ & $404.6 \pm 6.4$ & $560.6 \pm 18.2$ & $1041.1 \pm 36.5$ \\
\hline Consistency PL & $\mathbf{K}$ & Pass & $102.4 \pm 1.8$ & $132.5 \pm 2.1$ & $140.0 \pm 2.1$ & $221.0 \pm 4.5$ & $480.0 \pm 11.5$ & $517.1 \pm 16.0$ & $749.8 \pm 31.2$ & $1739.7 \pm 53.2$ \\
\hline Consistency HB & $\mathbf{K}$ & Pa's & $102.4 \pm 1.8$ & $132.5 \pm 2.1$ & $140.0 \pm 2.1$ & $191.9 \pm 3.5$ & $365.1 \pm 6.3$ & $377.9 \pm 5.5$ & $553.9 \pm 18.0$ & $1360.8 \pm 27.5$ \\
\hline $\begin{array}{l}\text { Flow Index } \\
\text { GRAPHIC }\end{array}$ & $n$ & & $0.99 \pm 0.01$ & $0.96 \pm 0.01$ & $0.96 \pm 0.01$ & $0.91 \pm 0.02$ & $0.81 \pm 0.02$ & $0.85 \pm 0.03$ & $0.83 \pm 0.03$ & $0.65 \pm 0.03$ \\
\hline Flow Index PL & $n$ & & $0.97 \pm 0.01$ & $0.96 \pm 0.01$ & $0.95 \pm 0.01$ & $0.93 \pm 0.01$ & $0.84 \pm 0.01$ & $0.90 \pm 0.02$ & $0.86 \pm 0.02$ & $0.67 \pm 0.03$ \\
\hline Flow Index HB & $n$ & & $0.97 \pm 0.01$ & $0.96 \pm 0.01$ & $0.95 \pm 0.01$ & $0.98 \pm 0.01$ & $0.95 \pm 0.01$ & $1.03 \pm 0.01$ & $1.01 \pm 0.02$ & $0.81 \pm 0.02$ \\
\hline Yield Strength B & $\sigma_{y}$ & $\mathbf{P a}$ & $24.6 \pm 32.7$ & $40.5 \pm 29.2$ & $43.3 \pm 28.5$ & $76.5 \pm 24.7$ & $223.8 \pm 30.6$ & $160.6 \pm 24.9$ & $228.6 \pm 55.2$ & $647.1 \pm 61.7$ \\
\hline Yield Strength HB & $\sigma_{y}$ & $\mathbf{P a}$ & $0 \pm 28.9$ & $0 \pm 26.4$ & $0 \pm 21.9$ & $55.9 \pm 24.3$ & $162.8 \pm 28.8$ & $197.4 \pm 22.4$ & $236.6 \pm 55.3$ & $356.7 \pm 40.8$ \\
\hline RMSD B & & & 25.37 & 19.11 & 20.44 & 17.09 & 20.7 & 12.71 & 24.32 & 39.12 \\
\hline RMSD PL & & & 22.33 & 16.87 & 15.39 & 19.24 & 26.77 & 26.25 & 31.66 & 34.68 \\
\hline RMSD HB & & & 22.33 & 16.87 & 15.39 & 16.61 & 18.83 & 11.66 & 24.31 & 22.55 \\
\hline SE B & & & 761 & 456 & 511 & 365 & 524 & 208 & 789 & 1913 \\
\hline SE PL & & & 589 & 356 & 289 & 463 & 876 & 886 & 1336 & 1503 \\
\hline SE HB & & & 648 & 407 & 326 & 394 & 488 & 204 & 946 & 726 \\
\hline
\end{tabular}

${ }^{1} \mathrm{~B}=$ Bingham; $\mathrm{PL}=$ power law; $\mathrm{HB}=$ Herschel-Bulkley

$\mathrm{SE}=$ standard error; $\mathrm{SE}=\left[\Sigma\left(\eta_{\mathrm{obs}}-\eta_{\text {calc }}\right)^{2}\right] /(\mathrm{n}-\mathrm{f})=\mathrm{RMSD}^{2} \mathrm{n} /(\mathrm{n}-\mathrm{f})$ where $\mathrm{n}=$ number of data points and $\mathrm{f}=$ number of fitted parameters.

Table 3.6 Fitted rheological parameters for subliquidus experiments and relative errors. 


\subsubsection{Experimental Sample Characterization}

The quenched material recovered at the end of each experimental run discloses the synexperimental phase equilibria, as attained before and maintained throughout data collection. We expect to have achieved physical and chemical equilibrium in the experiments, because we always attain of a stable viscosity reading at constant strain rate, which requires several hours (Supplementary Figure 3.2).

Crystal fraction estimates of subliquidus experimental runs (Fig. 3.8) show an increase from 0.02 to 0.11 with decreasing temperatures (from $1218{ }^{\circ} \mathrm{C}$ to $1160{ }^{\circ} \mathrm{C}$ ). Magnetite is the first phase to crystallize upon cooling. Its crystal fraction is approximately constant at 0.02 between 1218 and $1200^{\circ} \mathrm{C}$, and then increases linearly to a fraction of 0.05 at 1160 ${ }^{\circ} \mathrm{C}$. Magnetite crystals (aspect ratio of $\sim 1-3$ ) are extremely skeletal (Supplementary Figure 3.3). Additionally, their size decreases with increasing undercooling, as predicted by Tammann (1925). Plagioclase begins to form at $1168{ }^{\circ} \mathrm{C}$, and its volumetric increase is rapid, to 0.06 at $1160{ }^{\circ} \mathrm{C}$. Plagioclase crystals are euhedral, with modest aspect ratios of $<7$ (Supplementary Figure 3.3). No flow alignment was seen in sections cut in either radial or tangential orientation. Chemical analyses of the experimental phases are provided in Supplementary Table 3.3.

We determined the iron redox state of the whole rock sample collected in the field, and of each subliquidus experimental run. The measured $\mathrm{Fe}^{2+} / \Sigma \mathrm{Fe}$ ratio of the whole rock collected in the field was $0.75 \pm 0.03$. The measured $\mathrm{Fe}^{2+} / \Sigma \mathrm{Fe}$ ratio of the bulk experimental material (liquid + crystals) was $0.24 \pm 0.05$ across the whole temperature range (1218-1160 ${ }^{\circ} \mathrm{C}$; Table 3.2). Since magnetite $\left(\mathrm{Fe}_{3} \mathrm{O}_{4}\right)$ was always present as a crystalline phase, the liquid must be even more oxidized than this ratio would suggest, with a $\mathrm{Fe}^{2+} / \mathrm{Fe}_{\text {tot }}$ ratio of 
approximately 0.20 estimated from mass balance, using liquid and magnetite analyses from Supplementary Table 3.2.

The method of Kress and Carmichael (1988) allowed us to calculate the oxygen fugacity of the magma at eruption, which is $\log f \mathrm{O}_{2}=-6.2$ (corresponding to $\mathrm{FMQ}+2$ at the estimated eruption temperature of $\sim 110^{\circ} \mathrm{C}$, see below), and that of our experimental samples, which is $\log f \mathrm{O}_{2}=-3.9$ (corresponding to about $\mathrm{FMQ}+4$ at the experimental temperature range). The experimental samples are more oxidized than the natural flow due to their long residence in air at subliquidus conditions. 

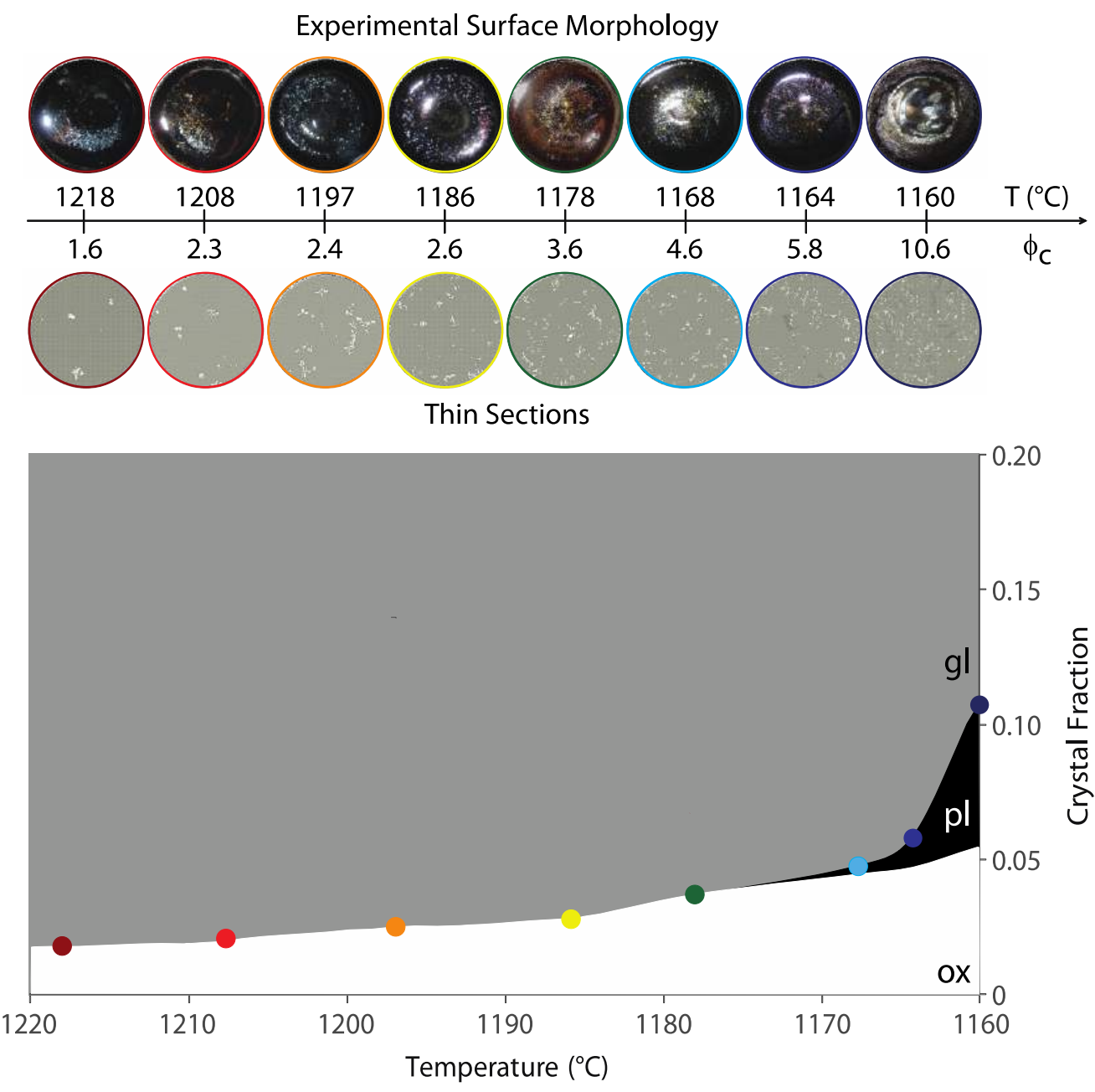

Figure 3.8 Top: surface morphology developed by each experimental run (crucible diameter $=$ $30.125 \mathrm{~mm}$ ). At the lowest temperature the surface retained a lobate morphology. Middle: Backscattered electron images of each experimental run (field of view $=1.9 \mathrm{~mm}$ ), showing how crystal fraction increases with decreasing temperature. The most abundant phase crystalized is magnetite (white), with minor plagioclase (dark grey) present; glass matrix is displayed in light grey. Bottom: Crystal fraction of each subliquidus experimental run as a function of temperature. Error bars are smaller than symbol size. 


\subsection{Discussion}

\subsubsection{Model assessment}

Several sources of uncertainty must be considered when fitting rheological data. Raw data obtained from subliquidus concentric cylinder consist of angular velocity and torque. Angular velocity is chosen by the operator, and typically remains constant during each experimental segment (standard deviation of zero as reported by the instrument throughout the data set). Corresponding torque values oscillate around an average value instead. In our data set, the maximum standard deviation of torque is $1.3 \%$ of the mean torque value. Torque uncertainty propagates to stress values, and then viscosity values. Another source of uncertainty is represented by spindle immersion depth, which also propagates first to stress and then to viscosity values. We assume the standard deviation of spindle immersion to be equal to $1 \mathrm{~mm}$ (based upon measurement precision) with a typical spindle immersion depth of $\sim 25 \mathrm{~mm}$. Additionally, the experimental assemblage dimensions (crucible and spindle radii) carry an uncertainty of $0.25 \mathrm{~mm}$ and $0.21 \mathrm{~mm}$ respectively (based upon repeated measurements), which propagate to stress, and, in the case of crucible radius, also to strain rate, and then to viscosity.

Fitted rheological parameters are also affected by the uncertainties described. Flow index, calculated as the slope of the standard deviation of the natural logarithm of torque over the standard deviation of natural logarithm of angular velocity values, contains torque uncertainties. Bingham viscosity, calculated as the slope of the standard deviation of stress over the standard deviation of strain rate, reflects torque uncertainties. Consistency, calculated as the slope of the standard deviation of stress over the standard deviation of 

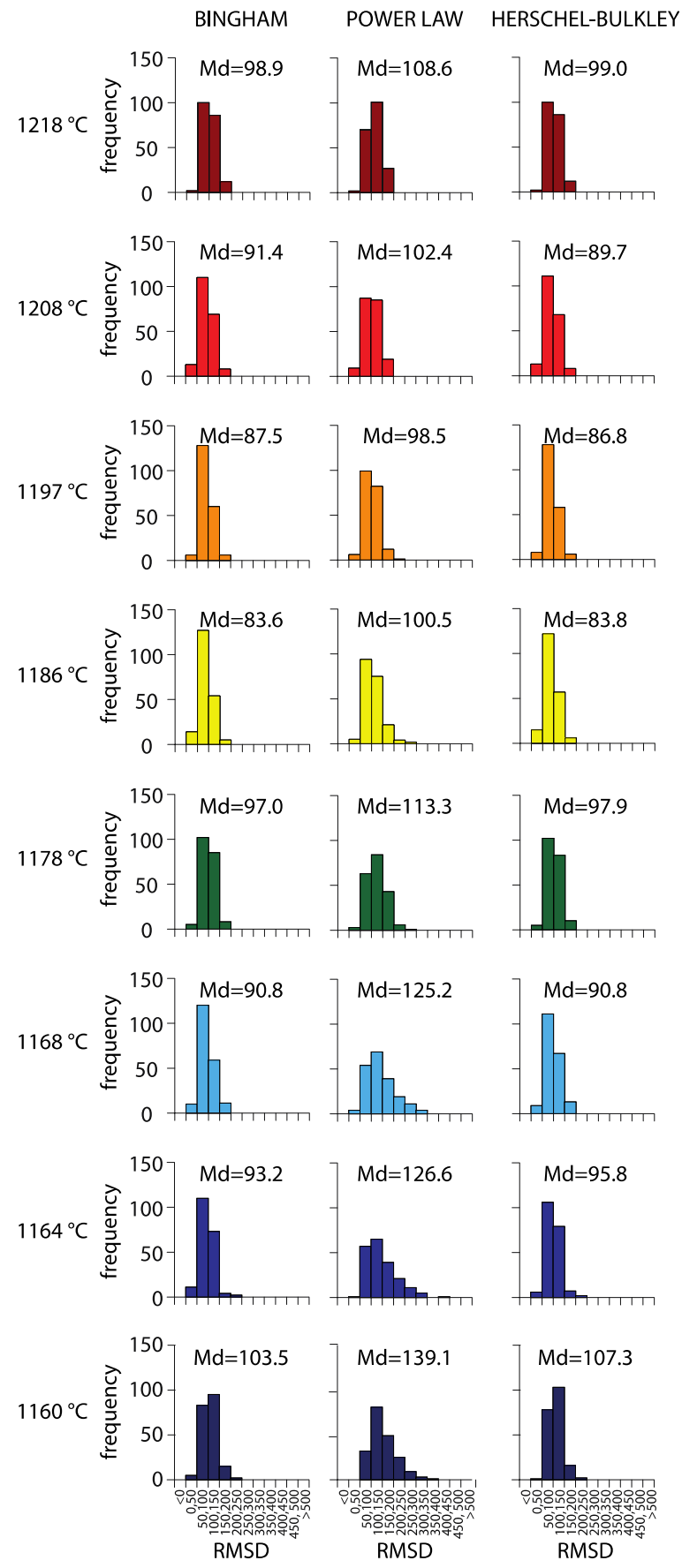

Figure 3.9 RMSD frequencies of Bingham, power law, and Herschel-Bulkley models compared, resulting from Monte Carlo simulations with 200 iterations. 
strain rate elevated to the flow index, is affected by torque and flow index uncertainties. Bingham yield strength, calculated as the slope of stress over the product of apparent strain rate and Bingham viscosity, encompasses torque, spindle diameter, crucible diameter, and viscosity uncertainties. Herschel-Bulkley yield strength, calculated as the slope of stress over the product of apparent strain rate and consistency, comprises torque, spindle diameter, crucible diameter, and consistency uncertainties.

In order to appropriately account for the influence of these various sources of error (torque, spindle immersion depth, crucible and spindle radii) on each fitting parameter (flow index, consistency, yield strength) of the three considered rheological models (Bingham, power law, and Herschel-Bulkley), as well as their overall RMSD (Table 3.7), we ran a Monte Carlo simulation that created a synthetic data set on the basis of mean and standard deviation values of experimentally derived data. By performing multiple iterations of the simulation, one can estimate the uncertainty inherent in the experimental results. In a Monte Carlo simulation, uncertainties are propagated throughout all of the calculations within each iteration. In order to estimate the minimum number of iterations required, we performed sensitivity analyses, which revealed that the results converge after approximately 150 iterations. We therefore performed 200 iterations of each simulation. Flow index values obtained with Monte Carlo simulations (Table 3.7) match those obtained with simple linear regression (Table 3.6). Bingham viscosity and consistency values obtained with Monte Carlo simulations (Table 3.7) are consistently lower than those obtained with the simple linear regression approach (Table 3.6). Monte Carlo

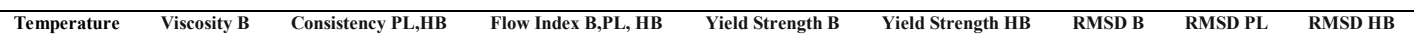




\begin{tabular}{|c|c|c|c|c|c|c|c|c|}
\hline $\begin{array}{c}T \\
{ }^{\circ} \mathbf{C} \\
\end{array}$ & $\begin{array}{c}\eta \\
\text { Pas }\end{array}$ & $\begin{array}{c}\text { K } \\
\text { Pass }\end{array}$ & $n$ & $\begin{array}{l}\sigma_{\mathrm{y}} \\
\mathrm{Pa} \\
\end{array}$ & $\begin{array}{c}\sigma_{\mathrm{y}} \\
\mathrm{Pa}\end{array}$ & & & \\
\hline $1218.3 \pm 0.9$ & $89.8 \pm 3.9$ & $89.0 \pm 3.5$ & $1.00 \pm 0.01$ & $7.1 \pm 61.5$ & $9.7 \pm 61.5$ & 103.06 & 112.51 & 103.14 \\
\hline $1209.0 \pm 0.7$ & $108.4 \pm 6.6$ & $122.5 \pm 5.2$ & $0.96 \pm 0.00$ & $28.6 \pm 64.4$ & $-8.03 \pm 64.4$ & 93.92 & 103.81 & 93.42 \\
\hline $1197.5 \pm 0.1$ & $121.5 \pm 2.9$ & $136.8 \pm 5.4$ & $0.96 \pm 0.00$ & $32.4 \pm 57.4$ & $-4.5 \pm 57.4$ & 90.74 & 100.32 & 90.12 \\
\hline $1186.5 \pm 0.3$ & $183.5 \pm 7.6$ & $237.7 \pm 9.9$ & $0.91 \pm 0.01$ & $64.0 \pm 56.51$ & $-29.9 \pm 56.51$ & 86.00 & 105.77 & 86.70 \\
\hline $1177.7 \pm 0.4$ & $275.4 \pm 14.4$ & $437.7 \pm 21.0$ & $0.81 \pm 0.01$ & $171.7 \pm 66.6$ & $-48.1 \pm 66.6$ & 96.86 & 122.67 & 99.11 \\
\hline $1168.4 \pm 0.2$ & $376.7 \pm 17.3$ & $533.65 \pm 29.8$ & $0.85 \pm 0.01$ & $136.4 \pm 83.1$ & $-67.79 \pm 83.1$ & 92.61 & 138.97 & 95.61 \\
\hline $1164.1 \pm 0.4$ & $380.1 \pm 18.1$ & $537.7 \pm 30.7$ & $0.85 \pm 0.01$ & $127.9 \pm 85.8$ & $-77.3 \pm 85.8$ & 95.23 & 145.96 & 98.74 \\
\hline $1159.9 \pm 0.4$ & $769.0 \pm 42.9$ & $1318.0 \pm 77.2$ & $0.65 \pm 0.01$ & $443.5 \pm 77.0$ & $-61.79 \pm 77.0$ & 106.84 & 151.04 & 108.66 \\
\hline
\end{tabular}

${ }^{1} \mathrm{~B}=$ =Bingham; $\mathrm{PL}=$ power law; $\mathrm{HB}=$ Herschel-Bulkley

${ }^{2}$ values provided are averages of Monte Carlo simulations with $n=200$

Table 3.7 Mean values and standard errors of rheological parameters for subliquidus experiments, obtained through Monte Carlo simulations with 200 iterations.

simulated Bingham yield strength values (Table 3.7) are lower than corresponding simple linear regression values (Table 3.6), but within error of them, with the exception of the lowest temperature value. Monte Carlo simulated Herschel-Bulkley yield strength values are all lower than the corresponding simple linear regression values.

The obtained RMSD values ( $\mathrm{n}=200$ for each temperature) for each rheological model were analyzed with the free software PAST v.3.15 (Harper et al. 2001). We first identified the median RMSD value of Bingham, power law, and Herschel-Bulkley models for each experimental temperature (Fig. 3.9). The lower the value, the better the model reproduces the fitted data. In order to establish whether or not RMSD median values of different models differ statistically from each other, we performed the non-parametric Bonferronicorrected Mann-Whitney $U$ test for medians. We assume a cutoff value below which values are considered statistically different $(\alpha)$ is 0.05 . At all temperatures, the Bingham and Herschel-Bulkley models are statistically indistinguishable from each other, however, their median RMSD values are consistently significantly lower than those of the power law model. This discrepancy increases as temperature decreases (from 0.003 to $8.44 \times 10^{-16}$ ). 
Although physical theory supports the increase of shear-thinning behavior and the development of yield strength as crystallinity increases, the results of Monte Carlo simulations seem to suggest that, at least in this case, allowing for the existence of shear thinning behavior does not improve the quality of fit. Comparative analyses of the three rheological models seems to suggest that allowing for the existence of yield strength does improve the quality of fit; however, caution must be exerted, as all yield strength values obtained with Monte Carlo simulations for the Herschel-Bulkley model are within error of zero, and so are the three highest temperature yield strength values for the Bingham model. Rheological data on dacites with a higher crystal content (up to $40 \mathrm{vol} \%$ ) at lower strain rates (up to $3 \times 10^{-4} \mathrm{~s}^{-1}$ ) than those explored in the present study also have been fitted without finding definitive evidence of yield strength (Avard and Whittington 2012), suggesting that our findings cannot be simply ascribed to the low crystallinity range considered.

It is worth noting that the median RMSD values calculated for all three models in the Monte Carlo simulations are substantially higher than those originally calculated directly on the basis of the experimental data simple linear regression. This results from accounting for the various sources of measurement error, and likely gives a more realistic perspective of the differences between the three rheological models considered. These results highlight the importance of accounting for measurement error, quantifying error propagation through calculations, and using iterative models (e.g. Monte Carlo simulations) to quantify model goodness-of-fit, rather than relying on a single estimate (e.g. best-fit approach to experimental data). 


\subsubsection{Effect of crystals on lava rheology}

Thermal, chemical, and physical effects all contribute to viscosity increase of a crystallizing lava flow, or to viscosity measured in a series of subliquidus experiments performed at decreasing temperatures (Fig. 3.10). The thermal contribution can be isolated by interpolating available superliquidus and near-glass transition viscosity measurements with a non-Arrhenian fit. The chemical effect on viscosity can be inferred at any given temperature by measuring and comparing the viscosity of the starting melt and of the evolved one at the same temperature (Getson and Whittington 2007). Finally, the physical effect is the viscosity difference between the pure melt and the melt+crystals mixture, at a specific temperature. In analog studies where chemically inert particles are added to an isothermal liquid, this physical effect is often quantified as the relative viscosity, which is the ratio of the viscosity of the mixture to that of the particle-free liquid.

Cooling from $1218{ }^{\circ} \mathrm{C}$ to $1160{ }^{\circ} \mathrm{C}$, the viscosity of the bulk remelt liquid increases by 2.8 times, from $54 \mathrm{~Pa} \cdot \mathrm{s}$ to $156 \mathrm{~Pa} \cdot \mathrm{s}$ (TVF fit), due to a purely thermal effect. The chemical effect of evolving melt composition, determined from the viscosity of the evolved liquid, reveals a further viscosity increase by a factor of 3.1 , from $156 \mathrm{~Pa} \cdot \mathrm{s}$ to $489 \mathrm{~Pa} \cdot \mathrm{s}$ at 1160 ${ }^{\circ} \mathrm{C}$. The viscosity of the crystal-bearing mixture (Herschel-Bulkley fitting) increased by more than an order of magnitude, from $102 \mathrm{~Pa} \cdot \mathrm{s}$ to $1,361 \mathrm{~Pa} \cdot \mathrm{s}$, over the same temperature range, as the crystal fraction increased from $\phi_{\mathrm{c}}=0.02$ to $\phi_{\mathrm{c}}=0.11$ (Fig. 3.10; Table 3.6). At a crystal fraction of 0.11 , the mixture viscosity is therefore 2.8 times the interstitial liquid viscosity. This is a slightly stronger physical effect of crystals than predicted by most previous studies and models, e.g. one calculates factors of 1.7-2 with the Einstein-Roscoe model (Roscoe, 1952), 1.3 with Phan-Thien and Pham (1997), and 1.6-1.9 with Mader et 
al. (2013). This may be due to the shape of the crystals present in the Cima melt. In particular, magnetite is skeletal rather than euhedral, and therefore it traps melt, resulting in a higher "effective crystal fraction" and therefore a larger effect on mixture viscosity than expected for low fractions of typically low aspect ratio crystals such as oxides.

The thermal, chemical and physical effects lead to a combined viscosity increase of a factor of $\sim 25$ from liquid viscosity at $1218{ }^{\circ} \mathrm{C}$ to lava consisting of evolved liquid and $11 \%$ crystals at $1160^{\circ} \mathrm{C}$ (Fig. 3.10). As shown in Fig. 3.10, such behavior is similar to what was observed in ocean island basalt (Mauna Ulu, Hawai'i; Sehlke et al. 2014), but quite different from what was observed for arc basalt (Pacaya, Guatemala; Soldati et al. 2016), where over the measured cooling span $\left(1234{ }^{\circ} \mathrm{C}\right.$ to $\left.1199{ }^{\circ} \mathrm{C}\right)$ the thermal and chemical effects combined less than doubled the initial viscosity, from $113 \mathrm{~Pa} \cdot \mathrm{s}$ to $218 \mathrm{~Pa} \cdot \mathrm{s}$. Specifically, the chemical effect is dramatically more important in the crystallization of Cima and Mauna Ulu lavas, which are both intraplate basalts. We ascribe this difference to the different chemical composition characteristic to each tectonic setting, which leads to different crystallization sequences. Specifically, Cima and Mauna Ulu basalts crystallized abundant oxides, therefore selectively removing iron from the melt, while Pacaya basalt predominantly crystallized plagioclase, overall closer in composition to the initial melt. The physical effect of crystals imposes a similar increasingly steep viscosity trend to Mauna Ulu and Cima lavas, but a shallower trend to Pacaya lavas. Notwithstanding the different mineral assemblages developed by samples in the laboratory and in nature, the presented experimental results can still inform us on the rheology of natural lava flows with some caveats. The composition of the interstitial melt is similar, although not 
identical, and the crystal size distribution in the experiments tends to more smaller crystals due to the formation of more oxides rather than olivine.

Up to a crystal fraction of 0.03 , consisting entirely of magnetite, our data for Cima basalt show a quasi-linear correlation between effective viscosity and crystal fraction, similar to that observed by Ishibashi and Sato (2010). As expected, magnetite crystallization has only a small physical effect on magma viscosity at the low crystal fractions considered. However, its crystallization leads to preferential iron removal from the melt, which results in increased melt polymerization and drives a strong chemical viscosity increase. At higher crystal fractions the viscosity increase is approximately exponential, as forecast by existing rheological models (e.g. Costa et al. 2009).

Over the $60{ }^{\circ} \mathrm{C}$ of undercooling explored during subliquidus experiments, the Cima composition developed a modest crystal fraction of 0.11 . No flow alignment was observed, which is to be expected at the low crystal fractions developed by Cima lavas and for the low aspect ratio of the crystallized minerals. Flow alignment, if existing (e.g. Sato 2005; Ishibashi and Sato 2007; Ishibashi 2009; Vona et al. 2011; Chevrel et al. 2015), is preserved despite textural disturbances that may be produced by spindle removal (e.g. Soldati et al. 2016). Consequently, we infer that no flow alignment existed during subliquidus rheological measurements of the Cima lava, as also inferred by Vetere et al. (2010) for a synthetic Unzen composition.

Cima lava displays a shear thinning behavior in all experiments except for the lowest crystal fraction of 0.02 , where the measured flow index value is within error of 1 . The threshold values determining the onset of pseudoplastic behavior in mafic lavas have previously been reported to range from 0.05 (Ishibashi and Sato 2007 on Fuji basalts) to 
0.25 (Ryerson et al. 1988 on picrite), depending on the mineral assemblages crystallized by each composition considered. Differences in experimental set up may also play a role in this order of magnitude range. For example, both stress and strain rate are calculated on the basis of spindle and crucible radii, and therefore using a narrow gap geometry (Ryerson et al. 1988) as opposed to a wide gap geometry (this study) may affect the observed onset of shear-thinning behavior. Time-temperature histories are also not homogenous across studies, introducing an additional variable. However, perhaps the single most important source of uncertainty is the rheological model chosen to fit the data, as shown by the comparison of the conclusions reached by Ishibashi (2009) and Ishibashi and Sato (2010) after analyzing the same data set according to Krieger-Dougherty and Bingham models, respectively. In Cima lavas, the onset of shear thinning behavior is observed at the low end of the range reported in the studies cited above. We suggest that this is due to the fact that the highly skeletal magnetite crystals produced during the experiments trap some melt, which becomes locked within the crystal, increasing the "effective" crystal fraction of the mixture. 

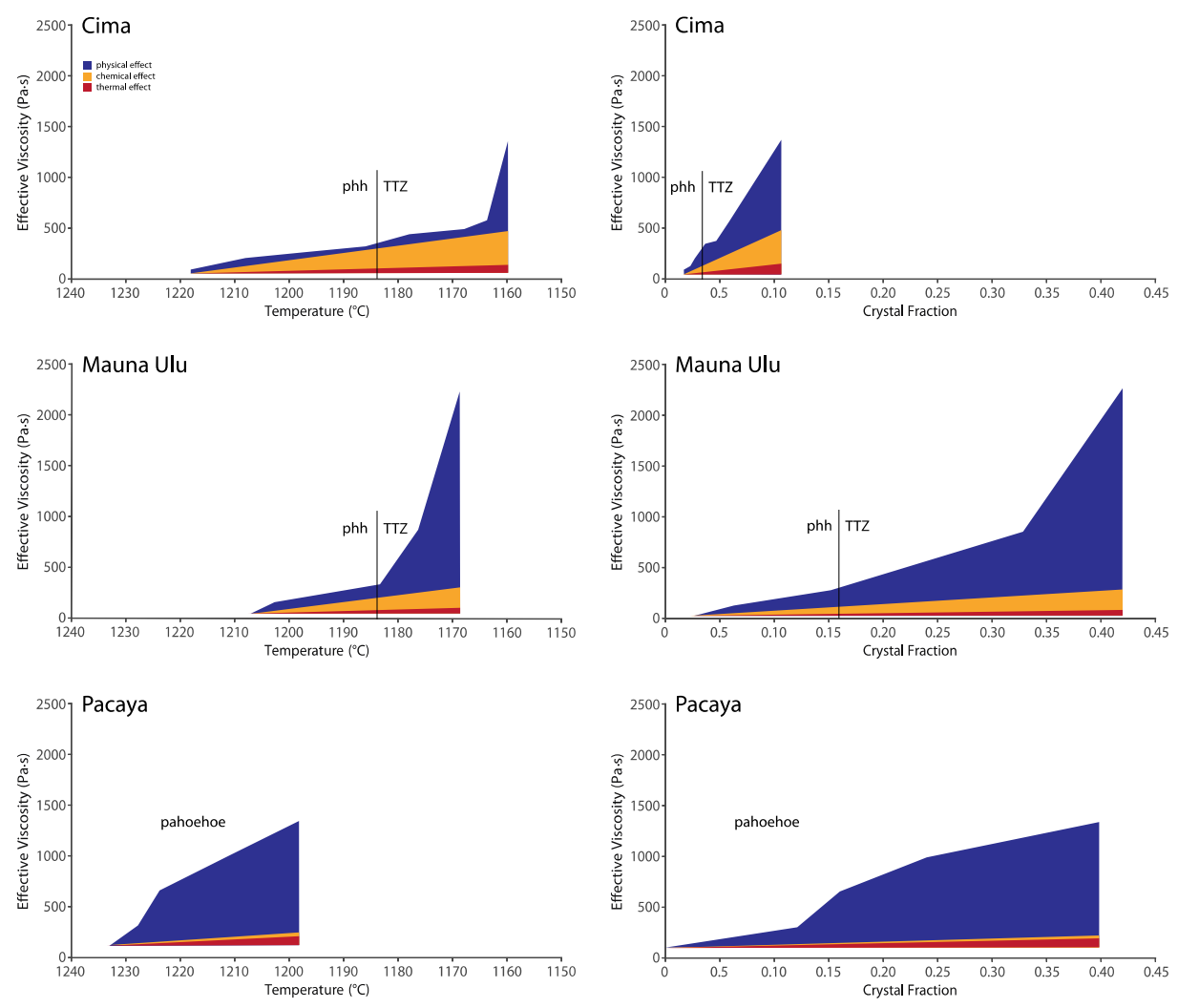

Figure 3.10 Viscosity of Cima, Mauna Ulu, and Pacaya basalts at a strain rate of $1 \mathrm{~s}^{-1}$ as a function of temperature and cristallinity across the whole subliquidus measurable range. Remelt is shown in red, evolved melt in orange, and two-phase (melt + crystals) mixture in blue. The pahoehoe (phh) to transition zone (TTZ) threshold is also marked.

\subsubsection{Yield strength: experimental constraints}

In the subliquidus experiments, yield strength becomes detectable (lobate structures remain visible on the crucible surface after quenching) at a surprisingly low crystal fraction of $\phi_{c}=0.023-0.026$, depending on whether the fitting follows a Bingham or Herschel-Bulkley model. It is interesting to note that the quality of fit is not actually very helpful in determining which of the two fits should be used, as at the highest crystal fractions yield strength is statistically well constrained (Fig. 3.11) but the absolute values obtained from 
the two fits differ significantly. Yield strength estimates relying on the empirical model of Mueller et al. (2010), based on analogue experiments, suggest the absence of significant yield strength (up to $0.08 \mathrm{~Pa}$ at the highest measured crystal fractions, for the plagioclase aspect ratio of 7 measured in our experimental samples). However, the Mueller et al. (2010) model is based on analogue experimental data in which particles are monodisperse (e.g. all spheres or all oblate particles), while in our experiments there is a bimodal particle distribution. This can significantly affect the rheological behavior of the suspension (Cimarelli et al. 2011). The increase in yield strength with crystal fraction shown by Cima lavas is also much steeper compared with the experimentally determined trends reported in the literature (e.g. Ryerson et al. 1988, Ishibashi and Sato 2010, Mueller et al. 2010, Sehlke et al. 2014, Soldati et al. 2016), and it is apparently linear $\left(\mathrm{R}^{2}=0.84\right)$ rather than exponential $\left(\mathrm{R}^{2}=0.71\right)$, as the overall best fit equation for yield strength values calculated with Bingham and Herschel-Bulkley is $\sigma_{y}=5263.2 \phi_{x t a l}-56.517$ (Fig. 3.11). We have shown that the model used to calculate yield strength (Bingham or Herschel-Bulkley) is not responsible for this difference, nor does the discrepancy appear to be due to compositional, mineralogical, or instrumental effects. The crystallizing assemblage is similar for lavas from Cima, Pacaya, and Mauna Ulu. The chemical composition is different, in that Cima has a higher alkali content, but there is no theoretical foundation which can correlate yield strength and alkali content. No surface layer oxidation was observed (Fig. 3.8), excluding the possibility of a local effect on the experimental data. The experimental apparatus used was the same for Cima, Pacaya, and Mauna Ulu, and yield strength values were much higher only for Cima compositions. The laboratory operator was the same for Cima and Pacaya compositions, ruling out a procedural heterogeneity. The reason why the yield 
strength displayed by Cima lavas at any given crystal fraction is higher than that found for other compositions may depend on the shape of the oxide phase crystallized by Cima melts. Magnetite crystals produced are highly skeletal, and therefore they entrap melt, which is no longer available to flow past them. Therefore the "effective" crystal fraction may be significantly higher than the nominal crystal fraction, making the yield strength-crystal fraction correlation appear unusually steep.

The surface morphology developed by the experimental product at $1160{ }^{\circ} \mathrm{C}$ (Fig. 3.8) reflects the marked increase in yield strength (Fig. 3.11). Such lobate morphology, consisting of raised, rounded lobes 3-6 $\mathrm{mm}$ wide around the spindle site, is retained upon cessation of the applied stress, indicating that the yield strength is high enough to preserve the established morphology at that relatively low viscosity. Sehlke et al (2014) observed a similar surface morphology in Mauna Ulu basalts beginning at higher temperatures (1176 ${ }^{\circ} \mathrm{C}$ and below). Such experimental lobate surface features are used to define the pahoehoe to ' $a$ 'a a transition zone (TTZ) for the considered composition (see emplacement conditions section), at the applied strain rates.

\subsubsection{Yield strength: morphological constraints}

Analogue experiments with materials of known rheological behavior (e.g. Fink and Griffiths 1992; Gregg and Fink 1996, 2000; Lyman et al. 2004) confirm that the morphology of a lava flow may be used to retrieve information about its rheology. In particular, rheological parameters (such as yield strength) derived from remote sensing together with thermodynamic calculations have the potential of improving our understanding of the complex behavior of extraterrestrial lava flows (e.g. Chevrel et al. 
2013). Testing the accuracy of these parameters on Earth on target flows whose rheology can be independently confirmed is fundamental for their confident application, and Cima is an ideal setting for doing so. We used levée height and underlying ground slope as measured from the DEM to infer apparent yield strength. The inferred values appear reasonable when compared with the laboratory results, as they lie along the same trend of crystal fraction-dependent yield strength increase (Fig. 3.11b). Field observations of high levées ( 17-10 $\mathrm{m}$ vent to toe) and shallow underlying slopes $\left(3^{\circ}\right)$, confirmed by DEM analyses, suggest a yield strength at final emplacement of $\sim 21,800 \mathrm{~Pa},\left(h_{c}=\sigma_{y} / \rho g \sin \alpha\right.$ where

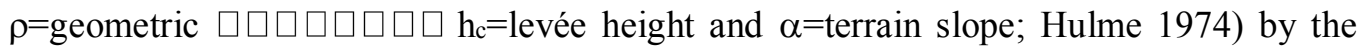
vent (flow lobes), and 12,800 Pa by the toe (Fig. 3.11b). These yield strength estimates are higher for the early crystalline lobes near the vent, and lower for the main flow, which is less crystalline.

The development of a thick channelized flow is in apparent contrast with the viscosity measured in the laboratory for the Cima trachybasalt composition, which is quite low compared to Hawaiian basalts (e.g. $\eta=378 \mathrm{~Pa} \cdot \mathrm{s}$ at $1168^{\circ} \mathrm{C}$ for $\mathrm{Cima}$ and $\eta=2268 \mathrm{~Pa} \cdot \mathrm{s}$ at $1169{ }^{\circ} \mathrm{C}$ for Mauna Ulu; Sehlke et al. 2014). However Cima field morphological observations and laboratory rheological measurements can be reconciled considering the higher phenocryst fraction of field samples (up to 0.26 ) and associated high yield strengths estimates of the order of $10^{4} \mathrm{~Pa}$ compared to the low crystal fraction (up to 0.11 ), low viscosity experimental data (Fig. 3.11b). Extrapolating the linear trend of yield strength increase delineated by low crystal fraction experimental data underestimates field-based yield strength values. The two datasets, laboratory- and field-based, are best fit $\left(\mathrm{R}^{2}=0.997\right)$ by the quadratic equation $\sigma_{\mathrm{y}}=12430 \phi_{\mathrm{xtal}}{ }^{2}+13791 \phi_{\mathrm{xtal}}-467.47$ (Fig. 3.11b). 

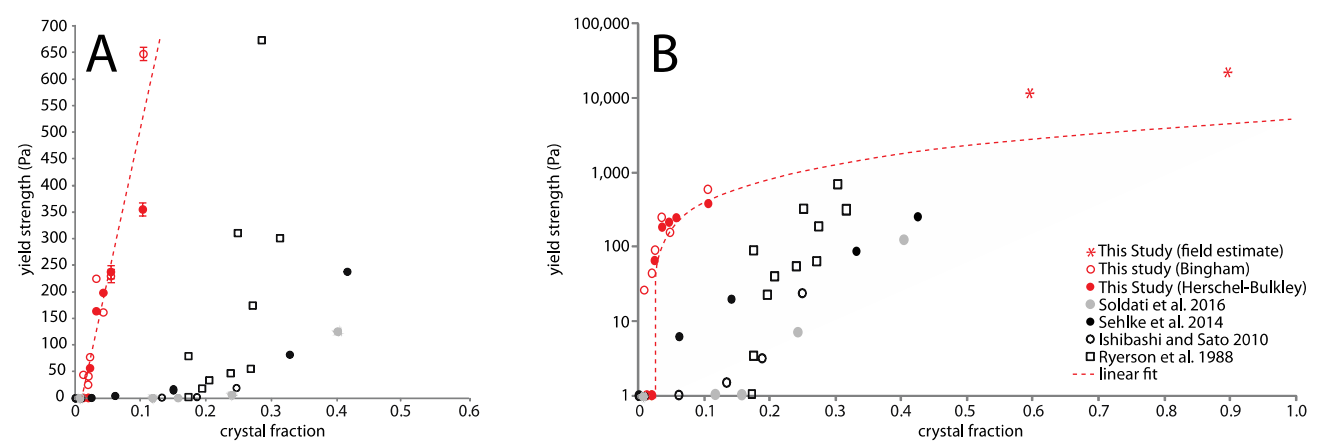

Figure 3.11 Yield strength vs. crystal fraction plot for all subliquidus experiments, compared to literature data; where no error bar is present, symbols are bigger than standard deviation. Soldati et al. (2016): Pacaya basalt; Sehlke et al. (2014): Mauna Ulu basalt; Ishibashi and Sato (2010): Fuji basalt; Ryeson et al. (1988): Kilauea Iki picritic basalt. (a) linear plot of experimental results (b) logarithmic plot including field estimates. Crystallinity of field samples pertains to sample 9 (early lobe) and 15 (main flow), located where levée measurements were undertaken.

\subsubsection{Pahoehoe to ' $a$ ' $\mathbf{a}$ transition}

Laboratory experiments have the capability of reproducing the rheological conditions under which the pahoehoe to 'a' $\bar{a}$ morphological transition takes place in the field (Sehlke et al. 2014). We assessed the composition-dependence of the pahoehoe to 'a'ā transition in a rheological map (Fig. 3.12) by comparing our results to similar experiments conducted on tholeiitic oceanic intraplate basalt from Mauna Ulu, Hawai'i (Sehlke et al. 2014). Alkali continental intraplate trachybasalt from Cima and ocean island tholeiite from Mauna Ulu both enter the transition from pahoehoe to 'a' $\bar{a}$ morphology at about the same temperature of $1183 \pm 10{ }^{\circ} \mathrm{C}$ for a strain rate of $1 \mathrm{~s}^{-1}$. However, the boundaries between the pahoehoe, transitional, and ' $a$ ' $\bar{a}$ fields are shifted towards higher apparent viscosities for Cima lavas, so that for any given strain rate-temperature conditions Cima lavas will enter the TTZ at a higher apparent viscosity then Hawaiian lavas. This indicates that the apparent viscosity at which morphological transitions occur is not composition-independent. The exact shape of 
the boundaries between the pahoehoe, transitional, and 'a' $\bar{a}$ fields cannot be assessed on the basis of experimental results only. However, it is possible to constrain their position relative to experimental temperatures in the effective viscosity - strain rate space based on the surface texture of the experimental samples. Furthermore, their shape must intersect that of the experimental curves, as the transitions can be crossed either by changing the temperature or the strain rate (Hon et al. 2003).

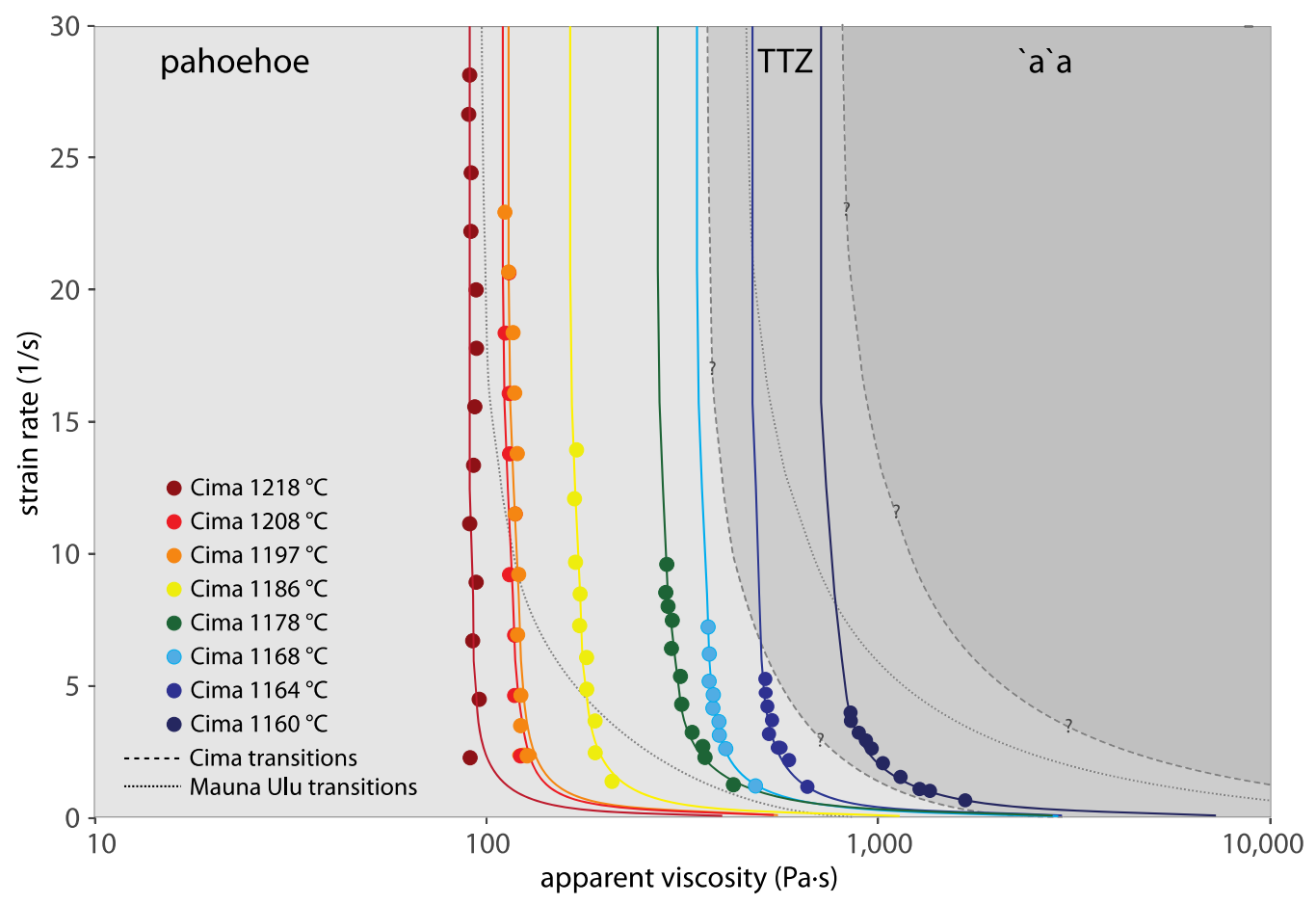

Figure 3.11 Strain rate vs. apparent viscosity plot showing the pahoehoe to ' $a$ ' $\bar{a}$ transitions for alkali (Cima; dotted line) and tholeiitic (Mauna Ulu; pointed line) basalts. The light grey field on the left of the diagram represents the pahoehoe zone, the dark grey area on the right of the diagram represents the 'a' $\bar{a}$ zone; in between lies the transition zone, in intermediate grey.

It is interesting to observe how the apparent viscosity changes quickly at low strain rates, especially those lower than about $3 \mathrm{~s}^{-1}$ (Fig. 3.12). For monogenetic volcanism in the 
Southwestern United States, where the flow substrate is frequently planar desert pavement, we can expect characteristic strain rates to be very low. At these low strain rates, apparent viscosity increases dramatically with decreasing strain rate (Fig. 3.12).

\subsubsection{Eruption temperature}

At Cima, the occurrence of prevalent 'a' ā morphology observed in the field, especially near the vent, combined with the temperature at which the pahoehoe to 'a' $\bar{a}$ transition occurs, determined in the laboratory for field-appropriate strain rates, constrains the maximum eruption temperature to $\sim 1164 \pm 5{ }^{\circ} \mathrm{C}$. The eruption temperature can be constrained more precisely on the basis of plagioclase geothermometry, MELTS simulations, and observed crystal fraction to $\sim 1110{ }^{\circ} \mathrm{C}$ (Fig. 3.13).

Additionally, magma chamber conditions can also be constrained on the basis of phenocryst content and MELTS simulations, to $\sim 1170{ }^{\circ} \mathrm{C}$ (Fig. 3.13). This was calculated assuming only phenocrysts were present in the magma chamber, and therefore represents an upper limit, while the eruptive crystal fraction is a maximum estimate based on total (phenocrysts + microlites) content. The difference between magma chamber and eruption temperatures indicates that magma cooled by as much as $60^{\circ} \mathrm{C}$ during conduit ascent. 


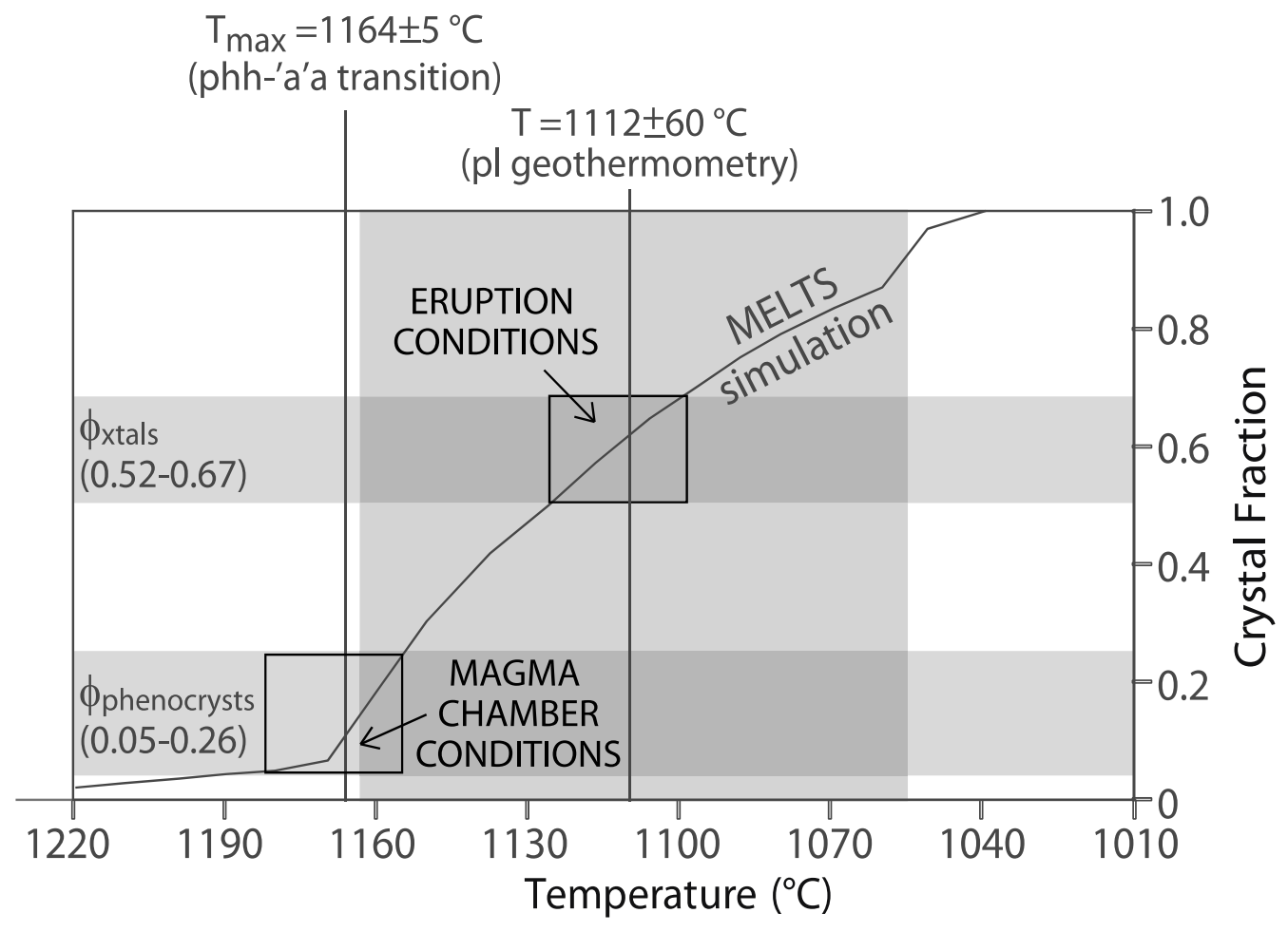

Figure 3.13 Morphological, geothermometrical, and textural constraints on magma chamber and eruption temperature. The grey areas indicate the observed crystal ranges and inferred temperature ranges. MELTS-predicted crystal fraction at an appropriate oxygen fugacity of FMQ+2 is also shown.

\subsubsection{Eruptive history}

The presence of proximal lobes on either side of the main channel (Fig. 3.4), characterized by a high crystal fraction (Fig. 3.6a), suggests that an initial eruptive phase emplaced them. Subsequently, less crystalline and hence more fluid lava (Fig. 3.6b) extended the flow's length to its final extent, with transport via both tubes and a surface channel.

The lower portion of the flow may have been primarily tube-fed, allowing it to reach its final length of about $2 \mathrm{~km}$ notwithstanding the flat pre-existing surface. The sparse outcrops 
of smooth lava found all over the flow are interpreted to be core extrusions, indicating places where lava disgorged from the tube system to the surface. The whaleback outcrop can also be interpreted as less viscous lava that emerged through a skylight in the tube.

We hence recognize the following four emplacement phases (Fig. 3.14) at Cima:

A. An early phase, which emplaced highly crystalline lava near the vent, producing the observed thick smooth flow lobes

B. A main phase, during which a break-out led to the emplacement of less crystalline lava through a tube

C. A phase opened by the collapse of the tube roof, possibly as the result of a sudden change in effusion rate (Greeley 1987), during which 'a'ā lava was emplaced through a wide, single channel that later partially drained, as testified by the low altitude of channel floor with respect to its levées

D. A late inflation phase, during which the flow was fed through a new tube system, which kept the lava insulated and allowed the sparse extrusion of smooth lava outcrops found downflow

The phenocrysts found in the early lobes are mainly plagioclase, which suggests that the magma chamber of cone A was likely stratified, and that its magma was extracted from the top down. Early plagioclase-rich lavas, followed by later less crystalline lavas, have also been reported at Lathrop Wells, NV (Valentine et al. 2007). 

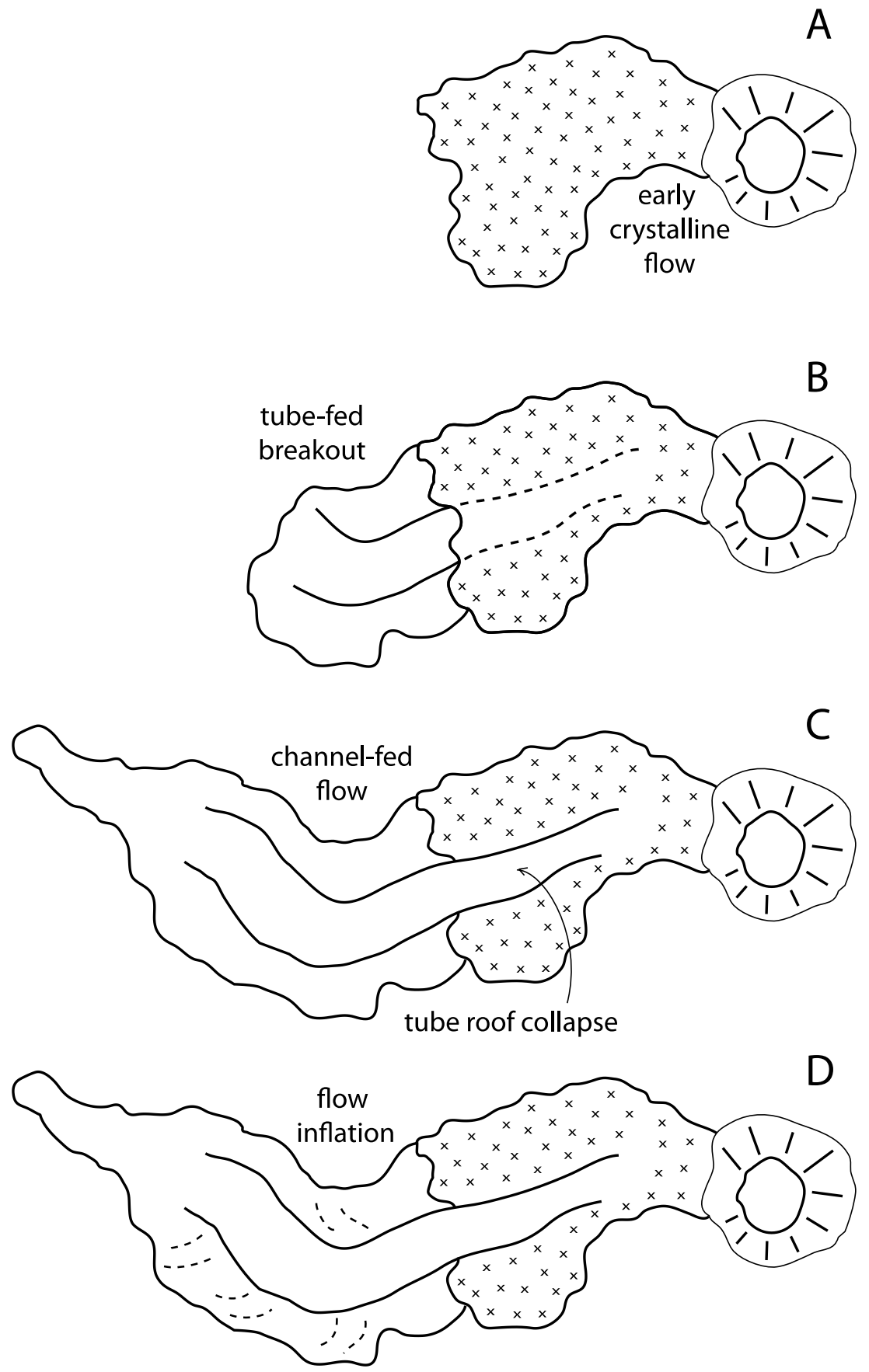

Figure 3.14 Emplacement history reconstruction: (a) highly crystalline, viscous lava erupted; (b) tube-fed breakout of less crystalline, less viscous lava (c) tube roof collapse and channel-fed emplacement of the remainder of the flow (d) flow inflation via lava tubes. 


\subsubsection{Emplacement timescale}

The estimated eruption temperature is $\sim 1115^{\circ} \mathrm{C}$, and the corresponding evolved liquid viscosity measured in the laboratory is $\sim 1200 \mathrm{~Pa} \cdot \mathrm{s}$. The lowest syn-emplacement crystal fraction of lava emplaced during phases 2 and 3 is represented by the average phenocryst fraction measured, 0.11, while the highest syn-emplacement crystal fraction of the main flow is represented by the average total crystal fraction measured, 0.66. We therefore assumed a reasonable (all phenocrysts $+2 / 3$ microlites) syn-eruptive crystal fraction of 0.48 . We used the Mader et al. (2013) algorithmic approach to calculate the viscosity of a liquid with $48 \%$ crystals at $1115^{\circ} \mathrm{C}$, and obtained a value of $74,082 \mathrm{~Pa} \cdot \mathrm{s}$ (for rough particles with an aspect ratio of 3). The average bubble fraction of the main flow is $0.13 \pm 0.08$ (with the exception of one very vesicular outlier; Table 3.3). We estimated the effect of this bubble fraction on the rheology of the flow following the model of Phan-Thien and Pham (1997). Regardless of the relative size of crystals and bubbles, the model predicts a lower viscosity for the three-phase mixture than experimentally observed for the two-phase (melt+crystals) mixture. However, the model assumes that bubbles are rigid and should therefore increase the overall mixture viscosity. We cannot therefore quantitatively account for the effect of bubbles on the flow rheology of Cima lavas. An alternative approach would be effective medium theory (Truby et al. 2014), but that cannot be applied to our case, as bubbles and crystals overlap in size. However, we note that for the purpose of estimating an emplacement timescale for the studied flow, the effect of such a small bubble fraction is likely within uncertainty. Given a channel cross-section area of $250 \mathrm{~m}^{2}(50 \mathrm{~m}$ wide, $5 \mathrm{~m}$ deep), Jeffreys' equation ( $v=g \rho \sin \alpha d^{2} / 3 \eta$, where $\rho=2100 \mathrm{~kg} / \mathrm{m}^{3}$ is geometric density, $\alpha=3^{\circ}$ is terrain slope, $\mathrm{d}=5 \mathrm{~m}$ is flow depth, and $\eta=7.4 \times 10^{4} \mathrm{~Pa} \cdot \mathrm{s}$ is lava viscosity; Jeffreys 1925) 
gives an average velocity of $\sim 0.12 \mathrm{~m} / \mathrm{s}$. This value is lower than the $1 \mathrm{~m} / \mathrm{s}$ estimate of Krauskopf (1948) for the Parícutin flows, the only flows emitted by a cinder cone ever directly observed; however, the Krauskopf(1948) value is reported as a maximum velocity, not as an average velocity. The Parícutin flows were erupted at a slightly lower temperature than ours (thermocouple measurement of $1070^{\circ} \mathrm{C}$ by the vent, while we estimate $1110^{\circ} \mathrm{C}$ ), but had a comparable estimated viscosity $\left(10^{4}-10^{5} \mathrm{~Pa} \cdot \mathrm{s}\right.$, compared to $\left.7.4 \times 10^{4} \mathrm{~Pa} \cdot \mathrm{s}\right)$, and flowed on a similarly shallow slope of $<5^{\circ}$. Use of Jeffreys' (Jeffreys 1925) equation is appropriate at Cima, as the channel appears approximately rectangular in section, and much wider than deep, along its entire length. However, the work of Lev and James (2014) indicates that application of Jeffreys' equation to irregular channel geometries leads to viscosity overestimates - or, in our case, velocity underestimates. Therefore our velocity estimate should be considered as a minimum value. It must also be noted that Jeffreys' equation is derived for Newtonian fluids, whereas we are considering the more complex case of a non-Newtonian fluid. However, the error introduced by making this simplifying assumption is minor in comparison with the uncertainty related to channel dimensions, and does not have a dramatic effect on the obtained velocity estimate. The effusion rate is estimated at $30 \mathrm{~m}^{3} / \mathrm{s}$, and based on the volumetric estimate of the Cima lava flow, $(\sim 0.015$ $\mathrm{km}^{3}$ ), the emplacement time is estimated at $\sim 6$ days. The uncertainty associated with these estimates is significant, and derives mainly from the simplifying one-stage emplacement assumption (which we know to be unlikely), as well as from channel dimensions and lava viscosity. While channel width is known precisely, flow thickness is not. The quoted value of $5 \mathrm{~m}$ is the likely average level to which the channel was filled during flow emplacement. It is an intermediate value between, $2 \mathrm{~m}$, i.e. the residual post-emplacement channel flow 
level, calculated as the altitude difference between the flow DEM and the interpolated ground surface, and $10 \mathrm{~m}$, i.e. the average altitude by which levées tower over the channel floor. Lava viscosity estimates obtained through the Mader et al. (2013) model are very sensitive to crystal fraction: a 0.05 variation in crystal fraction, compatible with textural analyses, results in a change in viscosity by a factor of 4 . Hence, we only use the estimated values to identify the correct order of magnitude of these parameters, i.e. an effusion rate of the order of $10^{2} \mathrm{~m}^{3} / \mathrm{s}$ and an emplacement time of a few days. Albeit vague, these estimates are the only ones available for lava flows emplaced in the context of cinder cones, due to the general lack of direct observations. As a comparison, at Parícutin, the only place where flow emplacement was directly observed, a $3 \mathrm{~km}$ flow is reported to have reached its full extent in 3 weeks (Krauskopf 1948).

\subsection{Conclusions}

Through field observations we inferred that the youngest Cima lava flow began with the emission of a batch of a highly crystalline lava, followed by less crystalline and less viscous lava emplaced initially as a tube-fed breakout, then through open channel flow, and later inflated via tube flow. Through laboratory experiments we found that the subliquidus rheological response of Cima lavas during cooling and crystallization is shearthinning at all temperatures considered (from $1228{ }^{\circ} \mathrm{C}$ to $1160{ }^{\circ} \mathrm{C}$ ), with significant yield strength development in concurrence with plagioclase crystallization, resulting in a Herschel-Bulkley rheological behavior at temperatures less than $1190^{\circ} \mathrm{C}$. Effective viscosity increases from $54 \mathrm{~Pa} \cdot \mathrm{s}$ to $1,361 \mathrm{~Pa} \cdot \mathrm{s}$ during cooling across the experimental temperature range, as crystal fraction increases from 0.02 to 0.11 . The thermal and 
especially chemical effect on the effective viscosity increase of this continental hostspot trachybasalt are significant, in contrast with what previously observed in an arc context. Through the synergy of field observation and laboratory measurements (e.g. channel dimensions, pahoehoe to ' $\mathrm{a}$ ' $\bar{a}$ transition location and rheological conditions, geothermometry, crystallinity, viscosity) we constrained the eruption temperature of the Cima flow to $\sim 1110{ }^{\circ} \mathrm{C}$ and its emplacement timescale to $\sim 3$ days, and recognized four flow emplacement phases. Our timescale estimate of a few days represents the only available estimate of its kind for lava flows associated with monogenetic cinder cones. 


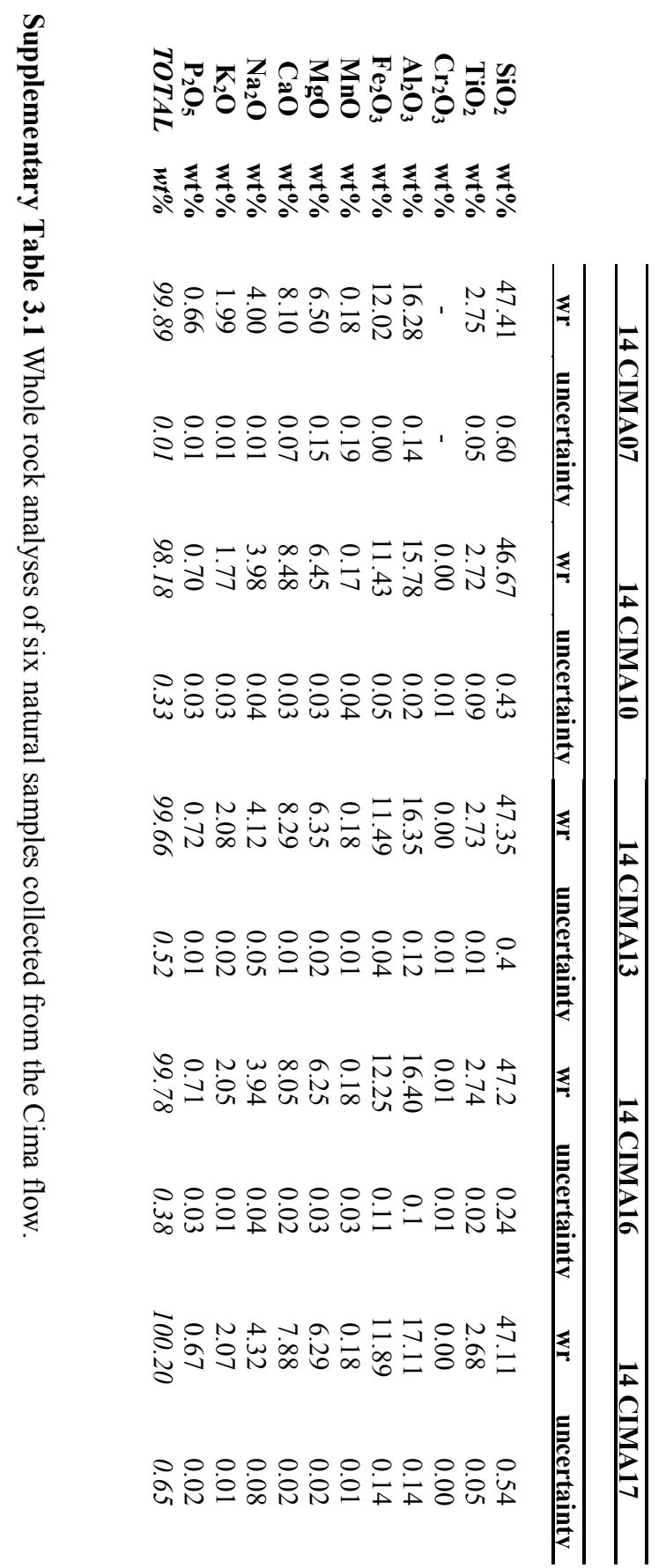




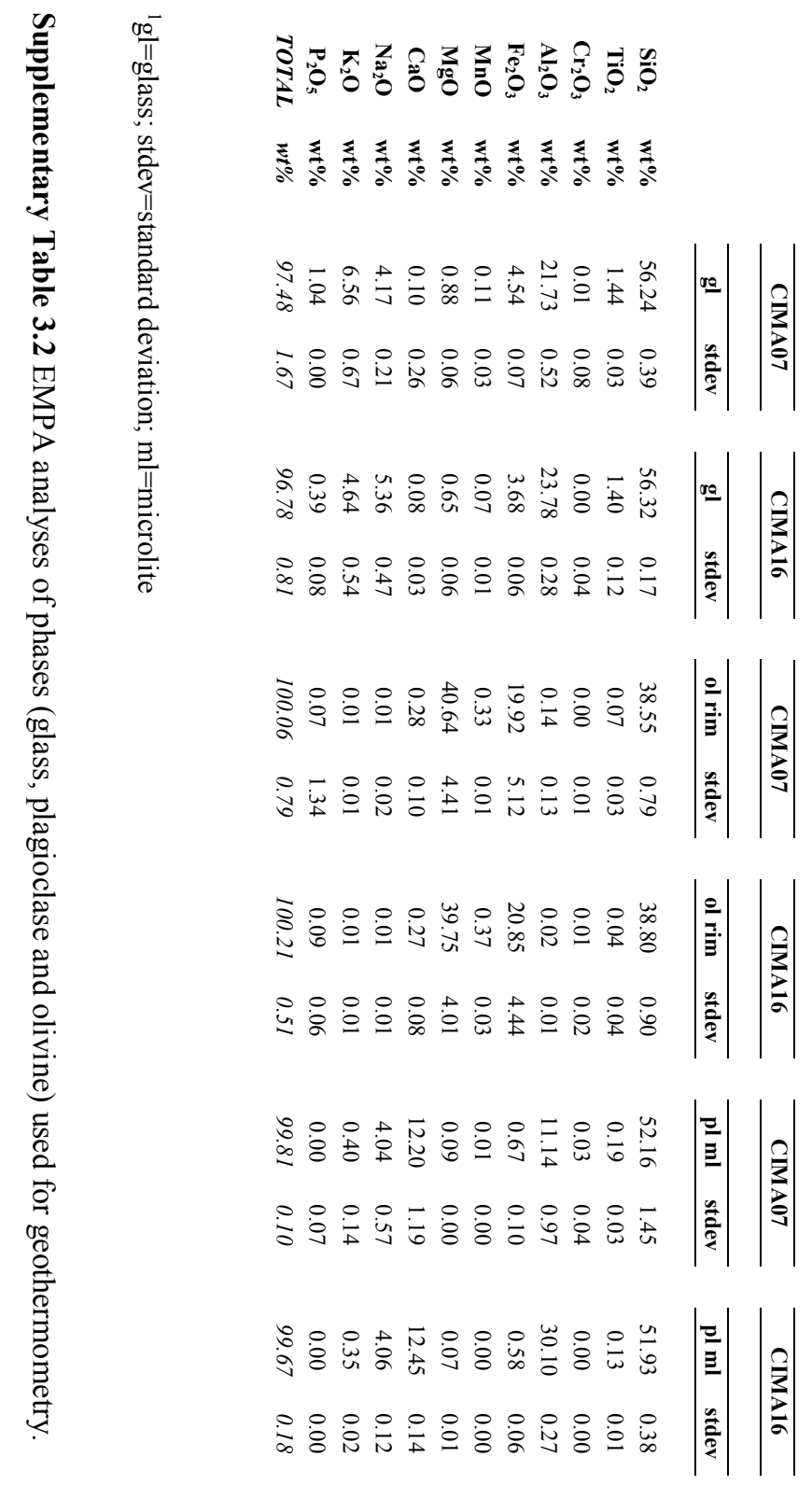




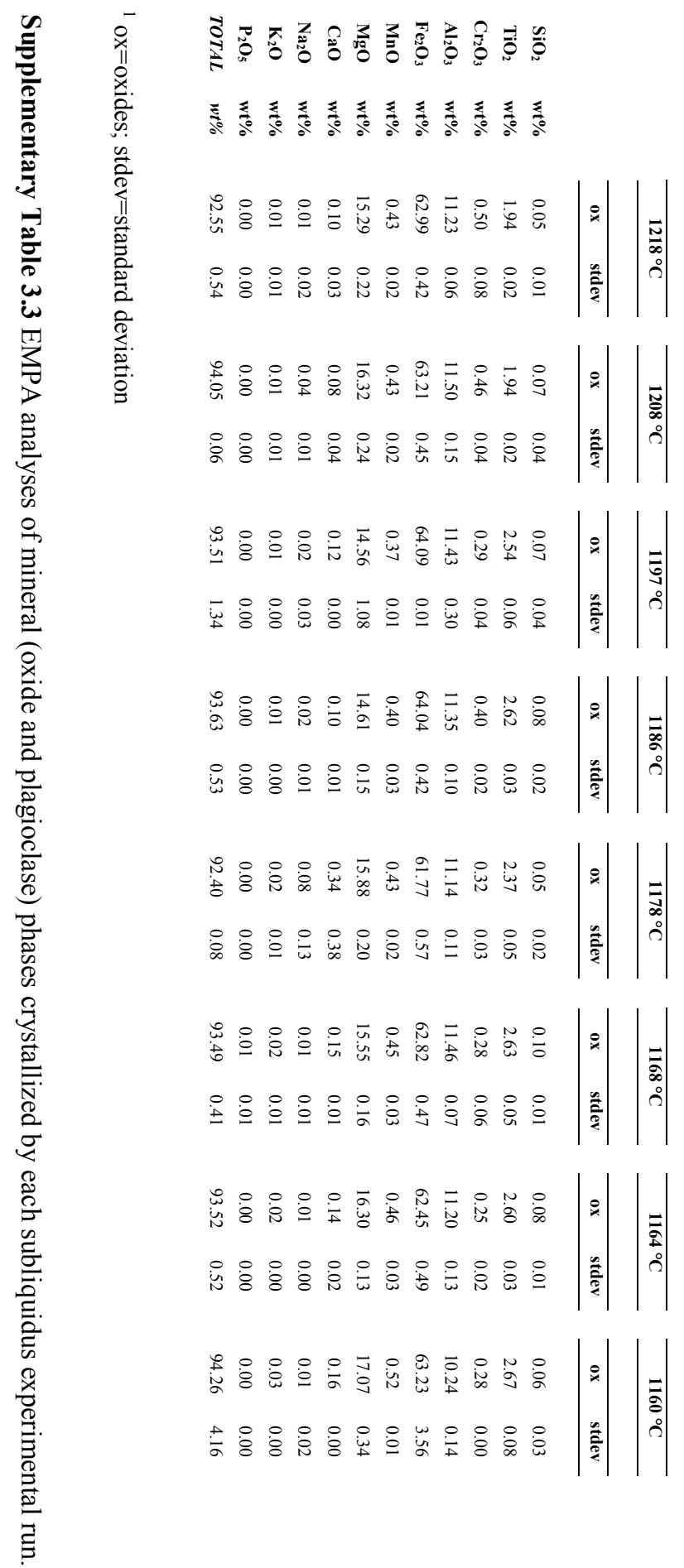




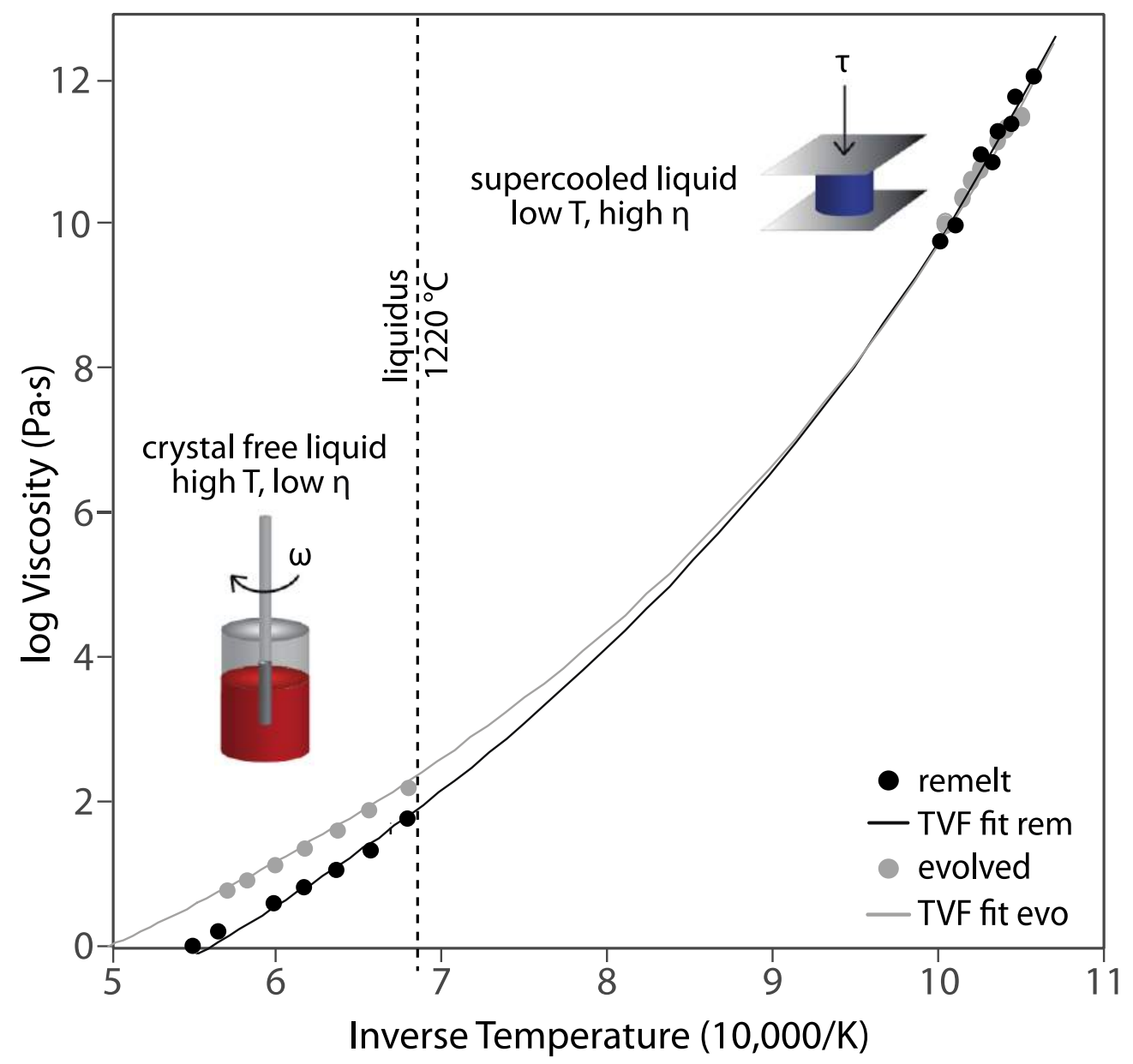

Supplementary Figure 3.1 Viscosity $(\eta)$ measurements obtained via concentric cylinder (1550$1200{ }^{\circ} \mathrm{C}$ ) and parallel plate $\left(725-671^{\circ} \mathrm{C}\right)$ viscometry on the remelt (black circles) and evolved (grey circles) compositions. The two data sets are fitted with the Tamman-Vogel-Fulcher (TVF) equations $\log \eta=-5.00+6072 /(T-588.8)$ (remelt composition; continuous black curve) and $\log \eta$ $=-4.33+6004 /(T-577.8)$ (evolved composition; continuous grey curve). $\omega=$ angular velocity; $\tau$ $=$ shear stress. 

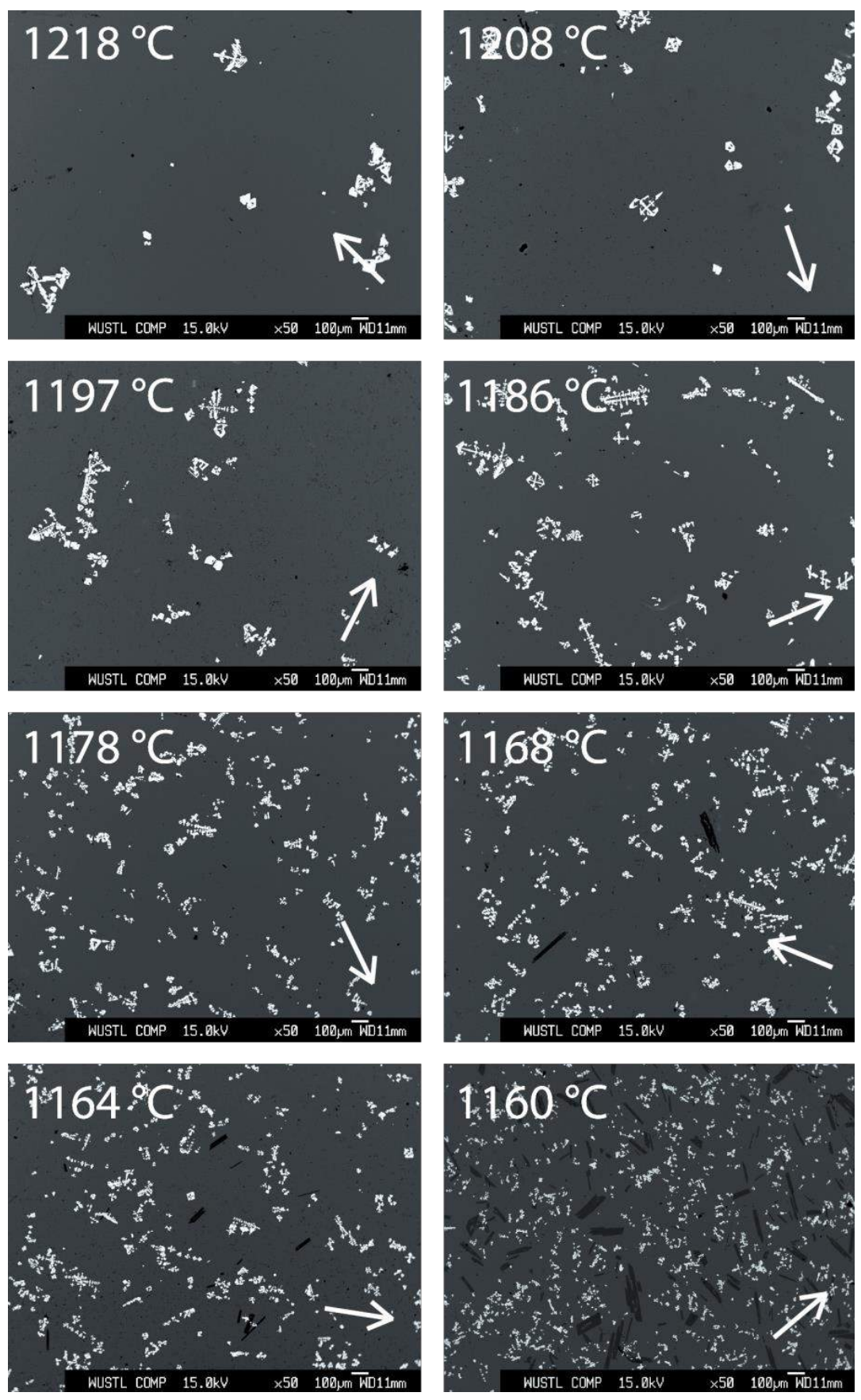

Supplementary Figure 3.2 SEM images of post-experimental samples for concentric cylinder, subliquidus runs. White arrows point towards spindle location. 


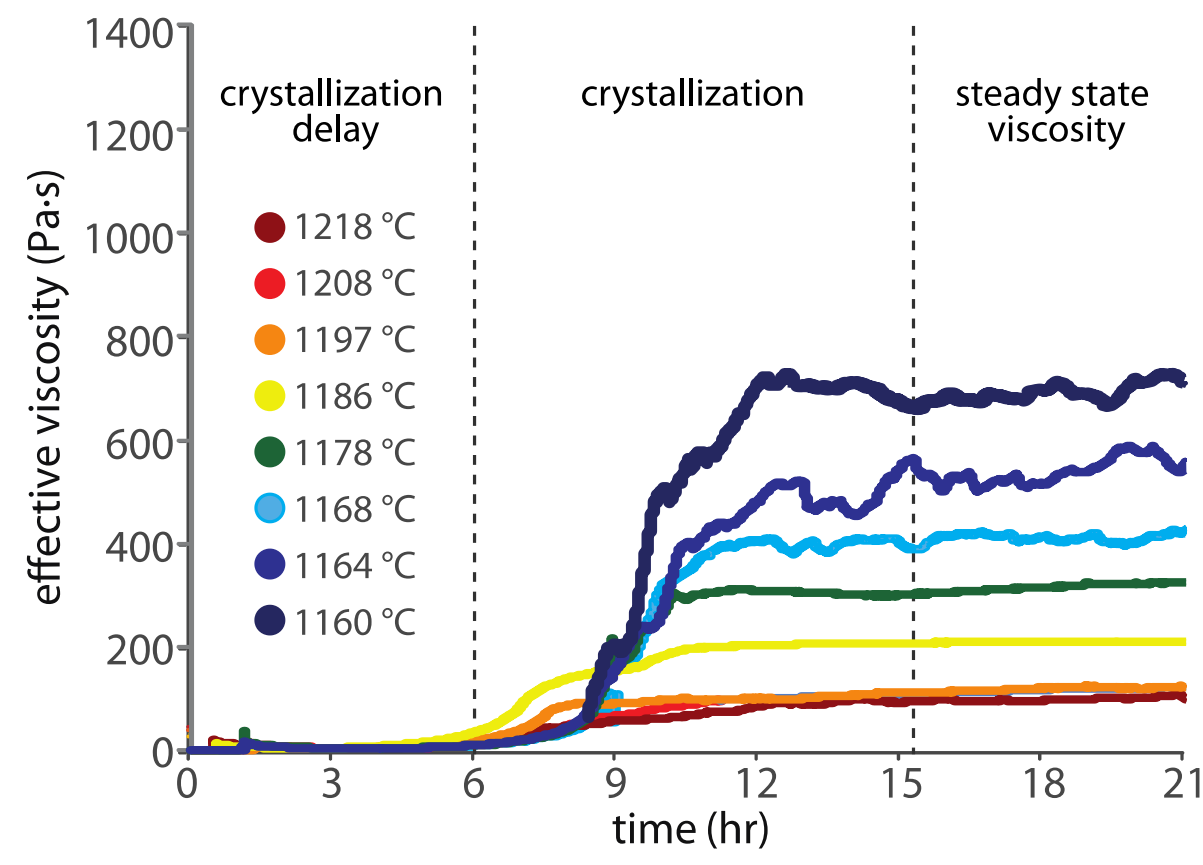

Supplementary Figure 3.3 Effective viscosity-time histories for subliquidus experimental runs, demonstrating attainment of steady-state effective viscosity prior to measurements. 


\section{Chapter Four}

\section{Textural, Thermal, and Topographic Constraints on Lava Flow System Structure: the December 2010 Eruption of Piton de La Fournaise}

\subsection{Introduction}

The architecture of a channel-fed lava flow system was classically described by Lipman and Banks (1987). At the flow-system scale, Lipman and Banks (1987) recognized four zones down a channel-fed lava flow: (i) a stable channel zone; (ii) a transitional channel zone, bounded by incipient rubble levées; (iii) a dispersed flow zone, and (iv) the flow front. This flow architecture has been recognized at several other volcanic systems on Earth, ranging in composition from basaltic (Kilburn and Guest 1993) to silicic (Harris et al. 2004), as well as on other terrestrial planets such as Mars (Garry et al. 2007). We define the channel as a zone of flowing lava contained between static levées (e.g. Sparks et al. 1976; Lipman and Banks 1987; Kilburn and Guest 1993), which typically begins to form quite close behind the dispersed flow zone (Rhéty et al. 2017). Following the definition of Lipman and Banks (1987), the dispersed flow zone is an unstructured zone where there are no levées present, and the flow core is covered in breccia all the way to the flow front. Rubble levées are laid down by the initial flow front passage (Sparks et al. 1976), and may later become overprinted with overflow levées (e.g. Lipman and Banks 1987; Naranjo et al. 1992; Bailey et al. 2006). Overflow levées are emplaced during periods of increased effusion rate, when flux exceeds channel capacity, causing the 
channel to overflow for a short period of time (Bailey et al. 2006). During waning flow, levées become accreted to the inner walls of the channel (Naranjo et al. 1992), and nested levées may form (Lipman and Banks 1987).

Pre-existing topography has been shown to affect the form of the channel network (single-channel versus braided) down such lava flow systems. Dietterich and Cashman (2014) studied the effect of slope on channel networks at Mauna Loa, finding that steeper slopes corresponded to higher braiding indices. Here, following Dietterich and Cashman (2014), we assess the effect of slope on the spatial variation of channel network architecture by comparing ground slope changes and observed channel network structure. Additionally, we examine the potential interactions of textural parameters with the flow structure by quantifying downflow cooling, crystallinity and porosity, and analyzing them in the context of the observed flow system architecture. We focus on the channelized flow system emplaced by the December 2010 eruption of Piton de La Fournaise (La Réunion, France). This system was emplaced during an extremely short-lived eruption, resulting in the simplest possible flow field, which minimized the number of emplacement variables to be considered. We find that the relation between slope and flow system architecture previously found in other systems (Krauskopf 1948; Dietterich and Cashman 2014), and at the same volcano (Rhéty et al. 2017), cannot be applied globally. 
4.1.1 Piton de La Fournaise: the December 2010 eruption and lava flow field

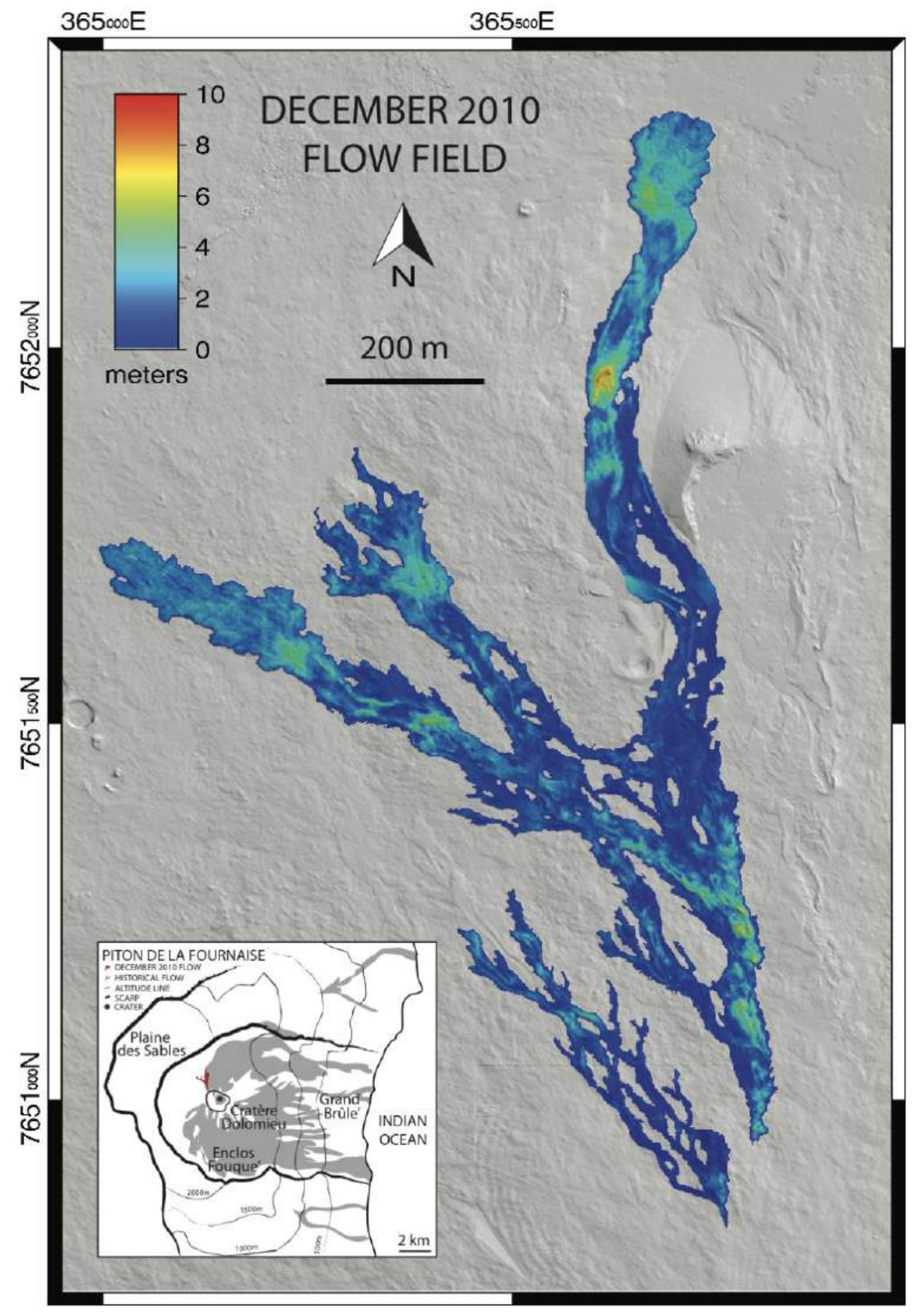

Fig. 4.1 DEM of the December 2010 flow field area, highlighting flow thickness. Inset: Piton de La Fournaise map showing the location of the December 2010 flow. 
Piton de La Fournaise is located on the Island of La Réunion, in the Indian Ocean. The most common present-day eruptive activity at Piton de la Fournaise consists of shortduration eruptions, lasting between one day and a few months (Bachèlery et al. 2016). These generally occur within the Enclos Fouqué (Fig. 1), i.e. the most recent caldera of the volcano (Villeneuve and Bachèlery 2006). Activity is typically effusive, and erupted volumes are generally low, with dense rock equivalent volumes of less than $10^{7} \mathrm{~m}^{3}$ per eruption (Roult et al. 2012; Bachèlery et al. 2016). Mean output rates (MOR) are generally $1-10 \mathrm{~m}^{3} / \mathrm{s}$ with peak time-averaged discharge rates (TADR) of up to $60 \mathrm{~m}^{3} / \mathrm{s}$ (Coppola et al. 2017). We define MOR as the total erupted volume divided by the total duration of the eruption, TADR as the volume erupted during a known time window within the eruptive period, and effusion rate as an instantaneous flux (Harris et al. 2007; 2017). Most effusive events at Piton de La Fournaise are characterized by TADR that decay rapidly with time and are coupled with syn-eruptive deflation of the summit (Coppola et al. 2017). This means that, during an eruption, TADRs and effusion rates begin at a level higher than the MOR and then decay, in an exponential fashion, through it (Harris et al. 2000; 2007). As argued by Coppola et al. (2017), this pattern is consistent with rapid withdrawal of magma from a pressurized source (Wadge 1981).

The December 2010 eruption was a typical Piton de la Fournaise short-duration, lowvolume, effusive eruption occurring within the Enclos Fouqué (Fig. 1). Enhanced seismicity was first reported between 07:48 and 08:01 (hh:mm, all times are local, UTC+4) on December 9 (Di Muro 2010a), and a second phase of enhanced seismicity was recorded between 08:35 and 09:53 on the same day (Di Muro 2010b). Both events were associated with summit inflation and a three-fold increase in $\mathrm{SO}_{2}$ emission (Di 
Muro 2010c). A third phase of enhanced seismicity and summit inflation began at 19:08 (Di Muro 2010d). The eruption began at the end of this seismic crisis around 22:40 from a location on the NNW flank of the volcano (Di Muro 2010e). Lava flows were reported as descending the North-West flank of Piton de La Fournaise at 06:45 on the following morning (Di Muro 2010f), but the eruption was declared over at 14:50, with no seismic activity having been recorded since 13:30 (Di Muro 2010g). The eruption thus lasted less than 15 hours.

We chose this channel system as the focus of our study for four main reasons. First, the flow field is easily accessible and its areal extent is limited, allowing high spatialresolution mapping and sampling. Second, the flow morphological features (main and secondary channels, multiple generations of levées, overflows, lava morphologies) are fresh and well-exposed, facilitating their identification. Third, because the eruption was of short duration, few channel sections were buried by later flow. Fourth, and most importantly, the flow consists of four different branches fed by the same magma over a short period of time, allowing us to focus solely on the effects of pre-existing topography and down-flow cooling and crystallization on channel system architecture. Google Earthbased mapping by Rhéty (2014) identified four en-échelon fissure segments associated with the December 2010 eruption. These were orientated SSE-NNW and extended over a distance of $225 \mathrm{~m}$ from an elevation of $2515 \mathrm{~m}$ a.s.l. down to $2450 \mathrm{~m}$ a.s.1.. The fissure segments fed four channelized 'a'ā flows, named South, West, North-West, and North, which extended to a distance of up to $1.2 \mathrm{~km}$ from the eruptive fissure (Rhéty 2014). The total flow area was previously estimated as being $0.269 \mathrm{~km}^{2}$ which, given a typical flow 
thickness of $2 \mathrm{~m}$, gives a flow field volume of $0.54 \times 10^{6} \mathrm{~m}^{3}$ for a MOR of $9.8 \mathrm{~m}^{3} / \mathrm{s}$ (Harris et al. 2016).

\subsection{Methods}

\subsubsection{Mapping}

A preliminary map of the December 2010 lava flow field was produced on the basis of satellite images provided by Google Earth $\odot$. Specifically, toggling between the preeruption image of December 4, 2010 (Image (C) 2018 Digital Globe) and the post-eruption image of February 16, 2012 (Image (C) 2018 Digital Globe) allowed us to delimit the flows emitted during the December 2010 eruption. The pre-eruptive images were also used to map and define pre-existing flows underlying and/or adjacent to the 2010 flow units, such as the 1957 and 2000 channel-fed 'a'à flows fields.

This preliminary map was later refined on the basis of two Digital Elevation Models (DEMs) of the study area. The first, pre-eruptive, DEM was produced in 2010 by the Institut Géographique National (IGN) from an airborne Light Detection and Ranging (LIDAR) dataset. That DEM was used to extract pre-existing terrain slope downflow. The second, post-eruptive DEM was produced in 2018 photogrammetrically using 209 images acquired with a Canon 5DSR camera (51 MegaPixel resolution) with a $50 \mathrm{~mm}$ lens mounted on a ultralight aircraft. From this photogrammetric DEM, cross-flow profiles were extracted every $10 \mathrm{~m}$ along the middle of each flow branch, allowing us to determine flow and channel width (Supplementary Material Table 1). The 
photogrammetric DEM was constructed in Agisoft Photoscan Pro. The two DEMs were downsampled to a horizontal resolution of $1 \mathrm{~m}$ and co-aligned using an affine transformation to minimize differences in spatial orientation (RMS error of $0.45 \mathrm{~m}$ for areas excluding the lava flow). The difference between the post-eruptive and pre-eruptive DEMs, calculated using ArcGIS, allowed us to precisely determine the flow thickness and volume.

Mapping was supported by analysis of thermal $(7.5-13 \mu \mathrm{m})$ images collected during the morning of December 10 using a hand-held thermal camera (Fig. 2). During a site visit by the Observatoire de Physique du Globe (Di Muro 2010g), 38 thermal images were acquired from Pas de Bellecombe, a location on the caldera rim $2.5 \mathrm{~km}$ west of the eruptive fissure, between 05:25 and 06:00. Images were collected with a hand-held FLIR Systems ThermaCam PM695 operating in the low gain $\left(-40-120{ }^{\circ} \mathrm{C}\right)$ range. Image size was $320 \times 240$ pixels with $1.3 \mathrm{mrad}$ pixels, which over a distance of $2.5 \mathrm{~km}$ gives a pixel size of $3.25 \mathrm{~m}$. Images were oblique, but provided an overview of the flow field allowing dimensions and relative surface temperatures of each flow to be analyzed.

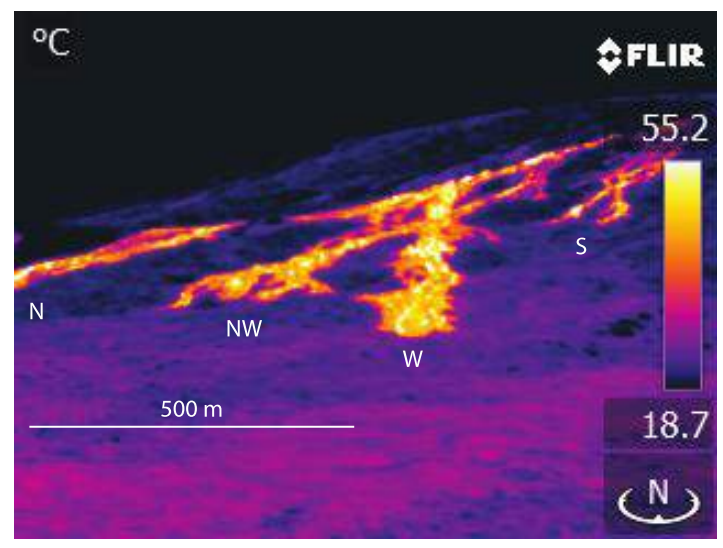

Fig. 4.2 Thermal imagery of the December 2010 flow field. field, including eruptive fissures, vents, levée rims, and substrate photos, as well as flow system architecture. 


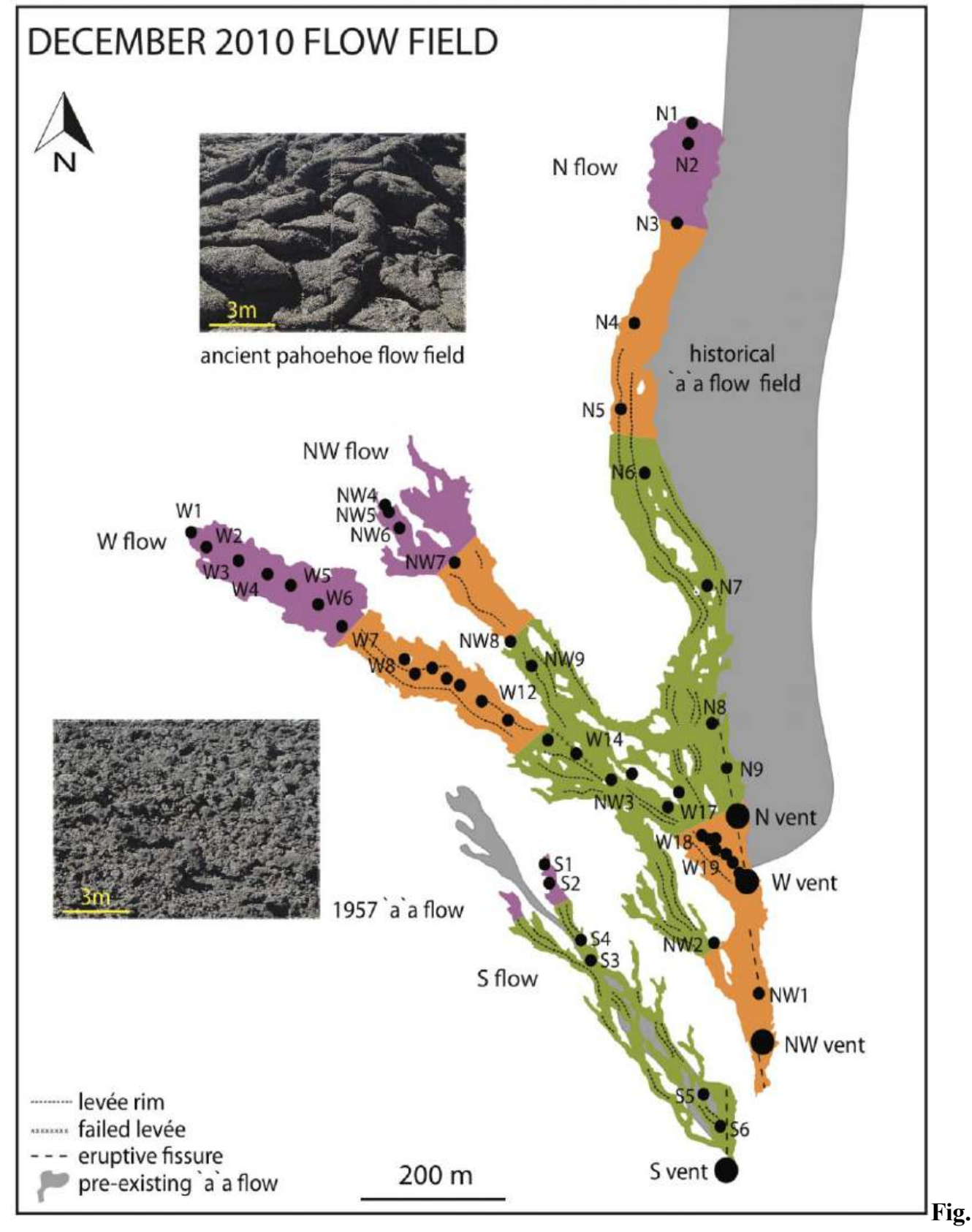

4.3 Structural map of the December 2010 flow field, including eruptive fissures, vents, levée rims, and substrate photos, as well as flow system architecture; sample locations are also plotted. 
Channel dimension measurements and sampling were conducted during three field visits in 2013, 2014 and 2016. All measurements and sampling sites were GPS-located. For each flow, the master channel was followed and the depth and width of the channel was measured with tape measure and compass-clinometer, as were the height and width of the levées. The depth of undrained lava in the channel was obtained by subtracting levée inner and outer height (see, for example, Fig. 11 of Favalli et al. (2018) for definition of the measured and derived channel/levée geometries). Where braided, the dimensions of each channel making up the total width of the channel system were measured, and the morphology of the channel lava and levée type (initial, nested, accretionary, or overflow) were noted. A total of 23 scaled morphological profiles were completed.

A total of 55 samples were collected (Fig. 3). The West flow was sampled in detail, with one sample being collected every $\sim 30 \mathrm{~m}$ down channel between the vent and the flow front. The other three flows were sampled focusing on the vent (i.e. the source), the flow front, and around slope breaks, resulting in the collection of six-to-nine samples per flow. Samples were collected in situ, and consisted mostly of core extrusions and accretionary levées where glass was visible (Table 1).

Flow areas and volumes were estimated from the flow map. The MOR was obtained by dividing the flow volume by the eruption duration, and effusion rates in master channels were estimated using field-based measurements of the channel dimensions. To do this, first we calculated mean flow velocity in the channel using Jeffreys equation (Jeffreys 1925 ) with an estimated lava viscosity of $380 \mathrm{~Pa}$ s (Harris et al. 2015) and a bulk density of $1080 \mathrm{~kg} / \mathrm{m}^{3}$. Multiplying the velocity by flow cross-sectional area (flow width $\times$ depth) provided an estimate of the peak effusion rate under bankfull conditions. 


\begin{tabular}{|c|c|c|c|c|c|c|}
\hline Sample & $\begin{array}{c}\text { Easting (zone 40K) } \\
\mathrm{m}\end{array}$ & $\begin{array}{c}\text { Southing } \\
\mathbf{m}\end{array}$ & $\begin{array}{c}\text { Elevation } \\
\mathbf{m}\end{array}$ & $\begin{array}{c}\text { Vent Distance } \\
\text { m }\end{array}$ & Location Notes & Description \\
\hline PF-10S-16-01 & 365492 & 7651230 & 2350 & 437 & flow center & spiny `a’a core extrusion \\
\hline PF-10S-16-02 & 365511 & 7651215 & 2358 & 413 & inner left levée base & spiny pahoehoe \\
\hline PF-10S-16-03 & 365526 & 7651204 & 2364 & 396 & central channel & spiny pahoehoe extrusion \\
\hline PF-10S-16-04 & 365530 & 7651196 & 2373 & 387 & central channel & spiny pahoehoe extrusion \\
\hline PF-10S-16-05 & 365712 & 7650931 & 2466 & 66 & right levée crest & pahoehoe overflow \\
\hline PF-10S-16-06 & 365745 & 7650911 & 2478 & 33 & inner left levée & pahoehoe overflow \\
\hline PF-10W-15-01 & 364994 & 7651736 & 2243 & 934 & flow front extrusion & spiny pahoehoe \\
\hline PF-10W-15-02 & 365019 & 7651718 & 2251 & 903 & incipient levée & up-bent slab, deformation levée \\
\hline PF-10W-15-03 & 365083 & 7651693 & 2257 & 836 & incipient levée & up-bent slab, deformation levée \\
\hline PF-10W-15-04 & 365124 & 7651661 & 2261 & 784 & flow center upwelling & spiny pahoehoe \\
\hline PF-10W-15-05 & 365153 & 7651646 & 2264 & 752 & flow center overflow & surface of accreted levée \\
\hline PF-10W-15-06 & 365191 & 7651622 & 2268 & 707 & flow center core & spiny pahoehoe \\
\hline PF-10W-15-07 & 365245 & 7651578 & 2271 & 638 & channel exit center & spiny pahoehoe \\
\hline PF-10W-15-08a & 365290 & 7651542 & 2280 & 580 & middle of channel & slab of spiny pahoehoe \\
\hline PF-10W-15-08b & 365275 & 7651516 & 2284 & 580 & overflow levée & 'a a margin \\
\hline PF-10W-15-09 & 365334 & 7651511 & 2292 & 527 & overflow levée & rough pahoehoe/'a'a swirls \\
\hline PF-10W-15-10 & 365367 & 7651500 & 2303 & 493 & overflow levée & rough pahoehoe/'a'a swirls \\
\hline PF-10W-15-11 & 365401 & 7651492 & 2309 & 460 & middle of channel & spiny rough pahoehoe \\
\hline PF-10W-15-12 & 365429 & 7651467 & 2313 & 423 & middle of channel & spiny rough pahoehoe \\
\hline PF-10W-15-13 & 365461 & 7651439 & 2322 & 381 & middle of channel & rough spiny pahoehoe \\
\hline PF-10W-15-14 & 365509 & 7651423 & 2326 & 332 & incipient channel & down flow spreading cleft \\
\hline PF-10W-15-15 & 365550 & 7651399 & 2336 & 285 & middle of channel & spiny pahoehoe slab \\
\hline PF-10W-15-16 & 365589 & 7651393 & 2341 & 250 & middle of channel & ooze out of spiny pahoehoe \\
\hline PF-10W-15-17 & 365636 & 7651360 & 2355 & 193 & right levée & accreted slab of spiny pahoehoe \\
\hline PF-10W-15-18 & 365688 & 7651326 & 2366 & 132 & levée overflow & spiny pahoehoe \\
\hline PF-10W-14-0A & 365787 & 7651225 & 2398 & 9 & & spiny pahoehoe \\
\hline PF-10W-14-0B & 365782 & 7651242 & 2392 & 11 & & spiny pahoehoe \\
\hline PF-10W-14-01 & 365765 & 7651255 & 2387 & 28 & & spiny pahoehoe \\
\hline PF-10W-14-02 & 365756 & 7651259 & 2385 & 37 & & spiny pahoehoe \\
\hline PF-10W-14-03 & 365741 & 7651272 & 2382 & 57 & & spiny pahoehoe \\
\hline PF-10W-14-04 & 365729 & 7651282 & 2377 & 72 & & spiny pahoehoe \\
\hline PF-10W-14-05 & 365713 & 7651288 & 2374 & 88 & & spiny pahoehoe \\
\hline PF-10W-14-06 & 365713 & 7651288 & 2374 & 88 & & spiny pahoehoe \\
\hline PF-10W-14-07 & 365706 & 7651296 & 2369 & 98 & & spiny pahoehoe \\
\hline PF-10W-14-08 & 365696 & 7651306 & 2366 & 113 & & spiny pahoehoe \\
\hline PF-10W-14-09 & 365691 & 7651310 & 2363 & 119 & & spiny pahoehoe \\
\hline PF-10W-14-10 & 365676 & 7651324 & 2359 & 140 & & spiny pahoehoe \\
\hline PF-10NW-16-01 & 365796 & 7651006 & 2462 & 52 & vent channel exit & rubbly pahoehoe overflow \\
\hline PF-10NW-16-02 & 365743 & 7651125 & 2421 & 87 & main channel & spiny pahoehoe \\
\hline PF-10NW-16-03 & 365621 & 7651343 & 2353 & 335 & channel, pre- intersection & spiny pahoehoe \\
\hline PF-10NW-16-04 & 365261 & 7651782 & 2251 & 901 & dispersed flow area & spiny pahoehoe surface extrusion \\
\hline PF-10NW-16-05 & 365260 & 7651771 & 2253 & 893 & incipient left levée outer rim & spiny pahoehoe \\
\hline PF-10NW-16-06 & 365284 & 7651741 & 2261 & 855 & first well formed levée & 'a a accretion on inner left levée \\
\hline PF-10NW-16-07 & 365419 & 7651650 & 2292 & 703 & groove & spiny pahoehoe slab \\
\hline PF-10NW-16-08 & 365487 & 7651531 & 2315 & 566 & smooth grooved inner wall & spiny pahoehoe accreted to left levée \\
\hline PF-10NW-16-09 & 365487 & 7651522 & 2317 & 559 & channel & spiny pahoehoe \\
\hline PF-10N-16-01 & 365709 & 7652301 & 2170 & 1173 & channel extrusion & spiny pahoehoe \\
\hline PF-10N-16-02 & 365655 & 7652275 & 2185 & 1152 & vertical slab in channel & spiny pahoehoe \\
\hline PF-10N-16-03 & 365659 & 7652169 & 2181 & 1046 & left levée pre slope break & spiny pahoehoe \\
\hline PF-10N-16-04 & 365631 & 7652012 & 2224 & 895 & steep channel by right levée & spiny pahoehoe \\
\hline PF-10N-16-05 & 365601 & 7651899 & 2265 & 790 & left levée, gentle slope zone & spiny pahoehoe \\
\hline PF-10N-16-06 & 365619 & 7651828 & 2274 & 717 & tube exit channel core crack & spiny pahoehoe \\
\hline PF-10N-16-07 & 365702 & 7651662 & 2311 & 538 & tube exit channel core crack & spiny pahoehoe \\
\hline PF-10N-16-08 & 365756 & 7651373 & 2358 & 245 & tube exit channel core crack & spiny pahoehoe \\
\hline PF-10N-16-09 & 365772 & 7651206 & 2395 & 77 & right levée just up the path & spiny pahoehoe \\
\hline
\end{tabular}

Table 1 Sample locations and descriptions. 


\subsubsection{Estimation of volume fluxes}

\subsubsection{Laboratory-based chemical analyses}

The bulk major element composition of lava samples was measured by ICP-AES at the Laboratoire Magmas et Volcans (LMV, Clermont-Ferrand, France). Thin sections were prepared from the upper-most part of the crust of each sample, which was air quenched, thus minimizing post-emplacement crystallization. Analyses were carried out on a Cameca SX100 Electron Microprobe, with operating conditions of $15 \mathrm{kV}$ acceleration voltage, $10 \mathrm{nA}$ beam current and a $10 \mu \mathrm{A}$ beam diameter. We obtained around ten glass analyses and five mineral analyses per phase per sample. Glass analytical spots were chosen as far as possible from crystals (at least $20 \mu \mathrm{m}$ ) so that the glass composition would not be affected by crystal growth. The emplacement temperature of the flows was then estimated on the basis of three $\mathrm{MgO}$-based liquid geothermometers: those of Heltz and Thornber (1987), Putirka (2008) and Rhéty et al. (2017). Temperatures were also obtained from three geothermometers based on liquid-mineral equilibrium: liquid-olivine (Putirka et al. 2007), liquid-pyroxene (Putirka et al. 1996), and liquid-plagioclase (Putirka et al. 2005).

\subsubsection{Laboratory-based textural analyses}

The density of each collected sample was measured following the methodology proposed by Houghton and Wilson (1989) based on the Archimedes principle, and the procedure described by Shea et al. (2010), Robert et al. (2014), and Rhéty et al. (2017). The dense rock equivalent (DRE) density was measured in a helium pycnometer and calculated through the Boyle-Mariotte law, and has a precision better than $2 \%$. 
For each flow, one near-vent sample and one near-toe sample were investigated. The largest vesicle and crystal populations were imaged by scanning both the sectioned sample and the thin section taken from it with a desktop scanner. Digitization of the thin sections was completed both in natural and polarized light using polarized paper placed at different angles with respect to the sample (Pioli et al. 2014). Subsequent higher magnification images were acquired using a Scanning Electron Microscope (SEM). Following Robert et al. (2014) and Rhéty et al. (2017), for each section we collected three images at $25 \times$ magnification and six images at $100 \times$. Images were prepared in Adobe Photoshop ${ }^{\circledR}$, where crystals, vesicles and glass were each assigned a different grey tone. Phase volume fraction was measured through FOAMS (Shea et al. 2010), a Matlab-based code that calculates the percentage of each grey tone, and therefore of crystals, vesicles, and glass for multiple same-sample images acquired at different magnifications. This method allowed us to account for the crystal and vesicle size range found in each sample, down to a minimum crystal size of $12.5 \mu \mathrm{m}$. To compare the crystallinity of different samples, crystallinity values were normalized to the sample-specific dense fraction with the following equation:

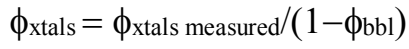

where $\phi_{x t a l s}$ is the corrected crystallinity, $\phi_{x}$ tals measured is the non-corrected crystallinity and $\phi_{\mathrm{bbl}}$ is the porosity obtained through density measurements.

Based on their size, three types of crystals were identified. Macrocrysts, are olivines greater than $0.5 \mathrm{~mm}$ in diameter as described by Welsch et al. (2009) for the recent products of Piton de La Fournaise. Mesocrysts are crystals of olivine, clinopyroxene and plagioclase, between 0.1 and $0.5 \mathrm{~mm}$ in diameter. Microcrysts are crystals of olivine, 
clinopyroxene and plagioclase less than $0.1 \mathrm{~mm}$ in diameter. The total crystallinity values reported in this study only comprise the macrocrysts and the mesocrysts, corresponding to the crystals that formed in the magma reservoir (Welsch et al. 2009), but exclude microcrysts that instead formed in the shallow reservoir and the conduit (Di Muro et al. 2015), as well as during flow emplacement and post-emplacement cooling (Rhéty et al. 2017). All the raw data are available in the DynVolc Database (2017).

\subsection{Results}

\subsubsection{Flow system dimensions}

DEM-based mapping identifies a $0.213 \mathrm{~km}^{2}$ flow field, subdivided between the South

$\left(0.023 \mathrm{~km}^{2}\right)$, West $\left(0.065 \mathrm{~km}^{2}\right)$, upper North-West $\left(0.016 \mathrm{~km}^{2}\right)$, lower North-West $(0.033$ $\left.\mathrm{km}^{2}\right)$, and North $\left(0.076 \mathrm{~km}^{2}\right)$ flow. This compares to an overall flow field areal extent of $\sim 0.25 \mathrm{~km}^{2}$ calculated through Google Earth. The thickness of the flow field (Fig. 1) varies between $0 \mathrm{~m}$ and $8.6 \mathrm{~m}$, with a mean value of $1.7 \mathrm{~m}$ and a median value of $1.5 \mathrm{~m}$. The overall flow volume is calculated to be of $0.35 \mathrm{~km}^{3}: 0.022 \mathrm{~km}^{3}$ for the South flow, 0.126 $\mathrm{km}^{3}$ for the West flow, $0.018 \mathrm{~km}^{3}$ for the upper North-West flow, $0.054 \mathrm{~km}^{3}$ for the lower North-West flow, and $0.131 \mathrm{~km}^{3}$ for the North flow.

\subsubsection{Flow system emplacement}

The order of emplacement of the four channel-fed 'a'ā flow units can be derived from the thermal camera imagery (Fig. 2). The long line of sight distance, pixel size and 
atmospheric effects mean that lava flow temperatures in the thermal imagery (of just $65^{\circ} \mathrm{C}$ in the 05:25 image) are low and not representative of the actual surface temperatures. The flows have approximately the shape and dimensions of those mapped in Figure 1, so that by 05:25 on December 10 it appears that the flow field had reached its full extent. This is consistent with the OVPF eruption bulletin of 06:45 on December 10 that noted that the lava flows were active but with a "weak flux" (Di Muro 2010f). Thus, most of the lava was erupted between 22:40 on December 9 and around 05:40 on December 10, meaning that the TADR over the first seven hours was no more than 20 $\mathrm{m}^{3} / \mathrm{s}$. Of the four flows, the West and North flows were the hottest with temperatures of up to $85{ }^{\circ} \mathrm{C}$ and $76{ }^{\circ} \mathrm{C}$, respectively. While the lower section of the North-West flow had temperatures of up to $72{ }^{\circ} \mathrm{C}$, the upper section had a maximum of just $61{ }^{\circ} \mathrm{C}$. Likewise, the South flow was relatively cool at $64{ }^{\circ} \mathrm{C}$. This indicates that, while activity at the West, North and lower North-West flows was waning at the time of imaging, activity at the upper North-West and South flows had already stopped some time before the image was acquired.

The South flow, $390 \mathrm{~m}$ long and oriented $\sim \mathrm{N} 320^{\circ}$, was fed by the highest-altitude section of the fissure (Fig. 3). It mostly followed the pre-existing channels of the 1957 flow, so that the December 2010 levées became nested inside the 1957 levées. Near-vent, the channel was $3.2 \mathrm{~m}$ wide on a $18^{\circ}$ slope, with late stage 'a'ā being $1.4 \mathrm{~m}$ below bank and the levées being $1.6 \mathrm{~m}$ high. Calculated velocity for initial, full-channel flow was $7.3 \mathrm{~m} / \mathrm{s}$, and velocity for late stage flow was $0.1 \mathrm{~m} / \mathrm{s}$. Using Jeffreys equation (Jeffreys 1925), this equates to effusion rates waning from an initial peak of $\sim 38 \mathrm{~m}^{3} / \mathrm{s}$ to $\sim 0.1 \mathrm{~m}^{3} / \mathrm{s}$. 
The West flow was $970 \mathrm{~m}$ long and oriented $\sim \mathrm{N} 300^{\circ}$ (Fig. 3). Its dimensions and emplacement characteristics have already been well described by Rhéty (2014) and Harris et al. (2015), with calculated peak flow velocities of $\sim 4.4 \mathrm{~m} / \mathrm{s}$ in a channel that was $1.4 \mathrm{~m}$ deep and $4.5 \mathrm{~m}$ wide, on a slope of $14^{\circ}$ for a peak effusion rate of $\sim 28 \mathrm{~m}^{3} / \mathrm{s}$. Late stage flow in the master channel was around $1 \mathrm{~m}$ below the banks, giving a velocity of $\sim 0.4 \mathrm{~m} / \mathrm{s}$ and an effusion rate of $\sim 0.6 \mathrm{~m}^{3} / \mathrm{s}$.

The North flow erupted from the lowermost section of the fissure (Fig. 3), and had an orientation of $\sim \mathrm{N} 350^{\circ}$. It followed the margin of the 2000 flow field, and attained a final length of $1100 \mathrm{~m}$, being the longest of the four flows erupted during the December 2010 event. Near-vent, the master channel had a width of $4 \mathrm{~m}$. Proximal levée height was 1.5 $\mathrm{m}$, and undrained flow depth was $1.6 \mathrm{~m}$. On a $11^{\circ}$ slope, this gives a peak flow velocity of $\sim 4.5 \mathrm{~m} / \mathrm{s}$, and a calculated peak effusion rate of $\sim 29 \mathrm{~m}^{3} / \mathrm{s}$. Late stage flow velocity was $\sim 0.02 \mathrm{~m} / \mathrm{s}$, which converts to an effusion rate of $\sim 0.01 \mathrm{~m}^{3} / \mathrm{s}$.

The North-West flow is oriented $\sim \mathrm{N} 330^{\circ}$, and is actually a $830 \mathrm{~m}$ long flow field that can be divided into two segments: upper and lower. The upper segment is a channel-fed 'a'ā flow that is cut by the West flow. The North-West flow has a channel width of around 2 $\mathrm{m}$ and depth of $1 \mathrm{~m}$ which, down a slope of $14^{\circ}$, gives an estimated velocity of $\sim 2.2 \mathrm{~m} / \mathrm{s}$ and a calculated effusion rate of $\sim 5 \mathrm{~m} / \mathrm{s}$. We interpret the field evidence as the West flow having established a channel across the path of the upper North-West flow, which then ran into it. This may have contributed to failure down a $30 \mathrm{~m}$ length of the right levée of the West flow, which fed the lower segment of the North-West flow. In the lower NorthWest flow a broad ( $\sim 6 \mathrm{~m})$, shallow (1.5-1.75 $\mathrm{m}$ deep), channel developed on a $10^{\circ}$ slope, with calculated effusion rates in the range $33-52 \mathrm{~m}^{3} / \mathrm{s}$, about twice as high as for the 
upper segment. The lower North-West, West and North flows have similar temperatures in the thermal image (Fig. 2), and therefore appear to have been concurrently active.

Peak effusion rate at the beginning of the eruption was obtained by summing the calculated effusion rates from all four active fissures. This would amount to an initial peak effusion rate of $\sim 132 \mathrm{~m}^{3} / \mathrm{s}$ just before 23:00 on December 9 . This peak effusion rate must have decreased quickly, because by 05:40 on December 10 the TADR for the first seven hours of eruption was no more than $20 \mathrm{~m}^{3} / \mathrm{s}$. This is also consistent with effusion rates during the final phase of effusion of $0.01-0.6 \mathrm{~m}^{3} / \mathrm{s}$.

\subsubsection{Flow system architecture}

The December 2010 flow field was mainly emplaced over historical inflated pāhoehoe. Pāhoehoe lobe thickness was $0.5-2 \mathrm{~m}$, and lobe width was about $3 \mathrm{~m}$. The exception was the South flow, which was largely emplaced within the $1957^{\prime} a^{\prime} a \bar{a}$ channels (Fig. 3). The North-West, West, and North flows all began as single channel flows (Fig. 4). As the underlying slope decreased, they transitioned to braided flows (Fig. 4). Distally, they reverted to single channels as the slope increased again. Only close to the flow front is flow dispersed (Fig. 4), as is commonly observed at channel-fed flow systems (e.g. Lipman and Banks 1987; Favalli et al. 2010; Rhéty et al 2017). In this respect, the zone of dispersed flow is a dynamic feature that moves forward as the channel system extends, and is then frozen in place when the channelized portion of the system ceases to extend (cf. Rhéty et al. 2017; Favalli et al. 2010). While a flow in extension that has had its supply cut will likely form a single unit (Walker 1972), a flow field that is fed for a longer period of time will likely take on a more complex, compound flow field form 
(Kilburn and Lopes 1988).
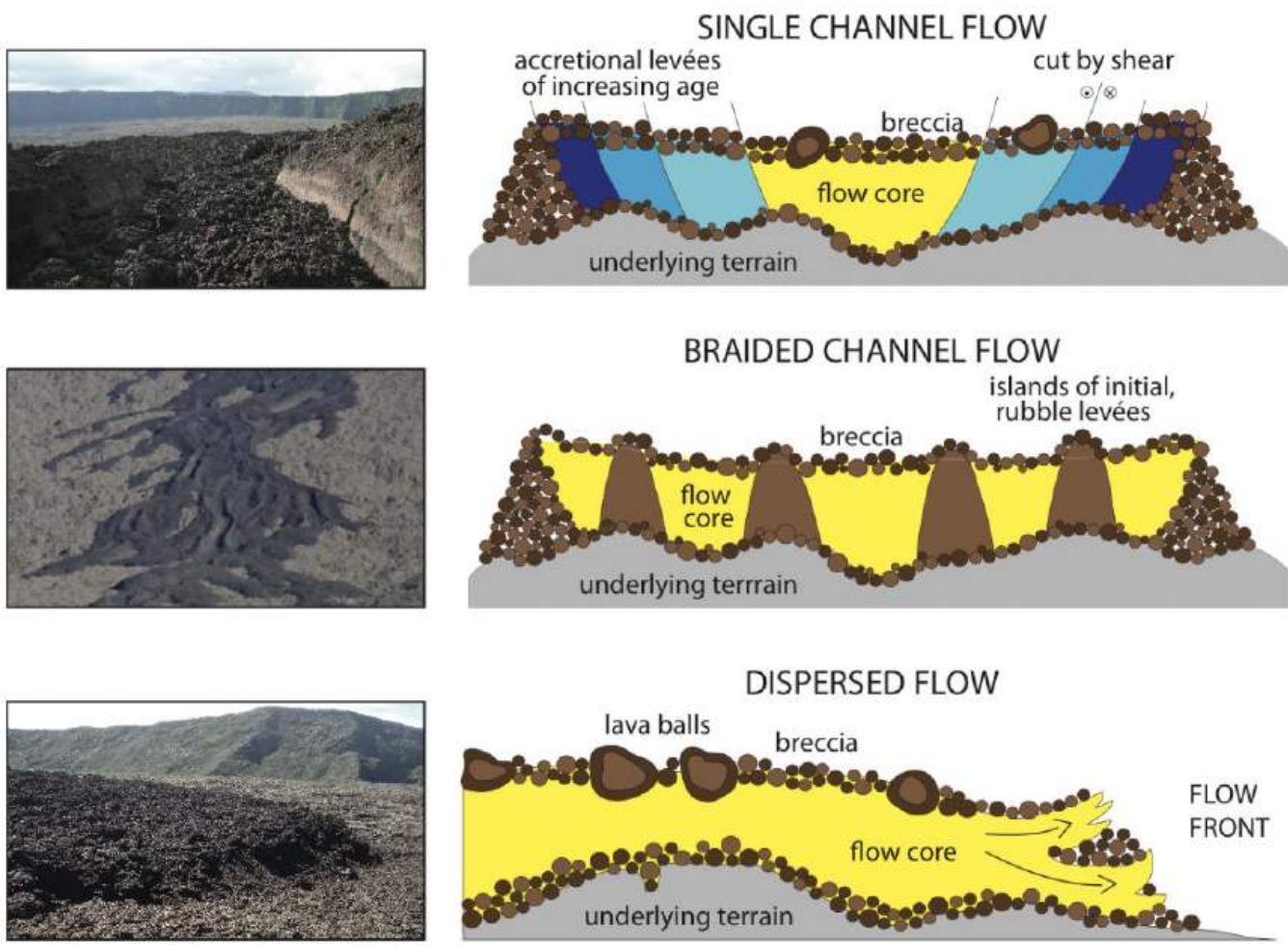

Fig. 4.4 Flow system architecture typifying photos (left) and cross-sections (right): single channel flow (transversal cross-section view), braided channel flow (transversal cross-section view), and dispersed flow (longitudinal cross-section view). The underlying terrain is represented in grey, the flow core in yellow, the flow levées are shown in blue, and the breccia and lava balls are in brown.

The South flow is braided throughout its length, with 2-4 channels 3-6 m wide, until it rapidly transitions to dispersed flow 45 meters before the flow front (Fig. 3). The South flow was emitted by the highest altitude vent at $\sim 2470 \mathrm{~m}$ a.s.l. It flowed down a steep $18 \pm 4^{\circ}$ slope for $350 \mathrm{~m}$. In the proximal area, the main channel is $50 \mathrm{~cm}$ deep and $60 \mathrm{~cm}$ 
wide. In the distal area, the main channel is $4 \mathrm{~m}$ wide and 65 to $90 \mathrm{~cm}$ deep. It is surrounded by two generations of rubble levées, each about $1 \mathrm{~m}$ high and having a $25^{\circ}$ outward slope. These are the pre-existing levées of the 1957 flow. The final $45 \mathrm{~m}$ were emplaced as dispersed flow over a $20 \pm 2^{\circ}$ slope, where the flow front is about $2 \mathrm{~m}$ high and lies just behind the 1957 flow front, which is about $1 \mathrm{~m}$ high.

The West flow was erupted from the lower half of the fissure, at around $2390 \mathrm{~m}$ a.s.l. It initially ran down a $14 \pm 2^{\circ}$ slope in a single, narrow (about $4 \mathrm{~m}$ wide) channel, before becoming braided after $130 \mathrm{~m}$ where the slope is $10 \pm 3^{\circ}$. Proximally, the single channel was well defined between initial, rubble levées with near vertical inner walls that were veneered with accreted, fine-grained ' $a$ 'a striated in the down-flow direction. The channel floor is composed of 'a'ā clasts and slabs of spiney pahoehoe (Fig. 5c). The braided flow has the form sketched in Fig. 4, where the flow unit is bounded by outer initial rubble levées lying on the pre-existing pāhoehoe, and the channels are separated by linear, narrow islands of initial rubble levées that run in and out of the single channel sections. At $530 \mathrm{~m}$ from the vent the slope steepens again to $11 \pm 5^{\circ}$, and the flow reverted to the single channeled form and morphology. This more distal channel is about $6 \mathrm{~m}$ wide, and is occasionally bounded by accreted wall slabs displaying down-flow striations (Fig. 5c). Up to three generations of deformation levées are recognized along the main channel. At $580 \mathrm{~m}$ from the vent, on a slope of $5 \pm 2^{\circ}$, the distal channel is defined by incipient sheardefined levées (Fig. 4). Dispersed flow extends about $260 \mathrm{~m}$ back from the flow front. The flow front overruns inflated pāhoehoe and tumuli that are $0.5-2 \mathrm{~m}$ tall, but lies on the pāhoehoe surface so that the contact can be observed. The flow front height measurement of $2 \mathrm{~m}$ is therefore reliable. The flow front is as sketched in Fig. $4 \mathrm{c}$, and comprises ' $\mathrm{a}$ ' $\overline{\mathrm{a}}$ 
clasts and lava balls through which interior lava has extruded as spiny pāhoehoe.

The upper section of the North-West flow was emitted from the fissure just above the West flow vent at an altitude of $2440 \mathrm{~m}$ a.s.1., and initially flowed down a $14 \pm 4^{\circ}$ slope in a single channel (Fig. 5c). The overall width of the flow unit (channel + levées) is about $10 \mathrm{~m}$ near the vent. At a distance of $390 \mathrm{~m}$ from the vent this channel is cut by the West flow. The lower section of the North-West flow is fed by a breach in the right bank levée of the West flow. Below this, the channel system is braided, where the slope decreased to $9 \pm 2^{\circ}$. At this point the flow unit is $65 \mathrm{~m}$ wide. Around $580 \mathrm{~m}$ from the vent, the slope increased to $10 \pm 2^{\circ}$ and the flow reverted to a single-channel form. Where sample NW7 was collected, i.e. $\sim 700 \mathrm{~m}$ from the vent, there is a broad master channel surrounded by nested rubble levées (Fig. 5b) with spiny pāhoehoe accretions (Fig. 5d). Incipient sheardefined levées are first observed $\sim 890 \mathrm{~m}$ from the vent, where sample NW5 was collected. At this location, a $15 \mathrm{~cm}$ deep crack associated with shearing at the stream edge separates the levée accreted on the left bank from the main channel (Fig. 5a). Finally, between $\sim 930 \mathrm{~m}$ from the vent and the flow front, where the slope is $9 \pm 1^{\circ}$, the flow is dispersed for $30 \mathrm{~m}$. The flow front is composed of fine-grained 'a'ā, with sparse pāhoehoe lava boats. The flow front is located in a zone of inflated pāhoehoe and tumuli that are $0.5-2 \mathrm{~m}$ tall. This means that the apparent thickness of the flow front is deceivingly thin $(35 \mathrm{~cm})$ because, at this location, the flow front has come to rest in a basin caused by inflation of pāhoehoe around it (Fig. 5b). The basin is $1.75 \mathrm{~m}$ deep, and the 'a'a flow front of the North-West flow overtops this by $0.35 \mathrm{~m}$, so the actual thickness of the flow at the front is around $2 \mathrm{~m}$, consistent with the thickness of flow fronts and levée heights elsewhere in the December 2010 lava flow field. 
The North flow began as a single channel, emitted from a vent at $2420 \mathrm{~m}$ a.s.l. on a $11 \pm 4^{\circ}$ slope. After $410 \mathrm{~m}$, the slope slightly decreased to $10 \pm 3^{\circ}$ and the North flow became braided. The surface lava texture is 'a'ā throughout, with spiny pāhoehoe accreted internally on to the levée walls (Fig. 5d). At $720 \mathrm{~m}$ from the vent, the pre-existing slope steepened to $17 \pm 5^{\circ}$, and the braided flow regrouped as a single $20 \mathrm{~m}$ wide channel. At $970 \mathrm{~m}$ from the vent, the underlying slope decreased to $2 \pm 2^{\circ}$ and the flow became dispersed and widened to $85 \mathrm{~m}$ (Fig. 3). The flow front is about $2 \mathrm{~m}$ high and $25^{\circ}$ steep. As the flow front lies over a visible pre-existing pāhoehoe surface, $2 \mathrm{~m}$ is the actual flow thickness.

\section{a}

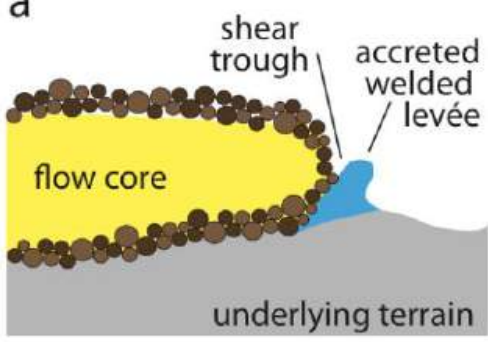

C
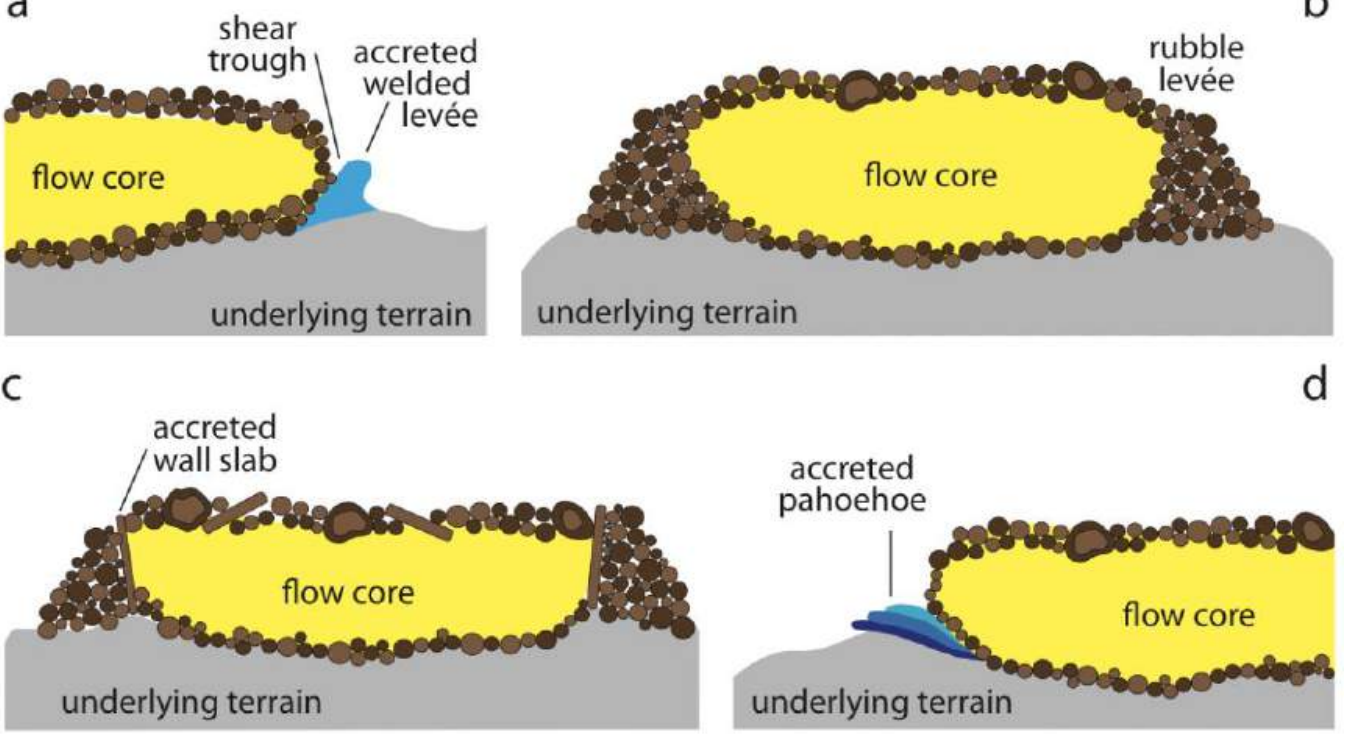

Fig. 4.5 Cross sections typifying the key features observed in the December 2010 flows: a) shear troughs and welded levées; b) rubble levées and uncertainty in the topography underlying the flow; c) accreted wall slabs; and d) accreted pāhoehoe. 


\subsubsection{Flow geochemistry and glass thermometry}

The 2010 lava is a tholeiitic basalt (Table 2). Its major element composition is typical of present-day activity of Piton de La Fournaise, falling within the steady state basalts (SSB) group, defined by Albarède et al. (1997) as containing 5-8 wt $\% \mathrm{MgO}, 0.5-1 \mathrm{wt} \% \mathrm{~K}_{2} \mathrm{O}$, and $10-12 \mathrm{wt} \% \mathrm{CaO}$. Steady state basalts have historically erupted at Piton de La Fournaise during low-volume eruptions occurring within the Enclos Fouqué (Albarède et al. 1997), as was the case for the December 2010 event.

\begin{tabular}{lrrrr}
\hline Analyte & PF-10W-14-0A & $\mathbf{2} \boldsymbol{\sigma}$ & PF-10W-14-0B & $\mathbf{2} \boldsymbol{\sigma}$ \\
\hline & & & & \\
$\mathrm{SiO}_{2}$ & 49.10 & 0.34 & 49.10 & 0.34 \\
$\mathrm{Al}_{2} \mathrm{O}_{3}$ & 14.49 & 0.30 & 14.44 & 0.30 \\
$\mathrm{Fe}_{2} \mathrm{O}_{3}$ & 12.12 & 0.01 & 12.16 & 0.01 \\
$\mathrm{MgO}$ & 6.64 & 0.08 & 6.66 & 0.08 \\
$\mathrm{CaO}$ & 11.35 & 0.04 & 11.39 & 0.04 \\
$\mathrm{Na}_{2} \mathrm{O}$ & 2.67 & 0.12 & 2.54 & 0.12 \\
$\mathrm{~K}_{2} \mathrm{O}$ & 0.76 & 0.06 & 0.79 & 0.06 \\
$\mathrm{TiO}_{2}$ & 2.76 & 0.10 & 2.77 & 0.10 \\
$\mathrm{MnO}$ & 0.17 & 0.00 & 0.17 & 0.00 \\
$\mathrm{P}_{2} \mathrm{O}_{5}$ & 0.32 & 0.01 & 0.33 & 0.01 \\
$\mathrm{H}_{2} \mathrm{O}^{+}$ & 0.11 & & 0.12 & \\
$\mathrm{H}_{2} \mathrm{O}^{-}$ & 0.56 & & 0.57 & \\
Total & 101.05 & & 101.05 & \\
& & & & \\
\hline
\end{tabular}

Table 2 Representative LA-ICP-AES bulk rock major elements analyses.

To estimate emplacement temperatures and cooling rates down-channel, we applied a selection of geothermometers to microprobe analyses of residual glass and minerals of the collected samples (Supplementary Tables 2-5; Fig. 6). Clean glass was found in a total of nine samples from all four flow branches. 

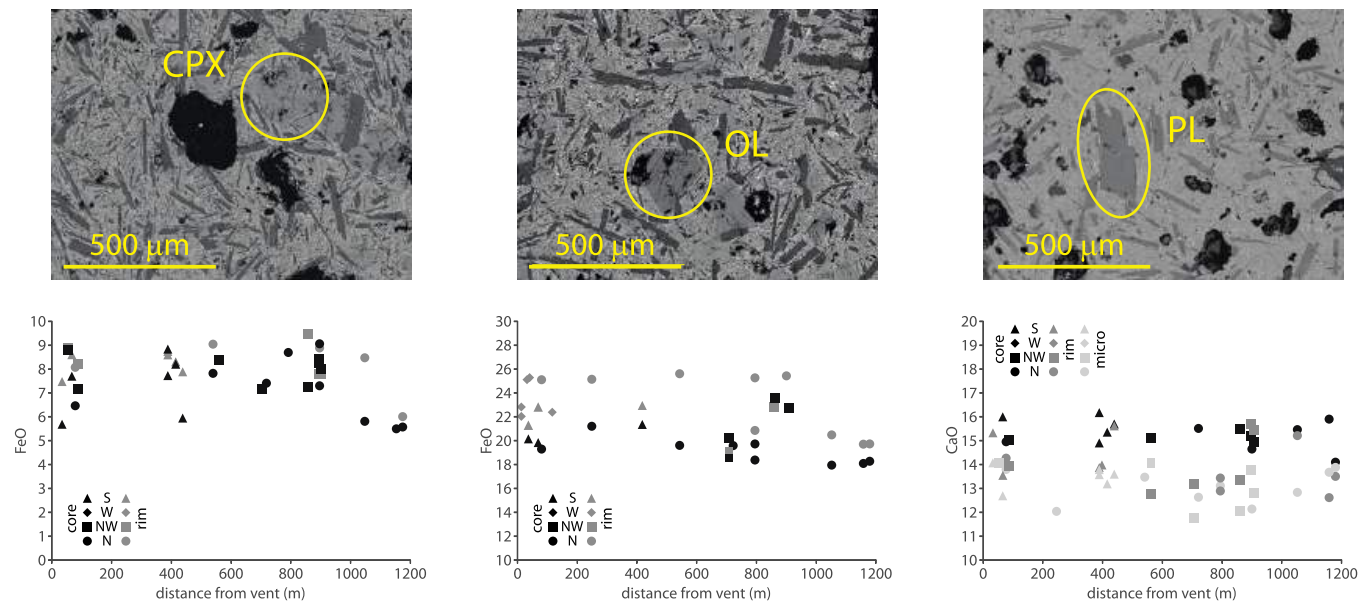

Fig. 4.6 Upper row: back-scattered SEM images exemplifying mineral texture and crystal morphology $(\mathrm{CPX}=$ clinopyroxene, sample NW06; $\mathrm{OL}=$ olivine, sample $\mathrm{NW} 08 ; \mathrm{PL}=$ plagioclase, sample NW01). Lower row: geochemical data for each mineral phase plotted against distance from the vent. Black symbols indicate core analyses, dark grey symbols indicate rim analyses, and light grey symbols indicate microlites analyses. Analyses from the South flow are plotted as triangles, from the West flow as diamonds, and from the North-West flow as circles.

Temperatures obtained with the Rhéty et al. (2017) liquid geothermometer are $1145 \pm 10$ ${ }^{\circ} \mathrm{C}$ at the vent, compared to $1134 \pm 10{ }^{\circ} \mathrm{C}$ obtained with the Helz and Thornber (1987) liquid geothermometer, and $1124 \pm 60{ }^{\circ} \mathrm{C}$ given by the Putirka (2008) liquid geothermometer (Fig. 7). Liquid-olivine (Putirka et al. 2007), liquid-pyroxene (Putirka et al. 1996) and liquid-plagioclase (Putirka 2005) geothermometers, based on mineral-liquid equilibrium, are mostly mutually consistent, indicating temperatures of $1127 \pm 60{ }^{\circ} \mathrm{C}$ for liquid-olivine to $1158 \pm 60{ }^{\circ} \mathrm{C}$ for liquid-pyroxene (Fig. 7). The average cooling rate inferred from the comparison of all geothermometers used is $13{ }^{\circ} \mathrm{C} / \mathrm{km}$, with individual geothermometers giving values between $\sim 11{ }^{\circ} \mathrm{C} / \mathrm{km}$ and $\sim 27{ }^{\circ} \mathrm{C} / \mathrm{km}$. Data points from 
different flow branches all lie on the same cooling trend. The eruptive temperature ranges, as inferred from considering samples collected less than $100 \mathrm{~m}$ from the vent, are between $1120^{\circ} \mathrm{C}$ and $1160{ }^{\circ} \mathrm{C}$, depending on the considered geothermometer. Because the Rhéty et al. (2017) geothermometer was calibrated specifically on Piton de La Fournaise lavas, we favor a likely eruptive temperature of $1145 \pm 10{ }^{\circ} \mathrm{C}$.
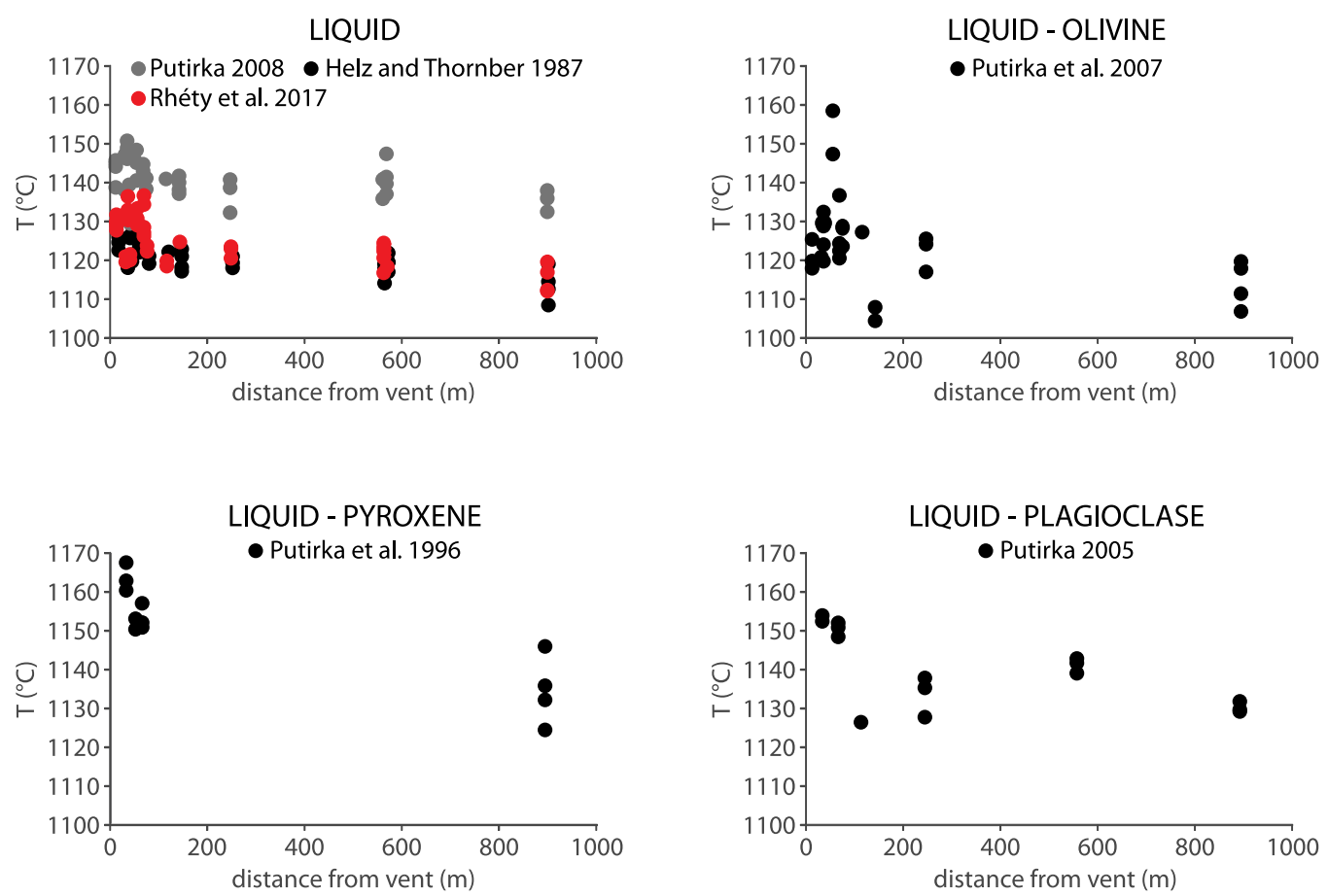

Fig. 4.7 Emplacement temperatures of each sample obtained through geothermometry. Geothermometers based on liquid MgO content (Helz and Thornber 1987 in black; Putirka 2008 in grey; Rhéty et al. 2017 in red), liquid-olivine equilibrium (Putirka et al. 2007), liquid-pyroxene equilibrium, (Putirka et al. 1996) and liquid-plagioclase equilibrium (Putirka 2005). 


\subsubsection{Textural analyses}

Macrocryst and mesocryst contents (Table 3; Fig. 8) are higher at the vent (50-70 vol\%) than at the toe ( $\sim 40 \mathrm{vol} \%)$ for the North and North-West flows, as has been observed for other lava flow systems at Piton de La Fournaise (Peltier et al. 2009, Rhéty et al. 2017). Conversely, the South flow displays a low crystallinity at the vent $(\sim 10$ vol\%), which increases dramatically at the flow front $(\sim 70 \mathrm{vol} \%)$. The West flow also displays a (more modest) crystallinity increase from $45 \mathrm{vol} \%$ at the vent to $55 \mathrm{vol} \%$ at $132 \mathrm{~m}$ from the vent. Density-derived porosity (Table 3) decreases from 55 to 18 vol\% from vent to toe, at a steady rate of increase of $\sim 3 \mathrm{vol} \%$ per $100 \mathrm{~m}$. Data from all four flow branches plot along the same trend, regardless of whether the local flow system architecture consists of a single channel, braided channels or dispersed flow (Fig. 9). Thus, there appears to be no textural (and hence rheological) control on channel architecture.

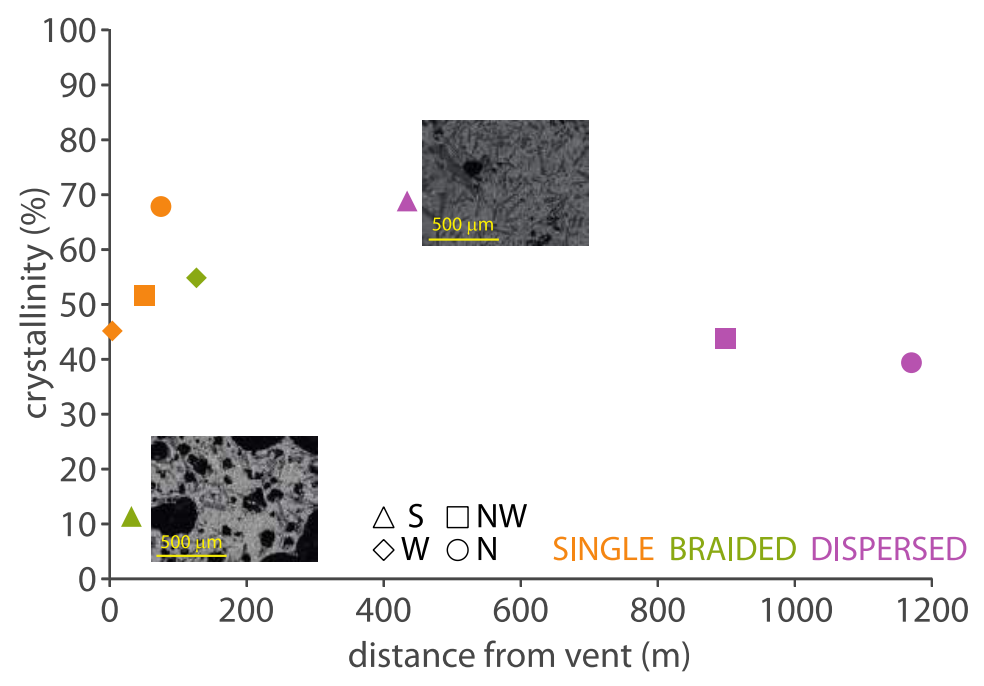

Fig. 4.8 Crystallinity of vent and toe samples of each flow. Analyses from the South flow are plotted as triangles, from the West flow as diamonds, from the North-West flow as squares, and from the North flow as circles. The two inset images illustrate the vent-to-toe (vent sample: S06; toe sample: S01) textural evolution of the South flow. 


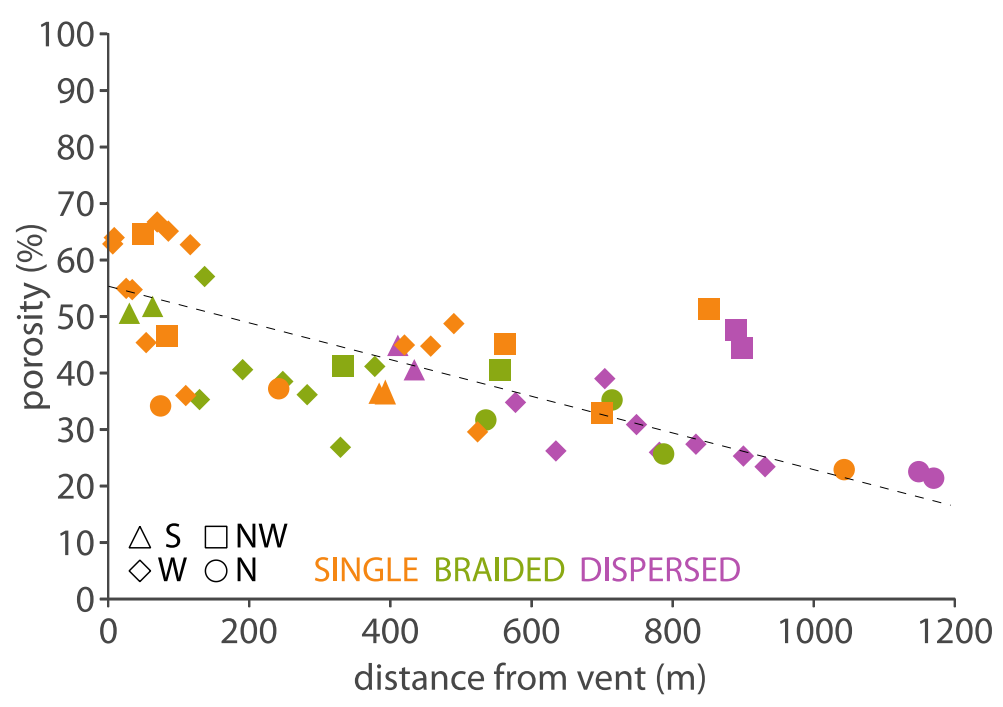

Fig. 4.9 Porosity trend of all collected samples. Analyses from the South flow are plotted as triangles, from the West flow as diamonds, from the North-West flow as squares, and from the North flow as circles. Samples collected within single channel flow sections are visualized in orange, samples collected in braided flow sections are displayed in green, and samples from dispersed flow sections are shown in purple. 


\begin{tabular}{|c|c|c|c|}
\hline \multirow[t]{2}{*}{ Sample } & \multicolumn{3}{|c|}{ Vent Distance Crystallinity ${ }^{1}$ Porosity } \\
\hline & $\mathbf{m}$ & $\%$ & $\%$ \\
\hline PF-10S-16-01 & 437 & 41 & 41 \\
\hline PF-10S-16-02 & 413 & & 45 \\
\hline PF-10S-16-03 & 396 & & 37 \\
\hline PF-10S-16-04 & 387 & & 36 \\
\hline PF-10S-16-05 & 66 & & 52 \\
\hline PF-10S-16-06 & 33 & 50 & 50 \\
\hline PF-10W-15-01 & 934 & & 23 \\
\hline PF-10W-15-02 & 903 & & 25 \\
\hline PF-10W-15-03 & 836 & & 27 \\
\hline PF-10W-15-04 & 784 & & 26 \\
\hline PF-10W-15-05 & 752 & & 31 \\
\hline PF-10W-15-06 & 707 & & 39 \\
\hline PF-10W-15-07 & 638 & & 26 \\
\hline PF-10W-15-08a & 580 & & 35 \\
\hline PF-10W-15-08b & 580 & & 35 \\
\hline PF-10W-15-09 & 527 & & 30 \\
\hline PF-10W-15-10 & 493 & & 49 \\
\hline PF-10W-15-11 & 460 & & 45 \\
\hline PF-10W-15-12 & 423 & & 45 \\
\hline PF-10W-15-13 & 381 & & 41 \\
\hline PF-10W-15-14 & 332 & & 27 \\
\hline PF-10W-15-15 & 285 & & 36 \\
\hline PF-10W-15-16 & 250 & & 38 \\
\hline PF-10W-15-17 & 193 & & 41 \\
\hline PF-10W-15-18 & 132 & 55 & 35 \\
\hline PF-10W-14-0A & 9 & 45 & 63 \\
\hline PF-10W-14-0B & 11 & & 64 \\
\hline PF-10W-14-01 & 28 & & 55 \\
\hline PF-10W-14-02 & 37 & & 55 \\
\hline PF-10W-14-03 & 57 & & 45 \\
\hline PF-10W-14-04 & 72 & & 67 \\
\hline PF-10W-14-05 & 88 & & 65 \\
\hline PF-10W-14-06 & 88 & & 63 \\
\hline PF-10W-14-07 & 98 & & 24 \\
\hline PF-10W-14-08 & 113 & & 36 \\
\hline PF-10W-14-09 & 119 & & 63 \\
\hline PF-10W-14-10 & 140 & & 57 \\
\hline PF-10NW-16-01 & 52 & 52 & 65 \\
\hline PF-10NW-16-02 & 87 & & 46 \\
\hline PF-10NW-16-03 & 335 & & 41 \\
\hline PF-10NW-16-04 & 901 & 44 & 44 \\
\hline PF-10NW-16-05 & 893 & & 48 \\
\hline PF-10NW-16-06 & 855 & & 51 \\
\hline PF-10NW-16-07 & 703 & & 33 \\
\hline PF-10NW-16-08 & 566 & & 45 \\
\hline PF-10NW-16-09 & 559 & & 40 \\
\hline PF-10N-16-01 & 1173 & 40 & 21 \\
\hline PF-10N-16-02 & 1152 & & 23 \\
\hline PF-10N-16-03 & 1046 & & 23 \\
\hline PF-10N-16-04 & 895 & & 24 \\
\hline PF-10N-16-05 & 790 & & 26 \\
\hline PF-10N-16-06 & 717 & & 35 \\
\hline PF-10N-16-07 & 538 & & 32 \\
\hline PF-10N-16-08 & 245 & & 37 \\
\hline PF-10N-16-09 & 77 & 68 & 34 \\
\hline
\end{tabular}

Table 4.3 Sample crystallinity and porosity. 


\subsection{Discussion}

At the onset of the eruption, all vents along the fissure were probably active simultaneously. The South vent, at the highest elevation on the fissure, had the highest calculated peak effusion rate of $38 \mathrm{~m}^{3} / \mathrm{s}$. The West, upper North-West, and North flows had calculated peak effusion rates of 28,5 , and $29 \mathrm{~m}^{3} / \mathrm{s}$ which sum to a total initial effusion rate from the fissure as a whole of around $96 \mathrm{~m}^{3} / \mathrm{s}$. However, activity was shortlived, with the entire flow field system being constructed in just seven hours. During this time, all four main flow fields (and hence channel systems) were active simultaneously, although the South and North-West vents shut down some time before the West and North vents. However, the four channel systems were fed at waning rates, where effusion rates are estimated to have been as low as $\sim 0.01 \mathrm{~m}^{3} / \mathrm{s}$ late in the eruption, so that the TADR for these first seven hours was as high as $20 \mathrm{~m}^{3} / \mathrm{s}$. The short duration of supply and its rapidly waning character is reflected in the simplicity of the channel and levée systems and their morphology, as well as the short length of the flow units. Outer levées are of the simple, rubble type. They have not been modified by increases in lava supply, which would have built overflow levées and led to compound forms. Instead, a single, short opening phase emplaced a single, simple set of levées that defined the channel down which all following lava flowed (Fig. 5c). Fluxes then steadily diminished, as we see no level markers consistent with the flow resting at a certain level for a period of time, but rather an even accretion of a single lava layer to the levée inner walls. Likewise, channel widths steadily decreased by accretion of nested levées whose stagnation and separation from down-flowing lava was marked by shear lines (Fig. 4). There was, 
however, downflow variation in the architecture of the channel network. The structure of the channel network thus varied with distance, rather than time, and that variation appears to be linked to the interaction of the lava with the underlying slope.

\subsubsection{Slope and Flow System Architecture}
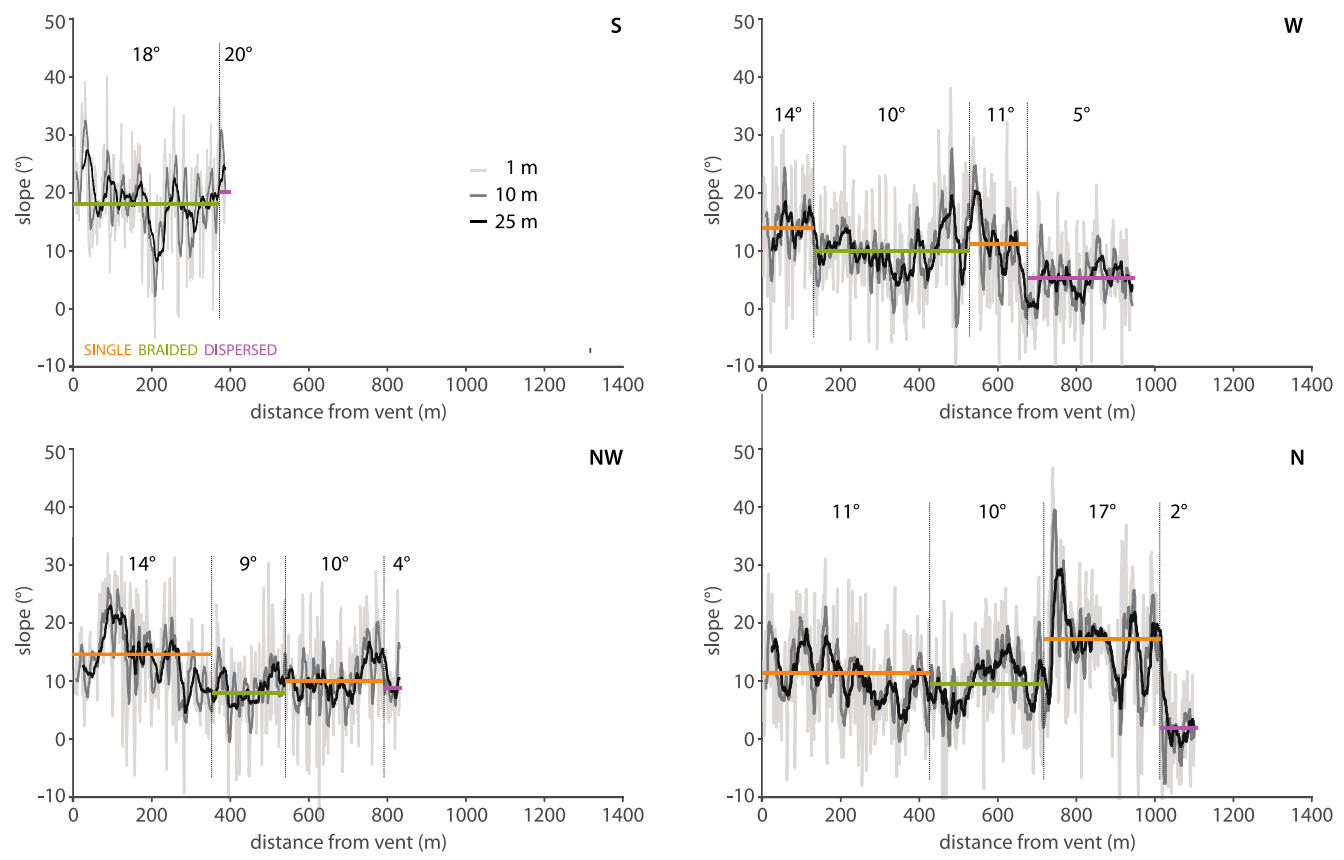

Fig. 4.10 Slope variations within of each flow: every $1 \mathrm{~m}$ (light grey), averaged over $10 \mathrm{~m}$ (dark grey), averaged over $25 \mathrm{~m}$ (black). Section averages are superimposed and color-coded according to flow system architecture: single channel flow in orange, braided flow sections in green, and dispersed flow in purple.

We extracted underlying terrain slope from the pre-eruptive DEM every $1 \mathrm{~m}$, and then averaged it every $10 \mathrm{~m}$ and every $25 \mathrm{~m}$ to better highlight slope trends at different spatial 
scales (Fig. 10). Averaging pre-existing terrain slope within flow sectors characterized by different channel network architecture as observed in the field, overall slope differences became evident (Fig. 10). The architecture of each flow branch evolves as lava flows over different underlying slopes, alternating between a single channel on steeper slopes and braided channels on shallower slopes. This proves that changes in the architecture of the flow are reversible, and that the flow can indeed switch back and forth between single and braided channel configurations multiple times during its emplacement. We developed a regime diagram (Fig. 11) that assesses the transition between single and braided channel flow independently of absolute slope values, but rather as a function of slope change with respect to the upflow section. This regime diagram shows that, for this flow field, the transition from braided to single channel always corresponds to a slope increase, whereas the transition from single to braided channel always corresponds to a slope decrease. Just behind the flow front, flow is always dispersed, with a single- or braided-channel network developing behind it depending on slope. We conclude that the key parameter controlling whether a channel system is merging or branching is the underlying slope variation. The South flow appears to violate this rule. The entire South flow pathway is much steeper than that of the three other flows. Our observations suggest that a steeper slope favors a single channel configuration. Instead, the South flow begins as a braided flow, and remains such throughout its length, until it becomes dispersed close to the flow front, on a $20^{\circ}$ slope (Fig. 10). This can be explained by considering the pre-existing topography underlying the December 2010 flow field (Fig. 3). Whereas the North, North-West, and West flows were emplaced over ancient pāhoehoe flow fields, the South flow was emplaced within the 1957 channel-fed 'a'a flow field, and re-used its 
braided channel network. Channel re-utilization exerts a first-order control on flow system architecture. In a case where the pre-existing system has internal relief that is of the same scale (or greater) than the new system, the new channel system will develop within the pre-existing channel system, and will thus inherit the channel network of the pre-existing system irrespective of underlying slope. The other three flows studied here were all emplaced over the same ancient pāhoehoe flow field, which had a vertical scale of relief that was less than the new flow thickness (about 2m). In these cases - channelfed ' $a$ 'a flows emplaced on a smooth surface - slope breaks exert the main control on determining whether the channel system is braided or not, as summarized by our regime diagram (Fig. 11).

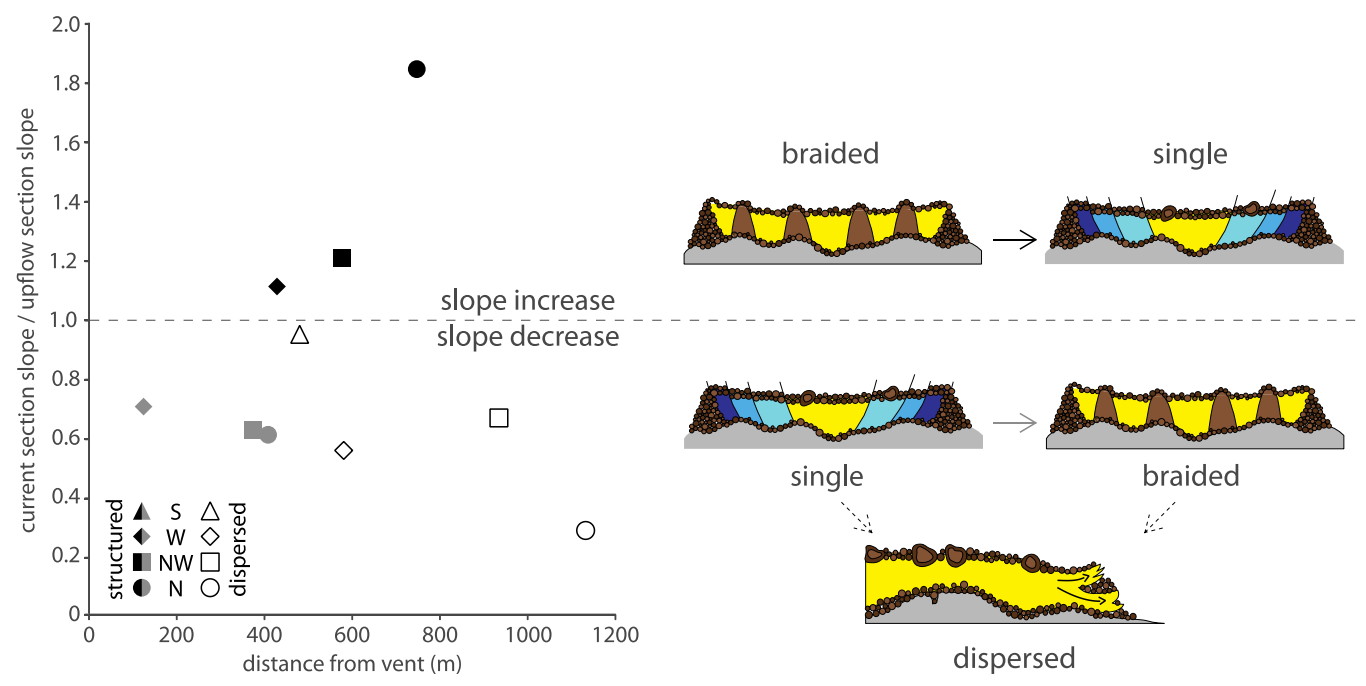

Fig. 4.11 Flow system architecture regime diagram. Values above 1 signify a slope increase, whereas values below 1 signify a slope decrease. Analyses from the South flow are plotted as triangles, from the West flow as diamonds, from the North-West flow as squares, and from the North flow as circles. Black symbols represent transitions from braided to single channel flow, grey symbols from single to braided flow, and white symbols from either single or braided to dispersed flow. 


\subsubsection{Comparison with previous studies}

The transition from a single flow channel to multiple braided channels can originate from a variety of phenomena, including topographic confinement (Dietterich and Cashman 2014), flow front interaction with topographic obstacles (Dietterich et al. 2015), levée breakouts and overflows, and possibly flow front fingering (Huppert 1982). Hereafter, we consider the case of a flow that is not topographically confined, but interacts with an obstacle. If the amplitude of the underlying topographic roughness is comparable to that of the flow front, it acts as an obstacle, causing the flow to braid. Obstacles decrease flow momentum by exerting a drag on it. At low effusion rate, and consequently low velocity and low momentum, the flow front will be more affected by the momentum decrease imposed by the obstacle, and will braid in response. Conversely, a high-effusion, highvelocity flow may have the kinetic energy necessary to overcome the obstacle unaffected (Soule et al. 2004). Lava flows characterized by low effusion rates should therefore be more prone to braiding compared to high-effusion rate flows on any given slope. However, when encountering a slope decrease, lava will momentarily slow down, leading to a lava backup. Such lava accumulation will result in an increase in the flow front amplitude, which will allow the previously braided flow to converge into a singlechannel flow. This scenario is supported by the experimental study of Dietterich et al. (2015), which shows that flows become thicker in proximity of an obstacle, producing a bow wave that can overcome the obstruction prompting its formation. Furthermore, faster flows produce higher bow waves (Dietterich et al. 2015). Since flow speed is directly proportional to slope (for any given effusion rate), lava flowing down a steeper slope will thicken more when interacting with a topographic obstacle, and as a result it will be more 
likely to overcome it, continuing to flow in a single channel (Dietterich et al. 2015). This directly applies to the studied flow field, whose underlying slopes are very steep, resulting in high calculated flow velocities, of up to $\sim 8.5 \mathrm{~m} / \mathrm{s}$. This may explain the architectural difference between thin near-vent pahoehoe sheet flows, that will likely flow into an increasingly small number of channels, and thick ' $a$ 'a flows that will likely begin as a well-defined channel and later braid on shallower slopes where flow stalls and spreads so as, in the ultimate case, to form perched ponds (Wilson and Parfitt 1993).

Our observation of steeper slopes favoring channel confluence and gentler slopes favoring channel divergence contrasts with the observations of Dietterich and Cashman (2014) at Mauna Loa, Rhéty et al. (2017) at Piton de La Fournaise, and Krauskopf (1948) at Paricutín. Effusion rate does not appear to explain the differences between our results and previous studies. The Mauna Loa flows analyzed by Dietterich and Cashman (2014) were fed at a rate $>100 \mathrm{~m}^{3} / \mathrm{s}$, and we calculate that the Piton de La Fournaise flows considered in this study had an initial peak effusion rate of $\sim 120 \mathrm{~m}^{3} / \mathrm{s}$, although they must have rapidly waned to much lower rates of $<20 \mathrm{~m}^{3} / \mathrm{s}$. Rhéty et al. (2017) report that the 2007 lava contained 43-60 vol\% of olivine macrocrysts (3-4 mm in diameter), whose content (indicative of effusion rate), varies throughout the system, increasing downflow (as the first lava emplaced has the highest transport capacity, and hence the highestmacrocryst—bedload). This suggests an initially high effusion rate, responsible for emplacing the distal macrocryst-rich lava, and therefore the effusion history of this flow closely resembles the 2010 eruption. Therefore the discrepancy between the flow system architecture observed at Mauna Loa and Piton de La Fournaise in 2007, and that observed in this study at Piton de La Fournaise during 2010, cannot be explained solely in terms of 
differences in effusion rate, suggesting that a further careful study of other parameters, such as emplacement conditions and textural parameters, is necessary.

While the study of Dietterich and Cashman (2014) and ours both focused on 'a'a flows, that of Rhéty et al. (2017) examined a pahoehoe sheet flow that became organized into channels that then turned into ' $a$ ' $\bar{a}$. The crystallinity of Mauna Loa lavas is generally quite low, with a phenocryst content of less than $0.5 \mathrm{vol} \%$ and a variable microphenocryst content of up to 30 vol\% (Lipman and Banks 1987), whereas Piton de La Fournaise lavas crystallize microlites in the shallow reservoir and during ascent in the conduit, leading to a high total crystallinity of up to 70 vol\%. Importantly, the study of Rhéty et al. (2017) focuses on oceanites, whose olivine crystal size vastly exceeds the crystal size range considered in our study. Analogue studies such as Del Gaudio et al. (2013) show that crystal size critically affects the rheological behavior of lava. Porosity values appear consistent across the two Mauna Loa and Piton de La Fournaise volcanic systems, although at Piton de La Fournaise porosity decreases more rapidly with increasing distance from the vent. Down-flow variations in crystallinity and porosity are not expected to affect the applicability of our results, as we showed that their variation has apparently no effect on flow system structure for the 2010 eruption of Piton de la Fournaise (Fig. 8).

\subsubsection{Effect of Textural Parameters}

Most previous studies on the surface morphology and the texture of basaltic lava flows focused on cooling-limited Hawaiian lava flows (Lipman and Banks 1987; Moore 1987; Crisp and Baloga 1994; Cashman et al. 1999; Riker et al. 2009; Robert et al. 2014). The 
thermal history of such flows is determined by the rate of heat loss from the surface through both radiation and convection, and from the base through conduction (Keszthelyi and Denlinger 1996), as well as by the entrainment of colder material (Crisp and Baloga 1994), all of which is modulated by the release of latent heat of crystallization (Crisp et al. 1994; Keszthelyi 1998). Cashman et al. (1999) noted that once the thermal profile of the flow becomes stratified, the surface morphology transitions from pāhoehoe to 'a' $\bar{a}$, starting at the channel edges and moving inward. The variation of rheological parameters, in particular the onset and development of yield strength associated with flow crystallization, also contributes to the morphological transition incurred by lava flows (Peterson and Tilling 1989; Sehlke et al. 2014). These factors all contribute to controlling flow regime and morphology (e.g. Harris and Rowland 2001; Soule et al. 1998; Favalli et al. 2018). Glaze et al. (2014) noted that slope breaks in the terrain underlying lava flows can create eddies that disrupt the flow surface, enhancing radiative heat loss and thus reducing the distance the flow can travel. However, for the highly crystalline lava emplaced during the 2010 Piton de La Fournaise eruption, this effect would be minor. Indeed, we do not find any evidence of abrupt cooling and increased crystallization immediately after slope breaks.

Crystallinity and porosity were analyzed for all flow branches to identify any possible relation to flow system architecture. Comparison of thin sections of samples collected in differently structured areas of the flow shows no systematic variation in crystal content, indicating that crystallinity evolution does not control flow structure. The observed preemplacement crystallinity trends (Fig. 8), increasing from vent to toe for the South and West flow, and decreasing from vent to toe for the North-West and North flows, have 
been interpreted to reveal variations in effusion rate where, as the effusion rate increases, so too does the transport capacity of the lava so that higher crystal loads can be carried at higher effusion rates (e.g. Rhéty et al. 2017; Hammer et al. 2000, Noguchi et al. 2008). According to this interpretation, the eruption began along the entire fissure, but different segments erupted at different effusion rates. Indeed, the highest crystal contents are observed at the vents for which effusion rate was calculated to be highest. For example, at the South vent peak effusion rates of $\sim 44 \mathrm{~m}^{3} / \mathrm{s}$ were capable of mobilizing lava containing $70 \mathrm{vol} \%$ crystals and to carry it to the distal portion of the system, revealing that it was the first lava emitted. At other vents, where effusion rates were lower, the carrying capacity was lower. At the West and North-West flows, peak effusion rates were between $\sim 10$ and $\sim 30 \mathrm{~m}^{3} / \mathrm{s}$, thus carrying a lower crystal load at peak flow of 40-50 vol $\%$ crystals. As effusion rates waned, so too did the carrying capacity. For example, in the final stage of effusion at the South flow effusion rates waned to $\sim 0.1 \mathrm{~m}^{3} / \mathrm{s}$ and the crystal cargo declined to $10 \mathrm{vol} \%$. Thus, near-vent we find the final, low crystallinity lava erupted at the lowest effusion rate as activity at the vent waned. In other flows, near-vent crystallinities of 50-70 vol\% (Fig. 8) likely indicate that magma was extracted from a heterogeneous, stratified magma chamber, with the crystal-rich material from the base of the shallow reservoir being erupted last (Gurioli et al. 2018).

In comparison, the 2007 flow of Piton de La Fournaise (Rhéty et al. 2017) has a near-vent crystallinity of $55 \mathrm{vol} \%$, increasing to $75 \mathrm{vol} \%$ at the flow front due to microlite crystallization. The 1974 Mauna Ulu flow (Robert et al. 2014) has a crystallinity of 15 vol\% near the vent, increasing to $45 \mathrm{vol} \% 6 \mathrm{~km}$ from the vent. In this case the crystallinity increase is due to the incremental crystallization of microlites, whereas the 
phenocryst content remains stable, suggesting a constant mass eruption rate (Robert et al. 2014).

For the December 2010 eruption, sample porosity decreases uniformly with distance from the vent, regardless of whether the analyzed samples belong to a single channel, braided, or dispersed section of the flow (Fig. 9). As a result, there is no correlation between flow system architecture and sample porosity. In comparison, the 2007 flow of Piton de La Fournaise as analyzed by Rhéty et al. (2017) shows a uniform trend of decreasing porosity along both flow channels considered, comparable in magnitude to that observed here. The 1974 Mauna Ulu flow (Robert et al. 2014), which maintained a single channel structure throughout its length, also shows a porosity decrease with increasing distance from the vent, although it is less pronounced than at Piton de La Fournaise.

Appraisal of these three cases (Piton de La Fournaise 2007 and 2010, and Mauna Ulu 1974) highlights that downflow trends in temperature, crystallinity, and porosity are the same for single and braided channel cases. Additionally, the case of the 2010 flow field of Piton de La Fournaise reveals that temperature, crystallinity, and porosity trends are uninterrupted across transitions between single and multiple channel flow. This supports a model within which cooling rate is depth-dependent, but independent of channel width (cf. Harris \& Rowland 2001; 2009).

Soldati et al. (2016) showed that changes in flow velocity across breaks in slope can be larger than would be predicted for example through Jeffreys equation (Jeffreys 1925). This is due to the non-Newtonian behavior of multi-phase lava, which results in nonlinear flow velocity variations that amplify the effect of even modest slope changes. For example, a steeper slope exerts a greater stress on the flowing lava, resulting in a faster 
flow velocity. Since lava is shear-thinning, a greater stress results in a lower effective viscosity (which would not happen for a Newtonian fluid). In turn, this lower effective viscosity causes velocity to increase, more so than it would for a Newtonian fluid. Because deviation from Newtonian behavior increases with crystallinity (Ryerson 1988), this effect will be more pronounced in highly crystalline lavas, such as those investigated in this study, as opposed to less crystalline ones.

\subsubsection{Implications}

Flow system architecture has fundamental implications well beyond flow morphological appearance. For any given lava effusion rate at the vent, the same supplied flux can feed either one large channel, or may be divided among multiple smaller channels. As a result, a single channel will have a higher volumetric flux than each branch of an equivalent braided channel system fed by the same flux. The increased viscous drag imposed by the larger wetted perimeter of a braided system will result in decreased flow speed, and, consequently, length. This is in accordance with the supply rate rule (Walker 1973) and with mass-energy analysis (Tarquini et al. 2017). Conversely, the transition from braided channels to a single channel will increase the flow speed and length, as demonstrated by Dietterich and Cashman (2014). If channel depth remains constant through the transition from single channel to braided channels, velocity and cooling rate will also remain constant, as will the cooling-limited flow length (Rhéty et al. 2017). Conversely, if partitioning the flux diminishes flow depth (Lister 1992), then, holding all else constant, velocity will decrease and cooling rate will increase (Harris and Rowland 2001), hence reducing the cooling-limited flow length. If the flow depth remains constant (as in the 
case analyzed here) then models become depth-independent. As a result, cooling-related models become unaffected by partitioning of a control volume so that simple 1-D models, such as FLOWGO (Harris and Rowland 2001) and MOLASSES (Richardson 2016) that assume flow depth remains approximately constant downflow, apply.

\subsection{Conclusions}

Slope variations have a primary influence over channel network architecture (e.g. Krauskopf 1948; Dietterich and Cashman 2014; Rhéty et al. 2017). On the basis of our data, we here develop a regime diagram that places the channel network architecture of relatively low-effusion rate lava flows in a dynamic setting. However, this regime diagram cannot be applied universally, as counter-examples exist in the literature for different effusion rates, compositions, and textures. We found that changes in the crystal and bubble content do not correlate with changes in the number of channels, implying that these textural parameters do not exert a direct control on channel network architecture. However, we know from previous studies that pre-existing topography can strongly affect the apparent viscosity of lava flows due to their non-Newtonian behavior (e.g. Peterson and Tilling 1980; Lev and James 2014; Soldati et al. 2016), and that crystal and bubble contents affect the degree of non-Newtonian behavior of lava (e.g. Costa et al. 2009; Llewellin et al. 2002; Mader et al. 2013 and references therein). Both morphological and rheological perspectives remain therefore necessary to fully characterize a channel fed flow system, and to adequately model its development. 


\begin{tabular}{|c|c|c|c|c|c|c|c|c|}
\hline $\begin{array}{r}\text { distance } \\
\text { from vent } \\
\mathrm{m}\end{array}$ & $\begin{array}{r}\text { S flow } \\
\text { slope } \\
\text { o }\end{array}$ & $\begin{array}{r}\text { W flow } \\
\text { slope } \\
\text { o }\end{array}$ & $\begin{array}{r}\text { NW flow } \\
\text { slope } \\
\text { o }\end{array}$ & $\begin{array}{r}\text { N flow } \\
\text { slope } \\
\text { o }\end{array}$ & $\begin{array}{r}\text { S flow } \\
\text { channel } \\
m\end{array}$ & $\begin{array}{r}\text { W flow } \\
\text { channel } \\
\text { m }\end{array}$ & $\begin{array}{r}\text { NW flow } \\
\text { channel } \\
\text { m }\end{array}$ & $\begin{array}{r}\text { N flow } \\
\text { channel } \\
m\end{array}$ \\
\hline 0 & 23 & 15 & 10 & 9 & & & 6 & 4 \\
\hline 10 & 19 & 9 & 14 & 19 & 1 & 5 & 7 & \\
\hline 20 & 31 & 9 & 10 & 16 & 2 & 4 & 6 & \\
\hline 30 & 26 & 16 & 9 & 11 & 1 & 5 & 5 & \\
\hline 40 & 15 & 12 & 15 & 7 & 3 & 4 & 4 & 8 \\
\hline 50 & 18 & 23 & 14 & 10 & 3 & 5 & 5 & 9 \\
\hline 60 & 16 & 8 & 17 & 7 & 3 & 2 & 4 & 8 \\
\hline 70 & 21 & 11 & 20 & 17 & 3 & 2 & 6 & 8 \\
\hline 80 & 26 & 14 & 26 & 12 & 3 & 2 & 7 & 9 \\
\hline 90 & 14 & 12 & 19 & 20 & 3 & 3 & 6 & 13 \\
\hline 100 & 20 & 17 & 20 & 16 & 3 & 3 & 6 & 11 \\
\hline 110 & 18 & 14 & 22 & 15 & 5 & 2 & 6 & 10 \\
\hline 120 & 23 & 15 & 17 & 9 & 4 & 3 & 4 & 12 \\
\hline 130 & 16 & 9 & 10 & 11 & 4 & 2 & 5 & 13 \\
\hline 140 & 18 & 5 & 20 & 13 & 4 & 3 & 6 & 9 \\
\hline 150 & 21 & 12 & 8 & 20 & 4 & 4 & 6 & 11 \\
\hline 160 & 23 & 12 & 19 & 14 & 4 & 5 & 5 & 13 \\
\hline 170 & 16 & 9 & 14 & 9 & 5 & & 5 & 13 \\
\hline 180 & 17 & 12 & 18 & 16 & 4 & & 5 & 12 \\
\hline 190 & 11 & 11 & 12 & 11 & 5 & & 5 & 11 \\
\hline 200 & 2 & 15 & 10 & 3 & 5 & & 4 & 14 \\
\hline 210 & 14 & 14 & 10 & 9 & 4 & 3 & 3 & 14 \\
\hline 220 & 11 & 6 & 15 & 14 & 3 & 3 & 4 & 13 \\
\hline 230 & 24 & 11 & 14 & 13 & 5 & 5 & 5 & 15 \\
\hline 240 & 19 & 6 & 19 & 8 & 4 & 6 & 4 & 13 \\
\hline 250 & 24 & 10 & 18 & 10 & 4 & 7 & 5 & 14 \\
\hline 260 & 11 & 9 & 6 & 9 & 6 & 7 & 5 & 15 \\
\hline 270 & 15 & 6 & 7 & 8 & 6 & 4 & 5 & 16 \\
\hline 280 & 21 & 11 & 3 & 7 & 5 & 5 & 5 & 15 \\
\hline 290 & 9 & 6 & 12 & 6 & 5 & & 5 & 15 \\
\hline 300 & 15 & 10 & 14 & 7 & 4 & & 5 & 18 \\
\hline 310 & 22 & 6 & 6 & 9 & 4 & 4 & 4 & 14 \\
\hline 320 & 17 & 9 & 9 & 12 & 4 & 4 & 5 & 16 \\
\hline 330 & 14 & 1 & 9 & 6 & 4 & 5 & 5 & 16 \\
\hline 340 & 22 & 6 & 5 & 3 & 3 & 5 & 4 & 16 \\
\hline 350 & 17 & 8 & 8 & 2 & 4 & & 5 & 17 \\
\hline 360 & 19 & 5 & 15 & 8 & & & 5 & 15 \\
\hline 370 & 29 & 3 & 10 & 10 & & 8 & 4 & 15 \\
\hline 380 & 20 & 10 & 8 & 9 & & 7 & 5 & 12 \\
\hline 390 & & 16 & 0 & 13 & & & 5 & 19 \\
\hline 400 & & 8 & 11 & 12 & & 5 & 4 & 15 \\
\hline 410 & & 6 & 5 & 4 & & & 6 & 16 \\
\hline 420 & & 5 & 7 & 9 & & 5 & 8 & 18 \\
\hline 430 & & 11 & 10 & 6 & & 5 & 7 & 20 \\
\hline 440 & & 12 & 3 & 11 & & 6 & & 19 \\
\hline 450 & & 14 & 7 & 7 & & 5 & & 17 \\
\hline 460 & & 16 & 9 & 7 & & 7 & & 18 \\
\hline 470 & & 13 & 9 & -1 & & 7 & & 16 \\
\hline 480 & & 25 & 11 & 11 & & 6 & & 12 \\
\hline 490 & & 5 & 9 & 2 & & & & 12 \\
\hline 500 & & 3 & 12 & 6 & & & & 11 \\
\hline 510 & & 10 & 11 & 7 & & & & 14 \\
\hline 520 & & 15 & 8 & 10 & & & 7 & 15 \\
\hline
\end{tabular}




\begin{tabular}{|c|c|c|c|c|c|c|}
\hline 530 & 16 & 13 & 10 & 6 & 6 & 12 \\
\hline 540 & 24 & 11 & 16 & & 8 & 11 \\
\hline 550 & 18 & 11 & 11 & & 7 & 11 \\
\hline 560 & 5 & 5 & 8 & 9 & 9 & 16 \\
\hline 570 & 15 & 6 & 15 & 7 & 9 & 16 \\
\hline 580 & 7 & 15 & 12 & 7 & 12 & 15 \\
\hline 590 & 16 & 5 & 16 & 6 & 10 & 16 \\
\hline 600 & 9 & 10 & 13 & 6 & 9 & 15 \\
\hline 610 & 1 & 12 & 12 & & 9 & 14 \\
\hline 620 & 11 & 7 & 20 & & 7 & 15 \\
\hline 630 & 14 & 16 & 13 & & 5 & 22 \\
\hline 640 & 9 & 3 & 8 & & 5 & 20 \\
\hline 650 & 12 & 7 & 14 & & 5 & 19 \\
\hline 660 & 2 & 8 & 10 & & 5 & 21 \\
\hline 670 & -1 & 9 & 4 & & 5 & 22 \\
\hline 680 & 1 & 10 & 5 & & 5 & 24 \\
\hline 690 & 1 & 5 & 11 & & 5 & 20 \\
\hline 700 & -2 & 11 & 20 & & 6 & 22 \\
\hline 710 & 14 & 9 & 2 & & 5 & 21 \\
\hline 720 & 4 & 10 & 7 & & 6 & 21 \\
\hline 730 & 3 & 15 & 18 & & 6 & 20 \\
\hline 740 & 8 & 17 & 40 & & 6 & 20 \\
\hline 750 & -1 & 14 & 17 & & 5 & 19 \\
\hline 760 & 9 & 10 & 27 & & 5 & 20 \\
\hline 770 & 4 & 19 & 17 & & 5 & 18 \\
\hline 780 & 7 & 13 & 15 & & 5 & 17 \\
\hline 790 & 1 & 10 & 18 & & 6 & 18 \\
\hline 800 & 0 & 7 & 14 & & 6 & 18 \\
\hline 810 & 6 & 8 & 15 & & 5 & 16 \\
\hline 820 & -1 & 11 & 20 & & 5 & 18 \\
\hline 830 & 9 & 10 & 18 & & 5 & 21 \\
\hline 840 & 4 & & 19 & & 5 & 21 \\
\hline 850 & 7 & & 18 & & 5 & 21 \\
\hline 860 & 11 & & 18 & & 5 & 20 \\
\hline 870 & 5 & & 17 & & 6 & 27 \\
\hline 880 & 3 & & 15 & & 5 & 30 \\
\hline 890 & 4 & & 8 & & 4 & 33 \\
\hline 900 & 10 & & 9 & & 4 & 34 \\
\hline 910 & 6 & & 2 & & 5 & 33 \\
\hline 920 & 3 & & 19 & & & 34 \\
\hline 930 & 6 & & 22 & & & 33 \\
\hline 940 & 3 & & 24 & & & 29 \\
\hline 950 & 3 & & 14 & & & 16 \\
\hline 960 & & & 4 & & & 15 \\
\hline 970 & & & 10 & & & \\
\hline 980 & & & 15 & & & \\
\hline 990 & & & 25 & & & \\
\hline 1000 & & & 15 & & & \\
\hline 1010 & & & 15 & & & \\
\hline
\end{tabular}

Supplementary Table 1 Flow dimensions and underlying terrain slope. 
E9I

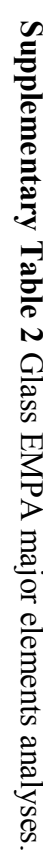

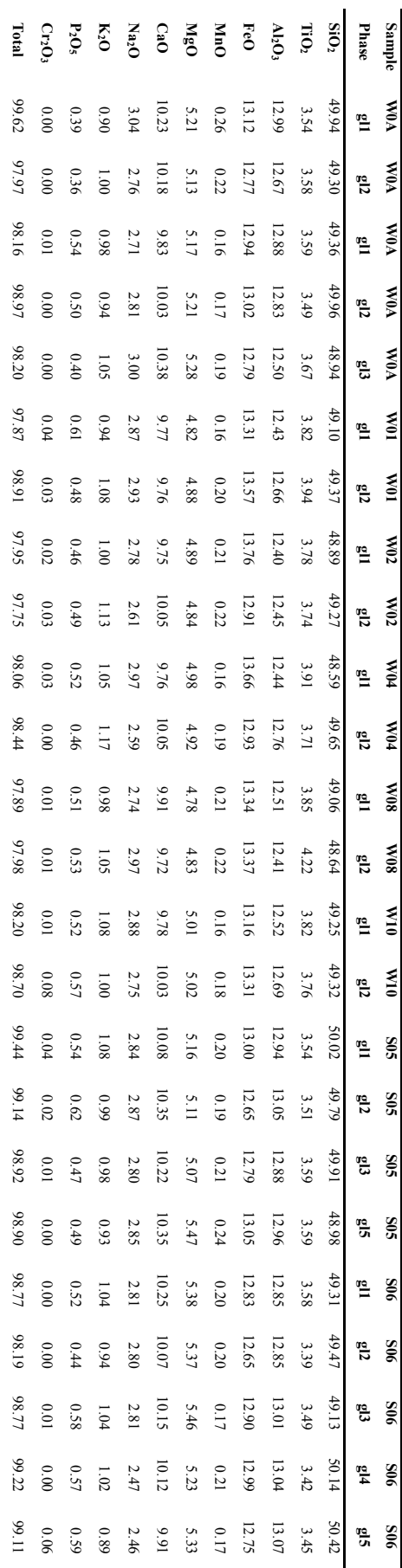

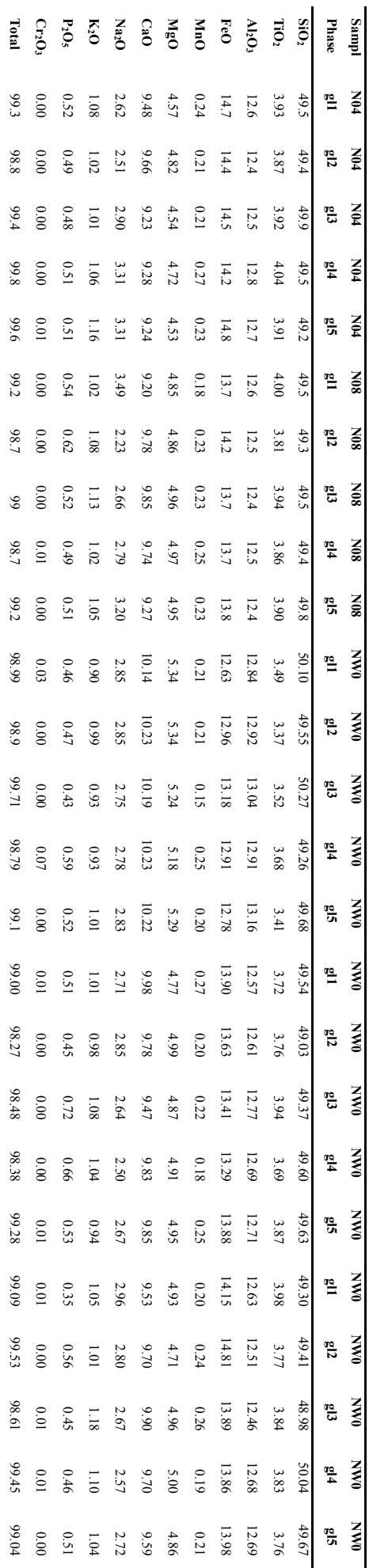


†9I

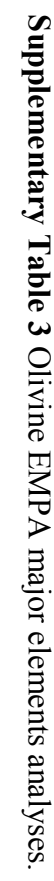

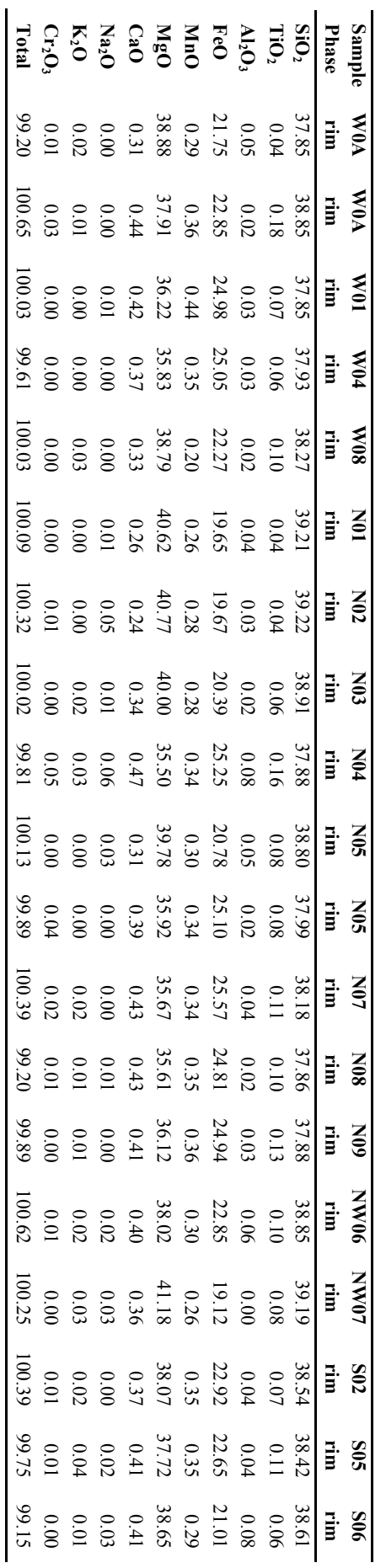

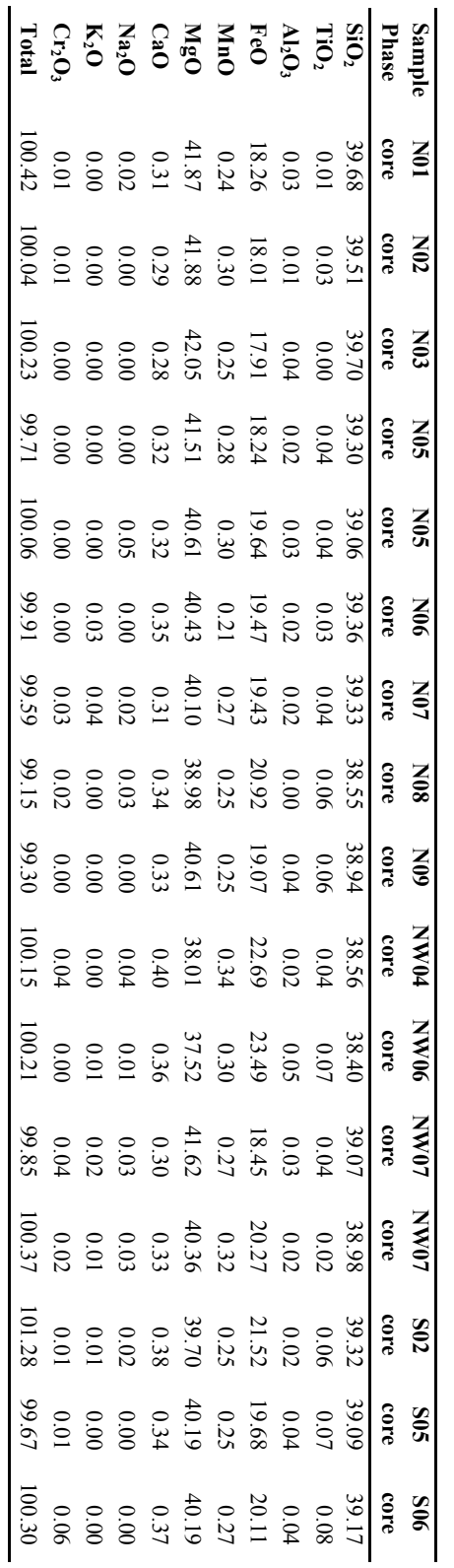



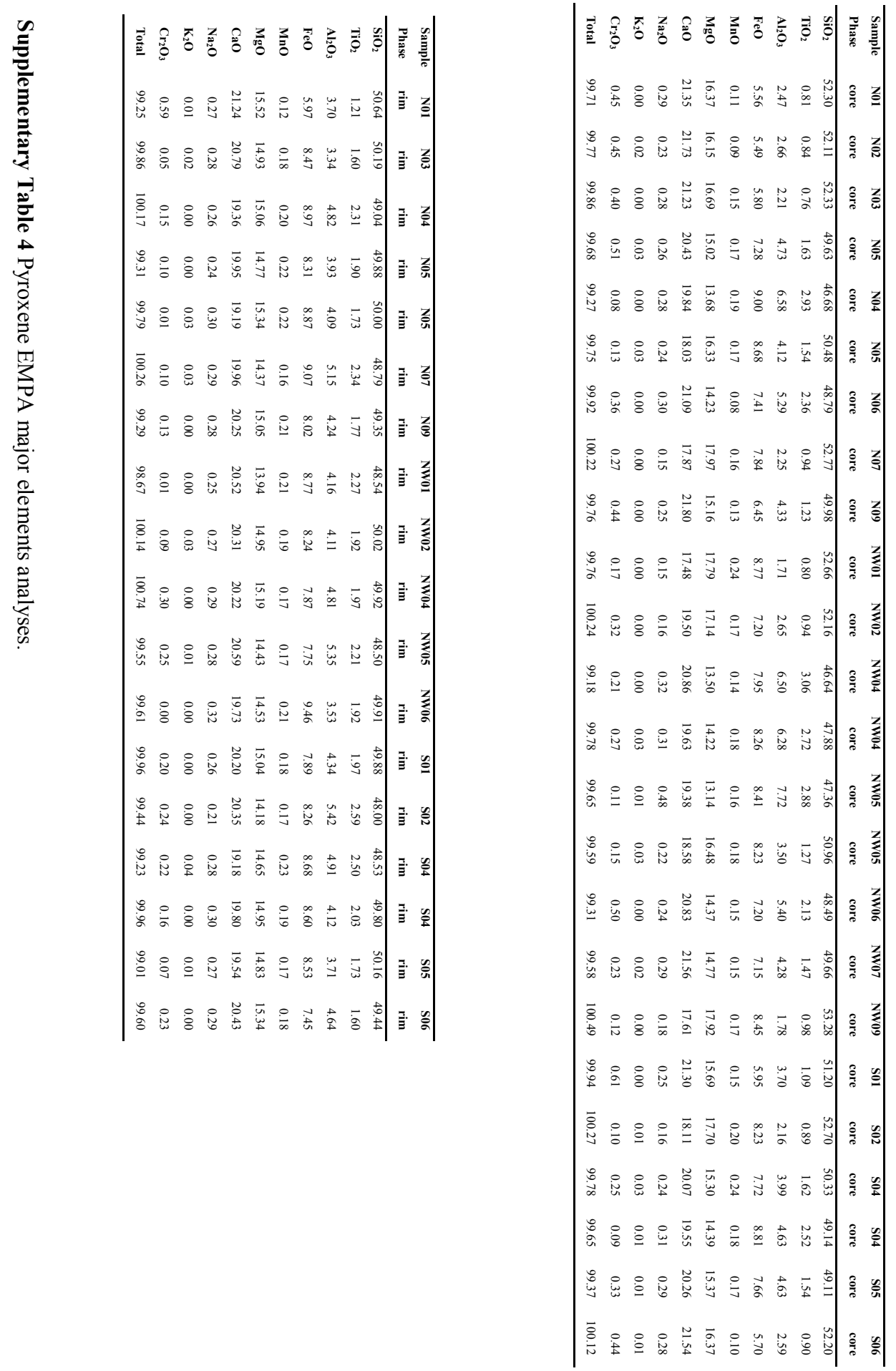

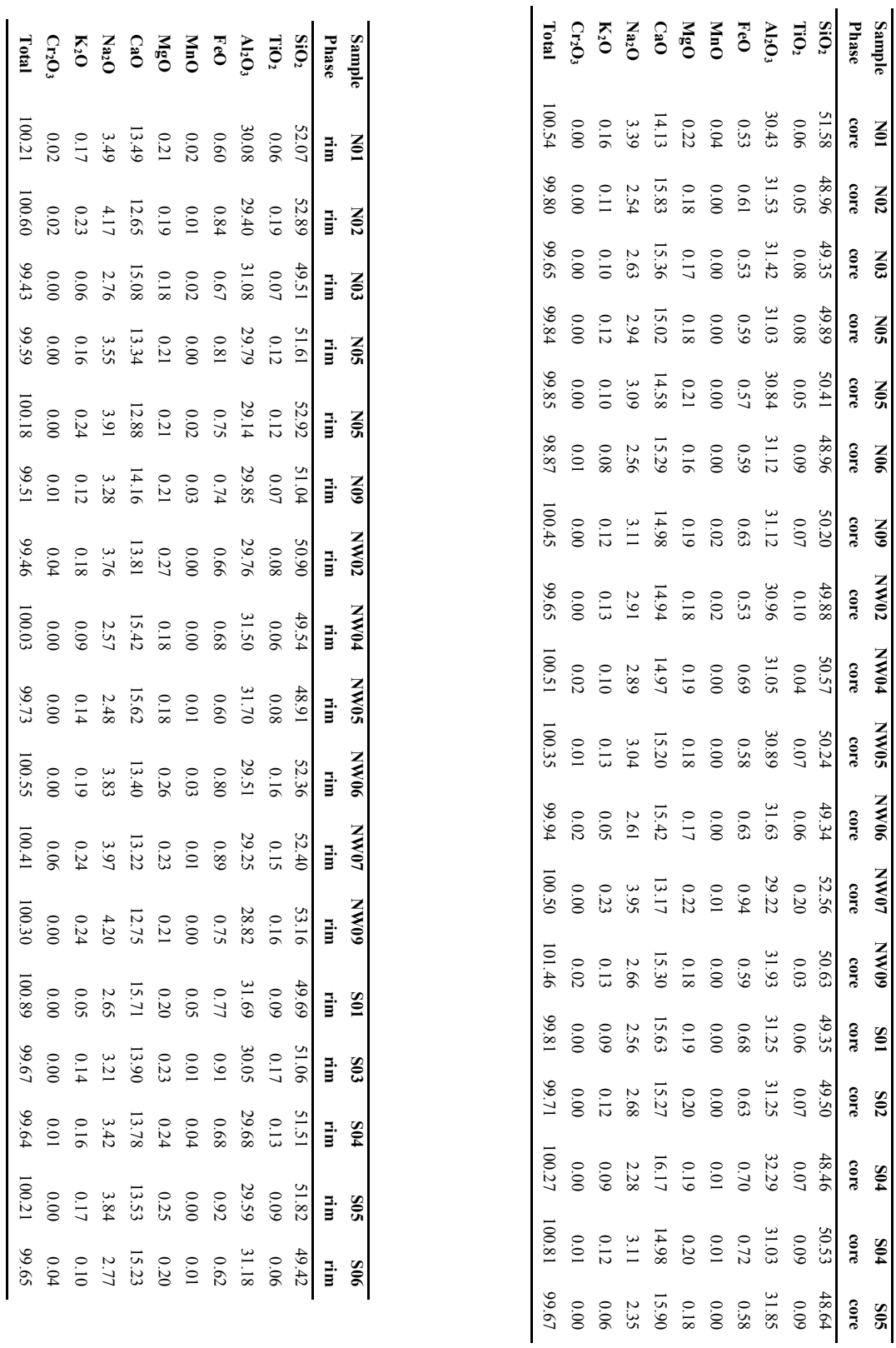


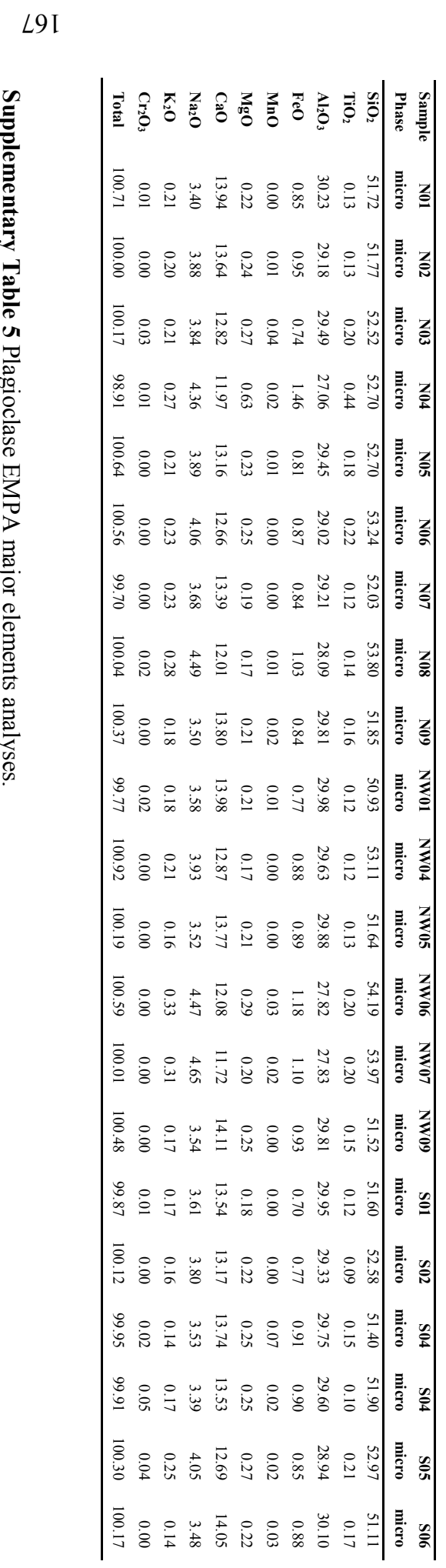




\section{CHAPTER 5}

\section{Conclusion}

\section{Summary}

For a lava flow of any given effusion rate and total volume, topography strongly affects flow dynamics in at least two different ways, eventually controlling all the major hazard parameters of a flow: length, speed, and covered area.

First of all, topography influences lava flow channel network architecture, and therefore length, speed, and direction, as shown in Chapter 4. Through field observations, we determined that in small volume-limited flows, such as the 2010 flow emitted by Piton de La Fournaise, channel network architecture (single channel vs. braided channels) is controlled solely by slope variations. Textural analyses confirmed that crystallinity and vesicularity evolve independently from channel network. We developed a regime diagram that may be used as a flow system structure predictive tool for small, volumelimited flows emplaced outside of pre-existing flow channels. The importance of this diagram consists in the fact that braiding causes a flow to disperse over a wider area, but to be shorter than a channelized one. This has the potential to have critical implications for hazard assessment, but has yet to be tested on other lava flow systems.

Topography also critically influences the effective viscosity of non-Newtonian lava, and therefore its speed, as assessed in Chapter 2. Our work on the Pacaya 2014 eruption focused on quantifying the relative importance of the intrinsic (thermal, chemical, and physical) and extrinsic (topography) control factors on lava flow rheology. Through a 
combination of field and laboratory work, we determined that among the intrinsic factors the physical effect of crystals dominates. This holds true in basaltic systems from different tectonic settings, as discussed in Chapter 3. By contrast, the relative importance of the direct thermal effect (i.e. temperature variation itself) on effective viscosity increase is always minor. The importance of the chemical effect varies, being negligible at Pacaya but more important at Mauna Ulu and even more at Cima. Further studies will be necessary to test whether this holds more generally true for the respective geodynamic settings. Furthermore, we determined that pre-existing slope can be the single most important factor in controlling the rheology of lava flows over short distances where slope changes significantly, due to the strongly shear thinning behavior of lava.

Our results overall indicate that incorporating the complex relations between pre-existing slope, lava rheology, and flow dynamics into models of lava flow emplacement is a critical need to be addressed to improve our hazard preparedness. It is necessary to combine field-based and experimental insights to adequately characterize a channel-fed flow system, and to successfully model its development.

The combination of field and experimental results may also help us reconstruct the emplacement history of flows that were not active at the time of fieldwork, both in terms of mechanism and timescale. For example, in Chapter 3 we reconstructed the history of the youngest flow in the Cima volcanic field. We determined that the first phase of the eruption emitted a batch of highly crystalline lava. Later on, less crystalline, less viscous lava was emplaced first through a lava tube, and then through open channel flow. Finally, the flow was inflated through a system of lava tubes. The eruption duration is estimated as a few days. Such insight pertaining to monogenetic basaltic volcanism, an eruptive 
style directly observed historically in only one case (Parícutin, 1943-1952; Krauskopf 1948), is critical for the correct volcanic hazard assessment of areas located nearby monogenetic volcanic fields. Volcanic fields are widespread in the western United States (notable examples include Carrizozo, Raton-Clayton, Zuni-Bandera), as well as in many other densely inhabited areas all over the world (e.g. Auckland Volcanic Field in New Zealand, Chaîne des Puys in France). Although not historical, their activity is recent in geologic time ( $<50,000$ years), and the associated hazard is significant (Valentine et al. 2017).

\section{Applications}

Data collected during this dissertation expanded our knowledge of the rheological behavior of lava compositions that had not previously been extensively investigated (e.g. trachybasalts, Chapter 3). Furthermore, our results clearly showed the two-fold effect of topography, both on the structure (Chapter 4) and the rheology (Chapter 2) of lava flows, highlighting the need to integrate both perspectives when studying lava flows. This wealth of data should be used as input to test and refine existing thermo-rheological models of lava flows (e.g. FLOWGO; Harris and Rowland 2001), and also suggests the need to integrate such models with stochastic (DOWNFLOW; Favalli et al. 2005) and

Cellular Automata (MAGFLOW; Del Negro et al. 2008) models, to gain a comprehensive perspective on flow dynamics and hazard. 


\section{Future Directions}

Much remains to be understood about lava flow dynamics, and fundamental insight can be gained through further rheological investigations. I have identified two main research directions worthy of being pursued that represent a natural progression of this dissertation work.

The first project consists of experimentally measuring the rheology of phenocrystbearing, and eventually phenocryst- and microlite-bearing melts. Crystallinity exerts by far the main control on the subliquidus rheology of lava flows (Roscoe 1952, Maron and Pierce 1956, Krieger and Dougherty 1959, Lejeune and Richet 1995, Costa et al. 2009, Soldati et al. 2016). The crystal population of a lava flow evolves during its emplacement (e.g. Marsh 1988). The content of phenocrysts (cogenetic crystals $>500 \mu \mathrm{m}$ ) remains stable, as they are typically formed in the magma chamber over long timescales. On the other hand, most microlites (cogenetic crystals $<500 \mu \mathrm{m}$ ) are produced during conduit ascent and, to a lesser extent, during flow emplacement, and therefore microlite content increases over time until the flow is completely solidified. The bimodal crystal size distribution commonly observed in lavas is therefore the result of a two-stage crystallization process (Cashman and Marsh 1988). Several experimental studies on natural lavas, including my own, have aimed at reproducing and understanding the second crystallization stage, i.e. the effect of microlites on the rheology of a lava flow, producing monodisperse microlitic textures (Ishibashi and Sato 2007, Ishibashi 2009, Vona et al. 2011, Chevrel et al. 2015, Sehlke et al. 2014, Soldati et al. 2016). Thus, firm experimental constraints exist on the incremental contributions of microlites to lava rheology, whereas the core effect of the phenocrysts is still relatively unconstrained in the 
natural lavas domain, with only one experimental study to date having investigated it (Vona et al. 2017). Tackling the rheological implications of the first stage of the crystallization history of magmas, i.e. the role of phenocrysts, is the key to advancing our understanding of flow rheology, by bridging the gap between natural and experimental textures and thereby making rheological experimental results directly applicable to natural scenarios. Concurrently, this will inform us on magmatic conduit ascent processes. To these ends, I would like to conduct rheological experiments on phenocrystbearing basalts.

The second project consists of scaling up our subliquidus experimental rheological work, at an intermediate scale between laboratory and field. Some work (e.g. Lev et al. 2012, Dietterich et al. 2015) at this scale has already been conducted at Syracuse University (http://lavaproject.syr.edu), and more recently at the University at Buffalo (http://artssciences.buffalo.edu/geology/research/volcanoes-geohazards.html), but always at superliquidus conditions, and therefore with limited direct applicability to the most common natural scenarios. Instead, I would like to produce subliquidus, two-phase (melt+crystals) flows, so as to capture the effect of crystals on lava flows under controlled laboratory conditions. To do that, I would use komatiitic compositions. In fact, komatiites are exceptionally fluid even at subliquidus temperatures (Sehlke and Whittington 2015), allowing for pouring from the experimental setup. This will provide us with the unique opportunity to conduct the first intermediate-scale experimental study of lava emplacement at subliquidus conditions, with potential relevance to modern-day terrestrial basalts. Using komatiites would also provide valuable data directly applicable to both the early Earth and other terrestrial bodies in our solar system (e.g. the Jovian 
moon Io). In fact, most terrestrial komatiites are Archean in age. The subsequent cooling of Earth reduced the degree of partial melting that can be achieved by the mantle, making komatiite production less and less frequent in the Proterozoic and early Phanerozoic, and ultimately impossible after the Mesozoic (Nisbet et al. 1993). However, komatiites may still be the main effusive volcanism product elsewhere in the solar system, e.g. on Io, where syn-eruptive composition and temperature data collected remotely by the Galileo mission indicate the likelihood of ongoing komatiite emplacement. Furthermore, it has been suggested that komatiites may have been emplaced at various times on other terrestrial bodies, including the Moon (Ringwood et al. 1987), Venus (Hess and Head 1990), and Mars (Reyes and Christensen 1994). Understanding and testing the rheological properties of these unique lavas is therefore crucial to the interpretation of planetary volcanic landscapes. 


\section{REFERENCES}

Agee CB (1998) Crystal-liquid density inversions in terrestrial and lunar magmas. hysicsof the Earth and Planetary Interiors, 107(1), 63-74

Albarède F, Luais B, Fitton G, Semet M, Kaminski E, Upton BG, Bachèlery P, Cheminée JL (1997) The geochemical regimes of Piton de la Fournaise volcano (Réunion) during the last 530000 years. Journal of Petrology, 38(2), 171-201

Allison CM, Porter RC, Fouch MJ, Semken S (2013) Seismic evidence for lithospheric modification beneath the Mojave Neovolcanic Province, Southern California. Geophysical Research Letters, 40(19), 5119-5124

Anderson DL (2007) The Eclogite Engine: Chemical Geodynamics as a Galileo Thermometer. In "Plates, Plumes, and Planetary Processes", Ed. by GR Foulger and D M Jurdy (Geol. Soc. Am. Spec. Paper 430, 2007), pp. 47-65

Annen C, Blundy, JD, \& Sparks, RSJ (2005) The genesis of intermediate and silicic magmas in deep crustal hot zones. Journal of Petrology, 47(3), 505-539.

Arculus RJ, Gust DA (1995). Regional petrology of the San Francisco volcanic field, Arizona, USA. Journal of Petrology, 36(3), 827-861

Armstrong JT (1995) CITZAF: a package of correction programs for the quantitative electron microbeam X-ray analysis of thick polished materials, thin films, and particles. Microbeam Anal 4:177-200

Asimow P. Melting the Mantle In Encyclopedia of volcanoes

Avard G, Whittington AG (2012) Rheology of arc dacite lavas: experimental determination at low strain rates. Bull Volcanol 74(5):1039-1056. doi: $10.1007 / \mathrm{s} 00445-012-0584-2$ 
Bachèlery P, Lénat JF, Di Muro A, Michon L (2016) Active Volcanoes of the Southwest Indian Ocean: Piton de la Fournaise and Karthala. Active Volcanoes of the World. Springer-Verlag, Berlin and Heidelberg, 1-428, DOI 10.1007/978-3-642-31395$0 \_12$

Bachèlery P, Saint-Ang F, Villeneuve N, Savoye B, Normand A, Le Drezen E, Deplus C (2010). Huge lava flows into the sea and caldera collapse, April 2007, Piton de la Fournaise volcano. Geophysical Research Letters, 34, L21301

Baldi, P., S. Bonvalot, P. Briole, M. Coltelli, K. Gwinner, M. Marsella, G. Puglisi, and D. Remy (2002) Validation and comparison of different techniques for the derivation of digital elevation models and volcanic monitoring (Vulcano Island, Italy), Int. J. Remote Sens., 23,4783-4800

Barca, D., Crisci, G. M., Gregorio, S. D., Nicoletta, F. (1994). Cellular Automata for simulating lava flows: a method and examples of the Etnean eruptions. Transport theory and statistical physics, 23(1-3), 195-232

Bardintzeff JM, Deniel C (1992) Magmatic evolution of Pacaya and Cerro Chiquito volcanological complex, Guatemala. Bull Volcanol 54(4):267-283

Barnes HA (1999) The yield stress - a review or ' $\pi \alpha v \tau \alpha \rho \varepsilon$ '-everything flows? J Nonnewt Fluid Mech 81(1): 133-178

Behncke, B., Neri, M., Nagay, A. (2005) Lava flow hazard at Mount Etna (Italy): new data from a GIS-based study. Geological Society of America Special Papers, 396, $189-208$ 
Bollasina AJ (2014) The May 2010 eruption of Pacaya volcano, Guatemala: An experimental study of subliquidus magma rheology. M.S. Disseration, University of Missouri

Brétar, F., Arab-Sedze, M., Champion, J., Pierrot-Deseilligny, M., Heggy, E., Jacquemoud, S. (2013) An advanced photogrammetric method to measure surface roughness: Application to volcanic terrains in the Piton de la Fournaise, Reunion Island. Remote Sensing of Environment, 135, 1-11

Brodu, N., Lague, D. (2013) 3D terrestrial lidar data classification of complex natural scenes using a multi-scale dimensionality criterion: Applications in geomorphology. ISPRS Journal of Photogrammetry and Remote Sensing, 68, 121-134

Calvari, S., Pinkerton, H. (1998) Formation of lava tubes and extensive flow field during the 1991-1993 eruption of Mount Etna. Journal of Geophysical Research: Solid Earth, 103(B11), 27291-27301

Cashman, K. V., Marsh, B. D. (1988) Crystal size distribution (CSD) in rocks and the kinetics and dynamics of crystallization II: Makaopuhi lava lake. Contributions to Mineralogy and Petrology, 99(3), 292-305

Cashman, K. V., Thornber, C., Kauahikaua, J. P. (1999) Cooling and crystallization of lava in open channels, and the transition of Pāhoehoe Lava to 'A'ā. Bulletin of Volcanology, 61(5), 306-323

Castruccio, A., Rust, A. C., Sparks, R. S. J. (2010) Rheology and flow of crystal-bearing lavas: Insights from analogue gravity currents. Earth and Planetary Science Letters, 297(3), 471-480 
Chadwick, W. W., Clague, D. A., Embley, R. W., Perfit, M. R., Butterfield, D. A., Caress, D. W., Bobbitt, A. M. (2013) The 1998 eruption of Axial Seamount: New insights on submarine lava flow emplacement from high-resolution mapping. Geochemistry, Geophysics, Geosystems, 14(10), 3939-3968

Chevrel, M. O., Cimarelli, C., deBiasi, L., Hanson, J. B., Lavallée, Y., Arzilli, F., Dingwell, D. B. (2015) Viscosity measurements of crystallizing andesite from Tungurahua volcano (Ecuador). Geochemistry, Geophysics, Geosystems,16(3), 870-889.

Chevrel, M. O., Giordano, D., Potuzak, M., Courtial, P., Dingwell, D. B. (2013). Physical properties of $\mathrm{CaAl}_{2} \mathrm{Si}_{2} \mathrm{O}_{8}-\mathrm{CaMgSi}_{2} \mathrm{O}_{6}-\mathrm{FeO}-\mathrm{Fe}_{2} \mathrm{O}_{3}$ melts: analogues for extraterrestrial basalt. Chemical Geology, 346, 93-105

Chevrel, M. O., Platz, T., Hauber, E., Baratoux, D., Lavallée, Y., Dingwell, D. B. (2013) Lava flow rheology: A comparison of morphological and petrological methods. Earth and Planetary Science Letters, 384, 109-120

Cimarelli, C., Costa, A., Mueller, S., Mader, H. M. (2011) Rheology of magmas with bimodal crystal size and shape distributions: Insights from analog experiments. Geochemistry, Geophysics, Geosystems, 12(7) Q07024

Conway, C. E., Townsend, D. B., Leonard, G. S., Wilson, C. J. N., Calvert, A. T., Gamble, J. A. (2015) Lava-ice interaction on a large composite volcano: a case study from Ruapehu, New Zealand. Bulletin of Volcanology, 77(3), 21

Coppola, D., N. Villeneuve, A. Di Muro, V. Ferrazzini, A. Peltier, M. Favalli, P. Bachèlery, L. Gurioli, A. Harris, S. Moune, I. Vlastélic, B. Galle, S. Arellano, and A. Aiuppa (2017) A Shallow system rejuvenation and magma discharge trends at 
Piton de la Fournaise volcano (La Réunion Island), Earth and Planetary Science Letters 463, 13-24

Costa, A. (2005) Viscosity of high crystal content melts: dependence on solid fraction. Geophysical Research Letters, 32(22) L22308

Costa, A., Caricchi, L., Bagdassarov, N. (2009) A model for the rheology of particlebearing suspensions and partially molten rocks. Geochemistry, Geophysics, Geosystems, 10(3)

Crisp, J., Baloga, S. (1994) Influence of crystallization and entrainment of cooler material on the emplacement of basaltic 'a'ā lava flows. Journal of Geophysical Research: Solid Earth, 99(B6), 11819-11831

Del Negro, C., Fortuna, L., Herault, A., Vicari, A. (2008) Simulations of the 2004 lava flow at Etna volcano using the magflow cellular automata model. Bulletin of Volcanology, 70(7), 805-812

Di Muro, A. 2010a. Bulletin Volcanologique du 09 Décembre. Daily Bulletin of the Observatoire Volcanologique du Piton de la Fournaise, 9 December 2010, OVPF_20101209_1

Di Muro, A. 2010b. Bulletin Volcanologique du 09 Décembre. Daily Bulletin of the Observatoire Volcanologique du Piton de la Fournaise, 9 December 2010, OVPF_20101209_2

Di Muro, A. 2010c. Bulletin Volcanologique du 09 Décembre. Daily Bulletin of the Observatoire Volcanologique du Piton de la Fournaise, 9 December 2010, OVPF_20101209_3 
Di Muro, A. 2010d. Bulletin Volcanologique du 09 Décembre. Daily Bulletin of the Observatoire Volcanologique du Piton de la Fournaise, 9 December 2010, OVPF_20101209_5

Di Muro, A. 2010e. Bulletin Volcanologique du 09 Décembre. Daily Bulletin of the Observatoire Volcanologique du Piton de la Fournaise, 9 December 2010, OVPF_20101209_6

Di Muro, A. 2010f. Bulletin Volcanologique du 09 Décembre. Daily Bulletin of the Observatoire Volcanologique du Piton de la Fournaise, 10 December 2010, OVPF_20101210_1

Di Muro, A. 2010g. Bulletin Volcanologique du 09 Décembre. Daily Bulletin of the Observatoire Volcanologique du Piton de la Fournaise, 10 December 2010, OVPF_20101210_2

Di Muro, A., T. Staudacher, V. Ferrazzini, N. Métrich, P. Besson, C. Garofalo, and B. Villemant (2015) Shallow magma storage at Piton de la Fournaise volcano after 2007 summit caldera collapse tracked in Pele's hairs, chap 9 of Carey, R. J., V. Cayol, M. P. Poland, and D. Weis (eds.), Hawaiian Volcanoes: From Source to Surface, American Geophysical Union Monograph 208, pp 189-212

Dickinson, W. R. (1973) Widths of modern arc-trench gaps proportional to past duration of igneous activity in associated magmatic arcs. Journal of Geophysical Research, 78(17), 3376-3389

Dietterich, H. R., Cashman, K. V. (2014) Channel networks within lava flows: Formation, evolution, and implications for flow behavior. Journal of Geophysical Research: Earth Surface, 119(8), 1704-1724 
Dietterich, H. R., Cashman, K. V., Rust, A. C., Lev, E. (2015) Diverting lava flows in the lab. Nature Geoscience, 8(7), 494-496

Dingwell DB (1995) Viscosity and Anelasticity of Melts. Mineral Physics \& Crystallography: A Handbook of Physical Constants 209-217. doi: 10.1029/RF002p0209

Dingwell DB, Virgo D (1988) Viscosities of melts in the $\mathrm{Na}_{2} \mathrm{O}-\mathrm{FeO}-\mathrm{Fe}_{2} \mathrm{O}_{3}-\mathrm{SiO}_{2}$ system and factors controlling relative viscosities of fully polymerized silicate melts. Geochim Cosmochim Ac 52(2):395-403

Dohrenwend, J. C., McFadden, L. D., Turrin, B. D., Wells, S. G. (1984) K-Ar dating of the Cima volcanic field, eastern Mojave Desert, California: Late Cenozoic volcanic history and landscape evolution. Geology, 12(3), 163-167

Dohrenwend, J. C., Wells, S. G., Turrin, B. D. (1986) Degradation of Quaternary cinder cones in the Cima volcanic field, Mojave Desert, California.Geological Society of America Bulletin, 97(4), 421-427

Dutton C (1884) Hawaiian Volcanoes. U.S. Geological Survey 4th Annual Report, 75219

DYNVOLC Database. Observatoire de Physique du Globe de Clermont-Ferrand, Aubière, France. DOI:10.25519/DYNVOLC-Database. Online access: http://dx.doi.org/10.25519/DYNVOLC-Database

Eggers AA (1971) The geology and petrology of the Amatitlán quadrangle, Guatemala. Dissertation, Dartmouth College 
Faroughi SA, Huber C (2015) A generalized equation for rheology of emulsions and suspensions of deformable particles subjected to simple shear at low Reynolds number. Rheol Acta 54(2):85-108

Faroughi, S. A., Huber, C. (2014) Crowding-based rheological model for suspensions of rigid bimodal-sized particles with interfering size ratios. Physical Review E, 90(5), 052303

Farr, T. G. (1992) Microtopographic evolution of lava flows at Cima volcanic field, Mojave Desert, California. Journal of Geophysical Research: Solid Earth, 97(B11), 15171-15179

Favalli M, Fornaciai A, Nannipieri L, Harris A, Calvari S, Lormand C (2018) UAVbased remote sensing surveys of lava flow fields: a case study from Etna's 1974 channel-fed lava flows. Bulletin of Volcanology 80:29 DOI 10.1007/s00445-0181192-6

Favalli M, Harris AJL, Fornaciai A, Pareschi MT, Mazzarini F (2010) The distal segment of Etna’s 2001 basaltic lava flow. Bull Volcanol 72:119-127

Favalli, M., Chirico, G. D., Papale, P., Pareschi, M. T., Boschi, E. (2009) Lava flow hazard at Nyiragongo volcano, DRC. Bulletin of Volcanology, 71(4), 363-374

Favalli, M., Pareschi, M. T., Neri, A., Isola, I. (2005) Forecasting lava flow paths by a stochastic approach. Geophysical Research Letters, 32(3)

Felpeto, A., Arana, V., Ortiz, R., Astiz, M., Garcia, A. (2001) Assessment and modelling of lava flow hazard on Lanzarote (Canary Islands). Natural hazards, 23(2-3), 247257 
Fink JH, Zimbelman JR (1986) Rheology of the 1983 Royal Gardens basalt flows, Kilauea volcano, Hawaii. Bull Volcanol 48(2-3):87-96

Fink, J. H., Griffiths, R. W. (1992) A laboratory analog study of the surface morphology of lava flows extruded from point and line sources. Journal of Volcanology and Geothermal Research, 54(1), 19-32

Fisher, R. V., Schmincke, H. U. (1984) Submarine volcaniclastic rocks. In Pyroclastic Rocks (pp. 265-296). Springer, Berlin, Heidelberg

Foshag, W. P., Gonzales, G. R. (1956) Birth and development of Paricutin volcano, Mexico (No. 965-D)

Foulger, G. R. (2007) The "plate"model for the genesis of melting anomalies. Special Papers-Geological Society of America, 430, 1

Foulger, G. R. (Ed.). (2005) Plates, plumes, and paradigms (Vol. 388). Geological Society of America

Foulger, G. R., Jurdy, D. M. (Eds.). (2007) Plates, plumes, and planetary processes (Vol. 430). Geological Society of America

Garry, W. B., Zimbelman, J. R., Gregg, T. K. (2007) Morphology and emplacement of a long channeled lava flow near Ascraeus Mons Volcano, Mars. Journal of Geophysical Research: Planets, 112(E8)

Gaudio, P., Ventura, G., Taddeucci, J. (2013) The effect of particle size on the rheology of liquid-solid mixtures with application to lava flows: Results from analogue experiments. Geochemistry, Geophysics, Geosystems, 14(8), 2661-2669

Gauthier F (1973) Field and laboratory studies of the rheology of Mount Etna lava. Philos T Roy Soc A 274(1238):83-98 
Getson JM, Whittington AG (2007) Liquid and magma viscosity in the anorthiteforsterite-diopside-quartz system and implications for the viscosity-temperature paths of cooling magmas. J Geophys Res-Sol Ea (1978-2012), 112(B10)

Ghiorso MS, Sack RO (1995) Chemical mass transfer in magmatic processes IV. A revised and internally consistent thermodynamic model for the interpolation and extrapolation of liquid-solid equilibria in magmatic systems at elevated temperatures and pressures. Contrib Mineral Petr 119(2-3):197-212

Giordano, D., Russell, J. K., Dingwell, D. B. (2008) Viscosity of magmatic liquids: a model. Earth and Planetary Science Letters, 271(1), 123-134

Glaze, L. S., Baloga, S. M., Fagents, S. A., Wright, R. (2014) The influence of slope breaks on lava flow surface disruption. Journal of Geophysical Research: Solid Earth, 119(3), 1837-1850

Greeley, R. (1987) The role of lava tubes in Hawaiian volcanoes. US Geol. Surv. Prof. Pap, 1350(2), 1589-1602

Greeley, R., Foing, B. H., McSween, H. Y., Neukum, G., Pinet, P., van Kan, M., Werner, S.C., Williams, D.A.,Zegers, T. E. (2005) Fluid lava flows in Gusev crater, Mars. Journal of Geophysical Research: Planets, 110(E5)

Gregg, T. K., Fink, J. H. (1996) Quantification of extraterrestrial lava flow effusion rates through laboratory simulations. Journal of Geophysical Research: Planets, 101(E7), 16891-16900

Gregg, T. K., Fink, J. H. (2000) A laboratory investigation into the effects of slope on lava flow morphology. Journal of Volcanology and Geothermal Research, 96(3), $145-159$ 
Griffiths, R. W. (2000). The dynamics of lava flows. Annual Review of Fluid Mechanics, 32(1), 477-518

Gualda, G. A., Ghiorso, M. S., Lemons, R. V., Carley, T. L. (2012) Rhyolite-MELTS: a modified calibration of MELTS optimized for silica-rich, fluid-bearing magmatic systems. Journal of Petrology, 53(5), 875-890

Guest, J. E., Kilburn, C. R. J., Pinkerton, H., Duncan, A. M. (1987) The evolution of lava flow-fields: observations of the 1981 and 1983 eruptions of Mount Etna, Sicily. Bulletin of Volcanology, 49(3), 527-540

Hamada, M., Fujii, T. (2007) H2O-rich island arc low-K tholeiite magma inferred from Ca-rich plagioclase-melt inclusion equilibria. Geochemical Journal, 41(6), 437461.

Hammer, J. E., Cashman, K. V., Voight, B. (2000) Magmatic processes revealed by textural and compositional trends in Merapi dome lavas. Journal of Volcanology and Geothermal Research, 100(1), 165-192

Hammer, Ø., Harper, D. A. T., Ryan, P. D. (2001) Paleontological Statistics Software: Package for Education and Data Analysis. Palaeontologia Electronica 4, 9 pp.

Harris A.J.L., Dehn J., Calvari S. (2007) Lava effusion rate definition and measurement: a review. Bulletin of Volcanolology 70:1-22

Harris, A. (2013) Thermal remote sensing of active volcanoes: a user's manual. Cambridge University Press, 728 pp

Harris, A. J. L., Rowland, S. K. (2009) Effusion rate controls on lava flow length and the role of heat loss: a review. Studies in volcanology: the legacy of George Walker. Special Publications of IAVCEI, 2, 33-51 
Harris, A. J. L., Rhéty, M., Gurioli, L., Villeneuve, N., Paris, R. (2016) Simulating the thermorheological evolution of channel-contained lava: FLOWGO and its implementation in EXCEL. Geological Society, London, Special Publications, 426(1), 313-336

Harris, A. J., Rowland, S. (2001) FLOWGO: a kinematic thermo-rheological model for lava flowing in a channel. Bulletin of Volcanology, 63(1), 20-44

Harris, A. J., Belousov, A., Calvari, S., Delgado-Granados, H., Hort, M., Koga, K., Mei, E., Harijoko A., Pacheco J., Prival, J., Solana, C., Poroarson, P., Thouret, J., Van Wyk De Vries, B. (2017) Translations of volcanological terms: cross-cultural standards for teaching, communication, and reporting. Bulletin of Volcanology, 79(7), 57

Harris, A. J., Flynn, L. P., Matias, O., Rose, W. I., Cornejo, J. (2004) The evolution of an active silicic lava flow field: an ETM+ perspective. Journal of Volcanology and Geothermal Research, 135(1), 147-168

Harris, A.J.L., Murray, J.B., Aries, S.E., Davies, M.A., Flynn, L.P., Wooster, M.J., Wright, R., Rothery, D.A. (2000) Effusion rate trends at Etna and Krafla and their implications for eruptive mechanisms. Journal of Volcanology and Geothermal Research 102, 237-270

Head, J. W., Crumpler, L. S., Aubele, J. C., Guest, J. E., Saunders, R. S. (1992) Venus volcanism: Classification of volcanic features and structures, associations, and global distribution from Magellan data. Journal of Geophysical Research: Planets, 97(E8), 13153-13197 
Heltz, R. T., Thornber, C. R. (1987) Geothermometry of Kîlauea Iki lavas, Hawaii. Bulletin of Volcanology, 49, 651-668

Herschel, W. H., Bulkley, R. (1926) Konsistenzmessungen von gummibenzollösungen. Colloid \& Polymer Science, 39(4), 291-300

Hess, P. C., Head, J. W. (1990) Derivation of primary magmas and melting of crustal materials on Venus: Some preliminary petrogenetic considerations. Earth, Moon, and Planets, 50(1), 57-80

Hon K, Gansecki C, Kauahikaua J (2003) The transition from `a ā to pāhoehoe crust on flows emplaced during the $\mathrm{Pu}$ 'u 'Ō'ō-Kūpaianaha eruption. In Heliker C, Swanson DA, Takahashi TJ (eds) The Pu`u `Ōō-Kūpaianaha eruption of Kilauea Volcano, Hawai i: the first 20 years. U S Geol Surv Prof Pap 1676: 63-87

Houghton, B. F., Wilson, C. J. N. (1989) A vesicularity index for pyroclastic deposits. Bulletin of Volcanology, 51(6), 451-462

Hui H, Zhang Y (2007) Toward a general viscosity equation for natural anhydrous and hydrous silicate melts. Geochim Cosmochim Ac 71(2):403-416

Hulme, G. (1974) The interpretation of lava flow morphology. Geophysical Journal International, 39(2), 361-383

Huppert, H. (1982) Flow and instability of a viscous current down a slope. Nature 300, 427-429

Irvine, T. N. J., Baragar, W. R. A. F. (1971) A guide to the chemical classification of the common volcanic rocks. Canadian journal of earth sciences, 8(5), 523-548 
Ishibashi, H. (2009). Non-Newtonian behavior of plagioclase-bearing basaltic magma: Subliquidus viscosity measurement of the 1707 basalt of Fuji volcano, Japan. Journal of Volcanology and Geothermal Research, 181(1), 78-88

Ishibashi, H., Sato, H. (2007) Viscosity measurements of subliquidus magmas: Alkali olivine basalt from the Higashi-Matsuura district, Southwest Japan. Journal of Volcanology and Geothermal Research, 160(3), 223-238

Ishibashi, H., Sato, H. (2010) Bingham fluid behavior of plagioclase-bearing basaltic magma: Reanalyses of laboratory viscosity measurements for Fuji 1707 basalt. Journal of Mineralogical and Petrological Sciences, 105(6), 334-339

Jeffreys, H. (1925) The flow of water in an inclined channel of rectangular section. Philosophical Magazine, 49, 793-807

Keszthelyi, L., Denlinger, R. (1996) The initial cooling of pāhoehoe flow lobes. Bulletin of Volcanology, 58(1), 5-18

Keszthelyi, L., Self, S. (1998) Some physical requirements for the emplacement of long basaltic lava flows. Journal of Geophysical Research: Solid Earth, 103(B11), $27447-27464$

Kilburn C. R. J. (2000) Lava Flows and Flow Fields In Encyclopedia of volcanoes 291305

Kilburn CRJ (1987) Rheological implications of the pahoehoe-aa transition in lavas. Abstr. International Union of Geodesy and Geophysics.

Kilburn, C. (Ed.). (1993) Active lavas: monitoring and modelling. CRC Press 
Kilburn, C. R. (1981) Pahoehoe and aa lavas: a discussion and continuation of the model of Peterson and Tilling. Journal of Volcanology and Geothermal Research, 11(24), 373-382

Kilburn, C. R. J. Lopes, R. M. C. (1988) The growth of aa lava fields on Mount Etna, Sicily. Journal of Geophysical Research, 93, 14,759-14,772

Komorowski, J. C. et al. (2002) The January 2002 eruption-The January 2002 flank eruption of Nyiragongo Volcano (Democratic Republic of Congo): chronology, evidence for a tectonic rift trigger, and impact of lava flows on the city of Goma. Acta vulcanologica, 14(1/2), 1000-1035

Krauskopf, K. B. (1948) Lava movement at Paricutin volcano, Mexico. Geological Society of America Bulletin, 59(12), 1267-1284

Krieger, I. M., Dougherty, T. J. (1959) A mechanism for non-Newtonian flow in suspensions of rigid spheres. Transactions of the Society of Rheology, 3(1), 137152

Le Maitre, R. W. (1984) A proposal by the IUGS Subcommission on the Systematics of Igneous Rocks for a chemical classification of volcanic rocks based on the total alkali silica (TAS) diagram: (on behalf of the IUGS Subcommission on the Systematics of Igneous Rocks). Australian Journal of Earth Sciences, 31(2), 243255

Lejeune, A. M., Richet, P. (1995) Rheology of crystal-bearing silicate melts: An experimental study at high viscosities. Journal of Geophysical Research: Solid Earth, 100(B3), 4215-4229 
Lev, E., James, M. R. (2014) The influence of cross-sectional channel geometry on rheology and flux estimates for active lava flows. Bulletin of Volcanology, 76(7), 829. doi: $10.1007 / \mathrm{s} 00445-014-0829-3$

Lev, E., Spiegelman, M., Wysocki, R. J., Karson, J. A. (2012) Investigating lava flow rheology using video analysis and numerical flow models. Journal of Volcanology and Geothermal Research, 247, 62-73

Lipman, P. W., Banks, N. G. (1987) 'A‘ā flow dynamics, Mauna Loa 1984. US Geological Survey Professional Papers, 1350, 1527-1567

Lister, J. R. (1992) Viscous flows down an inclined plane from point and line sources. Journal of Fluid Mechanics, 242, 631-653

Llewellin EW, Manga M (2005) Bubble suspension rheology and implications for conduit flow. J Volcanol Geotherm Res 143(1):205-217

Lyman, A. W., Koenig, E., Fink, J. H. (2004) Predicting yield strengths and effusion rates of lava domes from morphology and underlying topography.Journal of Volcanology and Geothermal Research, 129(1), 125-138

Macdonald GA (1953) Pahoehoe, aa, and block lava. American Journal of Science 251(3):169-191

MacDonald, G. A. (1963) Physical properties of erupting Hawaiian magmas. Geological Society of America Bulletin, 74(8), 1071-1078

Mader, H. M., Llewellin, E. W., Mueller, S. P. (2013) The rheology of two-phase magmas: a review and analysis. Journal of Volcanology and Geothermal Research, 257, 135-158. doi: 10.1016/j.jvolgeores.2013.02.014 
Manga M, Castro J, Cashman KV, Loewenberg M (1998) Rheology of bubble-bearing magmas. J Volcanol Geotherm Res 87(1):15-28

Manga M, Loewenberg M (2001) Viscosity of magmas containing highly deformable bubbles. J Volcanol Geotherm Res 105(1):19-24

Maron, S. H., Pierce, P. E. (1956) Application of Ree-Eyring generalized flow theory to suspensions of spherical particles. Journal of colloid science, 11(1), 80-95

Marsh BD (1981) On the crystallinity, probability of occurrence, and rheology of lava and magma. Contrib Mineral Petr 78(1):85-98

Matías Gomez RO (2009) Volcanological Map of the 1961-2009 eruption of Volcan de Pacaya, Guatemala. Dissertation, Michigan Technological University

Moitra, P., Gonnermann, H. M. (2015) Effects of crystal shape-and size-modality on magma rheology. Geochemistry, Geophysics, Geosystems, 16(1), 1-26

Moore HJ, Arthur DWG, Schaber GG (1978) Yield strengths of flows on the Earth, Mars, and Moon. P Lunar Planet Sci C 9:3351-3378

Moore, H. J. (1987) Preliminary estimates of the rheological properties of 1984 Mauna Loa lava. US Geological Survey Professional Papers, 1350, 1569-1588

Morgan HA, Harris A.J, Gurioli L (2013) Lava discharge rate estimates from thermal infrared satellite data for Pacaya Volcano during 2004-2010. J Volcanol Geotherm Res 264:1-11

Morgan, W. J. (1971) Convection plumes in the lower mantle. Nature, 230(5288), 42.

Mouginis-Mark, P. J., Wilson, L., Zuber, M. T. (1992) The physical volcanology of Mars. Mars, 424-452 
Mueller S, Llewellin EW, Mader HM (2010) The rheology of suspensions of solid particles. P Roy Soc A-Math Phy 466(2116): 1201-1228

Mueller, S., Llewellin, E. W., Mader, H. M. (2009) The rheology of suspensions of solid particles. In Proceedings of the Royal Society of London A: Mathematical, Physical and Engineering Sciences (p. rspa20090445). The Royal Society

Mueller, S., Llewellin, E. W., Mader, H. M. (2011) The effect of particle shape on suspension viscosity and implications for magmatic flows. Geophysical Research Letters, 38(13) L13316

Naranjo, J. A., Sparks, R. S. J., Stasiuk, M. V., Moreno, H., Ablay, G. J. (1992) Morphological, structural and textural variations in the 1988-1990 andesite lava of Lonquimay Volcano, Chile. Geological Magazine, 129(6), 657-678

Nisbet, E. G., Cheadle, M. J., Arndt, N. T., Bickle, M. J. (1993) Constraining the potential temperature of the Archaean mantle: a review of the evidence from komatiites. Lithos, 30(3-4), 291-307

Noguchi, S., Toramaru, A., Nakada, S. (2008) Relation between microlite textures and discharge rate during the 1991-1995 eruptions at Unzen, Japan. Journal of Volcanology and Geothermal Research, 175(1-2), 141-155

Pal R (2003) Rheological behavior of bubble-bearing magmas. Earth Planet Sc Lett 207(1):165-179

Peltier, A., Bachèlery, P., Staudacher, T. (2009) Magma transport and storage at Piton de La Fournaise (La Réunion) between 1972 and 2007: A review of geophysical and geochemical data. Journal of Volcanology and Geothermal Research, 184(1), 93108 
Perfit M. and. Davidson J. (2000) Plate Tectonics and Volcanism In Encyclopedia of volcanoes, 89-113

Peterson, D. W., Tilling, R. I. (1980) Transition of basaltic lava from pahoehoe to aa, Kilauea Volcano, Hawaii: field observations and key factors. Journal of Volcanology and Geothermal Research, 7(3), 271-293

Phan-Thien, N., Pham, D. C. (1997) Differential multiphase models for polydispersed suspensions and particulate solids. Journal of Non-Newtonian Fluid Mechanics, 72(2), 305-318

Pinkerton H, Norton G (1995) Rheological properties of basaltic lavas at sub-liquidus temperatures: laboratory and field measurements on lavas from Mount Etna. J Volcanol Geotherm Res 68(4):307-323

Pinkerton H, Stevenson RJ (1992) Methods of determining the rheological properties of magmas at sub-liquidus temperatures. J Volcanol Geotherm Res 53(1):47-66

Pioli, L., Pistolesi, M., Rosi, M. (2014). Transient explosions at open-vent volcanoes: The case of Stromboli (Italy). Geology, 42(10), 863-866

Putirka, K. D. (2005) Igneous thermometers and barometers based on plagioclase+ liquid equilibria: Tests of some existing models and new calibrations. American Mineralogist, 90(2-3), 336-346

Putirka, K. D. (2008) Thermometers and barometers for volcanic systems.Reviews in Mineralogy and Geochemistry, 69(1), 61-120

Putirka, K. D. (2008) Thermometers and barometers for volcanic systems. Reviews in Mineralogy and Geochemistry, 69(1), 61-120 
Putirka, K. D., Perfit, M., Ryerson, F. J., Jackson, M. G. (2007) Ambient and excess mantle temperatures, olivine thermometry, and active vs. passive upwelling. Chemical Geology, 241(3), 177-206

Putirka, K., Johnson, M., Kinzler, R., Longhi, J., Walker, D. (1996) Thermobarometry of mafic igneous rocks based on clinopyroxene-liquid equilibria, 0-30 kbar. Contributions to Mineralogy and Petrology, 123(1), 92-108

Reyes, D. P., Christensen, P. R. (1994) Evidence for Komatiite-type lavas on Mars from Phobos ISM data and other observations. Geophysical Research Letters, 21(10), 887-890

Rhéty M (2014) Down-channel cooling and crystallization of lava during a short-lived eruption. Master's Thesis (Laboratoire Magmas et Volcans, Université Blaise Pascal, Clermont Ferrand, France): 25 p

Rhéty M (2015) The transition between channelized and dispersed 'a'a flow: role of cooling, crystallization and rheology. Master's Thesis (Laboratoire Magmas et Volcans, Université Blaise Pascal, Clermont Ferrand, France): 50 p

Rhéty M, Harris A, Villeneuve N, Gurioli L, Médard E, O. Chevrel, Bachélery P (2017) A comparison of cooling-limited and volume-limited flow systems: Examples from channels in the Piton de la Fournaise April 2007 lava-flow field" G-Cubed 10.1002/2017GC006839

Richardson, J. A. (2016) Modeling the construction and evolution of distributed volcanic fields on Earth and Mars. University of South Florida. 242 pp 
Riker, J. M., Cashman, K. V., Kauahikaua, J. P., Montierth, C. M. (2009) The length of channelized lava flows: Insight from the 1859 eruption of Mauna Loa Volcano, Hawai ‘i. Journal of Volcanology and Geothermal Research, 183(3), 139-156

Ringwood, A. E., Seifert, S., Wänke, H. (1987) A komatiite component in Apollo 16 highland breccias: Implications for the nickel-cobalt systematics and bulk composition of the Moon. Earth and planetary science letters, 81(2-3), 105-117

Robert B, Harris A, Gurioli L, Médard E, Sehlke A, Whittington AG (2014) Textural and rheological evolution of basalt flowing down a lava channel. Bull Volcanol 76(6):1-21

Robert G (2014) The effects of volatiles on the viscosity and heat capacity of calcalkaline basaltic and basaltic andesite liquids. Dissertation, University of Missouri-Columbia

Robert, B., Harris, A., Gurioli, L., Médard, E., Sehlke, A., Whittington, A. (2014) Textural and rheological evolution of basalt flowing down a lava channel. Bulletin of Volcanology, 76(6), 824

Roeder, P. L., Emslie, R. (1970) Olivine-liquid equilibrium. Contributions to mineralogy and petrology, 29(4), 275-289

Rogers N. and Hawkesworth C. (2000) Composition of Magmas In Encyclopedia of volcanoes, 122-124

Roscoe, R. (1952) The viscosity of suspensions of rigid spheres. British Journal of Applied Physics, 3(8), 267

Rose WI, Palma JL, Wolf RE, Gomez RO (2013) A 50 yr eruption of a basaltic composite cone: Pacaya, Guatemala. Geol S Am S 498:1-21 
Roult, G., A. Peltier, T. Staudacher, V. Ferrazzini, B. Taisne, A. Di Muro, and The OVPF Team (2012) A comprehensive classification of the Piton de la Fournaise eruptions (La Réunion Island) spanning the 1986-2010 period. Search for eruption precursors from the broad-band GEOSCOPE RER station analysis and interpretation in terms of volcanic processes, Journal of Volcanology and Geothermal Research, 241, 78-104

Rowland, S. K., Walker, G. P. (1990) Pahoehoe and aa in Hawaii: volumetric flow rate controls the lava structure. Bulletin of Volcanology, 52(8), 615-628

Rust AC, Manga M (2002) Bubble shapes and orientations in low Re simple shear flow. J Colloid Interf Sci 249(2):476-480

Ryerson, F. J., Weed, H. C., Piwinskii, A. J. (1988) Rheology of subliquidus magmas: 1. Picritic compositions. Journal of Geophysical Research: Solid Earth, 93(B4), $3421-3436$

Sato, H. (2005) Viscosity measurement of subliquidus magmas: 1707 basalt of Fuji volcano. Journal of Mineralogical and Petrological Sciences, 100(4), 133-142

Schaefer LN, Oommen T, Corazzato C, Tibaldi A, Escobar-Wolf R, Rose WI (2013) An integrated field-numerical approach to assess slope stability hazards at volcanoes: the example of Pacaya, Guatemala. Bull Volcanol 75(6):1-18

Schuessler, J. A., Botcharnikov, R. E., Behrens, H., Misiti, V., Freda, C. (2008) Amorphous materials: properties, structure, and durability: oxidation state of iron in hydrous phono-tephritic melts. American Mineralogist, 93(10), 1493-1504 
Sehlke, A., Whittington, A. G. (2015) Rheology of lava flows on Mercury: An analog experimental study. Journal of Geophysical Research: Planets, 120(11), 19241955

Sehlke, A., Whittington, A., Robert, B., Harris, A., Gurioli, L., Médard, E. (2014) Pahoehoe toaa transition of Hawaiian lavas: an experimental study. Bulletin of Volcanology, 76(11), 876

Shaw HR, Wright TL, Peck DL, Okamura R (1968) The viscosity of basaltic magma; an analysis of field measurements in Makaopuhi lava lake, Hawaii. American Journal of Science, 266(4): 225-264

Shea, T., Houghton, B. F., Gurioli, L., Cashman, K. V., Hammer, J. E., Hobden, B. J. (2010) Textural studies of vesicles in volcanic rocks: an integrated methodology. Journal of Volcanology and Geothermal Research, 190(3), 271-289

Shepard, M. K., Campbell, B. A., Bulmer, M. H., Farr, T. G., Gaddis, L. R., Plaut, J. J. (2001) The roughness of natural terrain: A planetary and remote sensing perspective. Journal of Geophysical Research: Planets, 106(E12), 32777-32795

Small, C., Naumann, T. (2001) The global distribution of human population and recent volcanism. Global Environmental Change Part B: Environmental Hazards, 3(3-4), 93-109

Smith, G. A., Florence, P. S., Castrounis, A. D., Luongo, M., Moore, J. D., Throne, J., Zelley, K. (1999) Basaltic near-vent facies of Vulcan cone, Albuquerque volcanoes, New Mexico. New Mexico Geological Society Guidebook, 50, 211220 
Soldati, A., Sehlke, A., Chigna, G., Whittington, A. (2016) Field and experimental constraints on the rheology of arc basaltic lavas: the January 2014 Eruption of Pacaya (Guatemala). Bulletin of Volcanology, 78(6), 43

Soldati, A., Beem, J., Gomez, F., Huntley, J. W., Robertson, T., \& Whittington, A. (2017). Emplacement dynamics and timescale of a Holocene flow from the Cima Volcanic Field (CA): Insights from rheology and morphology. Journal of Volcanology and Geothermal Research, 347, 91-111

Soldati, A., Harris, A. J. L., Gurioli, L., Villenuve, N., Rhéty, M., Gomez, F., Whittington, A. (2018). Textural, Thermal and Topographic Constraints on Lava Flow System Structure: the December 2010 Eruption of Piton de La Fournaise (accepted in Bulletin of Volcanology)

Soule, S. A., Cashman, K. V. (2005) Shear rate dependence of the pāhoehoe-to-'a 'à transition: analog experiments. Geology, 33(5), 361-364

Soule, S. A., Cashman, K. V., \& Kauahikaua, J. P. (2004) Examining flow emplacement through the surface morphology of three rapidly emplaced, solidified lava flows, Kīlauea Volcano, Hawai'i. Bulletin of Volcanology, 66(1), 1-14

Sparks, R. S. J., Pinkerton, H., Hulme, G. (1976) Classification and formation of lava levees on Mount Etna, Sicily. Geology, 4(5), 269-271

Spera FJ (2000) Physical properties of magmas. In: Sigurdsson H, Houghton BF, McNutt SR, Rymer H, Stix J, McBirney AR (eds) Encyclopedia of volcanoes. Academic Press, San Diego, pp. 171-190 
Stein, D. J., Spera, F. J. (1998) New high-temperature rotational rheometer for silicate melts, magmatic suspensions, and emulsions. Review of scientific instruments, 69(9), 3398-3402

Stolper, E., Walker, D., Hager, B. H., Hays, J. F. (1981) Melt segregation from partially molten source regions: the importance of melt density and source region size. Journal of Geophysical Research: Solid Earth, 86(B7), 6261-6271

Stormer, J. C. (1972) Mineralogy and petrology of the Raton-Clayton volcanic field, northeastern New Mexico. Geological Society of America Bulletin, 83(11), 32993322.

Swanson, D. A., Wright, T. L., Helz, R. T. (1975). Linear vent systems and estimated rates of magma production and eruption for the Yakima Basalt on the Columbia Plateau. American Journal of Science, 275(8), 877-905

Tammann, G. (1925) The states of aggregation. Van Nostrand, New York

Tarquini, S. (2017) A review of mass and energy flow through a lava flow system: insights provided from a non-equilibrium perspective. Bulletin of Volcanology, 79(8), 64.

Tarquini, S., Coppola, D. (2018) Combined morphological and thermal analysis of lava flows: a way to boost understanding of emplacement dynamics. Terra Nova, 1-7

Tolan, T. L., Reidel, S. P., Beeson, M. H., Anderson, J. L., Fecht, K. R., Swanson, D. A. (1989) Revisions to the estimates of the areal extent and volume of the Columbia River Basalt Group. Geological Society of America Special Papers, 239, 1-20 
Truby JM, Mueller SP, Llewellin EW, Mader HM (2015) The rheology of three-phase suspensions at low bubble capillary number. P Roy Soc Lond A Mat 471(2173):20140557

Valentine, G. A., Connor, C. B. (2015) Basaltic volcanic fields. The Encyclopedia of Volcanoes. Elsevier, Amsterdam, 423-439.

Valentine, G. A., Gregg, T. K. P. (2008) Continental basaltic volcanoes-processes and problems. Journal of Volcanology and Geothermal Research, 177(4), 857-873

Valentine, G. A., Krier, D. J., Perry, F. V., Heiken, G. (2007) Eruptive and geomorphic processes at the Lathrop Wells scoria cone volcano. Journal of Volcanology and Geothermal Research, 161(1), 57-80

Vallance JW, Siebert L, Rose WI, Girón JR, Banks NG (1995) Edifice collapse and related hazards in Guatemala. J Volcanol Geotherm Res 66(1):337-355

Vetere, F., Behrens, H., Holtz, F., Vilardo, G., Ventura, G. (2010) Viscosity of crystalbearing melts and its implication for magma ascent. Journal of mineralogical and petrological sciences, 105(3), 151-163

Villeneuve, N., Bachèlery, P. (2006) Revue de la typologie des éruptions au Piton de La Fournaise, processus et risques volcaniques associés. Cybergeo: European Journal of Geography

Vogel, H. (1921) The law of the relation between the viscosity of liquids and the temperature. Zeitschrift für Physik, 22, 645-646

Vona, A., Romano, C., Dingwell, D. B., Giordano, D. (2011) The rheology of crystalbearing basaltic magmas from Stromboli and Etna. Geochimica et Cosmochimica Acta, 75(11), 3214-3236 
Vona, A., Di Piazza, A., Nicotra, E., Romano, C., Viccaro, M., Giordano, G. (2017) The complex rheology of megacryst-rich magmas: The case of the mugearitic “cicirara" lavas of Mt. Etna volcano. Chemical Geology, 458, 48-67

Wadge, G. (1981) The variation of magma discharge during basaltic eruptions. J. Volcanol. Geotherm. Res.11, 139-168

Walker, G. P. L. (1972) Compound and simple lava flows and flood basalts. Bulletin of Volcanology, 35, 579-590

Walker, G. P. L., Huntingdon, A. T., Sanders, A. T., Dinsdale, J. L. (1973) Lengths of lava flows. Philosophical Transactions of the Royal Society of London A: Mathematical, Physical and Engineering Sciences, 274(1238), 107-118

Wang, S., Liu, M. (2006) Moving hotspots or reorganized plates?. Geology, 34(6), 465468

Webb, S. L., Dingwell, D. B. (1990) The onset of non-Newtonian rheology of silicate melts. Physics and Chemistry of Minerals, 17(2), 125-132

Welsch, B., Faure, F., Bachèlery, P., Famin, V. (2009) Microcrysts record transient convection at Piton de la Fournaise volcano (La Réunion hotspot). Journal of Petrology, 50(12), 2287-2305

White, S. M., Crisp, J. A., Spera, F. J. (2006) Long-term volumetric eruption rates and magma budgets. Geochemistry, Geophysics, Geosystems, 7(3)

Whittington, A. G., Hellwig, B. M., Behrens, H., Joachim, B., Stechern, A., Vetere, F. (2009) The viscosity of hydrous dacitic liquids: implications for the rheology of evolving silicic magmas. Bulletin of Volcanology, 71(2), 185-199 
Wilson, A. D. (1960) The micro-determination of ferrous iron in silicate minerals by a volumetric and a colorimetric method. Analyst, 85(1016), 823-827

Wilson, J. T. (1963) A possible origin of the Hawaiian Islands. Canadian Journal of Physics, 41(6), 863-870

Wood, C. A., Kienle, J. (1992) Volcanoes of North America. Volcanoes of North America, Edited by Charles Arthur Wood and Jürgen Kienle, pp. 355. ISBN 052143811X. Cambridge, UK: Cambridge University Press, November 1992. 355

Young, P., Wadge, G. (1990) FLOWFRONT: simulation of a lava flow. Computers \& Geosciences, 16(8), 1171-1191 